Cochrane Database of Systematic Reviews

\title{
Chemotherapy for advanced gastric cancer (Review)
}

Wagner AD, Syn NLX, Moehler M, Grothe W, Yong WP, Tai BC, Ho J, Unverzagt S

Wagner AD, Syn NLX, Moehler M, Grothe W, Yong WP, Tai BC, Ho J, Unverzagt S.

Chemotherapy for advanced gastric cancer.

Cochrane Database of Systematic Reviews 2017, Issue 8. Art. No.: CD004064.

DOI: 10.1002/14651858.CD004064.pub4.

www.cochranelibrary.com 
TABLE OF CONTENTS

PLAIN LANGUAGE SUMMARY

SUMMARY OF FINDINGS

BACKGROUND

OBJECTIVES

METHODS

RESULTS

Figure 1.

Figure 2.

Figure 3.

DISCUSSION

AUTHORS' CONCLUSIONS

ACKNOWLEDGEMENTS

REFERENCES

CHARACTERISTICS OF STUDIES

DATA AND ANALYSES

Analysis 1.1. Comparison 1 Chemotherapy versus best supportive care, Outcome 1 Overall survival.

Analysis 1.2. Comparison 1 Chemotherapy versus best supportive care, Outcome 2 Time to progression.

Analysis 2.1. Comparison 2 Combination versus single-agent chemotherapy, Outcome 1 Overall survival.

Analysis 2.2. Comparison 2 Combination versus single-agent chemotherapy, Outcome 2 Tumour response.

Analysis 2.3. Comparison 2 Combination versus single-agent chemotherapy, Outcome 3 Time to progression.

Analysis 2.4. Comparison 2 Combination versus single-agent chemotherapy, Outcome 4 Treatment-related death.

Analysis 3.1. Comparison 3 5-FU/cisplatin/anthracycline combinations versus 5-FU/cisplatin combinations (without anthracyclines), Outcome 1 Overall survival.

Analysis 3.2. Comparison 3 5-FU/cisplatin/anthracycline combinations versus 5-FU/cisplatin combinations (without anthracyclines), Outcome 2 Tumour response.

Analysis 3.3. Comparison 3 5-FU/cisplatin/anthracycline combinations versus 5-FU/cisplatin combinations (without anthracyclines), Outcome 3 Time to progression.

Analysis 4.1. Comparison 4 5-FU/cisplatin/anthracycline combinations versus 5-FU/anthracycline combinations (without cisplatin), Outcome 1 Overall survival.

Analysis 5.1. Comparison 5 Chemotherapy with irinotecan versus non-irinotecan-containing regimes, Outcome 1 Overall survival.

Analysis 5.2. Comparison 5 Chemotherapy with irinotecan versus non-irinotecan-containing regimes, Outcome 2 Tumour response.

Analysis 5.3. Comparison 5 Chemotherapy with irinotecan versus non-irinotecan-containing regimes, Outcome 3 Progressionfree survival.

Analysis 5.4. Comparison 5 Chemotherapy with irinotecan versus non-irinotecan-containing regimes, Outcome 4 Treatmentrelated death.

Analysis 5.5. Comparison 5 Chemotherapy with irinotecan versus non-irinotecan-containing regimes, Outcome 5 Treatment discontinuation due to toxicity.

Analysis 6.1. Comparison 6 Chemotherapy with docetaxel versus non-docetaxel-containing regimes, Outcome 1 Overall survival.

Analysis 6.2. Comparison 6 Chemotherapy with docetaxel versus non-docetaxel-containing regimes, Outcome 2 Tumour response.

Analysis 6.3. Comparison 6 Chemotherapy with docetaxel versus non-docetaxel-containing regimes, Outcome 3 Time to progression.

Analysis 6.4. Comparison 6 Chemotherapy with docetaxel versus non-docetaxel-containing regimes, Outcome 4 Progressionfree survival.

Analysis 6.5. Comparison 6 Chemotherapy with docetaxel versus non-docetaxel-containing regimes, Outcome 5 Treatmentrelated death.

Analysis 6.6. Comparison 6 Chemotherapy with docetaxel versus non-docetaxel-containing regimes, Outcome 6 Treatment discontinuation due to toxicity.

Analysis 7.1. Comparison 7 Chemotherapy with capecitabine versus 5-FU-containing regimes, Outcome 1 Overall Survival. .... 
Analysis 7.2. Comparison 7 Chemotherapy with capecitabine versus 5-FU-containing regimes, Outcome 2 Tumour response. ...

Analysis 7.3. Comparison 7 Chemotherapy with capecitabine versus 5-FU-containing regimes, Outcome 3 Time to progression.

Analysis 7.4. Comparison 7 Chemotherapy with capecitabine versus 5-FU-containing regimes, Outcome 4 Progression-free survival.

Analysis 7.5. Comparison 7 Chemotherapy with capecitabine versus 5-FU-containing regimes, Outcome 5 Treatment-related death.

Analysis 7.6. Comparison 7 Chemotherapy with capecitabine versus 5-FU-containing regimes, Outcome 6 Treatment discontinuation due to toxicity.

Analysis 8.1. Comparison 8 Chemotherapy with oxaliplatin versus the same regime including cisplatin, Outcome 1 Overall Survival.

Analysis 8.2. Comparison 8 Chemotherapy with oxaliplatin versus the same regime including cisplatin, Outcome 2 Tumour response.

Analysis 8.3. Comparison 8 Chemotherapy with oxaliplatin versus the same regime including cisplatin, Outcome 3 Progressionfree survival.

Analysis 8.4. Comparison 8 Chemotherapy with oxaliplatin versus the same regime including cisplatin, Outcome 4 Treatmentrelated death.

Analysis 8.5. Comparison 8 Chemotherapy with oxaliplatin versus the same regime including cisplatin, Outcome 5 Treatment discontinuation due to toxicity.

Analysis 9.1. Comparison 9 Taxane-platinum-fluoropyrimidine combinations versus taxane-platinum (without fluoropyrimidine), Outcome 1 Overall survival.

Analysis 9.2. Comparison 9 Taxane-platinum-fluoropyrimidine combinations versus taxane-platinum (without fluoropyrimidine), Outcome 2 Tumour response.

Analysis 9.3. Comparison 9 Taxane-platinum-fluoropyrimidine combinations versus taxane-platinum (without fluoropyrimidine), Outcome 3 Progression-free survival.

Analysis 9.4. Comparison 9 Taxane-platinum-fluoropyrimidine combinations versus taxane-platinum (without fluoropyrimidine), Outcome 4 Treatment-related death.

Analysis 9.5. Comparison 9 Taxane-platinum-fluoropyrimidine combinations versus taxane-platinum (without fluoropyrimidine), Outcome 5 Treatment discontinuation due to toxicity.

Analysis 10.1. Comparison $10 \mathrm{~S}-1$ versus 5-FU-containing regimes, Outcome 1 Overall Survival.

Analysis 10.2. Comparison $10 \mathrm{~S}-1$ versus 5-FU-containing regimes, Outcome 2 Tumour response.

Analysis 10.3. Comparison $10 \mathrm{~S}-1$ versus 5-FU-containing regimes, Outcome 3 Progression-free survival.

Analysis 10.4. Comparison $10 \mathrm{~S}-1$ versus 5-FU-containing regimes, Outcome 4 Time-to treatment failure.

Analysis 10.5. Comparison $10 \mathrm{~S}-1$ versus 5-FU-containing regimes, Outcome 5 Treatment-related deaths.

Analysis 10.6. Comparison 10 S-1 versus 5-FU-containing regimes, Outcome 6 Treatment discontinuation due to toxicity. ....... 
[Intervention Review]

\section{Chemotherapy for advanced gastric cancer}

Anna Dorothea Wagner ${ }^{1}$, Nicholas LX Syn², Markus Moehler ${ }^{3}$, Wilfried Grothe ${ }^{4}$, Wei Peng Yong 2 , Bee-Choo Tai ${ }^{5}$, Jingshan Ho², Susanne Unverzagt 6

1Department of Oncology, Lausanne University Hospitals and Clinics, Lausanne, Switzerland. 2Department of Haematology-Oncology, National University Cancer Institute, Singapore, Singapore. ${ }^{3}$ Department of Internal Medicine, University Medical Center of the Johannes Gutenberg University, Mainz, Germany. ${ }^{4}$ Department of Internal Medicine I, Martin-Luther-University Halle-Wittenberg, Halle/Saale, Germany. ${ }^{5}$ Saw Swee Hock School of Public Health, National University of Singapore, Singapore, Singapore. 6 Institute of Medical Epidemiology, Biostatistics and Informatics, Martin-Luther-University Halle-Wittenberg, Halle/Saale, Germany

Contact: Anna Dorothea Wagner, Department of Oncology, Lausanne University Hospitals and Clinics, Rue du Bugnon 46, Lausanne, 1011, Switzerland.dorothea.wagner@chuv.ch.

Editorial group: Cochrane Upper GI and Pancreatic Diseases Group.

Publication status and date: New search for studies and content updated (conclusions changed), published in Issue 8, 2017.

Citation: Wagner AD, Syn NLX, Moehler M, Grothe W, Yong WP, Tai BC, Ho J, Unverzagt S. Chemotherapy for advanced gastric cancer. Cochrane Database of Systematic Reviews 2017, Issue 8. Art. No.: CD004064. DOI: 10.1002/14651858.CD004064.pub4.

Copyright () 2017 The Cochrane Collaboration. Published by John Wiley \& Sons, Ltd.

\section{A B S T R A C T}

\section{Background}

Gastric cancer is the fifth most common cancer worldwide. In "Western" countries, most people are either diagnosed at an advanced stage, or develop a relapse after surgery with curative intent. In people with advanced disease, significant benefits from targeted therapies are currently limited to HER-2 positive disease treated with trastuzumab, in combination with chemotherapy, in first-line. In second-line, ramucirumab, alone or in combination with paclitaxel, demonstrated significant survival benefits. Thus, systemic chemotherapy remains the mainstay of treatment for advanced gastric cancer. Uncertainty remains regarding the choice of the regimen.

\section{Objectives}

To assess the efficacy of chemotherapy versus best supportive care (BSC), combination versus single-agent chemotherapy and different chemotherapy combinations in advanced gastric cancer.

\section{Search methods}

We searched the Cochrane Central Register of Controlled Trials, MEDLINE and Embase up to June 2016, reference lists of studies, and contacted pharmaceutical companies and experts to identify randomised controlled trials (RCTs).

\section{Selection criteria}

We considered only RCTs on systemic, intravenous or oral chemotherapy versus BSC, combination versus single-agent chemotherapy and different chemotherapy regimens in advanced gastric cancer.

\section{Data collection and analysis}

Two review authors independently identified studies and extracted data. A third investigator was consulted in case of disagreements. We contacted study authors to obtain missing information.

\section{Main results}

We included 64 RCTs, of which 60 RCTs (11,698 participants) provided data for the meta-analysis of overall survival. We found chemotherapy extends overall survival (OS) by approximately 6.7 months more than BSC (hazard ratio (HR) $0.3,95 \%$ confidence intervals (CI) 0.24 to 0.55 , 184 participants, three studies, moderate-quality evidence). Combination chemotherapy extends OS slightly (by an additional month) 
versus single-agent chemotherapy ( $\mathrm{HR} 0.84,95 \% \mathrm{Cl} 0.79$ to $0.89,4447$ participants, 23 studies, moderate-quality evidence), which is partly counterbalanced by increased toxicity. The benefit of epirubicin in three-drug combinations, in which cisplatin is replaced by oxaliplatin and 5-FU is replaced by capecitabine is unknown.

Irinotecan extends OS slightly (by an additional 1.6 months) versus non-irinotecan-containing regimens ( $\mathrm{HR} 0.87,95 \% \mathrm{Cl} 0.80$ to $0.95,2135$ participants, 10 studies, high-quality evidence).

Docetaxel extends OS slightly (just over one month) compared to non-docetaxel-containing regimens ( $\mathrm{HR} 0.86,95 \% \mathrm{Cl} 0.78$ to $0.95,2001$ participants, eight studies, high-quality evidence). However, due to subgroup analyses, we are uncertain whether docetaxel-containing combinations (docetaxel added to a single-agent or two-drug combination) extends OS due to moderate-quality evidence (HR $0.80,95 \%$ $\mathrm{Cl} 0.71$ to $0.91,1466$ participants, four studies, moderate-quality evidence). When another chemotherapy was replaced by docetaxel, there is probably little or no difference in OS (HR 1.05; 0.87 to 1.27, 479 participants, three studies, moderate-quality evidence). We found there is probably little or no difference in OS when comparing capecitabine versus 5-FU-containing regimens $(\mathrm{HR} 0.94,95 \% \mathrm{Cl} 0.79$ to $1.11,732$ participants, five studies, moderate-quality evidence) .

Oxaliplatin may extend (by less than one month) OS versus cisplatin-containing regimens (HR $0.81,95 \% \mathrm{Cl} 0.67$ to $0.98,1105$ participants, five studies, low-quality evidence). We are uncertain whether taxane-platinum combinations with (versus without) fluoropyrimidines extend OS due to very low-quality evidence (HR 0.86, $95 \% \mathrm{Cl} 0.71$ to $1.06,482$ participants, three studies, very low-quality evidence). S-1 regimens improve OS slightly (by less than an additional month) versus 5-FU-containing regimens (HR $0.91,95 \% \mathrm{Cl} 0.83$ to $1.00,1793$ participants, four studies, high-quality evidence), however since S-1 is used in different doses and schedules between Asian and non-Asian population, the applicability of this finding to individual populations is uncertain.

\section{Authors' conclusions}

Chemotherapy improves survival (by an additional 6.7 months) in comparison to BSC, and combination chemotherapy improves survival (by an additional month) compared to single-agent 5-FU. Testing all patients for HER-2 status may help to identify patients with HER-2positive tumours, for whom, in the absence of contraindications, trastuzumab in combination with capecitabine or 5-FU in combination with cisplatin has been shown to be beneficial. For HER-2 negative people, all different two-and three-drug combinations including irinotecan, docetaxel, oxaliplatin or oral 5-FU prodrugs are valid treatment options for advanced gastric cancer, and consideration of the side effects of each regimen is essential in the treatment decision. Irinotecan-containing combinations and docetaxel-containing combinations (in which docetaxel was added to a single-agent or two-drug (platinum/5-FUcombination) show significant survival benefits in the comparisons studied above. Furthermore, docetaxel-containing three-drug regimens have increased response rates, but the advantages of the docetaxel-containing three-drug combinations (DCF, FLO-T) are counterbalanced by increased toxicity. Additionally, oxaliplatin-containing regimens demonstrated a benefit in OS as compared to the same regimen containing cisplatin, and there is a modest survival improvement of S-1 compared to 5-FU-containing regimens.

Whether the survival benefit for three-drug combinations including cisplatin, 5-FU, and epirubicin as compared to the same regimen without epirubicin is still valid when second-line therapy is routinely administered and when cisplatin is replaced by oxaliplatin and 5-FU by capecitabine is questionable. Furthermore, the magnitude of the observed survival benefits for the three-drug regimens is not large enough to be clinically meaningful as defined recently by the American Society for Clinical Oncology (Ellis 2014). In contrast to the comparisons in which a survival benefit was observed by adding a third drug to a two-drug regimen at the cost of increased toxicity, the comparison of regimens in which another chemotherapy was replaced by irinotecan was associated with a survival benefit (of borderline statistical significance), but without increased toxicity. For this reason irinotecan/5-FU-containing combinations are an attractive option for first-line treatment. Although they need to be interpreted with caution, subgroup analyses of one study suggest that elderly people have a greater benefit form oxaliplatin, as compared to cisplatin-based regimens, and that people with locally advanced disease or younger than 65 years might benefit more from a three-drug regimen including 5-FU, docetaxel, and oxaliplatin as compared to a two-drug combination of 5FU and oxaliplatin, a hypothesis that needs further confirmation. For people with good performance status, the benefit of second-line chemotherapy has been established in several RCTs.

\section{PLAIN LANGUAGE SUMMARY}

\section{Chemotherapy for advanced gastric cancer}

\section{Background}

Of all people with gastric cancer, in countries where screening is not routinely performed, $80 \%$ to $90 \%$ are either diagnosed at an advanced stage when the tumour is inoperable, or develop a recurrence within five years after surgery. Before starting any systemic chemotherapy in advanced disease, testing for over expression of the Human Epidermal growth factor Receptor-2 (abbreviated HER-2) testing is mandatory, and people with HER-2 over expression need, in the absence of contraindications, to be treated by a combination of a cisplatin/fluoropyrimidine-based chemotherapy and trastuzumab (i.e. a monoclonal antibody directed against the human epidermal growth factor receptor II).

\section{Study Characteristics}


We searched biomedical databases (MEDLINE, Embase, Cochrane Central Register of Clinical Trials) until June 2016. We included 64 RCTs, of which 60 studies with 11,698 participants contained data on overall survival, in this review. We excluded 195 studies with reasons.

\section{Quality of the evidence}

The quality of evidence ranged from very low to high, depending on the comparison and outcome being assessed. Reasons for down grading the quality were due to risk of bias due to lack of blinded or independent radiological review, imprecision or heterogeneity.

\section{Key results}

Chemotherapy improves survival (by approximately 6.7 months) and quality of life in comparison to best supportive care alone, and firstline combination chemotherapy improves survival (by one month) compared to single-agent 5-FU.

The addition of docetaxel to platinum-fluoropyrimidine-based chemotherapy regimens appears to extend survival (by just over one additional month) at the cost of increased toxicity. Whether the benefit from adding a third drug (docetaxel or epirubicin) to a two-drug platinum-fluoropyrimidine chemotherapy combination outweighs its toxicity is unclear.

Consideration of the profile of side effects and the impact of these side effects on the individual person's quality of life, as well as the tumour burden and necessity to obtain a response rapidly is therefore essential in the choice of the regimen. Additionally, irinotecan-containing regimens prolonged overall survival (by an additional 1.6 months) compared to non-irinotecan-containing regimens. 
SUMMARY OF FINDINGS

\section{Summary of findings for the main comparison. Chemotherapy versus best supportive care for advanced gastric cancer}

\section{Chemotherapy versus best supportive care for advanced gastric cancer}

Patient or population: people with advanced gastric cancer

Settings: outpatient clinics participating in international multicentre studies

Intervention: chemotherapy

Control: best supportive care alone

\begin{tabular}{|c|c|c|c|c|c|c|}
\hline \multirow[t]{3}{*}{ Outcomes } & \multicolumn{2}{|c|}{ Illustrative comparative risks ${ }^{\star}(95 \% \mathrm{Cl})$} & \multirow{3}{*}{$\begin{array}{l}\text { Relative effect } \\
(95 \% \mathrm{CI})\end{array}$} & \multirow{3}{*}{$\begin{array}{l}\text { No of Partici- } \\
\text { pants } \\
\text { (studies) }\end{array}$} & \multirow{3}{*}{$\begin{array}{l}\text { Quality of the } \\
\text { evidence } \\
\text { (GRADE) }\end{array}$} & \multirow[t]{3}{*}{ Comments } \\
\hline & Assumed risk & Corresponding risk & & & & \\
\hline & Best supportive care & Chemotherapy & & & & \\
\hline \multirow{2}{*}{$\begin{array}{l}\text { Overall sur- } \\
\text { vival }\end{array}$} & \multicolumn{2}{|l|}{ Study population } & \multirow{2}{*}{$\begin{array}{l}\text { HR } 0.37 \\
(0.24 \text { to } 0.55)\end{array}$} & \multirow{2}{*}{$\begin{array}{l}184 \\
\text { (3 studies) }\end{array}$} & \multirow{2}{*}{$\begin{array}{l}\oplus \oplus \oplus \ominus \\
\text { moderate } 1\end{array}$} & \multirow{2}{*}{$\begin{array}{l}\text { Weighted average of median survival } \\
\text { durations from included studies }\end{array}$} \\
\hline & 4.3 months & 11.0 months & & & & \\
\hline \multirow{2}{*}{$\begin{array}{l}\text { Time to pro- } \\
\text { gression }\end{array}$} & \multicolumn{2}{|l|}{ Study population } & \multirow{2}{*}{$\begin{array}{l}\text { HR } 0.31 \\
(0.22 \text { to } 0.43)\end{array}$} & \multirow{2}{*}{$\begin{array}{l}144 \\
\text { (2 studies) }\end{array}$} & \multirow{2}{*}{$\begin{array}{l}\oplus \oplus \oplus \ominus \\
\text { moderate } 1\end{array}$} & \multirow{2}{*}{$\begin{array}{l}\text { Weighted average of median survival } \\
\text { durations from included studies }\end{array}$} \\
\hline & 2.5 months & 7.4 months & & & & \\
\hline
\end{tabular}

${ }^{\star}$ For time-to-event outcomes, e.g. overall survival, the assumed and corresponding risks were obtained by calculating the weighted average of the median survival durations reported in included studies. For dichotomous outcomes, the assumed and corresponding risks (and their 95\% confidence interval) are based on proportions of events in the control and intervention groups respectively.

Cl: Confidence interval; HR: Hazard ratio;

GRADE Working Group grades of evidence

High quality: Further research is very unlikely to change our confidence in the estimate of effect.

Moderate quality: Further research is likely to have an important impact on our confidence in the estimate of effect and may change the estimate.

Low quality: Further research is very likely to have an important impact on our confidence in the estimate of effect and is likely to change the estimate.

Very low quality: We are very uncertain about the estimate.

1 Early termination of Pyrhönen 1995; downgraded by one level for risk of bias.

Outcomes shown include those which were measured in the studies, or reported in a consistent fashion across included studies. Several critical outcomes (e.g. tumour response, treatment-related death, and discontinuation due to toxicity) were not evaluated or reported in a consistent fashion in these studies, as they were mainly conducted before year 2000. 
Summary of findings 2 . Combination versus single-agent chemotherapy for advanced gastric cancer

Combination versus single-agent chemotherapy for advanced gastric cancer

Patient or population: people with advanced gastric cancer

Settings: outpatient clinics participating in international multicentre studies

Intervention: combination

Control: single-agent chemotherapy

\begin{tabular}{|c|c|c|c|c|c|c|}
\hline \multirow[t]{3}{*}{ Outcomes } & \multicolumn{2}{|c|}{ Illustrative comparative risks* $(95 \% \mathrm{Cl})$} & \multirow{3}{*}{$\begin{array}{l}\text { Relative effect } \\
(95 \% \mathrm{CI})\end{array}$} & \multirow{3}{*}{$\begin{array}{l}\text { No of Partici- } \\
\text { pants } \\
\text { (studies) }\end{array}$} & \multirow{3}{*}{$\begin{array}{l}\text { Quality of the } \\
\text { evidence } \\
\text { (GRADE) }\end{array}$} & \multirow[t]{3}{*}{ Comments } \\
\hline & Assumed risk & Corresponding risk & & & & \\
\hline & Single-agent chemotherapy & Combination & & & & \\
\hline \multirow{2}{*}{$\begin{array}{l}\text { Overall sur- } \\
\text { vival }\end{array}$} & \multicolumn{2}{|l|}{ Study population } & \multirow{2}{*}{$\begin{array}{l}\text { HR } \mathbf{0 . 8 4} \\
(0.79 \text { to } 0.89)\end{array}$} & \multirow{2}{*}{$\begin{array}{l}4447 \\
(23)\end{array}$} & \multirow{2}{*}{$\begin{array}{l}\oplus \oplus \oplus \ominus \\
\text { moderate } 1\end{array}$} & \multirow{2}{*}{$\begin{array}{l}\text { Weighted average } \\
\text { of median survival } \\
\text { durations from in- } \\
\text { cluded studies }\end{array}$} \\
\hline & $\begin{array}{l}\text { - } 10.5 \text { months in studies pub- } \\
\text { lished after year } 2000 \\
\text { - } 6.4 \text { months in studies pub- } \\
\text { lished before year } 2000\end{array}$ & $\begin{array}{l}\text { - } 11.6 \text { months in studies published } \\
\text { after year } 2000 \\
\text { - } 7.3 \text { months in studies published } \\
\text { before year } 2000\end{array}$ & & & & \\
\hline \multirow{4}{*}{$\begin{array}{l}\text { Tumour re- } \\
\text { sponse }\end{array}$} & \multicolumn{2}{|l|}{ Study population } & \multirow{4}{*}{$\begin{array}{l}\text { OR 2.30 } \\
\text { (1.94 to } 2.72)\end{array}$} & \multirow{4}{*}{$\begin{array}{l}2833 \\
(18)\end{array}$} & \multirow{4}{*}{$\begin{array}{l}\oplus \oplus \oplus \oplus \\
\text { high } 1\end{array}$} & \\
\hline & 226 per 1000 & $\begin{array}{l}\mathbf{4 0 2} \text { per } \mathbf{1 0 0 0} \\
\text { (361 to } 442)\end{array}$ & & & & \\
\hline & \multicolumn{2}{|l|}{ Moderate } & & & & \\
\hline & 231 per 1000 & $\begin{array}{l}\mathbf{4 0 9} \text { per } \mathbf{1 0 0 0} \\
\text { (368 to } 450)\end{array}$ & & & & \\
\hline \multirow{2}{*}{$\begin{array}{l}\text { Time to pro- } \\
\text { gression }\end{array}$} & \multicolumn{2}{|l|}{ Study population } & \multirow{2}{*}{$\begin{array}{l}\text { HR } \mathbf{0 . 6 9} \\
(0.55 \text { to } 0.87)\end{array}$} & \multirow{2}{*}{$\begin{array}{l}720 \\
(4)\end{array}$} & \multirow{2}{*}{$\begin{array}{l}\oplus \oplus \oplus \ominus \\
\text { moderate } 1\end{array}$} & \multirow{2}{*}{$\begin{array}{l}\text { Weighted average } \\
\text { of median survival } \\
\text { durations from in- } \\
\text { cluded studies }\end{array}$} \\
\hline & 2.8 months & 4.1 months & & & & \\
\hline \multirow{3}{*}{$\begin{array}{l}\text { Treatment-re- } \\
\text { lated death }\end{array}$} & \multicolumn{2}{|l|}{ Study population } & \multirow{3}{*}{$\begin{array}{l}\text { OR } 1.64 \\
(0.83 \text { to } 3.24)\end{array}$} & \multirow{3}{*}{$\begin{array}{l}3876 \\
(18)\end{array}$} & \multirow{3}{*}{$\begin{array}{l}\oplus \oplus \ominus \ominus \\
\text { moderate } 2\end{array}$} & \\
\hline & 5 per 1000 & $\begin{array}{l}9 \text { per } 1000 \\
(4 \text { to } 17)\end{array}$ & & & & \\
\hline & Moderate & & & & & \\
\hline
\end{tabular}


${ }^{\star}$ For time-to-event outcomes, e.g. overall survival, the assumed and corresponding risks were obtained by calculating the weighted average of the median survival durations reported in included studies. For dichotomous outcomes, the assumed and corresponding risks (and their 95\% confidence interval) are based on proportions of events in the control and intervention groups respectively.

Cl: Confidence interval; OR: Odds ratio; HR: Hazard ratio;

GRADE Working Group grades of evidence

High quality: Further research is very unlikely to change our confidence in the estimate of effect.

Moderate quality: Further research is likely to have an important impact on our confidence in the estimate of effect and may change the estimate.

Low quality: Further research is very likely to have an important impact on our confidence in the estimate of effect and is likely to change the estimate.

Very low quality: We are very uncertain about the estimate.

1 Downgraded by one level for risk of bias.

2 Downgraded by two levels for serious imprecision.

Summary of findings 3. 5-FU/cisplatin/anthracycline combinations versus 5-FU/cisplatin combinations (without anthracyclines) for advanced gastric cancer

\section{5-FU/cisplatin/anthracycline combinations versus 5-FU/cisplatin combinations (without anthracyclines) for advanced gastric cancer}

Patient or population: people with advanced gastric cancer

Settings: outpatient clinics participating in international multicentre studies

Intervention: 5-FU/cisplatin/anthracycline combinations

Control: 5-FU/cisplatin combinations (without anthracyclines)

\begin{tabular}{|c|c|c|c|c|c|c|}
\hline \multirow[t]{3}{*}{ Outcomes } & \multicolumn{2}{|c|}{ Illustrative comparative risks ${ }^{\star}(95 \% \mathrm{Cl})$} & \multirow{3}{*}{$\begin{array}{l}\text { Relative effect } \\
(95 \% \mathrm{Cl})\end{array}$} & \multirow{3}{*}{$\begin{array}{l}\text { No of Partici- } \\
\text { pants } \\
\text { (studies) }\end{array}$} & \multirow{3}{*}{$\begin{array}{l}\text { Quality of the } \\
\text { evidence } \\
\text { (GRADE) }\end{array}$} & \multirow[t]{3}{*}{ Comments } \\
\hline & Assumed risk & Corresponding risk & & & & \\
\hline & $\begin{array}{l}\text { 5-FU/cisplatin combina- } \\
\text { tions (without anthracy- } \\
\text { clines) }\end{array}$ & $\begin{array}{l}\text { 5-FU/cisplatin/anthracycline } \\
\text { combinations }\end{array}$ & & & & \\
\hline \multirow{2}{*}{$\begin{array}{l}\text { Overall sur- } \\
\text { vival }\end{array}$} & Study population & & \multirow{2}{*}{$\begin{array}{l}\text { HR } 0.74 \\
(0.61 \text { to } 0.89)\end{array}$} & \multirow{2}{*}{$\begin{array}{l}579 \\
(4)\end{array}$} & \multirow{2}{*}{$\begin{array}{l}\oplus \oplus \oplus \ominus \\
\text { moderate } 1\end{array}$} & \multirow{2}{*}{$\begin{array}{l}\text { Weighted average of } \\
\text { median survival dura- } \\
\text { tions from included } \\
\text { studies }\end{array}$} \\
\hline & 8.6 months & 9.9 months & & & & \\
\hline $\begin{array}{l}\text { Tumour re- } \\
\text { sponse }\end{array}$ & Study population & & $\begin{array}{l}\text { OR } 2.86 \\
\text { (1.14 to } 7.16)\end{array}$ & $\begin{array}{l}78 \\
(1)\end{array}$ & $\begin{array}{l}\oplus \oplus \oplus \ominus \\
\text { low } 2\end{array}$ & \\
\hline
\end{tabular}




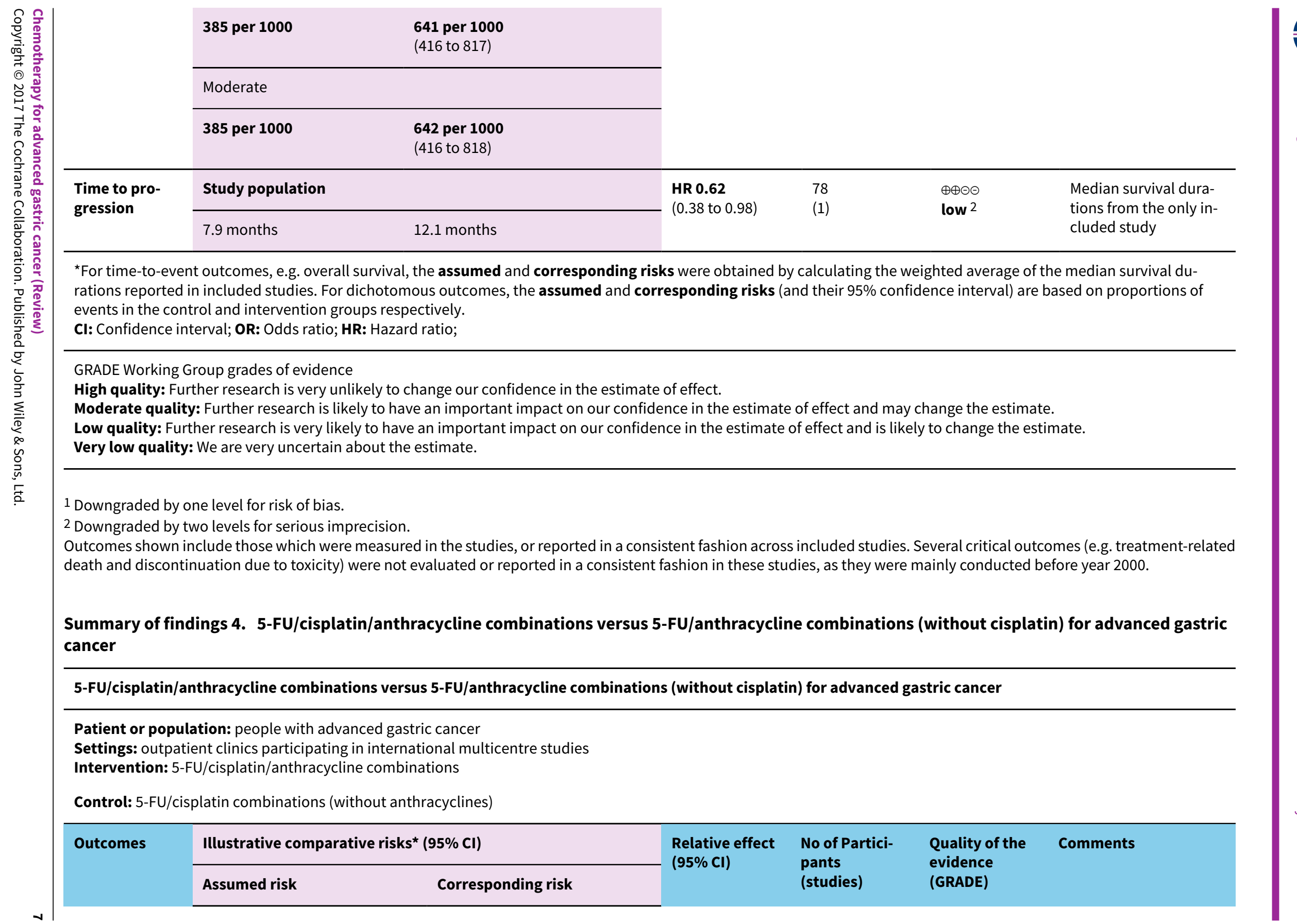




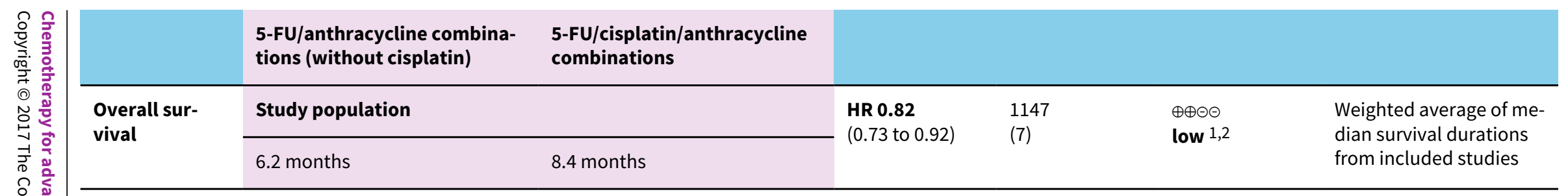

*For time-to-event outcomes, e.g. overall survival, the assumed and corresponding risks were obtained by calculating the weighted average of the median survival durations reported in included studies. For dichotomous outcomes, the assumed and corresponding risks (and their $95 \%$ confidence interval) are based on proportions of events in the control and intervention groups respectively.

Cl: Confidence interval; HR: Hazard ratio;

GRADE Working Group grades of evidence

High quality: Further research is very unlikely to change our confidence in the estimate of effect.

Moderate quality: Further research is likely to have an important impact on our confidence in the estimate of effect and may change the estimate.

Low quality: Further research is very likely to have an important impact on our confidence in the estimate of effect and is likely to change the estimate.

Very low quality: We are very uncertain about the estimate.

1 Downgraded by one level for risk of bias.

2 Downgraded by one level for statistical heterogeneity.

Several critical outcomes (i.e. tumour response, progression-free survival, treatment-related death and discontinuation due to toxicity) were not evaluated or reported in a consistent fashion in these studies, most of which were conducted before year 2000.

Summary of findings 5. Irinotecan versus non-irinotecan-containing regimens for advanced gastric cancer

Irinotecan versus non-irinotecan-containing regimens for advanced gastric cancer

Patient or population: people with advanced gastric cancer

Settings: outpatient clinics participating in international multicentre studies

intervention: irinotecan

Control: non-irinotecan-containing regimens

\begin{tabular}{|c|c|c|c|c|c|c|}
\hline \multirow[t]{3}{*}{ Outcomes } & \multicolumn{2}{|c|}{ Illustrative comparative risks* $(95 \% \mathrm{CI})$} & \multirow{3}{*}{$\begin{array}{l}\text { Relative effect } \\
(95 \% \mathrm{CI})\end{array}$} & \multirow{3}{*}{$\begin{array}{l}\text { No of Partici- } \\
\text { pants } \\
\text { (studies) }\end{array}$} & \multirow{3}{*}{$\begin{array}{l}\text { Quality of the } \\
\text { evidence } \\
\text { (GRADE) }\end{array}$} & \multirow[t]{3}{*}{ Comments } \\
\hline & Assumed risk & Corresponding risk & & & & \\
\hline & $\begin{array}{l}\text { Non-irinotecan-con- } \\
\text { taining regimens }\end{array}$ & Chemotherapy with Irinotecan & & & & \\
\hline Overall survival & Study population & & $\begin{array}{l}\text { HR } \mathbf{0 . 8 7} \\
(0.80 \text { to } 0.95)\end{array}$ & $\begin{array}{l}2135 \\
\text { (10 studies) }\end{array}$ & $\begin{array}{l}\oplus \oplus \oplus \ominus \\
\text { moderate } 1\end{array}$ & $\begin{array}{l}\text { Weighted average of me- } \\
\text { dian survival durations } \\
\text { from included studies }\end{array}$ \\
\hline
\end{tabular}




\begin{tabular}{|c|c|c|c|c|c|c|}
\hline \multirow{3}{*}{ 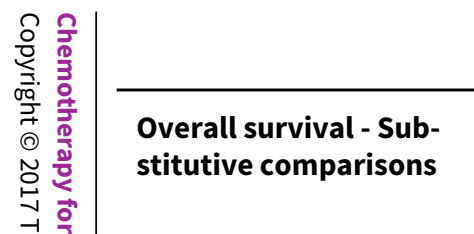 } & 9.7 months & 11.3 months & \multirow{3}{*}{$\begin{array}{l}\text { HR } 0.87 \\
(0.75 \text { to } 1.00)\end{array}$} & \multirow{3}{*}{$\begin{array}{l}826 \\
\text { (6 studies) }\end{array}$} & \multirow{3}{*}{$\begin{array}{l}\oplus \oplus \oplus \ominus \\
\text { moderate } 1\end{array}$} & \multirow{3}{*}{$\begin{array}{l}\text { Weighted average of me- } \\
\text { dian survival durations } \\
\text { from included studies }\end{array}$} \\
\hline & \multicolumn{2}{|c|}{ Study population } & & & & \\
\hline & 9.1 months & 9.9 months & & & & \\
\hline Overall survival - Addi- & \multicolumn{2}{|c|}{ Study population } & \multirow{2}{*}{$\begin{array}{l}\text { HR } 0.88 \\
(0.76 \text { to } 1.03)\end{array}$} & \multirow{2}{*}{$\begin{array}{l}500 \\
\text { (3 studies) }\end{array}$} & \multirow{2}{*}{$\begin{array}{l}\oplus \oplus \ominus \ominus \\
\text { low } 1,2\end{array}$} & \multirow{2}{*}{$\begin{array}{l}\text { Weighted average of me } \\
\text { dian survival durations } \\
\text { from included studies }\end{array}$} \\
\hline 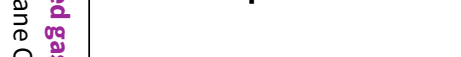 & 10.9 months & 11.9 months & & & & \\
\hline \multirow{2}{*}{$\begin{array}{l}\text { Overall survival - Other } \\
\text { comparisons }\end{array}$} & \multicolumn{2}{|c|}{ Study population } & \multirow{2}{*}{$\begin{array}{l}\text { HR } 0.87 \\
(0.76 \text { to } 1.00)\end{array}$} & \multirow{2}{*}{$\begin{array}{l}809 \\
\text { (2 studies) }\end{array}$} & \multirow{2}{*}{$\begin{array}{l}\oplus \odot \Theta \odot \\
\text { very low 1,3 }\end{array}$} & \multirow{2}{*}{$\begin{array}{l}\text { Weighted average of me } \\
\text { dian survival durations } \\
\text { from included studies }\end{array}$} \\
\hline & 11.4 months & 12.6 months & & & & \\
\hline \multirow[t]{4}{*}{ Tumour response } & \multicolumn{2}{|c|}{ Study population } & \multirow{4}{*}{$\begin{array}{l}\text { OR } 1.72 \\
\text { (1.24 to } 2.40)\end{array}$} & \multirow{4}{*}{$\begin{array}{l}1266 \\
\text { (10 studies) }\end{array}$} & \multirow{4}{*}{$\begin{array}{l}\oplus \oplus \ominus \ominus \\
\text { low } 3\end{array}$} & \\
\hline & 288 per 1000 & $\begin{array}{l}\mathbf{4 1 0} \text { per } 1000 \\
\text { (334 to } 493 \text { ) }\end{array}$ & & & & \\
\hline & \multicolumn{2}{|l|}{ Moderate } & & & & \\
\hline & 275 per 1000 & $\begin{array}{l}395 \text { per } 1000 \\
\text { (320 to } 477)\end{array}$ & & & & \\
\hline \multirow{4}{*}{$\begin{array}{l}\text { Tumour response - } \\
\text { Substitutive compar- } \\
\text { isons }\end{array}$} & \multicolumn{2}{|c|}{ Study population } & \multirow{4}{*}{$\begin{array}{l}\text { OR } 1.53 \\
\text { (0.93 to } 2.50)\end{array}$} & \multirow{4}{*}{$\begin{array}{l}756 \\
\text { (6 studies) }\end{array}$} & \multirow{4}{*}{$\begin{array}{l}\oplus \oplus \ominus \ominus \\
\text { low } 3\end{array}$} & \\
\hline & 297 per 1000 & $\begin{array}{l}\mathbf{3 9 3} \text { per } \mathbf{1 0 0 0} \\
(282 \text { to } 514)\end{array}$ & & & & \\
\hline & \multicolumn{2}{|l|}{ Moderate } & & & & \\
\hline & 294 per 1000 & $\begin{array}{l}389 \text { per } 1000 \\
(279 \text { to } 510)\end{array}$ & & & & \\
\hline \multirow{4}{*}{$\begin{array}{l}\text { Tumour response - Ad- } \\
\text { ditive comparisons }\end{array}$} & \multicolumn{2}{|c|}{ Study population } & \multirow{4}{*}{$\begin{array}{l}\text { OR } 2.18 \\
(1.25 \text { to } 3.80)\end{array}$} & \multirow{4}{*}{$\begin{array}{l}345 \\
\text { (3 studies) }\end{array}$} & \multirow{4}{*}{$\begin{array}{l}\oplus \oplus \ominus \ominus \\
\text { low } 1,2\end{array}$} & \\
\hline & 224 per 1000 & $\begin{array}{l}\mathbf{3 8 6} \text { per } \mathbf{1 0 0 0} \\
\text { (265 to } 522)\end{array}$ & & & & \\
\hline & \multicolumn{2}{|l|}{ Moderate } & & & & \\
\hline & 219 per 1000 & $\begin{array}{l}379 \text { per } 1000 \\
(260 \text { to } 516)\end{array}$ & & & & \\
\hline
\end{tabular}




\begin{tabular}{|c|c|c|c|c|c|c|c|c|}
\hline \multirow{6}{*}{\multicolumn{2}{|c|}{ 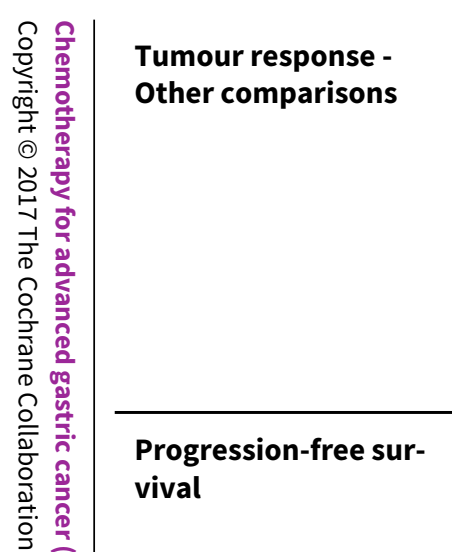 }} & \multicolumn{2}{|c|}{ Study population } & \multirow{4}{*}{$\begin{array}{l}\text { OR } 1.87 \\
(0.89 \text { to } 3.91)\end{array}$} & \multirow{4}{*}{$\begin{array}{l}165 \\
\text { (2 studies) }\end{array}$} & \multirow{4}{*}{$\begin{array}{l}\oplus \Theta \Theta \Theta \\
\text { very low } 1,2,4\end{array}$} & & \multirow{4}{*}{ 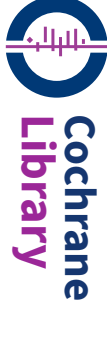 } \\
\hline & & 376 per 1000 & $\begin{array}{l}\mathbf{5 3 0} \text { per } \mathbf{1 0 0 0} \\
\text { (350 to } 702)\end{array}$ & & & & & \\
\hline & & \multicolumn{2}{|l|}{ Moderate } & & & & & \\
\hline & & 367 per 1000 & $\begin{array}{l}\mathbf{5 2 0} \text { per } \mathbf{1 0 0 0} \\
\text { (340 to } 694)\end{array}$ & & & & & \\
\hline & & \multicolumn{2}{|c|}{ Study population } & \multirow{2}{*}{$\begin{array}{l}\text { HR } 0.76 \\
(0.69 \text { to } 0.84)\end{array}$} & \multirow{2}{*}{$\begin{array}{l}1640 \\
\text { (7 studies) }\end{array}$} & \multirow{2}{*}{$\begin{array}{l}\oplus \oplus \oplus \oplus \\
\text { high }\end{array}$} & \multirow{2}{*}{$\begin{array}{l}\text { Weighted average of me- } \\
\text { dian survival durations } \\
\text { from included studies }\end{array}$} & \\
\hline & & 4.4 months & 5.9 months & & & & & 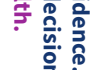 \\
\hline 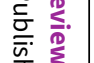 & \multirow{2}{*}{$\begin{array}{l}\text { Progression-free sur- } \\
\text { vival - Substitutive } \\
\text { comparison }\end{array}$} & \multicolumn{2}{|c|}{ Study population } & \multirow{2}{*}{$\begin{array}{l}\text { HR } 0.85 \\
(0.72 \text { to } 1.00)\end{array}$} & \multirow{2}{*}{$\begin{array}{l}741 \\
\text { (5 studies) }\end{array}$} & \multirow{2}{*}{$\begin{array}{l}\oplus \oplus \oplus \ominus \\
\text { moderate } 1\end{array}$} & \multirow{2}{*}{$\begin{array}{l}\text { Weighted average of me- } \\
\text { dian survival durations } \\
\text { from included studies }\end{array}$} & \\
\hline & & 4.2 months & 5.3 months & & & & & \\
\hline$\frac{0}{5}$ & \multirow{2}{*}{$\begin{array}{l}\text { Progression-free sur- } \\
\text { vival - Additive com- } \\
\text { parisons }\end{array}$} & \multicolumn{2}{|c|}{ Study population } & \multirow{2}{*}{$\begin{array}{l}\text { HR } \mathbf{0 . 5 1} \\
(0.33 \text { to } 0.77)\end{array}$} & \multirow{2}{*}{$\begin{array}{l}90 \\
(1)\end{array}$} & \multirow{2}{*}{$\begin{array}{l}\oplus \oplus \oplus \ominus \\
\text { moderate } 2\end{array}$} & \multirow{2}{*}{$\begin{array}{l}\text { Median survival dura- } \\
\text { tions from the only in- } \\
\text { cluded study }\end{array}$} & \\
\hline$\underbrace{\infty}_{\infty}$ & & 3.2 months & 6.9 months & & & & & \\
\hline$\stackrel{n}{\llcorner}$ & \multirow{2}{*}{$\begin{array}{l}\text { Progression-free sur- } \\
\text { vival - Other compar- } \\
\text { isons }\end{array}$} & \multicolumn{2}{|c|}{ Study population } & \multirow{2}{*}{$\begin{array}{l}\text { HR } 0.74 \\
(0.66 \text { to } 0.84)\end{array}$} & \multirow{2}{*}{$\begin{array}{l}809 \\
\text { (2 studies) }\end{array}$} & \multirow{2}{*}{$\begin{array}{l}\oplus \oplus \oplus \oplus \\
\text { high }\end{array}$} & \multirow{2}{*}{$\begin{array}{l}\text { Weighted average of me- } \\
\text { dian survival durations } \\
\text { from included studies }\end{array}$} & \\
\hline & & 5.4 months & 6.6 months & & & & & \\
\hline & \multirow{4}{*}{$\begin{array}{l}\text { Treatment-related } \\
\text { death }\end{array}$} & \multicolumn{2}{|c|}{ Study population } & \multirow{4}{*}{$\begin{array}{l}\text { OR } \mathbf{0 . 8 8} \\
(0.23 \text { to } 3.32)\end{array}$} & \multirow{4}{*}{$\begin{array}{l}1979 \\
\text { (9 studies) }\end{array}$} & \multirow{4}{*}{$\begin{array}{l}\oplus \oplus \ominus \ominus \\
\text { low 2,4 }\end{array}$} & & \\
\hline & & 10 per 1000 & $\begin{array}{l}9 \text { per } 1000 \\
(2 \text { to } 32)\end{array}$ & & & & & \\
\hline & & Moderate & & & & & & \\
\hline & & 2 per 1000 & $\begin{array}{l}2 \text { per } 1000 \\
(0 \text { to } 7)\end{array}$ & & & & & 等 \\
\hline & Treatment discontinu- & Study popula & & OR 1.00 & 1979 & $\oplus \odot \ominus \odot$ & & 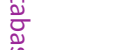 \\
\hline & & 137 per 1000 & $\begin{array}{l}137 \text { per } 1000 \\
(68 \text { to } 258)\end{array}$ & (0.46 to 2.20$)$ & & & & 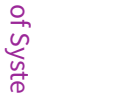 \\
\hline & & Moderate & & & & & & ก. \\
\hline 능 & & 215 per 1000 & 215 per 1000 & & & & & $\sum_{i=0}^{0}$ \\
\hline
\end{tabular}




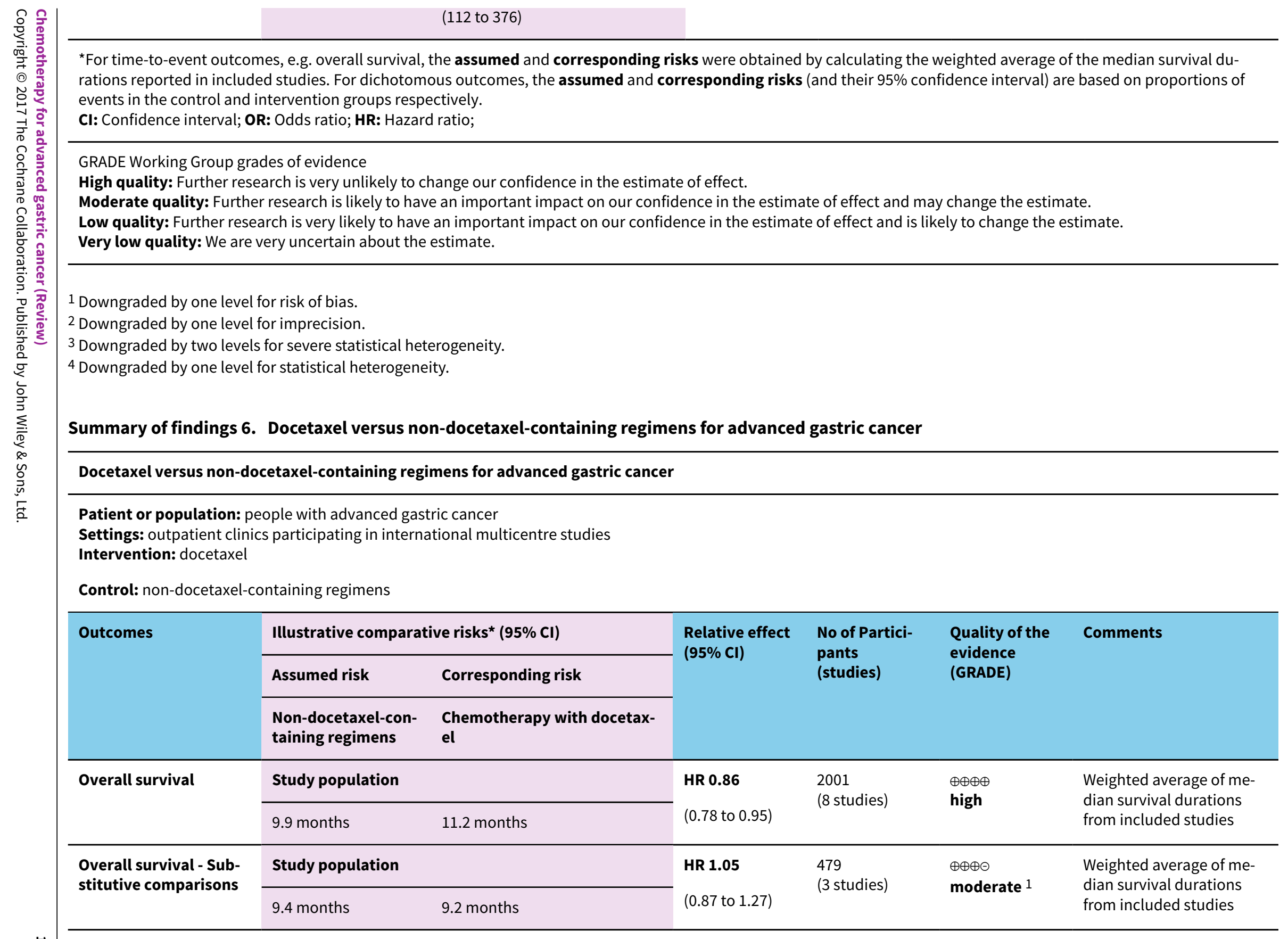

GRADE Working Group grades of evidence

High quality: Further research is very unlikely to change our confidence in the estimate of effect.

.

1 Downgraded by one level for risk of bias.

2 Downgraded by one level for imprecision.

3 Downgraded by two levels for severe statistical heterogeneity.

Summary of findings 6 . Docetaxel versus non-docetaxel-containing regimens for advanced gastric cance

Patient or population: people with advanced gastric cance

Settings: outpatient clinics participating in international multicentre studies 


\begin{tabular}{|c|c|c|c|c|c|c|c|c|}
\hline \multirow{4}{*}{\multicolumn{2}{|c|}{ 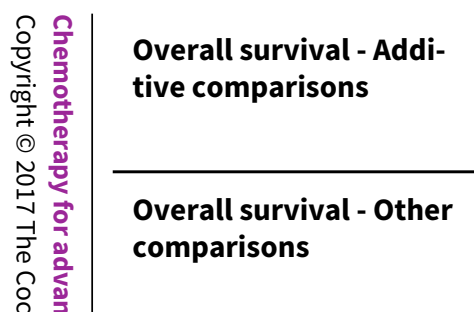 }} & \multicolumn{2}{|c|}{ Study population } & \multirow{2}{*}{$\begin{array}{l}\text { HR } 0.80 \\
(0.71 \text { to } 0.91)\end{array}$} & \multirow{2}{*}{$\begin{array}{l}1466 \\
\text { (4 studies) }\end{array}$} & \multirow{2}{*}{$\begin{array}{l}\oplus \oplus \oplus \ominus \\
\text { moderate } 2\end{array}$} & \multirow{2}{*}{$\begin{array}{l}\text { Weighted average of me- } \\
\text { dian survival durations } \\
\text { from included studies }\end{array}$} & \multirow{4}{*}{ 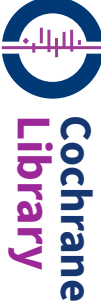 } \\
\hline & & 10.6 months & 12.3 months & & & & & \\
\hline & & \multicolumn{2}{|c|}{ Study population } & \multirow{2}{*}{$\begin{array}{l}\text { HR } 0.80 \\
(0.46 \text { to } 1.39)\end{array}$} & \multirow{2}{*}{$\begin{array}{l}56 \\
\text { (1 study) }\end{array}$} & \multirow{2}{*}{$\begin{array}{l}\oplus \ominus \ominus \ominus \\
\text { very low } 1,2,3\end{array}$} & \multirow{2}{*}{$\begin{array}{l}\text { Median survival durations } \\
\text { from the only included } \\
\text { study }\end{array}$} & \\
\hline & & 9.5 months & 11.9 months & & & & & \\
\hline 爱 & \multirow[t]{4}{*}{ Tumour response } & \multicolumn{2}{|c|}{ Study population } & \multirow{4}{*}{$\begin{array}{l}\text { OR } 1.37 \\
\text { (1.03 to } 1.83)\end{array}$} & \multirow{4}{*}{$\begin{array}{l}1820 \\
\text { (9 studies) }\end{array}$} & \multirow{4}{*}{$\begin{array}{l}\oplus \oplus \oplus \ominus \\
\text { moderate } 4\end{array}$} & & \multirow{4}{*}{ 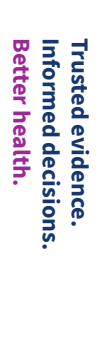 } \\
\hline 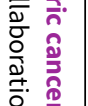 & & 311 per 1000 & $\begin{array}{l}\mathbf{3 8 2} \text { per } \mathbf{1 0 0 0} \\
\text { (317 to } 452)\end{array}$ & & & & & \\
\hline 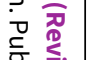 & & \multicolumn{2}{|l|}{ Moderate } & & & & & \\
\hline 每 & & 310 per 1000 & $\begin{array}{l}\mathbf{3 8 1} \text { per } \mathbf{1 0 0 0} \\
(316 \text { to } 451)\end{array}$ & & & & & \\
\hline$\sum_{s}^{5}$ & \multirow{4}{*}{$\begin{array}{l}\text { Tumour response - } \\
\text { Substitutive compari- } \\
\text { son }\end{array}$} & \multicolumn{2}{|c|}{ Study population } & \multirow{4}{*}{$\begin{array}{l}\text { OR } 1.03 \\
(0.71 \text { to } 1.50)\end{array}$} & \multirow{4}{*}{$\begin{array}{l}525 \\
\text { (4 studies) }\end{array}$} & \multirow{4}{*}{$\begin{array}{l}\oplus \oplus \oplus \ominus \\
\text { moderate } 1\end{array}$} & & \\
\hline $\begin{array}{l}\infty \\
\varkappa \\
0\end{array}$ & & 314 per 1000 & $\begin{array}{l}320 \text { per } 1000 \\
(245 \text { to } 407)\end{array}$ & & & & & \\
\hline$\stackrel{t}{0}$ & & \multicolumn{2}{|l|}{ Moderate } & & & & & \\
\hline & & 327 per 1000 & $\begin{array}{l}\mathbf{3 3 4} \text { per } \mathbf{1 0 0 0} \\
\text { (256 to } 422)\end{array}$ & & & & & \\
\hline & \multirow{4}{*}{$\begin{array}{l}\text { Tumour response - Ad- } \\
\text { ditive comparison }\end{array}$} & \multicolumn{2}{|c|}{ Study population } & \multirow{4}{*}{$\begin{array}{l}\text { OR } 1.83 \\
(1.45 \text { to } 2.32)\end{array}$} & \multirow{4}{*}{$\begin{array}{l}1235 \\
\text { (4 studies) }\end{array}$} & \multirow{4}{*}{$\begin{array}{l}\oplus \oplus \oplus \oplus \\
\text { high }\end{array}$} & & \\
\hline & & 295 per 1000 & $\begin{array}{l}\mathbf{4 3 4} \text { per } \mathbf{1 0 0 0} \\
\text { (378 to } 493)\end{array}$ & & & & & \\
\hline & & \multicolumn{2}{|l|}{ Moderate } & & & & & 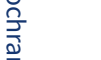 \\
\hline & & 296 per 1000 & $\begin{array}{l}\mathbf{4 3 5} \text { per } \mathbf{1 0 0 0} \\
(379 \text { to } 494)\end{array}$ & & & & & 离 \\
\hline & \multirow{2}{*}{$\begin{array}{l}\text { Tumour response - } \\
\text { Other comparison }\end{array}$} & \multicolumn{2}{|c|}{ Study population } & \multirow{2}{*}{$\begin{array}{l}\text { OR } 0.33 \\
(0.12 \text { to } 0.96)\end{array}$} & \multirow{2}{*}{$\begin{array}{l}60 \\
\text { (1 study) }\end{array}$} & \multirow{2}{*}{$\begin{array}{l}\oplus \ominus \ominus \ominus \\
\text { very low } 1,3\end{array}$} & & $\stackrel{n}{\infty}$ \\
\hline & & 600 per 1000 & $\begin{array}{l}331 \text { per } 1000 \\
\text { (153 to } 590)\end{array}$ & & & & & . \\
\hline
\end{tabular}




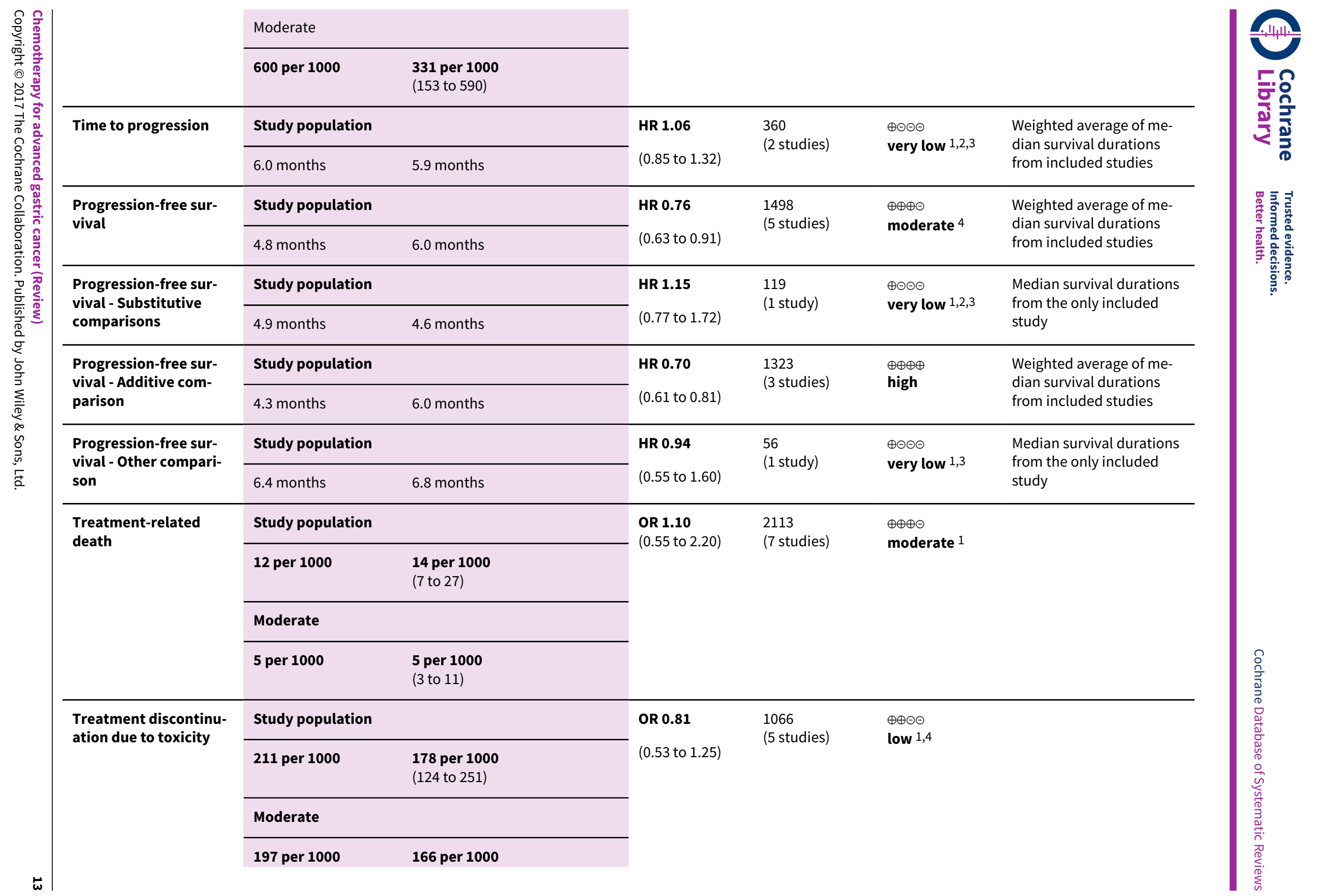


*For time-to-event outcomes, e.g. overall survival, the assumed and corresponding risks were obtained by calculating the weighted average of the median survival durations reported in included studies. For dichotomous outcomes, the assumed and corresponding risks (and their 95\% confidence interval) are based on proportions of events in the control and intervention groups respectively.

Cl: Confidence interval; OR: Odds ratio; HR: Hazard ratio;

GRADE Working Group grades of evidence

High quality: Further research is very unlikely to change our confidence in the estimate of effect.

Moderate quality: Further research is likely to have an important impact on our confidence in the estimate of effect and may change the estimate.

Low quality: Further research is very likely to have an important impact on our confidence in the estimate of effect and is likely to change the estimate.

Very low quality: We are very uncertain about the estimate.

1 Downgraded by one level for imprecision.

2 Downgraded by one level for risk of bias.

3 Downgraded by two levels for serious imprecision.

4 Downgraded by one level for statistical heterogeneity.

\section{Summary of findings 7. Capecitabine versus 5-FU-containing regimens for advanced gastric cancer}

\section{Capecitabine versus 5-FU-containing regimens for advanced gastric cance}

Patient or population: people with advanced gastric cancer

Settings: outpatient clinics participating in international multicentre studies with approximately half of all participants enrolled from Asian countries Intervention: capecitabine

Control: 5-FU-containing regimens

\begin{tabular}{|c|c|c|c|c|c|c|}
\hline \multirow[t]{3}{*}{ Outcomes } & \multicolumn{2}{|c|}{ Illustrative comparative risks* $(95 \% \mathrm{CI})$} & \multirow{3}{*}{$\begin{array}{l}\text { Relative effect } \\
(95 \% \mathrm{CI})\end{array}$} & \multirow{3}{*}{$\begin{array}{l}\text { No of Partici- } \\
\text { pants } \\
\text { (studies) }\end{array}$} & \multirow{3}{*}{$\begin{array}{l}\text { Quality of the } \\
\text { evidence } \\
\text { (GRADE) }\end{array}$} & \multirow[t]{3}{*}{ Comments } \\
\hline & Assumed risk & Corresponding risk & & & & \\
\hline & $\begin{array}{l}\text { 5-FU-containing regi- } \\
\text { mens }\end{array}$ & Capecitabine-containing regimens & & & & \\
\hline \multirow{2}{*}{$\begin{array}{l}\text { Overall Sur- } \\
\text { vival }\end{array}$} & Study population & & \multirow{2}{*}{$\begin{array}{l}\text { HR } 0.94 \\
(0.79 \text { to } 1.11)\end{array}$} & \multirow{2}{*}{$\begin{array}{l}732 \\
\text { (5 studies) }\end{array}$} & \multirow{2}{*}{$\begin{array}{l}\oplus \oplus \oplus \ominus \\
\text { moderate } 1\end{array}$} & \multirow{2}{*}{$\begin{array}{l}\text { Weighted average of } \\
\text { median survival du- } \\
\text { rations from includ- } \\
\text { ed studies }\end{array}$} \\
\hline & 10.9 months & 10.8 months & & & & \\
\hline \multirow{2}{*}{$\begin{array}{l}\text { Tumour re- } \\
\text { sponse }\end{array}$} & Study population & & \multirow{2}{*}{$\begin{array}{l}\text { OR } 0.85 \\
(0.40 \text { to } 1.79)\end{array}$} & \multirow{2}{*}{$\begin{array}{l}636 \\
\text { (4 studies) }\end{array}$} & \multirow{2}{*}{$\begin{array}{l}\oplus \ominus \ominus \ominus \\
\text { very low 2,3 }\end{array}$} & \\
\hline & 384 per 1000 & 347 per 1000 & & & & \\
\hline
\end{tabular}




\begin{tabular}{|c|c|c|c|c|c|c|}
\hline \multirow{5}{*}{ 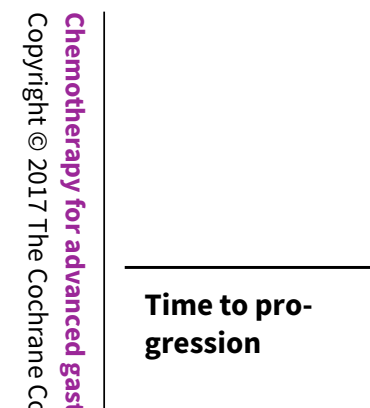 } & \multicolumn{2}{|c|}{ (200 to 528$)$} & & & & \\
\hline & \multicolumn{2}{|l|}{ Moderate } & & & & \\
\hline & 394 per 1000 & $\begin{array}{l}\mathbf{3 5 6} \text { per } \mathbf{1 0 0 0} \\
\text { (206 to 538) }\end{array}$ & & & & \\
\hline & \multicolumn{2}{|c|}{ Study population } & \multirow{2}{*}{$\begin{array}{l}\text { HR } 0.72 \\
(0.47 \text { to } 1.12)\end{array}$} & \multirow{2}{*}{$\begin{array}{l}85 \\
\text { (1 study) }\end{array}$} & \multirow{2}{*}{$\begin{array}{l}\oplus \odot \odot \ominus \\
\text { very low 1,3 }\end{array}$} & \multirow{2}{*}{$\begin{array}{l}\text { Median survival du- } \\
\text { rations from the only } \\
\text { included study }\end{array}$} \\
\hline & 5.5 months & 6.8 months & & & & \\
\hline \multirow{2}{*}{$\begin{array}{l}\text { Progres- } \\
\text { sion-free sur- } \\
\text { vival }\end{array}$} & \multicolumn{2}{|c|}{ Study population } & \multirow{2}{*}{$\begin{array}{l}\text { HR } 0.98 \\
(0.77 \text { to } 1.23)\end{array}$} & \multirow{2}{*}{$\begin{array}{l}647 \\
\text { (4 studies) }\end{array}$} & \multirow{2}{*}{$\begin{array}{l}\oplus \odot \odot \ominus \\
\text { very low } 1,3,4\end{array}$} & \multirow{2}{*}{$\begin{array}{l}\text { Weighted average of } \\
\text { median survival du- } \\
\text { rations from includ- } \\
\text { ed studies }\end{array}$} \\
\hline & 6.7 months & 6.5 months & & & & \\
\hline \multirow{4}{*}{$\begin{array}{l}\text { Treatment-re- } \\
\text { lated death }\end{array}$} & \multicolumn{2}{|c|}{ Study population } & \multirow{4}{*}{$\begin{array}{l}\text { OR } 1.88 \\
(0.23 \text { to } 15.15)\end{array}$} & \multirow{4}{*}{$\begin{array}{l}481 \\
\text { (2 studies) }\end{array}$} & \multirow{4}{*}{$\begin{array}{l}\oplus \odot \Theta \Theta \\
\text { very low 1,2,3 }\end{array}$} & \\
\hline & 21 per 1000 & $\begin{array}{l}38 \text { per } 1000 \\
(5 \text { to } 241)\end{array}$ & & & & \\
\hline & \multicolumn{2}{|l|}{ Moderate } & & & & \\
\hline & 24 per 1000 & $\begin{array}{l}44 \text { per } 1000 \\
(6 \text { to } 271)\end{array}$ & & & & \\
\hline \multirow{4}{*}{$\begin{array}{l}\text { Treatment dis- } \\
\text { continuation } \\
\text { due to toxicity }\end{array}$} & \multicolumn{2}{|c|}{ Study population } & \multirow{4}{*}{$\begin{array}{l}\text { OR } 0.99 \\
\text { (0.56 to } 1.77 \text { ) }\end{array}$} & \multirow{4}{*}{$\begin{array}{l}311 \\
\text { (1 study) }\end{array}$} & \multirow{4}{*}{$\begin{array}{l}\oplus \oplus \ominus \ominus \\
\text { low }^{3}\end{array}$} & \\
\hline & 181 per 1000 & $\begin{array}{l}\mathbf{1 7 9} \text { per } \mathbf{1 0 0 0} \\
\text { (110 to } 281)\end{array}$ & & & & \\
\hline & \multicolumn{2}{|l|}{ Moderate } & & & & \\
\hline & 181 per 1000 & $\begin{array}{l}\mathbf{1 8 0} \text { per } \mathbf{1 0 0 0} \\
\text { (110 to } 281)\end{array}$ & & & & \\
\hline
\end{tabular}

*For time-to-event outcomes, e.g. overall survival, the assumed and corresponding risks were obtained by calculating the weighted average of the median survival durations reported in included studies. For dichotomous outcomes, the assumed and corresponding risks (and their $95 \%$ confidence interval) are based on proportions of events in the control and intervention groups respectively.

Cl: Confidence interval; OR: Odds ratio; HR: Hazard ratio;

GRADE Working Group grades of evidence

High quality: Further research is very unlikely to change our confidence in the estimate of effect.

Moderate quality: Further research is likely to have an important impact on our confidence in the estimate of effect and may change the estimate. 
1 Downgraded by one level for risk of bias.

2 Downgraded by two levels for severe statistical heterogeneity.

3 Downgraded by two levels for serious imprecision.

4 Downgraded by one level for statistical heterogeneity.

Summary of findings 8. Oxaliplatin versus the same regimen including cisplatin for advanced gastric cancer

Oxaliplatin versus the same regimen including cisplatin for advanced gastric cancer

Patient or population: people with advanced gastric cance

Settings: outpatient clinics participating in international multicentre studies with the majority of participants enrolled in Asia

Intervention: oxaliplatin-containing regimen

Control: the same regimen including cisplatin

\begin{tabular}{|c|c|c|c|c|c|c|}
\hline \multirow[t]{3}{*}{ Outcomes } & \multicolumn{2}{|c|}{ Illustrative comparative risks* $(95 \% \mathrm{CI})$} & \multirow{3}{*}{$\begin{array}{l}\text { Relative effect } \\
(95 \% \mathrm{CI})\end{array}$} & \multirow{3}{*}{$\begin{array}{l}\text { No of Partici- } \\
\text { pants } \\
\text { (studies) }\end{array}$} & \multirow{3}{*}{$\begin{array}{l}\text { Quality of the } \\
\text { evidence } \\
\text { (GRADE) }\end{array}$} & \multirow[t]{3}{*}{ Comments } \\
\hline & Assumed risk & Corresponding risk & & & & \\
\hline & $\begin{array}{l}\text { Cisplatin-containing reg- } \\
\text { imen }\end{array}$ & Oxaliplatin-containing regimen & & & & \\
\hline $\begin{array}{l}\text { Overall Sur- } \\
\text { vival }\end{array}$ & \multicolumn{2}{|l|}{ Study population } & $\begin{array}{l}\text { HR } \mathbf{0 . 8 1} \\
(0.67 \text { to } 0.98)\end{array}$ & $\begin{array}{l}1105 \\
\text { (5 studies) }\end{array}$ & $\begin{array}{l}\oplus \oplus \ominus \ominus \\
\text { low } 1,2\end{array}$ & $\begin{array}{l}\text { Weighted aver- } \\
\text { age of median } \\
\text { survival dura- } \\
\text { tions from includ- } \\
\text { ed studies }\end{array}$ \\
\hline \multirow{4}{*}{$\begin{array}{l}\text { Tumour re- } \\
\text { sponse }\end{array}$} & \multicolumn{2}{|l|}{ Study population } & \multirow{4}{*}{$\begin{array}{l}\text { OR } 1.38 \\
\text { (1.08 to } 1.76)\end{array}$} & \multirow{4}{*}{$\begin{array}{l}1081 \\
\text { (5 studies) }\end{array}$} & \multirow{4}{*}{$\begin{array}{l}\oplus \oplus \oplus \odot \\
\text { moderate } 1\end{array}$} & \\
\hline & 468 per 1000 & $\begin{array}{l}\mathbf{5 4 8} \text { per } 1000 \\
(487 \text { to } 607)\end{array}$ & & & & \\
\hline & \multicolumn{2}{|l|}{ Moderate } & & & & \\
\hline & 458 per 1000 & $\begin{array}{l}\mathbf{5 3 8} \text { per } \mathbf{1 0 0 0} \\
\text { (477 to } 598)\end{array}$ & & & & \\
\hline \multirow{2}{*}{$\begin{array}{l}\text { Progres- } \\
\text { sion-free sur- } \\
\text { vival }\end{array}$} & \multicolumn{2}{|l|}{ Study population } & \multirow{2}{*}{$\begin{array}{l}\text { HR } 0.88 \\
(0.66 \text { to } 1.19)\end{array}$} & \multirow{2}{*}{$\begin{array}{l}1034 \\
\text { (4 studies) }\end{array}$} & \multirow{2}{*}{$\begin{array}{l}\oplus \oplus \ominus \ominus \\
\text { low } 1,3\end{array}$} & \multirow{2}{*}{$\begin{array}{l}\text { Weighted aver- } \\
\text { age of median } \\
\text { survival dura- }\end{array}$} \\
\hline & 4.9 months & 6.0 months & & & & \\
\hline
\end{tabular}




\begin{tabular}{|c|c|c|c|c|c|c|}
\hline & & & & & & $\begin{array}{l}\text { tions from includ- } \\
\text { ed studies }\end{array}$ \\
\hline \multirow{4}{*}{$\begin{array}{l}\text { Treatment-re- } \\
\text { lated death }\end{array}$} & \multicolumn{2}{|c|}{ Study population } & \multirow{4}{*}{$\begin{array}{l}\text { OR } \mathbf{0 . 4 7} \\
(0.17 \text { to } 1.30)\end{array}$} & \multirow{4}{*}{$\begin{array}{l}1132 \\
\text { (5 studies) }\end{array}$} & \multirow{4}{*}{$\begin{array}{l}\oplus \oplus \ominus \ominus \\
\text { low } 1,3\end{array}$} & \\
\hline & 20 per 1000 & $\begin{array}{l}9 \text { per } 1000 \\
(3 \text { to } 25)\end{array}$ & & & & \\
\hline & \multicolumn{2}{|l|}{ Moderate } & & & & \\
\hline & 24 per 1000 & $\begin{array}{l}11 \text { per } 1000 \\
\text { (4 to } 31)\end{array}$ & & & & \\
\hline \multirow{4}{*}{$\begin{array}{l}\text { Treatment dis- } \\
\text { continuation } \\
\text { due to toxicity }\end{array}$} & \multicolumn{2}{|c|}{ Study population } & \multirow{4}{*}{$\begin{array}{l}\text { OR } 0.97 \\
\text { (0.44 to } 2.13)\end{array}$} & \multirow{4}{*}{$\begin{array}{l}970 \\
\text { (3 studies) }\end{array}$} & \multirow{4}{*}{$\begin{array}{l}\oplus \ominus \Theta \odot \\
\text { very low 1,2,3 }\end{array}$} & \\
\hline & 95 per 1000 & $\begin{array}{l}93 \text { per } 1000 \\
\text { (44 to } 183)\end{array}$ & & & & \\
\hline & \multicolumn{2}{|l|}{ Moderate } & & & & \\
\hline & 102 per 1000 & $\begin{array}{l}99 \text { per } 1000 \\
\text { (48 to } 195 \text { ) }\end{array}$ & & & & \\
\hline
\end{tabular}

*For time-to-event outcomes, e.g. overall survival, the assumed and corresponding risks were obtained by calculating the weighted average of the median survival durations reported in included studies. For dichotomous outcomes, the assumed and corresponding risks (and their $95 \%$ confidence interval) are based on proportions of events in the control and intervention groups respectively.

Cl: Confidence interval; OR: Odds ratio; HR: Hazard ratio;

GRADE Working Group grades of evidence

High quality: Further research is very unlikely to change our confidence in the estimate of effect.

Moderate quality: Further research is likely to have an important impact on our confidence in the estimate of effect and may change the estimate.

Low quality: Further research is very likely to have an important impact on our confidence in the estimate of effect and is likely to change the estimate.

Very low quality: We are very uncertain about the estimate.

1 Downgraded by one level for risk of bias.

2 Downgraded by one level for statistical heterogeneity.

3 Downgraded by one level for imprecision.

Summary of findings 9. Taxane-platinum-fluoropyrimidine combinations versus taxane-platinum (without fluoropyrimidine) for advanced gastric cancer

Taxane-platinum-fluoropyrimidine combinations versus taxane-platinum (without fluoropyrimidine) for advanced gastric cancer 


\begin{tabular}{|c|c|c|c|c|c|c|}
\hline \multirow{4}{*}{ 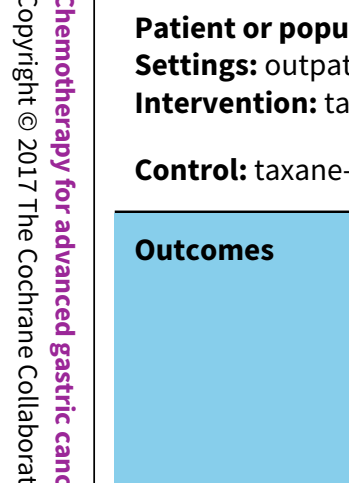 } & \multicolumn{6}{|c|}{$\begin{array}{l}\text { ulation: people with advanced gastric cancer } \\
\text { atient clinics participating in international multicentre studies, without Asian rep } \\
\text { taxane-platinum-fluoropyrimidine combinations } \\
\text { e-platinum (without fluoropyrimidine) }\end{array}$} \\
\hline & \multicolumn{2}{|c|}{ Illustrative comparative risks* $(95 \% \mathrm{CI})$} & \multirow{3}{*}{$\begin{array}{l}\text { Relative effect } \\
(95 \% \mathrm{CI})\end{array}$} & \multirow{3}{*}{$\begin{array}{l}\text { No of Partici- } \\
\text { pants } \\
\text { (studies) }\end{array}$} & \multirow{3}{*}{$\begin{array}{l}\text { Quality of the } \\
\text { evidence } \\
\text { (GRADE) }\end{array}$} & \multirow[t]{3}{*}{ Comments } \\
\hline & Assumed risk & Corresponding risk & & & & \\
\hline & $\begin{array}{l}\text { Taxane-platinum (without } \\
\text { fluoropyrimidine) }\end{array}$ & $\begin{array}{l}\text { Taxane-platinum-fluoropyrimidine com- } \\
\text { bination }\end{array}$ & & & & \\
\hline \multirow{2}{*}{$\begin{array}{l}\text { Overall sur- } \\
\text { vival }\end{array}$} & Study population & & \multirow{2}{*}{$\begin{array}{l}\text { OR } \mathbf{0 . 8 6} \\
\text { (0.71 to } 1.06)\end{array}$} & \multirow{2}{*}{$\begin{array}{l}482 \\
\text { (3 studies) }\end{array}$} & \multirow{2}{*}{$\begin{array}{l}\oplus \ominus \ominus \ominus \\
\text { very low } 1,2\end{array}$} & \multirow{2}{*}{$\begin{array}{l}\text { Weighted aver- } \\
\text { age of median } \\
\text { survival dura- } \\
\text { tions from in- } \\
\text { cluded studies }\end{array}$} \\
\hline & 10.0 months & 11.7 months & & & & \\
\hline \multirow{4}{*}{$\begin{array}{l}\text { Tumour re- } \\
\text { sponse }\end{array}$} & Study population & & \multirow{4}{*}{$\begin{array}{l}\text { OR } 2.08 \\
(1.37 \text { to } 3.15)\end{array}$} & \multirow{4}{*}{$\begin{array}{l}482 \\
\text { (3 studies) }\end{array}$} & \multirow{4}{*}{$\begin{array}{l}\oplus \oplus \ominus \ominus \\
\text { low } 1,3\end{array}$} & \\
\hline & 234 per 1000 & $\begin{array}{l}\mathbf{3 8 9} \text { per } \mathbf{1 0 0 0} \\
\text { (295 to } 491)\end{array}$ & & & & \\
\hline & \multicolumn{2}{|l|}{ Moderate } & & & & \\
\hline & 231 per 1000 & $\begin{array}{l}\mathbf{3 8 5} \text { per } \mathbf{1 0 0 0} \\
\text { (292 to } 486 \text { ) }\end{array}$ & & & & \\
\hline \multirow{2}{*}{$\begin{array}{l}\text { Progres- } \\
\text { sion-free sur- } \\
\text { vival }\end{array}$} & \multicolumn{2}{|l|}{ Study population } & \multirow{2}{*}{$\begin{array}{l}\text { OR } 0.74 \\
(0.59 \text { to } 0.93)\end{array}$} & \multirow{2}{*}{$\begin{array}{l}482 \\
\text { (3 studies) }\end{array}$} & \multirow{2}{*}{$\begin{array}{l}\oplus \oplus \oplus \ominus \\
\text { moderate } 1\end{array}$} & \multirow{2}{*}{$\begin{array}{l}\text { Weighted aver- } \\
\text { age of median } \\
\text { survival dura- } \\
\text { tions from in- } \\
\text { cluded studies }\end{array}$} \\
\hline & 4.4 months & 5.7 months & & & & \\
\hline \multirow{4}{*}{$\begin{array}{l}\text { Treatment-re- } \\
\text { lated death }\end{array}$} & Study population & & \multirow{4}{*}{$\begin{array}{l}\text { OR } 1.95 \\
(0.73 \text { to } 5.17)\end{array}$} & \multirow{4}{*}{$\begin{array}{l}482 \\
\text { (3 studies) }\end{array}$} & \multirow{4}{*}{$\begin{array}{l}\oplus \odot \ominus \ominus \\
\text { very low } 1,4\end{array}$} & \\
\hline & 26 per 1000 & $\begin{array}{l}\mathbf{5 0} \text { per } \mathbf{1 0 0 0} \\
(19 \text { to } 121)\end{array}$ & & & & \\
\hline & \multicolumn{2}{|l|}{ Moderate } & & & & \\
\hline & 13 per 1000 & $\begin{array}{l}25 \text { per } 1000 \\
\text { (10 to } 64)\end{array}$ & & & & \\
\hline
\end{tabular}




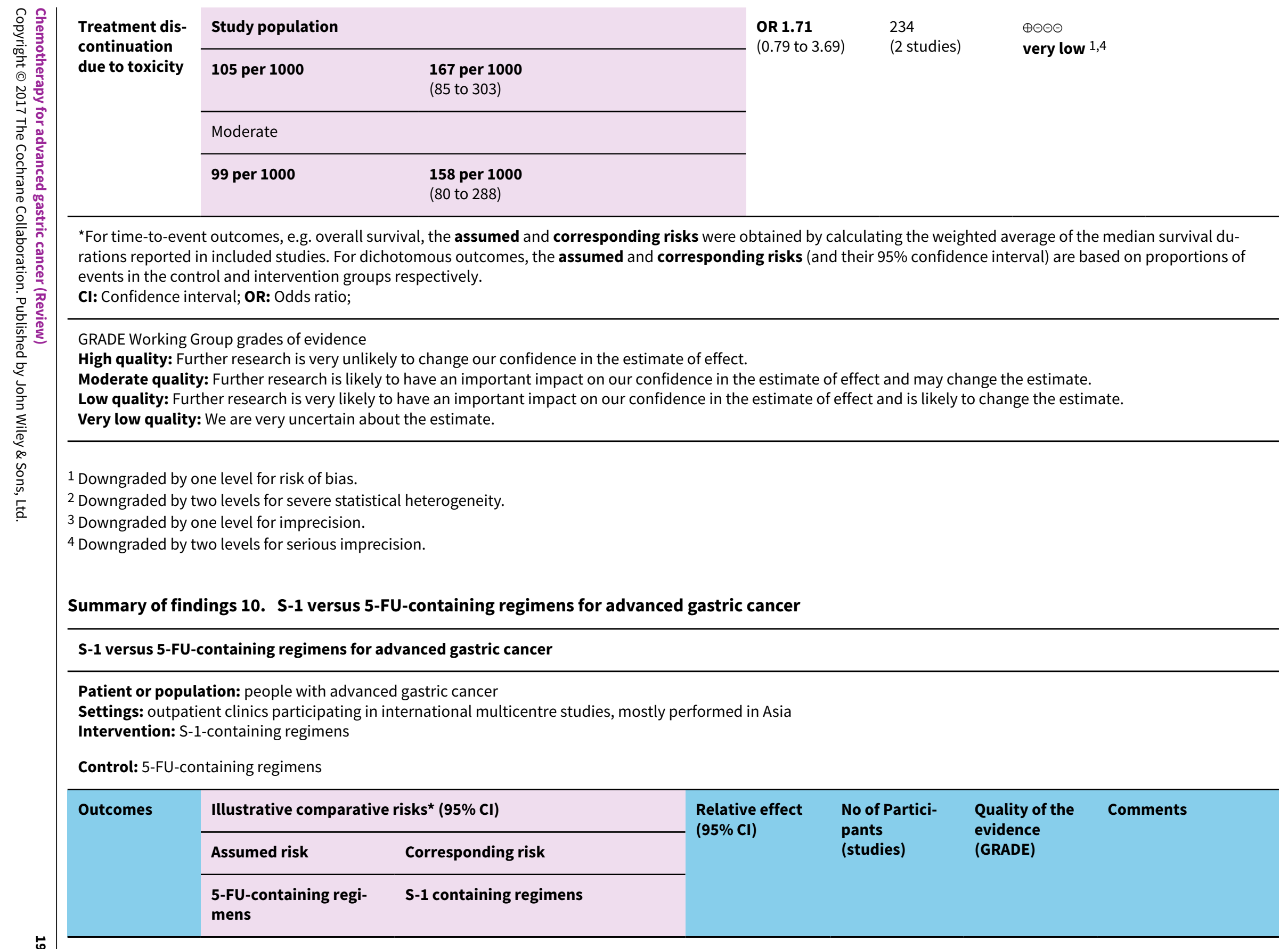

GRADE Working Group grades of evidence

作

1 Downgraded by one level for risk of bias.

2 Downgraded by two levels for severe statistical heterogeneity.

3 Downgraded by one level for imprecision.

\section{Summary of findings 10. S-1 versus 5-FU-containing regimens for advanced gastric cancer}

Patient or population: people with advanced gastric cance

Settings: outpatient clinics participating in international multicentre studies, mostly performed in Asia

Intervention: S-1-containing regimens

Control: 5-FU-containing regimens 


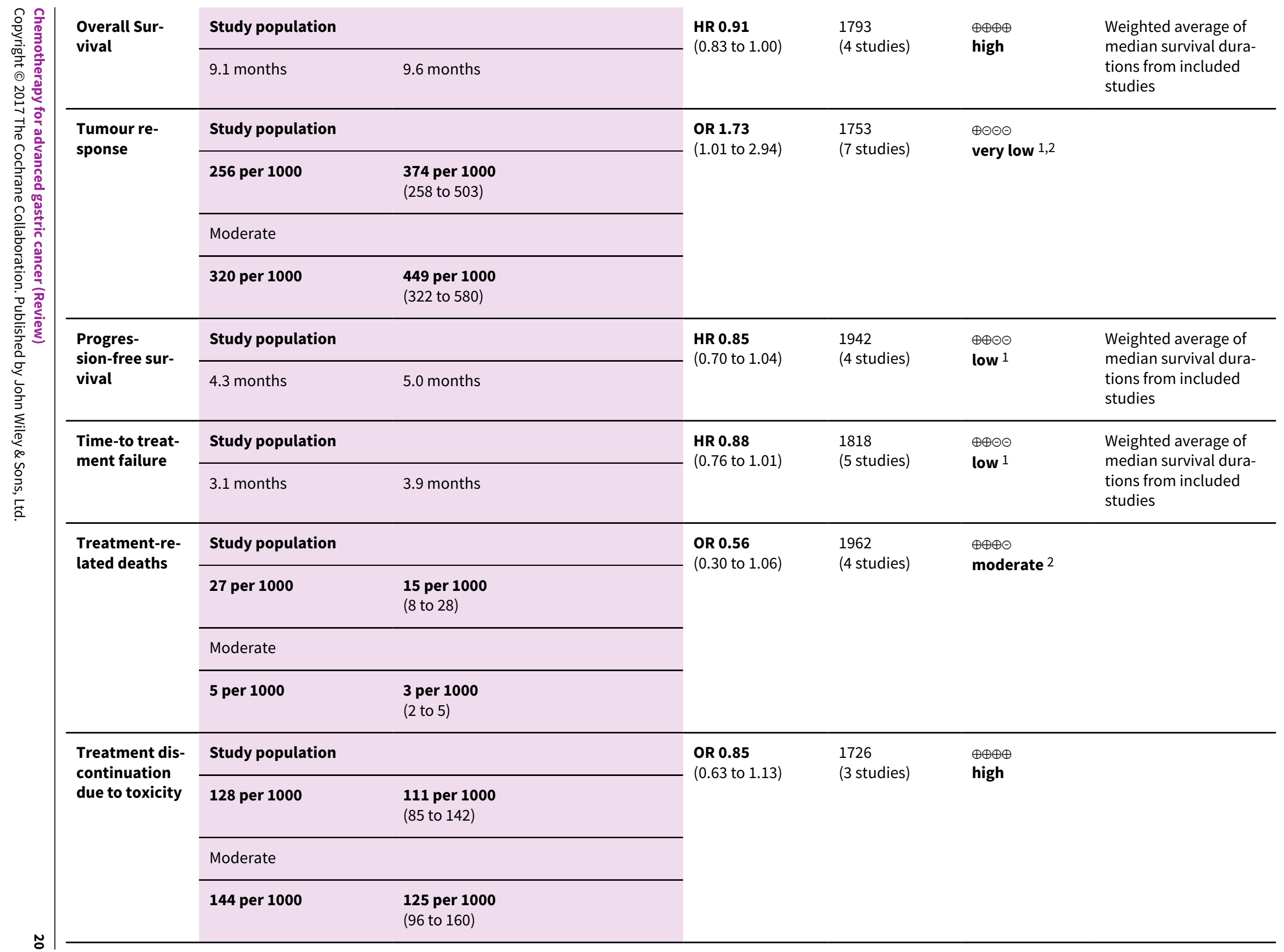




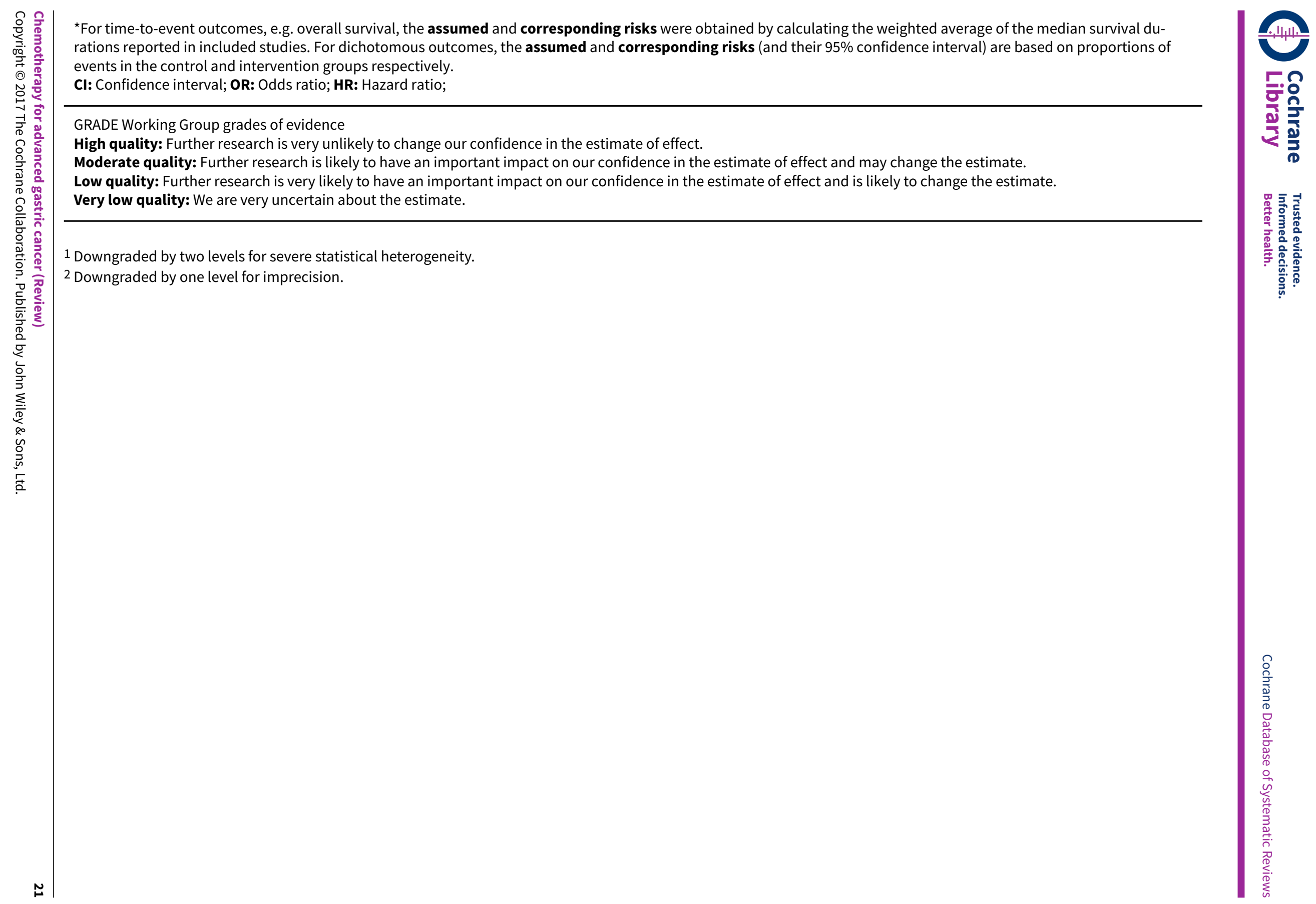




\section{B A C K G R O U N D}

\section{Description of the condition}

\section{Epidemiology and pathogenesis}

With an estimated 1.3 million new cases in 2015, gastric cancer is currently the fifth most common malignancy and the third leading cause of cancer-related mortality worldwide (GBD Cancer Collaboration 2017). Only approximately $25 \%$ of all people with gastric cancer have resectable disease at presentation. Stomach cancer incidence rates show substantial variation internationally, with endemic regions in Asia, Eastern Europe and South America (Ferro 2014). Helicobacter pylori, atrophic gastritis, intestinal metaplasia, and dysplasia have been identified as important steps in the pathogenesis of gastric cancer (Correa 1996). Due to improvements in food conservation and diet, as well as eradication of Helicobacter pylori, gastric cancer incidence and mortality has steadily fallen in the last 50 years (Peleteiro 2012).

In contrast, a dramatic rise in cardial and gastroesophageal junction tumour incidence rates has been observed in middleaged, male, white Caucasians (Abrams 2013; Sharma 2003; Wu 2001). A proportion of these cases seems to be associated with Barrett's epithelium (intestinal metaplasia of the distal oesophagus), developing from chronic oesophageal reflux disease (MacDonald 1992; Wu-Williams 1990). Although it is difficult to determine whether these cancers are gastroesophageal junction tumours or distal oesophageal malignancies (Rusch 2004), in clinical studies for advanced disease they are usually treated in the same manner.

Gastric cancer is a heterogenous disease entity, with major differences in growth patterns, differentiation, and molecular pathogenesis. More than $90 \%$ of stomach tumours are adenocarcinomas. While Lauren already in 1965 distinguished (Lauren 1965) the well-differentiated or intestinal type and the undifferentiated or diffuse-type, the current World Health Organization (WHO) classification Bosman 2010 differentiates the following five major histopathological subtypes: papillary, tubular, and mucinous adenocarcinoma, as well as poorly cohesive (with or without signet cells) and mixed carcinoma. While the first three types correspond to the former "well differentiated or intestinal type", the undifferentiated or diffuse type according to Lauren corresponds to the poorly cohesive type in the current classification.

While the intestinal type is more common in males, older age groups, and in high-risk geographic areas, diffuse-type carcinomas have a more equal male to female distribution, are more frequent in younger individuals, and have a more uniform geographic distribution (Crew 2004; Kelley 2003; Lauren 1965; Munoz 1968). Ninety per cent of gastric cancers are sporadic. Hereditary diffuse gastric cancer is rare, with less than $3 \%$ of cases. According to a recently published landmark paper (TCGA 2014), which describes the results of a comprehensive molecular evaluation of 295 primary gastric adenocarcinomas as part of The Cancer Genome Atlas (TCGA), the following four molecular subtypes can be distinguished.

1. Tumours positive for Epstein-Barr virus, which display recurrent PIK3CA mutations, extreme DNA hyper methylation, and amplification of JAK2, CD274 (also known as PD-L1) and PDCD1LG2 (also known as PD-L2).
2. Microsatellite unstable tumours, which show elevated mutation rates.

3. Genomically stable tumours, which are enriched for the diffuse histological variant and mutations of RHOA or fusions involving RHO-family GTPase-activating proteins.

4. Tumours with chromosomal instability, which show marked aneuploidy and focal amplification of receptor tyrosine kinases.

While this classification has no impact in the choice of systemic treatment at present, it will provide a roadmap for patient stratification and development of targeted therapies in the future.

In contrast, the over expression of the Human Epidermal growth factor Receptor-2 (HER-2), which is observed in $10 \%$ to $20 \%$ of the people, is clinically relevant today as it predicts a significant benefit from treatment with trastuzumab (Bang 2010). Further details of the pathogenesis of gastric cancer have been reviewed recently by Wadhwa and colleagues (Wadhwa 2013).

\section{Prognosis and management options}

Apart from endoscopic treatment for a minority of very small tumours, partial or complete gastrectomy with lymphadenectomy is the only potentially curative therapy for gastric cancer. Stage I to IV M0 tumours are principally resectable (MacDonald 2001a). However, although surgery carries a high cure rate for stage IA and IB cancers, the results for stage IIIA and IIIB cancers are poor. Many people with advanced disease, especially stage IIIA/B, are technically inoperable. Results for both resectable and locally advanced gastric cancer may be improved by either perioperative (e.g. Cunningham 2006; Ychou 2011) or adjuvant chemotherapy (Bang 2012; Paoletti 2013; Sakuramoto 2007). Unfortunately, even after an apparently 'curative' gastrectomy, relapse rates in prospective studies remain in the range of $40 \%$ to $60 \%$ (Bonenkamp 1999; Cunningham 2006; MacDonald 2001b; Songun 2010) in European studies. In the Western world, most people are diagnosed at an advanced stage, when the tumour is inoperable. People with inoperable, recurrent or metastatic tumours have a poor prognosis with a median survival time of three to five months without chemotherapy. Several small randomised studies have provided evidence that first-line chemotherapy improves survival in these people (Glimelius 1994; Pyrhönen 1995; Scheithauer 1996), but benefit has to be weighed against treatment-related toxicities. Furthermore, second-line chemotherapy has shown to improve survival and quality of life in several recent randomised studies (Ford 2014; Kang 2012; Thuss-Patience 2011).

While a significant number of phase-III studies have studied the value of targeted therapies in advanced gastric cancer (e.g. Lordick 2013; Ohtsu 2011; Ohtsu 2013; Satoh 2014), only three phase III studies (Bang 2010; Fuchs 2014; Wilke 2014) have had positive results and impact on clinical practice:

According to the randomised phase III "TOGA" study (Bang 2010), response rate, progression-free- and overall survival are greatly improved by adding the monoclonal antibody trastuzumab to the combination of cisplatin and capecitabine in HER-2 positive gastric cancer, and introduced trastuzumab as a standard of care for HER-2 positive disease. This study changed the workup of all people with advanced gastric cancer since all people with advanced gastric cancer must now undergo HER-2 testing before the initiation of any chemotherapy and, in the absence of contraindications, be treated with trastuzumab in combination with cisplatin and 5-FU 
or capecitabine in case of HER-2 over expression on IHC (IHC 3+, or $\mathrm{IHC} 2+/ \mathrm{FISH}+$ ). All other treatment options discussed in this review (oxaliplatin, irinotecan, docetaxel, as well as the anthracyclinecontaining regimen ECF) are therefore valid only for people with HER-2 negative disease. Studies on combinations of other chemotherapies with trastuzumab are currently limited to phase II and cannot be recommended for this reason. Furthermore, the VEGF-receptor-targeting antibody ramucirumab, with or without chemotherapy, has been evaluated in two phase III studies as second-line treatment, and emerged as a new treatment option in this indication. Thus, despite this recent progress, chemotherapy remains the mainstay of treatment for the majority of people with advanced gastric cancer.

\section{Description of the intervention}

\section{Systemic chemotherapy}

5-FU is not only the most important and extensively studied single agent in this disease, but it is part of most combination chemotherapy regimens as well. Its single-agent response rate is about 20\%. Differences in effect and toxicity profile are the reasons for its application as continuous infusion. Oral capecitabine (Cunningham 2008) or S-1 (Ajani 2010) may replace infusional 5-FU, thus avoiding the risk and inconvenience associated with portable pumps. Other single agents with relevant activities are cisplatin (Leichman 1991) and anthracyclines (Preusser 1988). Furthermore, oxaliplatin, docetaxel, and irinotecan have been evaluated in recent phase III studies (Al Batran 2008; Cunningham 2008; Dank 2008; Van Cutsem 2006).

\section{How the intervention might work}

5-FU, an antimetabolite, pyrimidine-antagonist and inhibitor of thymidilate-synthethase is the backbone of chemotherapy in gastric cancer. Capecitabine is an oral fluoropyrimidine that is selectively activated in tumour tissue by a three-step enzymatic conversion, S-1 another oral fluoropyrimidine. Cisplatin is an alkylan, which acts through induction of intra- and interstrand crosslinks. The diamino-cyclohexane platinum derivative oxaliplatin also leads to the formation of DNA crosslinks, but they are not recognised by the intracellular mismatch repair system. Docetaxel, as well as paclitaxel are agents which inhibit depolymerization of micro tubuli. Irinotecan is an inhibitor of topoisomerase I, thereby disrupting DNA replication and cell division. These drugs have major differences in their toxicity profile.

\section{Why it is important to do this review}

Combination chemotherapy has become an accepted standard for first-line treatment. Although a large number of different regimens have been tested in randomised studies, uncertainty remains regarding the choice of the regimen.

\section{O B JECTIVES}

To evaluate the effect of chemotherapy in participants with advanced adenocarcinoma of the stomach and gastroesophageal junction.

\section{Comparisons were as follows.}

1. First-line chemotherapy plus best supportive care (BSC) versus BSC alone.
2. First-line combination versus single-agent chemotherapy.

3. First-line 5-FU/cisplatin/anthracycline-containing combinations versus 5-FU/cisplatin combinations (without anthracyclines).

4. First-line 5-FU/cisplatin/anthracycline-containing combinations versus 5-FU/anthracycline combinations (without cisplatin).

5. First-line chemotherapy with irinotecan versus non-irinotecancontaining regimens.

6. First-line chemotherapy with docetaxel versus non-docetaxelcontaining regimens.

7. First-line chemotherapy with capecitabine versus 5-FUcontaining regimens.

8. First-line chemotherapy with oxaliplatin versus the same regimen containing cisplatin.

9. First-line taxane-platinum-fluoropyrimidine combinations versus taxane-platinum (without fluoropyrimidine).

10.First-line S-1 versus 5-FU-containing regimens.

Due to limited information, we considered second-line therapy only in selected sensitivity analyses of first-line therapy where data were available. In addition to comparisons 1 and 2, which were planned and described in the first version of the protocol, we performed two more comparisons ( 3 and 4 ) in the original version of the review (Wagner 2005). As there was a large number of categories of different combination chemotherapy regimens and the number of relevant studies in each category was not known when writing the protocol, it was impossible to plan in advance the best way to compare directly the different categories of combination chemotherapies. We chose to perform these additional comparisons based on their clinical relevance and the availability of a sufficient number of relevant studies.

In the first update of this review (Other published versions of this review, Wagner 2010), comparisons (5) to (8) (5: First-line chemotherapy with irinotecan versus non-irinotecan-containing regimens, 6: First-line chemotherapy with docetaxel versus non-docetaxel-containing regimens, 7: First-line chemotherapy with capecitabine versus 5-FU-containing regimens, 8: First-line chemotherapy with oxaliplatin versus the same regimen containing cisplatin were added. In this second update,comparisons (9) to (10) (9: First-line taxane-platinum-fluoropyrimidine combinations versus taxane-platinum (without fluoropyrimidine) and 10: Firstline S-1 versus 5-FU-containing regimens) were added (see Differences between protocol and review).

\section{METHODS}

\section{Criteria for considering studies for this review}

\section{Types of studies}

We included only randomised controlled studies, with or without blinding. We included abstracts or unpublished data if sufficient information on study design, characteristics of participants, interventions, and outcomes was available and if full information and final results were confirmed by the first author. We excluded cross-over studies in order to assess the overall treatment effect on survival. We excluded quasi-randomised studies, e.g. treatment allocation alternate or by date of birth, as we considered this study design to be not of sufficiently high quality. 


\section{Types of participants}

We included participants with histologically confirmed, unresectable (as decided by a multidisciplinary team), recurrent or metastatic adenocarcinoma of the stomach or gastroesophageal junction without any prior chemotherapy or radiotherapy for comparisons 1 to 10. We also included studies which included participants with adenocarcinoma of the distal oesophagus. Most studies included participants with locally advanced, relapsed and/ or metastatic tumours, with the greater number of participants already having metastatic disease. However, in some studies only participants with locally advanced cancer of the stomach were reported in order to assess secondary resectability. We did not consider these studies in this review. The proportion of participants with locally advanced versus metastatic tumours is given for each study.

\section{Types of interventions}

We included studies of systemic intravenous or oral, first-line chemotherapy and/or best supportive care (BSC). Chemotherapy encompasses all cytotoxic or anti-neoplastic drug treatment, but excluding hormonal, biological, or targeted therapies, which are the subject of a separate Cochrane review (Song 2016). However, studies on targeted therapies with clinical impact, as well as studies on second-line chemotherapy are considered in the discussion.

We included single-agent as well as combination chemotherapy studies in all doses and schedules, but did not consider combined radio-chemotherapy.

\section{Types of outcome measures}

\section{Primary outcomes}

1. Overall survival on intention-to-treat analysis. Median, one-, two- and three-year as well as five-year survival in participants with locally advanced, secondary resectable tumours.

\section{Secondary outcomes}

1. Tumour response.

2. Time to progression.

3. Secondary resectability in participants with locally advanced gastric cancer.

4. Toxicity, classified according to WHO or National Cancer Institute Common Toxicity Criteria ( $\mathrm{NCl}-\mathrm{CTC}$ ).

Quality of life is difficult to measure and was assessed with various instruments. Quality of life results of recent phase-III studies are described in the results section and considered in the discussion if available.

\section{Search methods for identification of studies}

\section{Electronic searches}

We originally identified studies by searching the Cochrane Central Register of Controlled Trials (CENTRAL) (the Cochrane Library 2004, Issue 1), MEDLINE, and Embase up to February 2004 and reference lists of articles. We also contacted pharmaceutical companies as well as national and international experts. We updated searches in all databases in March 2009, January 2013, February 2014 and June 2016.
The Cochrane Highly Sensitive Search Strategy for identifying randomised studies in MEDLINE, sensitivity-maximising version, Ovid format (Higgins 2008) was combined with the search terms in the Appendices to identify randomised controlled studies in MEDLINE. The MEDLINE search strategy was adapted for use in the other databases searched. The search strategies are documented in Appendix 1; Appendix 2 and Appendix 3. We did not confine our search to English language publications.

In addition, we searched the following databases of ongoing studies: http://www.controlled-trials.com; http:// www.clinicaltrials.nci.nih.gov; http://www.eortc.be; http:// www.update-software.com/National/nrr-frame.html and http:// www.CenterWatch.com.

\section{Searching other resources}

We handsearched reference lists from studies selected by electronic searching to identify further relevant studies. We also handsearched published abstracts from conference proceedings from the European Society for Medical Oncology from 1978 (published in the Annals of Oncology), the European Council of Clinical Oncology from 1981 (published in the European Journal of Cancer), as well as the American Society for Clinical Oncology from 1981. All searches were updated in June 2016.

\section{Data collection and analysis}

\section{Selection of studies}

Two independent review authors initially scanned the title, abstract section, and keywords of every record retrieved. We retrieved full-text articles for further assessment if the information given suggested that the study included participants with histologically confirmed, inoperable adenocarcinoma of the stomach or gastroesophageal junction, used random allocation to the comparison groups and compared the following.

1. Best supportive care (BSC) versus chemotherapy plus BSC.

2. Combination versus single-agent chemotherapy.

3. 5-FU/cisplatin/anthracycline-containing combinations versus 5$\mathrm{FU} /$ cisplatin combinations (without anthracyclines).

4. 5-FU/cisplatin/anthracycline-containing combinations versus 5$\mathrm{FU} /$ anthracycline combinations (without cisplatin).

5. Irinotecan versus non-irinotecan-containing regimens.

6. Docetaxel versus non-docetaxel-containing regimens.

7. Capecitabine versus 5-FU-containing regimens.

8. Oxaliplatin versus the same regimen including cisplatin.

9. Taxane-platinum-fluoropyrimidin combinations versus taxaneplatinum (without fluoropyrimidine).

10.S-1 versus 5-FU-containing regimens.

If there was any doubt regarding these criteria from the information given in the title and abstract, we retrieved the full-text article for clarification. If differences in opinion existed, they were resolved by discussion.

\section{Data extraction and management}

Two review authors independently extracted details of study population, interventions, and outcomes. We resolved differences in data extraction by consensus with a third review author, referring 
back to the original article. If data were missing in a published report, we contacted the primary author.

Data extraction included the following items.

1. General information: title, authors, source, contact address, country, published/unpublished, language and year of publication, sponsoring of study.

2. Study characteristics, including design, duration/follow up, and quality assessment criteria as specified above.

3. Participants: inclusion and exclusion criteria, sample size, baseline characteristics, similarity of groups at baseline, withdrawals, and losses to follow-up.

4. Interventions: dose, route, timing of chemotherapy, and comparison intervention.

5. Outcomes: hazard ratios and their $95 \%$ confidence intervals or standard error, log rank $\mathrm{Chi}^{2}$, log rank $\mathrm{P}$ values, number of events, number of participants per group, median, one-, two- and three-year survival rates and five-year survival rates in participants with locally advanced, secondary resectable tumours.

\section{Assessment of risk of bias in included studies}

In this updated version of the review, we independently assessed the risk of bias of the included studies using the 'Risk of bias' assessment tool described in Chapter 8 of theCochrane Handbook for Systematic Reviews of Interventions (Higgins 2011). We compared the evaluations, and discussed and resolved any inconsistencies between the review authors' decisions.

We rated the following domains separately for each of the included studies as 'low risk of bias', 'high risk of bias', and 'unclear' when the risk of bias was uncertain or unknown:

1. generation of allocation sequence ('sequence generation');

2. concealment of allocation ('allocation concealment');

3. prevention of knowledge of the allocated interventions during the study ('blinding');

4. methods used to address incomplete outcome data;

5. selective outcome reporting;

6. other sources of bias that could put a study at high risk of bias, including whether a calculation of sample size was carried out including baseline comparability. We considered tumour stage (advanced versus metastatic disease) and activity index (Eastern Cooperative Oncology Group status 0 to 1 versus 2 to 3), as well as the number of organs involved in metastatic disease (one versus more than one) as the most important prognostic factors. We considered a difference of more than 15\% between study arms as an important difference. For age, as a further important factor, we considered baseline differences of five years as important. We also assessed intention-to-treat (ITT) analysis. We considered ITT analysis as randomised analysis, with the analysis restricted to participants who received at least one cycle of chemotherapy, and for which survival data were available. Alternatively, we also considered studies including all participants as randomised in the analysis as ITT. In addition, we analysed the risk of bias and described this in the 'Risk of bias' tables.

These assessments are reported in the 'Risk of bias' table for each individual study in the 'Characteristics of included studies' section of the review, and in the 'Risk of bias in included studies' section of this review.

\section{Measures of treatment effect}

\section{Data analysis}

We estimated hazard ratios (HR) and $95 \%$ confidence intervals (CI) as relevant effect measures directly or indirectly from the given data (Altman 2001). For each individual study, we extracted HRs and their variances. If the figures were not given directly, methods of indirect determination were used. HRs can be estimated (under some assumptions) from log rank $\mathrm{Chi}^{2}$, from log rank $\mathrm{P}$ values, from observed to expected event ratios and from ratios of median survival times or time point survival rates (Machin 1997; Parmar 1998; Tierney 2007). In several instances, medians and/or number of events had to be read from the graphs. If both medians and survival rates at fixed time points were given, the medians were preferred. If we had to pool several arms of a study, we approximated the common median by the weighted mean of the medians given for the various arms.

For instance, statistical measures were taken to avoid doublecounting the irinotecan-treated population in Bouche 2004, which was a three-arm study which compared 5-fluorouracil versus 5fluorouracil plus cisplatin versus 5 -fluorouracil plus irinotecan. For Comparison 5, we estimated the hazard ratios for the irinotecancontaining arm $(\mathrm{N}=45)$ versus the non-irinotecan-containing arms $(\mathrm{N}=89)$, which was not provided in the original report by Bouche 2004.

\section{Unit of analysis issues}

Participants were individually randomised into two or more treatment groups. The effect of the intervention was measured and analysed on the basis of single measurements for each outcome for each participant. For studies with more than one intervention arm, we combined groups to create a single pair-wise comparison as follows: the single-agent therapy arm with the pooled results of both combination chemotherapy arms; the combination-therapy arm was compared with the pooled results of both single agent arms; or the pooled results of the sequential therapy arms were compared with the pooled results of the concurrent therapy arms.

\section{Dealing with missing data}

We attempted to contact investigators to obtain missing data.

\section{Assessment of heterogeneity}

We assessed the heterogeneity in each pair-wise comparison by assessing the Higgins $\mathrm{I}^{2}$ (Higgins 2003), the $\mathrm{Chi}^{2}$ test with significance set at a $\mathrm{P}$ value less than 0.1 , and by visual inspection.

\section{Data synthesis}

We used the fixed-effect model for meta-analysis, with overall survival as the primary outcome measure. Where heterogeneity levels were high $\left(I^{2}>20 \%\right.$ or $P$ value $\left.<0.1\right)$, we used a random-effects model (see Differences between protocol and review). We used Review Manager software for data synthesis (RevMan). . Previously SAS was used for more sophisticated analysis. We recalculated (or at least approximated) all outcomes concerning overall survival by using hazard ratios. 


\section{Quality of Evidence (GRADE) and 'Summary of findings' tables}

We used the GRADEprofiler (GRADEpro) software to assist with the preparation of the 'Summary of findings' tables. The 'Summary of findings' tables provide key information about the pooled estimate of the magnitude of the effect in relative terms, assumed and control risks, numbers of participants and studies addressing each important outcome, and the quality of evidence for the comparisons for each outcome.

We included the following outcomes in the 'Summary of findings' tables.

1. Overall survival

2. Tumour response

3. Progression-free survival; and/or time-to-progression; and/or time-to-treatment failure

4. Treatment-related death

5. Treatment discontinuation due to toxicity

We assessed the quality of evidence as 'High', 'Moderate', 'Low' or 'Very Low' using the Grades of Recommendation, Assessment, Development and Evaluation (GRADE) methodology, which evaluates the totality of included studies for their risk of bias (study limitations), consistency, imprecision, indirectness, and publication bias.

\section{Subgroup analysis and investigation of heterogeneity}

In seeking statistical heterogeneity between studies, we performed Cochrane's Q-test (with a significance threshold of alpha = 0.1 ). Additionally, we calculated heterogeneity quantitatively
(Thompson 2002). We considered the following factors as possible sources of heterogeneity:

1. differences in prognostic factors;

2. quality of studies;

3. second-line therapy permitted versus no second-line therapy;

4. Asian versus non-Asian studies;

5. substitutive, additive, and other comparisons in comparisons 5 and 6.

\section{Sensitivity analysis}

We conducted a sensitivity analysis by repeating the primary analysis and investigated the influence of risk of bias, adequate allocation concealment, excluding those studies which were conducted in Asia and studies with second-line therapies.

\section{RE S U L T S}

\section{Description of studies}

\section{Results of the search}

We identified a total of 2925 records through electronic searches of CENTRAL, MEDLINE, Embase and databases of clinical trials. After removing duplicates, 2597 records remained. We excluded 2495 references which were clearly irrelevant through screening titles and reading abstracts. We retrieved 102 references for further assessment. We excluded 195 studies and are listed in the table Characteristics of excluded studies. Twenty-six new studies were identified for inclusion. Please see Figure 1 for the flowchart of the systematic search performed in June 2016. 
Figure 1. Study flow diagram: review update

\section{8 studies included in previous} version of review

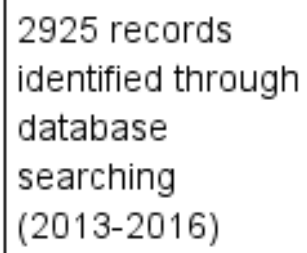

16 additional records identified through other sources

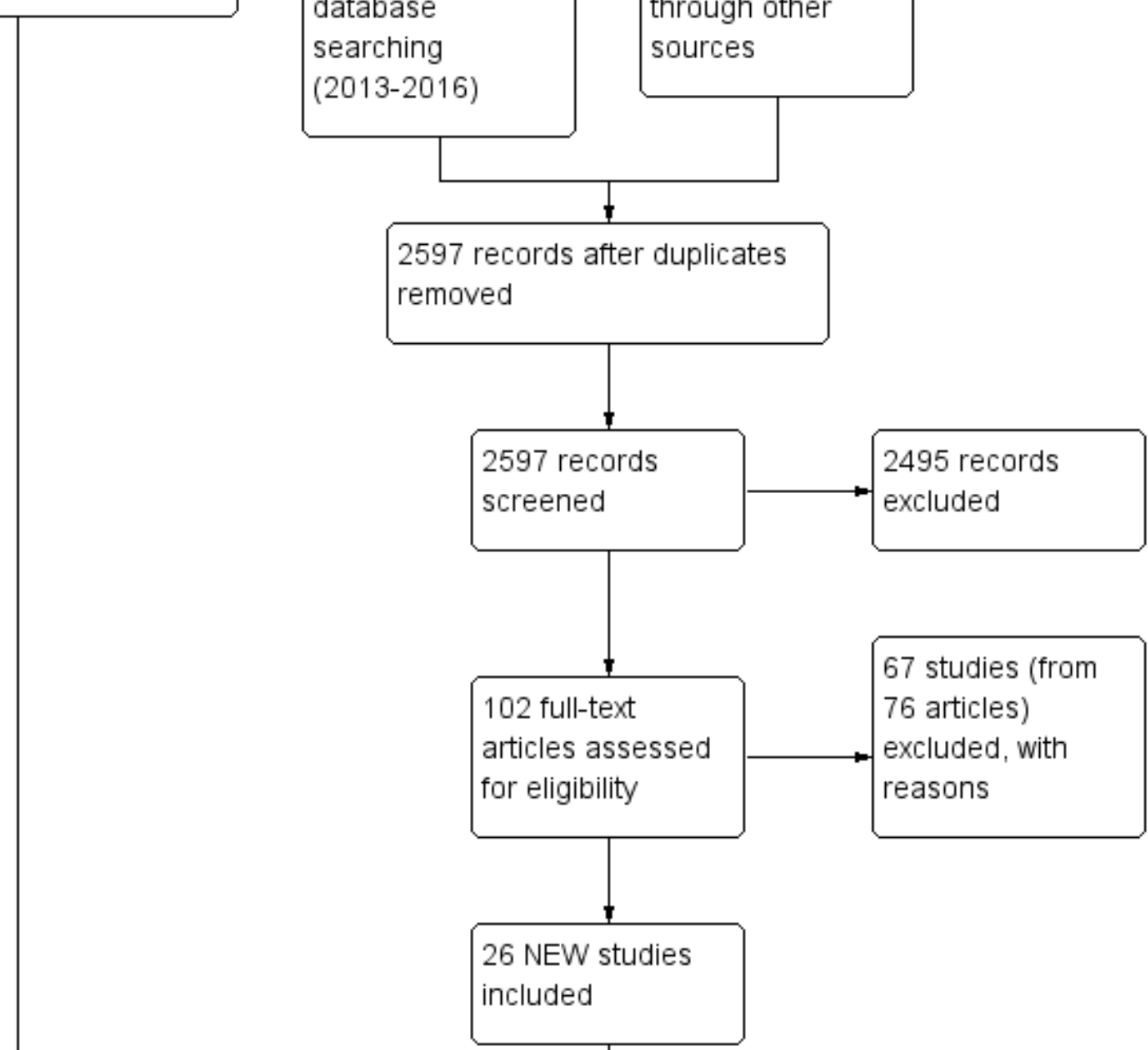

64 studies included in qualitative synthesis

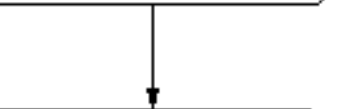

60 studies included in quantitative synthesis (meta-analysis) 


\section{Included studies}

Three eligible studies with 184 participants were identified for analysis of comparison 1: chemotherapy versus best supportive care (BSC). The study by Scheithauer 1996 was published as an abstract only, but all relevant information was provided by the author. For more details of the included studies, please see Characteristics of included studies.

Approximately $50 \%$ of the study investigators provided further information. Data about survival and response rates were given in most publications. Information about second-line therapy was either reported in the text or provided by the authors only in a limited number of studies.

Twenty-three studies, which included 4447 participants, were included in the analysis of comparison 2, which is combination versus single-agent chemotherapy. In studies that included more than one single or combination chemotherapy arm, different arms were combined in the analysis as specified below. Comparisons 3 and4 included 579 and 1147 participants in four and seven studies. Comparison 5 included 10 studies with a total of 2135 participants and comparison 6 includes at present overall survival data from eight studies including a total of 2001 participants. Comparisons 7 and $\mathbf{8}$ included 732 and 1105 participants from two and five studies, respectively. Two new comparisons (9) and (10) with 482 and 1793 participants from three and four randomised studies, respectively were added in the current update.

It should be noted that some studies may appear in more than one comparison if they meet relevant criteria for inclusion. For instance, Hironaka 2016; Koizumi 2014; Komatsu 2011; Narahara 2011; Ochenduszko 2015 were included in two comparisons; while Boku 2009 was included in three comparisons.

\section{Participants}

The median age of the participants in the population of studies included in the analysis of comparisons $\mathbf{1}$ and $\mathbf{2}$ was in the range of 56 to 67 years. The proportion of participants with metastatic disease was between 62\% (Cullinan 1985) and 100\% (Bouche 2004; Koizumi 2008; Yamamura 1998). When comparing the different arms of one study, a difference in the proportion of participants with advanced versus metastatic disease greater than $15 \%$ between study arms was identified in only one study (Popov 2002), with a larger number of metastatic participants in the combination chemotherapy arm (90\% versus $73 \%)$. Performance status was well-balanced in all studies with no differences greater than $15 \%$ between study arms. The percentage of participants with ECOG $2+3$ was in the range of $0 \%$ to $48 \%$. Thirteen studies, which included 3182 participants (Boku 2009; Hironaka 2016; Koizumi 2008; Koizumi 2014; Komatsu 2011; Lu 2014; Narahara 2011; Nishikawa 2012; Ohtsu 2003; Shirao 2013; Wang 2013; Wu 2015; Yamamura 1998), were conducted in Asia.

Regarding comparisons 3 and4, the median age of participants included in these 11 studies was between 58 and 65 years. Between 46\% (Kikuchi 1990) and 90\% (Cascinu 2011; Kim 2001) of participants had metastatic disease, the percentage of participants with ECOG 2+3 was between 6\% (Cascinu 2011) and 88\% (Kikuchi 1990). The percentage of participants with advanced versus metastatic disease was well-balanced in all studies included in these two comparisons.
The participants in comparison $\mathbf{5}$ had a median age between 58 (Dank 2008) and 70 (Komatsu 2011) years in the different study arms, with the majority of participants having metastatic disease.

The median age of the participants in comparison $\mathbf{6}$ was between 55 (Roth 2007; Van Cutsem 2006) and 70 years (Al-Batran 2013). The percentage of participants with metastatic disease was between 69\% (Al-Batran 2013; Ochenduszko 2015) and 98\% (Thuss-Patience 2005), with the largest study having $97 \%$ of participants with metastatic disease and a median age of 55 years (Van Cutsem 2006). Most participants in these studies had a performance status of 0 or 1.

Regarding comparisons $\mathbf{7}$ and8, the median age of participants included in these studies was between 55 (Ocvirk 2012) and 65 years (Yamada 2015). Between 62\% (Kim 2014) and 100\% (Li 2016) had metastatic disease and most participants had a performance status of 0 or 1 . Only in Popov 2008 the percentage of participants with ECOG 2-3 was $29 \%$.

The median age of the participants included in comparisons 9 and $\mathbf{1 0}$ was between 54 (Ajani 2005; Huang 2013; Li 2015) and 76 years (Boku 2009), between $86 \%$ (Roth 2007) and 95\% to $100 \%$ of participants (Ajani 2005; Ajani 2010; Chen 2015) had metastatic disease. Most participants in these studies had a performance status of 0 or 1 .

Groups of participants were well-balanced regarding the most important prognostic factors as specified above in all studies included into comparisons 3 to 8 .

\section{Interventions}

Participants were individually randomised into two or more treatment groups. The effect of the intervention was measured and analysed on the basis of single measurements for each outcome for each participant. In 11 studies, more than two groups with different interventions were compared (Boku 2009; Bouche 2004; Cullinan 1985; Cullinan 1994; Hironaka 2016; Loehrer 1994; Lutz 2007; Nishikawa 2012; Ohtsu 2003; Roth 2007).

In the studies by Bouche 2004, Lutz 2007, Ohtsu 2003, and Hironaka 2016 the single-agent therapy arm was compared with the pooled results of both combination chemotherapy arms. In Loehrer 1994, Cullinan 1994, and Boku 2009 , the combination-therapy arm was compared with the pooled results of both single-agent arms. In Nishikawa 2012, the pooled results of the sequential therapy arms were compared with the pooled results of the concurrent therapy arms. All these studies were included in the comparison of singleagent versus combination chemotherapy.

Furthermore, the irinotecan-containing combination chemotherapy was compared to the pooled results of the nonirinotecan-containing combination chemotherapies and included in comparison 5 in 10 studies (Boku 2009; Bouche 2004; Dank 2008; Komatsu 2011; Li 2016; Moehler 2005; Moehler 2010; Narahara 2011; Roy 2012; Sugimoto 2014), and the pooled results of the docetaxel-containing chemotherapies were compared with the non-docetaxel-containing combination chemotherapy and included in comparison 6 in eight studies (Al-Batran 2013; Koizumi 2014; Ochenduszko 2015; Ridwelski 2008; Roth 2007; ThussPatience 2005; Van Cutsem 2006; Wang 2016). 
All three studies included in the analysis of comparison 1 used combination therapy regimens in the chemotherapy arm (Murad 1993: FAMTX; Pyrhönen 1995: FEMTX; Scheithauer 1996: 5-FU/LV/ Epirubicin).

Regarding comparison 2, most studies used 5-FU in the singleagent arm. In six of 17 studies (Barone 1998; Colucci 1995; Cullinan 1985; Cullinan 1994; De Lisi 1986; Loehrer 1994), 5-FU was given as a bolus in doses of approximately $500 \mathrm{mg} / \mathrm{m}^{2}$ days one to five every four weeks. A continuous infusion regimen was used in two studies, with either $2600 \mathrm{mg} / \mathrm{m}^{2}$ every two weeks (Popov 2002), $800 \mathrm{mg} / \mathrm{m}^{2}$ per day (Ohtsu 2003) on days one to three every four weeks or a bolus of $400 \mathrm{mg} / \mathrm{m}^{2} 5$-FU, followed by 600 $\mathrm{mg} / \mathrm{m}^{2}$ as a two-hour continuous infusion on days one and two every two weeks (Bouche 2004). One study (Levi 1986), applied doxorubicin $60 \mathrm{mg} / \mathrm{m}^{2}$ every four weeks in the single-agent arm. In the study by Loehrer 1994, the results from two single-agent arms (5-FU bolus $500 \mathrm{mg} / \mathrm{m}^{2}$ days one to five and epirubicin 90 $\mathrm{mg} / \mathrm{m}^{2}$ day one every four weeks) were combined in the analysis. In addition, in the studies by Bouche 2004, Lutz 2007, Nishikawa 2012, and Ohtsu 2003 , the results of two combination therapy arms (LV5FU2/cisplatin and LV5FU2/irinotecan, D-FU/FA and HD-FU/FA/ cisplatin, 5-FU/paclitaxel and S-1/paclitaxel, 5-FU/cisplatin, and tegafur/mitomycin C) were combined in the analysis. Nishikawa 2012 used 5-FU in doses of $800 \mathrm{mg} / \mathrm{m}^{2}$ in days one to five every four weeks in one group or daily S-1 in doses of $80 \mathrm{mg} / \mathrm{m}^{2}$ for four weeks and a two-week rest in the single-agent arm until progression. This therapy was followed by paclitaxel $\left(80 \mathrm{mg} / \mathrm{m}^{2}\right.$ on days one, eight and 15 every four weeks). A similar regimen of S-1 was used in Narahara 2011 and Komatsu 2011. Boku 2009 used the same 5-FU regimen in one arm or lower doses of S-1 $\left(40 \mathrm{mg} / \mathrm{m}^{2}\right.$ for four weeks and a two-week rest) in the single-agent arm. Results of two arms were combined in the single-agent arm in Boku 2009; Cullinan 1994 and Nishikawa 2012. Wang 2013 used S-1 according to body-surface area with $40 \mathrm{mg}$ twice daily for participants with a body surface area greater than 1.25 and lower than 1.5 for two out of four weeks. Koizumi 2008 and Hironaka 2016 as well used the oral prodrug S-1.

In six of 23 studies, combination chemotherapy arms did contain an anthracycline (epirubicin $60 \mathrm{mg} / \mathrm{m}^{2}$ every three weeks or $90 \mathrm{mg} / \mathrm{m}^{2}$ every four weeks or doxorubicin $40 \mathrm{mg} / \mathrm{m}^{2}$ every four to seven weeks) in addition to 5-FU. Non 5-FU-based combination chemotherapy regimens, which instead included etoposide, irinotecan and cisplatin, S-1 and irinotecan, S-1 and paclitaxel or an anthracycline and cisplatin were applied in six studies (Barone 1998; Boku 2009; Komatsu 2011; Narahara 2011; Popov 2002; Wang 2013).

In comparisons $\mathbf{3}$ and4, regimens containing 5-FU, an anthracycline and cisplatin were mainly FAP (5-FU bolus $300 \mathrm{mg} /$ $\mathrm{m}^{2}$ either days one, eight, 15,22 or days one to five, adriamycin 25 to $40 \mathrm{mg} / \mathrm{m}^{2}$ and cisplatin 60 to $100 \mathrm{mg} / \mathrm{m}^{2}$ once every three to five weeks) (Cullinan 1994; GITSG 1988; Kikuchi 1990), and PELF (cisplatin $40 \mathrm{mg} / \mathrm{m}^{2}$ days one and five, epirubicin $30 \mathrm{mg} / \mathrm{m}^{2}$ days one and five, leucovorin $200 \mathrm{mg} / \mathrm{m}^{2}$ and 5-FU bolus $300 \mathrm{mg} / \mathrm{m}^{2}$ days one to four every eight weeks) (Cocconi 1994) in studies published before 1995 (Kim 2001; Ross 2002; Webb 1997). used mostly ECF (epirubicin $50 \mathrm{mg} / \mathrm{m}^{2}$ and cisplatin $60 \mathrm{mg} / \mathrm{m}^{2}$ once every three weeks, with 5-FU as a continuous intravenous infusion of $200 \mathrm{mg} /$ $\mathrm{m}^{2}$ for up to six months) or LdCF (pegylated liposomal doxorubicin $20 \mathrm{mg} / \mathrm{m}^{2}$ and cisplatin $50 \mathrm{mg} / \mathrm{m}^{2}$ once every two weeks, with 5-
FU $400 \mathrm{mg} / \mathrm{m}^{2}$ bolus followed by $600 \mathrm{mg} / \mathrm{m}^{2}$ as 22 -hour continuous infusion on days one and two every two weeks) in Cascinu 2011.

In comparison 5, irinotecan was given in the following studies to substitute either cisplatin (Bouche 2004; Dank 2008; Moehler 2010), etoposide (Moehler 2005) or 5-FU (Roy 2012) or paclitaxel (Sugimoto 2014). In contrast, irinotecan was given in addition to the treatment in the other arm in studies by Bouche 2004; Komatsu 2011; and Narahara 2011; or as other comparisons ( $\mathrm{Li}$ 2016). Irinotecan was given weekly at $80 \mathrm{mg} / \mathrm{m}^{2}$ for six weeks every 50 days in combination with infusional 5-FU $2000 \mathrm{mg} / \mathrm{m}^{2}$ and FA 500 $\mathrm{mg} / \mathrm{m}^{2}$ (Dank 2008; Moehler 2005). Moehler 2010 used irinotecan $250 \mathrm{mg} / \mathrm{m}^{2}$ on day one in combination with capecitabine $1000 \mathrm{mg} /$ $\mathrm{m}^{2}$ orally days one to 14 every 22 days and Roy 2012 used irinotecan $250 \mathrm{mg} / \mathrm{m}^{2}$ on day one in combination with docetaxel $60 \mathrm{mg} / \mathrm{m}^{2}$ as infusion on day one every 22 days. Bouche 2004 used irinotecan at $180 \mathrm{mg} / \mathrm{m}^{2}$ in combination with infusional 5-FU every two weeks. Komatsu 2011 and Narahara 2011 used doses of $75 \mathrm{mg} / \mathrm{m}^{2}$ and $80 \mathrm{mg} / \mathrm{m}^{2}$ on days one and 15 every four weeks or six weeks in combination with oral S-1 (initial doses of $40 \mathrm{mg} / \mathrm{m}^{2}$ to $60 \mathrm{mg} / \mathrm{m}^{2}$ twice daily on days one to 14 every four weeks or $80 \mathrm{mg} / \mathrm{m}^{2} /$ day on days one to 21 every six weeks). In subsequent cycles, doses were varied according to the most severe adverse events during the preceding cycle.

In comparison 6, docetaxel was given to substitute either epirubicin and cisplatin (Roth 2007; Thuss-Patience 2005) or 5FU and leucovorin (Ridwelski 2008). On the other hand, it was given in addition to the treatment in the other study arm in the studies by Wang 2016, Koizumi 2014, Van Cutsem 2006 and Al-Batran 2013. The largest studies included in comparison 6's meta-analysis of overall survival used the three-drug regimen DCF (docetaxel $75 \mathrm{mg} / \mathrm{m}^{2}$ intravenously day one, cisplatin $75 \mathrm{mg} / \mathrm{m}^{2}$ intravenously day one, 5 -FU $750 \mathrm{mg} / \mathrm{m}^{2}$ as a 24-hour infusion) on days one to five every three weeks (Van Cutsem 2006), and the two-drug regimen of docetaxel $75 \mathrm{mg} / \mathrm{m}^{2}$ intravenously day one, in combination with cisplatin $75 \mathrm{mg} / \mathrm{m}^{2}$ intravenously on day one every three weeks (Ridwelski 2008). In Koizumi 2014, docetaxel $\left(40 \mathrm{mg} / \mathrm{m}^{2}\right.$ intravenously on day one) was given with S-1 (tailored to body surface area; days one to 14) every 21 days. In Roth 2007, the DCF regimen was used as described previously. Sadighi 2006 and colleagues used a modification of DCF with reduced doses of docetaxel and cisplatin (both at $60 \mathrm{mg} / \mathrm{m}^{2}$ ) every three weeks. Thuss-Patience 2005 applied docetaxel $75 \mathrm{mg} / \mathrm{mg} / \mathrm{m}^{2}$ intravenously on day one in combination with $5-\mathrm{FU} 200 \mathrm{mg} / \mathrm{m}^{2} /$ day over 24 hours on days one to 21 every three weeks. Al-Batran 2013 used docetaxel $50 \mathrm{mg} / \mathrm{m}^{2}$ intravenously on day one in combination with oxaliplatin $85 \mathrm{mg} / \mathrm{m}^{2}$ and leucovorin $200 \mathrm{mg} / \mathrm{m}^{2}$ followed by 5-FU $2600 \mathrm{mg} / \mathrm{m}^{2}$ as a 24-hour continuous infusion.

Five studies (Kang 2009; Li 2016; Ocvirk 2012; Ochenduszko 2015; Van Cutsem 2015) are eligible for comparison 7. In Kang 2009 and Ocvirk 2012, the oral 5-FU prodrug capecitabine $\left(1000 \mathrm{mg} / \mathrm{m}^{2}\right.$ or $825 \mathrm{mg} / \mathrm{m}^{2}$ twice daily on days one to 14 of a 21-day regimen) was compared with 5-FU (both in combination with cisplatin). In comparison 8 , oxaliplatin was given once at $85 \mathrm{mg} / \mathrm{m}^{2}$ in two weeks and compared with cisplatin $50 \mathrm{mg} / \mathrm{m}^{2}$ in Al Batran 2008 and Popov 2008. Both agents were combined with FU/ leucovorin in Al Batran 2008 and Popov 2008. In Kim 2014 a combination of weekly docetaxel $\left(35 \mathrm{mg} / \mathrm{m}^{2}\right)$ on days one and eight every three weeks, in combination with either cisplatin $\left(60 \mathrm{mg} / \mathrm{m}^{2}\right)$ or oxaliplatin $(120$ $\mathrm{mg} / \mathrm{m}^{2}$ ) on day one was administered. In Yamada 2015, S-1 (twice 
daily for the first three weeks of a five-week cycle) plus (cisplatin $60 \mathrm{mg} / \mathrm{m}^{2}$ on day eight) was compared against S-1 (twice daily for first two weeks of a three-week cycle) plus oxaliplatin $\left(100 \mathrm{mg} / \mathrm{m}^{2}\right.$ infused for two hours on day one). For comparison 9, three studies (Ajani 2005; Roth 2007; Van Cutsem 2015) are available. Fluorouracil $200 \mathrm{mg} / \mathrm{m}^{2} /$ day was given as a 24-hour continuous infusion in or in doses of $750 \mathrm{mg} / \mathrm{m}^{2} /$ day on days one to five every three weeks in Roth 2007. It was combined with docetaxel and cisplatin in Ajani 2005 and Roth 2007, and docetaxel and oxaliplatin in Van Cutsem 2015.

In comparison $10, \mathrm{~S}-150 \mathrm{mg} / \mathrm{m}^{2}$ was given orally in two daily doses on days one to 21 of a four-week cycle (Ajani 2010), or in a lower dosage of $40 \mathrm{mg} / \mathrm{m}^{2}$ orally in two daily doses on days one to 28 of a six-week cycle (Boku 2009) and compared with continuous infusions of $5-\mathrm{FU}$ in doses of $1000 \mathrm{mg} / \mathrm{m}^{2} / 24$ hours as 120-hour infusion (Ajani 2010) or $800 \mathrm{mg} / \mathrm{m}^{2} /$ day on days one to five, respectively. Of note, S-1 was combined with $75 \mathrm{mg} / \mathrm{m}^{2}$ of cisplatin every three weeks, and 5-FU with $100 \mathrm{mg} / \mathrm{m}^{2}$ of cisplatin every three weeks in the study by Ajani 2010. Huang 2013 compared the combination of weekly paclitaxel $\left(60 \mathrm{mg} / \mathrm{m}^{2}\right)$ on days one eight, and 15 every four-week cycle and S-1 $\left(80 \mathrm{mg} / \mathrm{m}^{2}\right.$ to $\left.120 \mathrm{mg} / \mathrm{m}^{2}\right)$, dependent on the body-surface area for two out of four weeks, with the same regimen of paclitaxel, but with $5-\mathrm{FU}\left(500 \mathrm{mg} / \mathrm{m}^{2}\right.$, in combination with leucovorin $20 \mathrm{mg} / \mathrm{m}^{2}$ on days one to five every four weeks).

\section{Outcomes}

Median survival and response rates were the outcomes most commonly described in the included studies. The newer studies reported progression-free survival instead of time to progression. Toxicity was not always classified according to WHO or NCl-CTC and was reported in different ways (per number of participants, per number of cycles and only the worst toxicity per participant). A comparison across studies was therefore not possible. For this reason, the numbers of participants who discontinued treatment due to toxicity as well as the numbers of treatment-related deaths were analysed. Information about second-line therapies and secondary resectability was unavailable for most studies. Details are listed in the Characteristics of included studies table.

\section{Excluded studies}

Please see Characteristics of excluded studies. Reasons for exclusion of references in the updated search are specified in Figure 1 according to the recommendations of the PRISMA statement (Moher 2009).

According to the protocol, we excluded studies in which crossover after failure was encouraged or planned. Information about second-line therapy was generally unavailable in most first-line studies. However, in some large recent studies full information about second-line therapy was provided after contacting the first author and a limited number of participants did in fact cross over in the second-line therapy. After discussion and balancing the loss of information when excluding these studies against the possible bias caused by a limited number of participants crossing over, we decided to include studies in which the number of participants who crossed over between study arms was less than 10\% of the whole study population. Exclusion of these studies would have provoked a bias in favour of studies where less information was available.Two studies which have repeatedly been quoted in the literature are especially mentioned: Glimelius 1994 was excluded because of cross-over, as the research ethics committee had requested that chemotherapy had to be provided to participants upon request in the BSC group, and 12 of 30 participants in the BSC group finally received chemotherapy. Kim 1993 was excluded since the allocation of participants was done by alternate allocation (information provided by author YSP). Several studies currently published as abstracts only were not included at this stage, because full information and final results were currently unavailable or were not provided after contacting the author or sponsor. They are classified as 'Studies awaiting classification'. We excluded studies using oral 5-FU because of its varying bioavailability and unreliable effect. The landmark 'REAL-2' study (Cunningham 2008), which evaluated the non-inferiority of oxaliplatin as compared to cisplatin and of capecitabine as compared to 5-FU, was not included in this meta-analysis after discussion because it included participants with squamous cell cancer of the oesophagus (more than 10\%), which were not eligible according to the inclusion criteria for this meta-analysis. We sought separate data on participants with adenocarcinoma only, but they were not provided by the study investigator. The study by Sadighi 2006 could not be included in the meta-analysis of overall survival because published data for calculation of the hazard ratio is not sufficient at present, but data on the other outcomes were included. The study by Park 2006 was not included in the comparison of docetaxel versus non-docetaxelcontaining regimens because both study arms included a taxane. Thus, the analyses are essentially a comparison of docetaxel and paclitaxel. If further studies relevant for this comparison are published in the future, a separate comparison of paclitaxel versus docetaxel-containing regimens will be included in the metaanalysis.The studies Gubanski 2010 and Guimbaud 2014 were excluded because of systematic cross-over between study arms.

\section{Risk of bias in included studies}

We summarised the overall risk of bias in Figure 2 and Figure 3. 
Figure 2. 'Risk of bias' summary: review authors' judgements about each risk of bias item for each included study.

\begin{tabular}{|c|c|c|c|c|c|c|c|}
\hline & 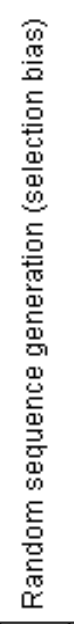 & 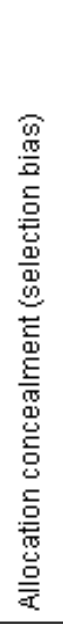 & 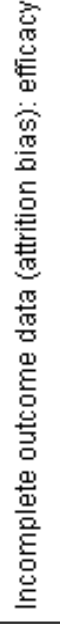 & 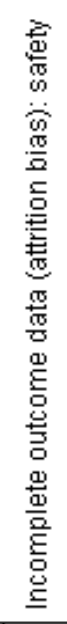 & 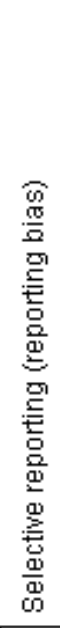 & 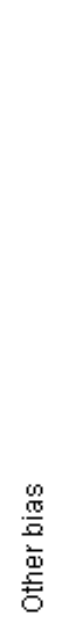 & 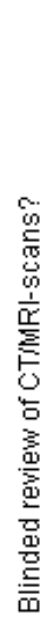 \\
\hline Ajani 2005 & $\odot$ & $\odot$ & $\odot$ & + & $?$ & $?$ & $\odot$ \\
\hline Ajani 2010 & + & $\odot$ & $\odot$ & $\odot$ & + & + & + \\
\hline Al Batran 2008 & $?$ & $?$ & $\odot$ & $\odot$ & $?$ & - & $?$ \\
\hline Al-Batran 2013 & + & $\odot$ & $\odot$ & + & + & + & $\odot$ \\
\hline Barone 1998 & $\odot$ & $\odot$ & $\odot$ & $\odot$ & + & 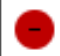 & - \\
\hline Boku 2009 & + & + & $\odot$ & + & + & + & + \\
\hline Bouche 2004 & $?$ & + & $\odot$ & + & + & $?$ & $?$ \\
\hline Cascinu 2011 & + & + & $\odot$ & + & + & + & + \\
\hline Chen 2015 & + & $?$ & $?$ & $?$ & $?$ & $?$ & $?$ \\
\hline Cocconi 1994 & $?$ & + & $\odot$ & + & + & + & + \\
\hline Cocconi 2003 & $?$ & + & $?$ & $?$ & $?$ & $?$ & $?$ \\
\hline Colucci 1995 & $?$ & $?$ & $\odot$ & $\odot$ & + & $?$ & O \\
\hline Cullinan 1985 & $?$ & $?$ & $\odot$ & $\odot$ & + & - & - \\
\hline Cullinan 1994 & $?$ & $?$ & + & + & $?$ & $\theta$ & $?$ \\
\hline Dank 2008 & + & $?$ & $\odot$ & $\odot$ & + & 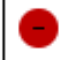 & $\odot$ \\
\hline De Lisi 1986 & $?$ & $\odot$ & $\odot$ & $\odot$ & + & $?$ & $\Theta$ \\
\hline Dong 2014 & + & $?$ & $?$ & $?$ & 1 & $?$ & $?$ \\
\hline GITSG 1988 & $?$ & $?$ & $?$ & $?$ & $?$ & $?$ & $?$ \\
\hline Hironaka 2016 & + & + & $\odot$ & $\odot$ & + & $?$ & + \\
\hline Huang 2013 & $?$ & + & $\odot$ & + & + & $?$ & $?$ \\
\hline Kang 2009 & + & $?$ & $\odot$ & $\odot$ & + & + & 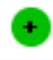 \\
\hline Kikuchi 1990 & $?$ & + & + & + & + & $?$ & ? \\
\hline
\end{tabular}


Figure 2. (Continued)

\begin{tabular}{|c|c|c|c|c|c|c|c|}
\hline Kikuchi 1990 & $?$ & $\odot$ & + & + & $\oplus$ & $?$ & $\odot$ \\
\hline Kim 2001 & $?$ & $?$ & $?$ & $?$ & $\oplus$ & $?$ & $\odot$ \\
\hline Kim 2014 & $?$ & $?$ & $\odot$ & $\oplus$ & $\oplus$ & $\odot$ & $?$ \\
\hline Koizumi 2008 & $\odot$ & $\odot$ & + & + & $\oplus$ & $\odot$ & $\oplus$ \\
\hline Koizumi 2014 & $?$ & $?$ & + & + & $\oplus$ & $\odot$ & $?$ \\
\hline Komatsu 2011 & + & $?$ & $?$ & + & + & $\odot$ & $\odot$ \\
\hline KRGGC 1992 & $?$ & $\odot$ & - & $?$ & + & $?$ & $?$ \\
\hline Levi 1986 & $?$ & $\odot$ & 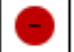 & $\odot$ & + & $?$ & $?$ \\
\hline Li 2014 & $\odot$ & $?$ & 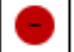 & $\odot$ & $?$ & $?$ & $?$ \\
\hline Li 2015 & $?$ & $\odot$ & $?$ & $?$ & $?$ & $\odot$ & $\Theta$ \\
\hline Li 2016 & $?$ & $?$ & $?$ & $?$ & $?$ & $?$ & ? \\
\hline Loehrer 1994 & $\odot$ & $\odot$ & $O$ & ? & $\Theta$ & $\odot$ & $\Theta$ \\
\hline Lu 2014 & $\odot$ & $\odot$ & + & + & ? & $?$ & ? \\
\hline Lutz 2007 & $\odot$ & $\odot$ & + & + & + & $\Theta$ & $\Theta$ \\
\hline Moehler 2005 & ? & $\odot$ & + & + & + & $\odot$ & $?$ \\
\hline Moehler 2010 & $?$ & $\odot$ & + & + & + & $\odot$ & ? \\
\hline Murad 1993 & $?$ & $?$ & 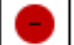 & ? & + & $?$ & ? \\
\hline Narahara 2011 & $\odot$ & $\odot$ & + & ? & + & - & ? \\
\hline Nishikawa 2012 & $\odot$ & $\odot$ & $\odot$ & + & + & $?$ & ? \\
\hline Ochenduszko 2015 & $?$ & $?$ & + & + & ? & $\odot$ & ? \\
\hline Ocvirk 2012 & $?$ & $\odot$ & + & + & + & $\odot$ & 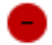 \\
\hline Ohtsu 2003 & $\odot$ & $\odot$ & + & + & + & $\odot$ & ? \\
\hline Popov 2002 & $\odot$ & $?$ & + & + & + & $?$ & + \\
\hline Popov 2008 & $?$ & $?$ & 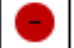 & + & + & $?$ & + \\
\hline Pyrhönen 1995 & $\odot$ & $\odot$ & + & + & + & $\odot$ & - \\
\hline Ridwelski 2008 & 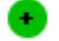 & + & + & + & + & $?$ & $\Theta$ \\
\hline Ross 2002 & $?$ & $?$ & + & + & + & $?$ & $\Theta$ \\
\hline Roth 1999 & $?$ & $?$ & + & + & + & $?$ & - \\
\hline Roth 2007 & $?$ & + & + & + & + & $?$ & + \\
\hline Roy 2012 & $?$ & $?$ & + & + & + & $?$ & $?$ \\
\hline Sadighi 2006 & $?$ & $?$ & $?$ & $\Theta$ & - & $?$ & ? \\
\hline
\end{tabular}


Figure 2. (Continued)

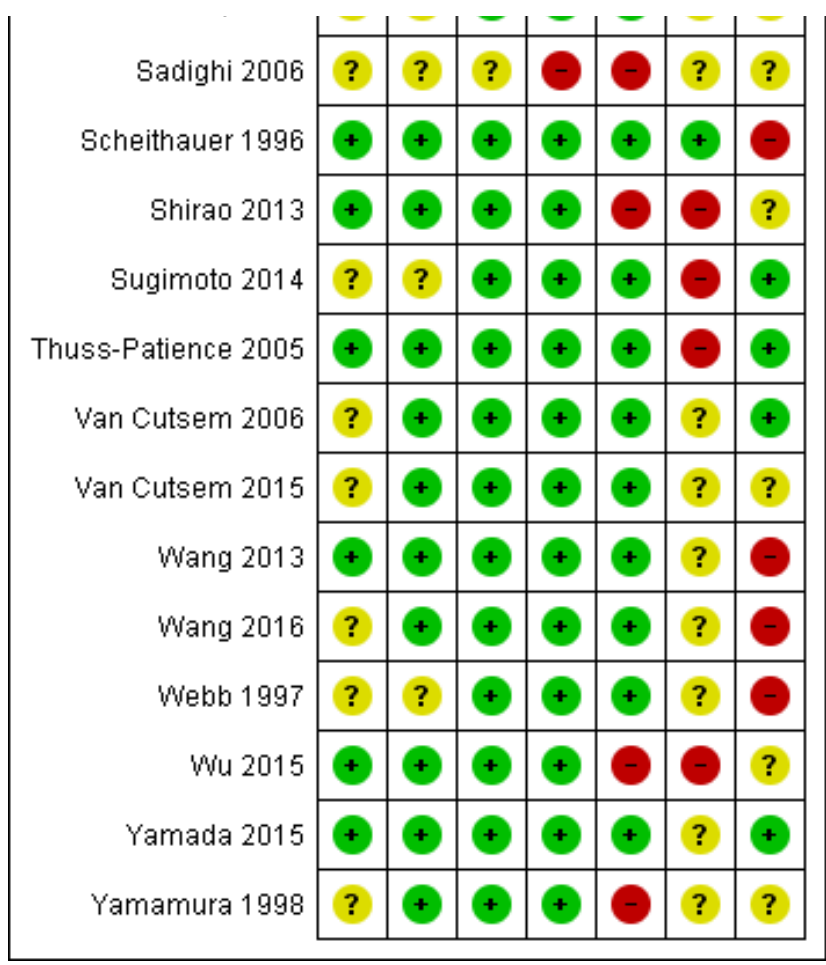

Figure 3. 'Risk of bias' graph: review authors' judgements about each risk of bias item presented as percentages across all included studies.

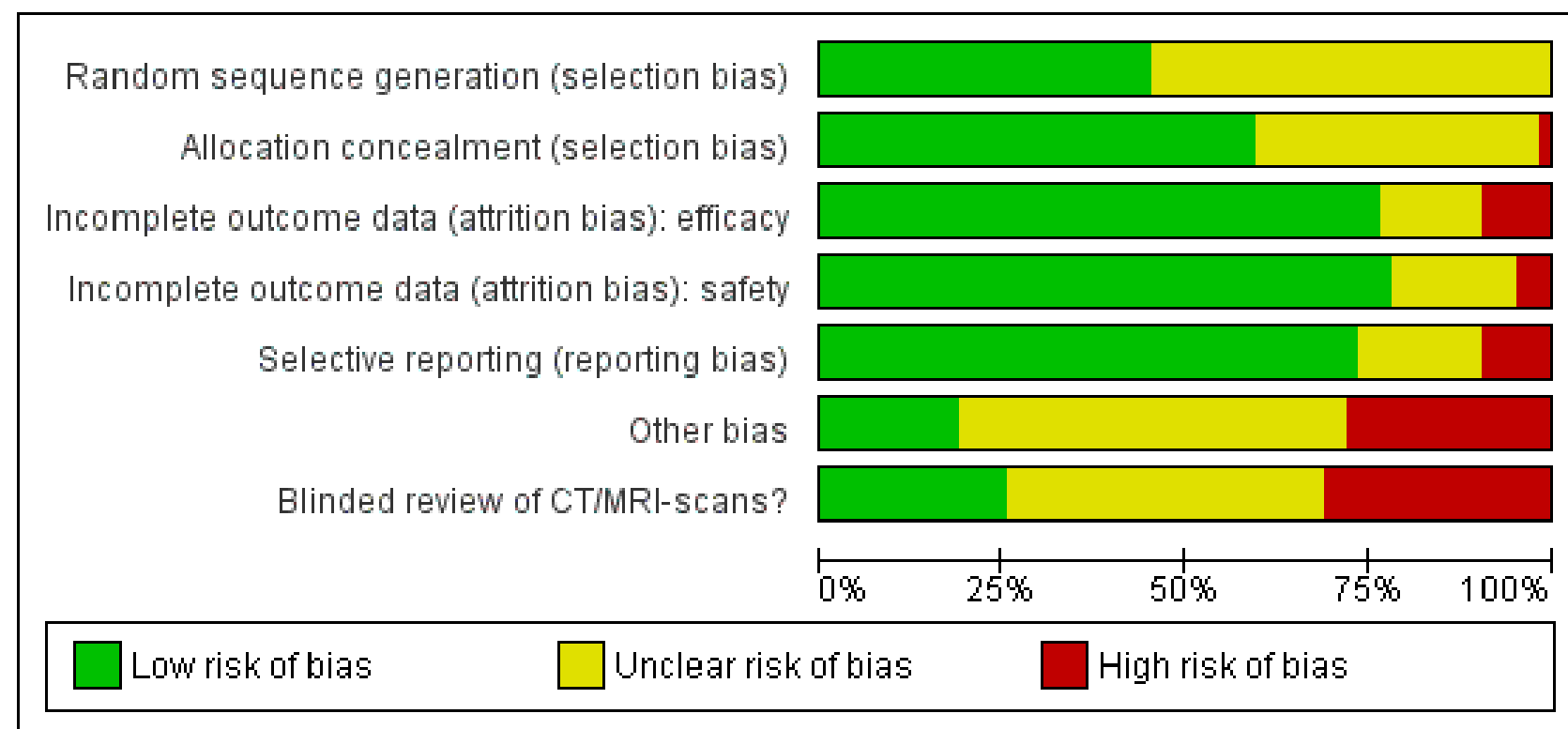

\section{Allocation}

The risk of selection bias due to issues with random sequence generation was not stated in most instances $(n=35 / 64,55 \%)$, while the remaining studies which described the allocation sequence generation approach used acceptable, unbiased methods ( $\mathrm{n}=$ 29/64, 45\%).

\section{Blinding}

Potential bias arising from allocation concealment was low in 38 studies (59\%), unclear in 25 studies (39\%), and high in one study (2\%). 


\section{Incomplete outcome data}

The risk of bias due to incomplete efficacy data was low in 49 studies (77\%), unclear in nine9 studies (14\%), and high in six studies (9\%). On the other hand, incomplete safety concern was a low concern in 50 studies (78\%), unclear in 11 studies (17\%), and high in three studies (5\%).

\section{Selective reporting}

The potential for selective reporting was deemed to be low in 47 studies (73\%), unclear in 11 studies (17\%), and high in six studies (9\%).

\section{Other potential sources of bias}

The risk of bias due to lack of blinded or independent radiological review was a low concern in 16 studies (25\%), unclear in 28 studies (44\%), and high in 20 studies (31\%). The potential for bias due to other causes was assessed to be low in 12 studies (19\%), unclear in 34 studies (53\%), and high in 18 studies (28\%).

\section{Effects of interventions}

See: Summary of findings for the main comparison Chemotherapy versus best supportive care for advanced gastric cancer; Summary of findings $\mathbf{2}$ Combination versus single-agent chemotherapy for advanced gastric cancer; Summary of findings 3 5-FU/cisplatin/anthracycline combinations versus 5-FU/cisplatin combinations (without anthracyclines) for advanced gastric cancer; Summary of findings 4 5-FU/cisplatin/anthracycline combinations versus 5-FU/anthracycline combinations (without cisplatin) for advanced gastric cancer; Summary of findings 5 Irinotecan versus non-irinotecan-containing regimens for advanced gastric cancer; Summary of findings 6 Docetaxel versus non-docetaxel-containing regimens for advanced gastric cancer; Summary of findings 7 Capecitabine versus 5-FU-containing regimens for advanced gastric cancer; Summary of findings 8 Oxaliplatin versus the same regimen including cisplatin for advanced gastric cancer; Summary of findings 9 Taxane-platinumfluoropyrimidine combinations versus taxane-platinum (without fluoropyrimidine) for advanced gastric cancer; Summary of findings $10 \mathrm{~S}-1$ versus 5 -FU-containing regimens for advanced gastric cancer

\section{(1) Chemotherapy versus best supportive care}

\section{Overall survival}

A total of three studies ( $\mathrm{N}=184$ ) reported overall survival (Murad 1993; Pyrhönen 1995; Scheithauer 1996). The overall hazard ratio (HR) of 0.37 (95\% confidence interval $(\mathrm{Cl}) 0.24$ to 0.55 , moderatequality evidence) (Analysis 1.1) in favour of the chemotherapy arms demonstrates a convincing benefit over best supportive care (BSC) alone, which can be interpreted as an improvement in median survival from 4.3 months (weighted average in BSC) to 11 months (with chemotherapy). Cochrane's $Q$ test $(P=0.19)$ as well as the index of homogeneity according to Thompson $\left(I^{2}\right.$ $=39.7$ ) demonstrate a significant statistical heterogeneity among the results of these studies, based on the differences in the chemotherapy regimens studied. A sensitivity analysis including only studies with adequate allocation concealment (Pyrhönen 1995; Scheithauer 1996), does not change the overall HR of 0.37 (95\% $\mathrm{Cl} 0.19$ to 0.70$)$.

\section{Secondary outcomes}

\section{Tumour response}

Data were available for 88 participants in the chemotherapy arms of the three eligible studies. Response rates were between $33 \%$ (Pyrhönen 1995) and 50\% (Murad 1993).

\section{Time to progression}

In the chemotherapy and BSC arms time to progression was 7.8 versus $2.7(P=0.0001)$ and 6.5 versus $2.0(P=0.0001)$ months in the studies by Murad 1993 and Scheithauer 1996 ( $N=144)$. The overall HR was $0.31(95 \% \mathrm{Cl} 0.22$ to 0.43 , moderate-quality evidence) (Analysis 1.2).

\section{Secondary resectability}

Information about secondary resectable participants was not given in the text or provided by the authors in any of the three studies.

\section{Toxicity}

In the study by Murad 1993, WHO grade III/IV toxicities occurred in 22 of 128 cycles in 30 participants treated with chemotherapy, with one toxic death. Pyrhönen 1995 described WHO gastrointestinal grade III/IV toxicities in 13 of 20 participants. Haematological toxicities occurred in the same frequency. Scheithauer 1996 observed haematological grade III/IV toxicities in $12 \%$, gastrointestinal grade III/IV toxicities in $21 \%$, and other grade III/IV toxicities in $32.7 \%$ of 226 available cycles.

\section{Quality of life}

Quality of life was not analysed in any of the three included studies. Pyrhönen 1995 assessed the palliative measures and observed an increased use of analgesics in the control versus treated participants after two months.

\section{(2) Combination versus single-agent therapy}

\section{Overall survival}

Twenty-three studies including 4447 participants were summarised in this meta-analysis (Barone 1998; Boku 2009; Bouche 2004; Colucci 1995; Cullinan 1985; Cullinan 1994; De Lisi 1986; Hironaka 2016; Koizumi 2008; Koizumi 2014; Komatsu 2011; Levi 1986; Loehrer 1994; Lu 2014; Lutz 2007; Narahara 2011; Nishikawa 2012; Ohtsu 2003; Popov 2002; Shirao 2013; Wang 2013; Wu 2015; Yamamura 1998). The overall HR in favour of combination chemotherapy (HR $0.84,95 \% \mathrm{Cl} 0.79$ to 0.89 , moderate quality) provides evidence for a statistically significant, but modest survival benefit of combination versus single-agent chemotherapy in the studied regimens (Analysis 2.1). Cochrane's $Q$ test for heterogeneity showed non-significant heterogeneity $\left(I^{2}=0 \%, P=0.48\right)$, indicating that results of the different studies were consistent in their findings. As the chemotherapy regimens in studies published before 2000 might not have the same efficacy as modern regimens, the median survival difference between single and combination chemotherapy was calculated separately for studies published before the year 2000 and thereafter. For studies published before 2000 , the weighted median survival was approximately 7.3 with combination therapy and 6.4 months with single-agent therapy. In studies published after 2000 (Boku 2009; Bouche 2004; Hironaka 2016; Koizumi 2008; Koizumi 2014; Komatsu 2011; Lu 2014; Lutz 2007; Narahara 2011; Nishikawa 2012; Ohtsu 2003; Popov 2002; Wang 2013, Wu 2015), median survival was 11.6 months with 
combination therapy, as compared to 10.5 months with singleagent therapy.

To evaluate the influence of second-line therapy, which was previously specified as a possible cause of heterogeneity, a second analysis was performed excluding the studies by Boku 2009, Koizumi 2008, Koizumi 2014, Narahara 2011, Ohtsu 2003, and Wang 2013 in which more than 50\% of participants received a secondline therapy. Exclusion of theses studies had no influence on heterogeneity $\left(I^{2}=0 \%\right.$ and $\left.P=0.56\right)$ and the overall HR of $0.82(95 \%$ $\mathrm{Cl} 0.75$ to 0.90 ) in favour of combination chemotherapy. Sensitivity analysis excluding those studies which were conducted in Asia (Boku 2009; Hironaka 2016; Koizumi 2008; Koizumi 2014 ; Komatsu 2011; Lu 2014; Narahara 2011; Nishikawa 2012; Ohtsu 2003; Shirao 2013; Wang 2013; Wu 2015; Yamamura 1998) resulted in a HR of 0.77 (95\% $\mathrm{Cl} 0.68$ to 0.87$)\left(\mathrm{I}^{2}=0 \%, \mathrm{P}=0.57\right)$, with no appreciable change in heterogeneity as compared to the original analysis. When only those studies with adequate allocation concealment were included in the analysis (Barone 1998; Boku 2009; Bouche 2004; De Lisi 1986; Koizumi 2008; Levi 1986; Loehrer 1994; Lu 2014; Lutz 2007; Narahara 2011; Nishikawa 2012; Ohtsu 2003; Shirao 2013; Wang 2013; Wu 2015; Yamamura 1998), the resulting overall HR was $0.83(95 \% \mathrm{Cl}$ 0.77 to 0.89$)\left(I^{2}=24 \%\right.$ and $\left.P=0.19\right)$. For these reasons, the results of this comparison can be considered to be highly robust.

\section{Secondary outcome measures}

\section{Tumour response}

Data were available from 2833 participants in 18 eligible studies. The pooled objective response rate was 39\% in the combination therapy arms versus $23 \%$ of the single-agent arms. The corresponding odds ratio (OR $2.30,95 \% \mathrm{Cl} 1.94$ to 2.72 , highquality evidence) confirms a statistically significant advantage in tumour response in favour of combination therapy (Analysis 2.2). Very low heterogeneity was observed across studies $\left(\mathrm{I}^{2}=0 \%, \mathrm{P}=\right.$ 0.60).

\section{Time to progression}

Data from four studies with 720 participants were available. The overall HR for time to progression for combination versus singleagent chemotherapy was $0.69(95 \% \mathrm{Cl} 0.55$ to 0.87 , moderatequality evidence) (Analysis 2.3). Results across studies were consistent, with moderate heterogeneity $\left(I^{2}=23 \%, P=0.27\right)$. Other studies (Boku 2009; Bouche 2004; Hironaka 2016; Koizumi 2014; Lutz 2007; Lu 2014; Wu 2015) reported progression-free survival instead of time to progression or time-to treatment failure (Komatsu 2011; Narahara 2011; Nishikawa 2012).

\section{Secondary resectability}

Only one study (Colucci 1995) reported on a single participant who became secondary resectable and was operated on with a pathologic complete remission.

\section{Toxicity}

Because of the different ways of reporting (per number of participants, per number of cycles or only the maximum toxicity per participant), grade I to IV toxicities can be compared only within, but not between studies. Overall, treatment-associated toxicities were higher in the combination chemotherapy arms, but this was usually not statistically significant. In contrast, the rate of treatment-associated deaths may be summarised across studies. Eighteen of 23 studies $(N=3876)$ in this comparison reported treatment-related deaths (Analysis 2.4). The overall rate of toxic deaths in these studies was $1.1 \%$ versus $0.5 \%$ for combination versus single-agent therapy (OR $1.64,95 \% \mathrm{Cl} 0.83$ to 3.24). Six studies observed no treatment-related deaths (Hironaka 2016; Koizumi 2008; Komatsu 2011; Lu 2014; Wang 2013; Wu 2015).

\section{Quality of life}

This was assessed in only one of these studies (Bouche 2004). All participants in the single-agent and both combination chemotherapy arms had a significant improvement in quality of life compared with pretreatment scores.

\section{(3) 5-FU/cisplatin/anthracycline combinations versus 5-FU/ cisplatin combinations (without anthracyclines)}

\section{Overall survival}

This meta-analysis was based on 579 participants in four randomised studies (Cascinu 2011; Kim 2001; KRGGC 1992; Ross 2002). The data from the largest study in this comparison (published by Ross 2002) which was included in this analysis were provided by the authors and include people with gastric and GEjunction adenocarcinoma only (the original publication included people with squamous cell carcinoma of the oesophagus as well). The resulting HR for overall survival of $0.74(95 \% \mathrm{Cl} 0.61$ to 0.89 , moderate-quality evidence) demonstrates a statistically significant benefit with very low heterogeneity $\left(I^{2}=0 \%, P=0.63\right)$ in overall survival in favour of the three-drug combination, with a weighted average survival of 9.9 and 8.6 months, respectively. Allocation concealment was adequate in all three studies included in this comparison and heterogeneity was non-significant $\left(I^{2}=0 \%\right.$; $\mathrm{P}=$ 0.63) (Analysis 3.1).

\section{(4) 5-FU/cisplatin/anthracycline combinations versus 5-FU/ anthracycline combinations (without cisplatin)}

Summarising the results for the comparison of FU/cisplatin/ anthracycline combinations versus FU/anthracycline (without cisplatin) results in a HR of $0.82(95 \% \mathrm{Cl} 0.73$ to 0.92 , lowquality evidence) in favour of the three-drug regimen (Analysis 4.1). Combination chemotherapy arms only from the study by Cullinan 1994 were included in this comparison. This meta-analysis, which included 1147 participants in seven studies (Cocconi 1994; Cocconi 2003; Cullinan 1994; GITSG 1988; Kikuchi 1990; Roth 1999; Webb 1997), once more confirms a overall survival benefit in favour of the three-drug combination, which corresponds to a difference in weighted mean average survival of approximately two months. A sensitivity analysis according to the quality score has only little impact on the resulting HR $(0.79,95 \% \mathrm{Cl} 0.68$ to 0.91$)$. There was only moderate heterogeneity $\left(I^{2}=28 \%, P=0.21\right)$.

The two regimens containing FU, an anthracycline and cisplatin, which were evaluated in the largest number of participants are cisplatin, epirubicin, leucovorin, and FU administered as bolus (PELF; 184 participants) (Cocconi 1994; Cocconi 2003) and epirubicin, cisplatin, and protracted venous-infusion FU (ECF; 327 participants) (Kim 2001; Ross 2002; Webb 1997). The rate of treatment-related deaths was 3.3\% for PELF versus $0.6 \%$ for ECF (OR 5.36, 95\% Cl 1.1 to 27.4; Fisher's exact test, $P=.02834$ ), suggesting an increased toxicity of PELF. Quality of life was analysed in two studies evaluating ECF compared with FU, doxorubicin, and methotrexate (Webb 1997), as well as ECF compared with mitomycin, cisplatin, and FU (Ross 2002). Quality of life was superior in participants treated with ECF. 
(5) Chemotherapy with irinotecan versus non-irinotecancontaining regimens

\section{Overall survival}

Ten studies ( $\mathrm{N}=2135)$ were summarised in this meta-analysis (Boku 2009; Bouche 2004; Dank 2008; Komatsu 2011; Li 2016; Moehler 2005; Moehler 2010; Narahara 2011; Roy 2012; Sugimoto 2014). To avoid double-counting the irinotecan-treated population in the study by Bouche 2004, we approximated a within-study hazard ratio of 0.72 ( $95 \% \mathrm{Cl} 0.30$ to 1.72 ) for the study's irinotecan-treated population $(\mathrm{N}=45)$ and non-irinotecan-treated population $(\mathrm{N}=89)$. Overall, the pooled hazard ratio of irinotecan-containing regimens compared to non-irinotecan containing regimens was $0.87(95 \%$ $\mathrm{Cl} 0.80$ to 0.95 , high-quality evidence), with low heterogeneity $\left(\mathrm{I}^{2}=0 \%, \mathrm{P}=0.86\right)$ (Analysis 5.1), and corresponds to pooled median survival times of 11.3 and 9.7 months, with a small, but significant benefit for the irinotecan-containing regimens. When only those studies with information about adequate allocation concealment are included in the analysis (Boku 2009; Bouche 2004; Moehler 2005; Moehler 2010; Narahara 2011; Roy 2012) the resulting overall HR was $0.84(95 \% \mathrm{Cl} 0.76$ to 0.93$)\left(\mathrm{P}=0.84\right.$ and $\left.\mathrm{I}^{2}=0 \%\right)$ when all studies were pooled. For these reasons, the results of this comparison can be considered as robust. Further sensitivity analyses were not performed due to the low number of studies.

Next, the HR for overall survival was separately investigated for studies with substitutive (i.e. studies in which another chemotherapy was substituted by irinotecan), additive (i.e. studies in which irinotecan was added to other chemotherapies), and other comparisons of irinotecan and non-irinotecan-containing regimens (Analysis 5.1). The summary of the six studies (826 participants) with substitutive comparisons (Bouche 2004; Dank 2008; Moehler 2005; Moehler 2010; Roy 2012; Sugimoto 2014) results in a HR of 0.87 ( $95 \% \mathrm{Cl} 0.75$ to 1.00 , high-quality evidence), with low heterogeneity between study results $\left(I^{2}=0 \%, P=0.94\right)$.

The meta-analysis of the three studies (Bouche 2004; Komatsu 2011; Narahara 2011), including a total of 500 participants, where irinotecan was given in addition to the treatment in the nonirinotecan-containing arm shows a non-significant benefit for participants treated with irinotecan (HR $0.88,95 \% \mathrm{Cl} 0.76$ to 1.03 , low-quality evidence) and small heterogeneity between treatment effects of individual studies $\left(I^{2}=6 \%, P=0.34\right)$. This result corresponds to a pooled median survival duration of 11.9 months with compared to 10.9 months without irinotecan. Bouche 2004 and Narahara 2011 stated a higher benefit of four and two months, respectively. However, Komatsu 2011 showed a disadvantage of three months for participants treated with irinotecan and S-1 compared to participants with S-1 monotherapy.

The meta-analysis of two studies (Boku 2009; Li 2016), which could neither be classified as substitutive nor additive, including a total of 809 participants, revealed a slight benefit for participants treated with irinotecan ( $\mathrm{HR} 0.87,95 \% \mathrm{Cl} 0.76$ to 1.00 , very low-quality evidence). However, the pooled result needs to be interpreted with caution in light of the considerable clinical differences between studies included under 'Other Comparisons' as well as their significant statistical heterogeneity $\left(I^{2}=65 \%, P=0.04\right)$. For instance, Li 2016 allowed participants to switch to second-line therapy after failure of first-line. The study by Boku 2009 alone, which contributed the majority of participants $(n=704)$, showed a HR of $0.84,95 \% \mathrm{Cl} 0.73$ to 0.95 and a corresponding benefit in median survival of around one month in favour of participants treated with irinotecan.

\section{Secondary outcome measures}

\section{Tumour response}

Data were available from 1266 participants in 10 eligible studies (Analysis 5.2). In six studies (756 participants) with substitutive comparisons (Bouche 2004; Dank 2008; Moehler 2005; Moehler 2010; Roy 2012; Sugimoto 2014) response rates were $38 \%$ and $30 \%$ (OR $1.53,95 \% \mathrm{Cl} 0.93$ to 2.50 , low-quality evidence), with substantial heterogeneity $\left(I^{2}=56 \%, P=0.04\right)$. In three studies (345 participants) with additive comparisons, pooled response rates of $38 \%$ and $22 \%$ were observed (OR $2.18,95 \% \mathrm{Cl} 1.25$ to 3.80 , lowquality evidence), with moderate heterogeneity $\left(I^{2}=19 \%, P=0.29\right)$. In two studies (165 participants) of other comparisons, response rates were $53 \%$ and $38 \%(\mathrm{OR} 1.87,95 \% \mathrm{Cl} 0.89$ to 3.91 , very lowquality evidence) with considerable heterogeneity $\left(I^{2}=26 \%, P=\right.$ 0.25).

\section{Progression-free survival}

Most studies reported progression-free survival instead of time to progression. Again, a within-study hazard ratio was computed for the irinotecan-treated population $(\mathrm{N}=45)$ and non-irinotecantreated population ( $\mathrm{N}=89$ ) in Bouche 2004 to avoid counting the irinotecan-treated population twice $(\mathrm{HR}=0.59,95 \% \mathrm{Cl} 0.50$ to 0.68$)$. Overall, the pooled hazard ratio of irinotecan-containing regimens compared to non-irinotecan-containing regimens was $0.76(95 \% \mathrm{Cl}$ 0.69 to 0.84 , high-quality evidence), with low heterogeneity $\left(I^{2}=0 \%\right.$, $\mathrm{P}=0.59$ ) (Analysis 5.3).

Among five studies ( $\mathrm{N}$ - 741) with substitutive comparisons (Bouche 2004; Dank 2008; Moehler 2005; Moehler 2010; Sugimoto 2014), the hazard ratio for progression-free survival was $0.85(95 \% \mathrm{Cl} 0.72$ to 1.00 , moderate-quality evidence) in favour of the participants treated with irinotecan (Analysis 5.3). The heterogeneity for this comparison was low $\left(I^{2}=0 \%, P=0.54\right)$.

The single study ( $\mathrm{N}=90$ ) from the additive comparisons, from which data for progression-free survival are available observed a large benefit (HR of $0.51,95 \% \mathrm{Cl} 0.33$ to 0.77 , moderate-quality evidence) with a median PFS of 6.9 and 3.2 months for participants treated with and without irinotecan (Bouche 2004). A smaller difference in TTP was reported by Komatsu 2011, with a median TTP of 4.8 and 3.8 months for participants treated with and without irinotecan. Two additional studies belonging to other comparisons (Boku 2009; Li 2016) with a total of 809 participants stated a pooled benefit for participants with irinotecan compared to control (HR $0.74,95 \% \mathrm{Cl}$ 0.66 to 0.84 , high-quality evidence) with low heterogeneity $\left(I^{2}=0 \%\right.$, $P=0.39$ ). The study by Boku 2009 alone demonstrated a HR of 0.73 $(95 \% \mathrm{Cl} 0.64$ to 0.83 ) with median progression-free survival of 4.8 months in the group treated with irinotecan and 4.2 and 2.9 months in the control groups without irinotecan.

\section{Secondary resectability}

Information about secondary resectable participants was not provided.

\section{Toxicity}

Rates of treatment-related deaths and treatment discontinuation due to toxicity showed substantial heterogeneity between studies $\left(P=0.19, I^{2}=32 \%\right)$ and $\left(P<0.00001, I^{2}=87 \%\right)$, as well as a low event 
rate for treatment-related deaths ( $0.8 \%$ versus $1.0 \%)$; hence, the significance of pooled results are unclear and will not be discussed in the text of this review (Analysis 5.4; Analysis 5.5). Three studies (Komatsu 2011; Roy 2012; Sugimoto 2014) observed no treatmentrelated deaths.

\section{Quality of life}

Quality of life was assessed in the studies by Bouche 2004, Dank 2008, and Roy 2012. However, in the study by Bouche 2004, which used the EORTC-QLQ C-30 as an assessment tool, the absolute number of participants with follow-up data in the different study arms was very small (between 21 and 29 participants at six months). As compared to treatment with $5-\mathrm{FU} /$ cisplatin, treatment with 5-FU/irinotecan in this study was associated with higher global quality of life and functional scores, as well as lower symptom scores. Dank 2008 compared the time to 5\% deterioration of the global health status, as measured by the EORTC QLQ-C30 questionnaire in both treatment arms. In 288 assessable participants (86.5\%), the median time to $5 \%$ deterioration of the global health status was 4.9 months $(95 \% \mathrm{Cl} 3.7$ to 7.0$)$ in the irinotecan-containing arm and 5.9 months $(95 \% \mathrm{Cl} 4.8$ to 7.7$)$ in the platinum-containing arm. In contrast, the results of the EQ-5D instrument (data from 192 participants): time to definite worsening of Karnofsky performance status, appetite, weight loss, and painfree survival all favoured the irinotecan-containing arm. Detailed quality-of life results of this study have been published by Curran 2009. Roy 2012 assessed the clinical benefit in terms of times from baseline to definitive worsening of the Karnofsky performance status (KPS) by at least one category, definitive weight loss by at least $5 \%$ and worsening of appetite by at least one grade on a scale of 1 to 5 and added pain-free survival. Median time to definitive deterioration of KPS (4.9 months; $95 \% \mathrm{Cl} 1.9$ to 11.2 versus 2.6 months; $95 \% \mathrm{Cl}$ not reached) and median time to definitive $5 \%$ weight loss (not reached versus 7.6 months) were better without irinotecan. Median time to definitive worsening of appetite was 4.9 months ( $95 \% \mathrm{Cl}$ not reached) with no difference between groups. Median pain-free survival was not reached in both groups.

\section{(6) Chemotherapy with docetaxel versus non-docetaxel- containing regimens}

\section{Overall survival}

Eight studies ( $\mathrm{N}=2001$ ) were summarised in this meta-analysis (Al-Batran 2013; Koizumi 2014; Ochenduszko 2015; Ridwelski 2008; Roth 2007; Thuss-Patience 2005; Van Cutsem 2006; Wang 2016). The resulting HR for overall survival was estimated separately for studies with substitutive (i.e. studies in which another chemotherapy was substituted by docetaxel), additive (i.e. studies in which docetaxel was added to other chemotherapies), and other comparisons (Analysis 6.1).

The summary of the three studies (479 participants) with substitutive comparisons (Ridwelski 2008; Roth 2007; ThussPatience 2005) slightly favours the non-docetaxel-containing regimens ( $\mathrm{HR} 1.05,95 \% \mathrm{Cl} 0.87$ to 1.27 , moderate-quality evidence), but does not reach statistical significance. The index of homogeneity according to Thompson $\left(\mathrm{I}^{2}=0 \%\right)$ shows a low statistical heterogeneity among the results of these studies (Analysis 6.1). Because necessary data for calculation of the HR in the studies by Sadighi 2006 were missing, this study could not be included in the meta-analysis of this comparison. Differences in pooled median survival between the docetaxel-containing regimens (9.2 months) and the non-docetaxel-containing regimens (9.4 months) are neither statistically significant nor clinically relevant. All publications describe an adequate allocation concealment and all studies were conducted in Europe.

The meta-analysis of the four studies ( $\mathrm{N}=1466)$ (Al-Batran 2013; Koizumi 2014; Van Cutsem 2006; Wang 2016), including a total of 1466 participants, where docetaxel was given in addition to the treatment in the non-docetaxel-containing arm favours the docetaxel-containing regimens (HR $0.80,95 \% \mathrm{Cl} 0.71$ to 0.91 , moderate-quality evidence) with little heterogeneity between treatment effects of individual studies $\left(\mathrm{I}^{2}=0 \%, \mathrm{P}=0.82\right)$. This result corresponds to pooled median survival times of 12.3 and 10.6 months, with a small benefit for the docetaxel-containing regimens. Al-Batran 2013 was conducted in Germany, Koizumi 2014 in Japan and Korea, Wang 2016 in China, and the fourth study (Van Cutsem 2006) was an international study that recruited participants in America, Europe, and Asia. Due to the small number of studies in the primary analysis, we did not perform sensitivity analyses.

The single study belonging to other comparisons (Ochenduszko 2015) with 56 participants demonstrated a non-statistically significant $(P=0.43)$ advantage of docetaxel-containing regimens compared to control (HR $0.80,95 \% \mathrm{Cl} 0.46$ to 1.39 , very lowquality evidence). This study permitted second-line therapy with irinotecan monotherapy.

\section{Secondary outcome measures}

\section{Tumour response}

Data were available from nine eligible studies of 1820 participants (Al-Batran 2013; Dong 2014; Koizumi 2014; Ridwelski 2008; Roth 2007; Sadighi 2006; Thuss-Patience 2005; Van Cutsem 2006; Wang 2016) (Analysis 6.2) (OR $1.37,95 \% \mathrm{Cl} 1.03$ to 1.83 , moderate-quality evidence).

In studies with substitutive comparisons (Ridwelski 2008; Roth 2007; Sadighi 2006; Thuss-Patience 2005) response rates of 525 participants were $31 \%$ in both arms (OR $1.03,95 \% \mathrm{Cl} 0.71$ to 1.50 , moderate-quality evidence). However, in four studies with additive comparisons and 1235 participants (Al-Batran 2013; Koizumi 2014; Van Cutsem 2006; Wang 2016), pooled response rates of $43 \%$ and $30 \%$ were observed (OR $1.83,95 \% \mathrm{Cl} 1.45$ to 2.32 , high-quality evidence). Heterogeneity between results of different studies was very low in both comparisons $\left(I^{2}=0 \%, P=0.98\right.$ and $P=0.69$, respectively). Among other comparisons, the study by Dong 2014 with 60 participants showed a substantial survival advantage with docetaxel-containing regimens (OR $0.33,95 \% \mathrm{Cl} 0.12$ to 0.96 , very low-quality evidence).

\section{Time to progression and progression-free survival}

Data on time to progression were available for two studies $(N=360)$ (Ridwelski 2008; Thuss-Patience 2005) (Analysis 6.3) and data for progression-free survival were available for five studies $(N=1498)$ (Koizumi 2014; Ochenduszko 2015; Roth 2007; Van Cutsem 2006; Wang 2016) (Analysis 6.4).

In the case of time to progression, data based on 360 participants from two studies revealed a non-significant difference between docetaxel and non-docetaxel-containing regimens (HR 1.06, 95\% Cl 0.85 to 1.32 , very low-quality evidence) (Analysis 6.3). 
In the case of progression-free survival, the pooled hazard ratio was 0.76 ( $95 \% \mathrm{Cl} 0.63$ to 0.91 , moderate-quality evidence) in favour of docetaxel-containing regimens based on 1498 participants in five studies, but a high level of heterogeneity was observed $\left(\mathrm{I}^{2}=\right.$ $52 \%, P=0.08$ ) (Analysis 6.4). When only additive comparisons were considered (Koizumi 2014; Van Cutsem 2006; Wang 2016) ( $N=1323)$, the pooled hazard ratio was $0.70(95 \% \mathrm{Cl} 0.61$ to 0.81 , high-quality evidence), and a lower level of heterogeneity was observed $\left(1^{2}=\right.$ $20 \%, P=0.29$ ).

\section{Secondary resectability}

This outcome was not reported in any of the studies.

\section{Toxicity}

Seven studies ( $N=2113$ ) reported rates of treatment-related deaths, which were $1.4 \%$ in the docetaxel-containing arms versus $1.2 \%$ in the non-docetaxel-containing arms (OR 1.10, 95\% Cl 0.55 to 2.20 , moderate-quality evidence, $I^{2}=0 \%, P=0.44$ ) (Analysis 6.5). Treatment discontinuation due to toxicity was numerically less frequent for the participants treated with docetaxel $(18.4 \%$ versus $21.1 \%$, corresponding to an OR of $0.81(95 \% \mathrm{Cl} 0.53$ to 1.25 , low-quality evidence), and different results between the studies $\left(I^{2}=35 \%, P=0.19\right)$ (Analysis 6.6). In contrast, discontinuation of treatment due to withdrawal of consent was observed approximately twice as frequently in the participants treated with DCF as compared to CF (22\% versus $12 \%)$ in the study by Van Cutsem 2006.

\section{Quality of life}

Quality of life was assessed by Sadighi 2006, Roth 2007, Van Cutsem 2006, and Al-Batran 2013 with the EORTC-QLQ C30. Furthermore, "clinical benefit", defined as the time to definitive decrease in performance status by $\geq$ one category was analysed in the study by Van Cutsem 2006 and demonstrated a clinical benefit for participants treated with DCF (Ajani 2007).

Sadighi 2006 used the Iranian version of the EORTC-QLQ C30. The report by Ajani 2007a demonstrated a better preservation of Quality of life in the participants treated with DCF. In Roth 2007, global health status improved in participants treated with ECF, but remained stable with both docetaxel regimens. Van Cutsem 2006 measured a longer time to $5 \%$ deterioration of the global health status in the docetaxel-containing arm as compared to the nondocetaxel-containing arm ( $\mathrm{HR} 1.44,95 \% \mathrm{Cl} 1.08$ to 1.93). ThussPatience 2005 measured subjective symptom improvement rates. Al-Batran 2013 (Kripp 2014) administered both EORTC QLQ-C30 and the gastric module STO22, and found that despite the higher toxicity in elderly participants (aged 65 years or older) receiving FLOT, the intensified chemotherapy regimen did not affect quality of life parameters in the elderly.

\section{(7) Chemotherapy with capecitabine versus 5-FU-containing regimens}

\section{Overall survival}

The results for this comparison are based on 732 randomised participants in five studies (Kang 2009; Li 2016; Ocvirk 2012; Ochenduszko 2015; Van Cutsem 2015). The HR for overall survival of 0.94 ( $95 \% \mathrm{Cl} 0.79$ to 1.11 , moderate-quality evidence) favours the oral regimen, but does not reach statistical significance (Analysis 7.1). The index of heterogeneity for this comparison was small $\left(I^{2}\right.$
$=12 \%, \mathrm{P}=0.34)$. The corresponding pooled median survival are 10.8 and 10.9 months, respectively for the capecitabine and 5-FUcontaining arms respectively. When the studies which permitted second-line therapy were excluded as part of sensitivity analysis (Li 2016; Ochenduszko 2015), the pooled HR for overall survival remained stable at 0.93 ( $95 \% \mathrm{Cl} 0.77$ to 1.14$)$.

\section{Secondary outcome measures}

\section{Tumour response}

Data were available in 636 participants in four studies (Kang 2009; Li 2016; Ocvirk 2012; Van Cutsem 2015). The objective response rate was $38 \%$ in both arms, corresponding to an OR of $0.85(95 \% \mathrm{Cl} 0.40$ to 1.79 , very low-quality evidence) with a non-significant advantage for the capecitabine-containing regimen (Analysis 7.2).

\section{Time to progression}

Data from one study of 85 participants (Ocvirk 2012) showed a small benefit for participants treated with capecitabine (HR 0.72 , $95 \% \mathrm{Cl} 0.47$ to 1.12 , very low-quality evidence), with improved median time to progression times of 6.8 versus 5.5 months for the participants treated with and without capecitabine.

Kang 2009 provided the largest number of participants for the evaluation of progression-free survival and showed a nonsignificant advantage for the capecitabine-containing arm (HR 0.80, $95 \% \mathrm{Cl} 0.62$ to 1.03 ), corresponding to an improvement in median progression-free survival time of 5.6 versus 5.0 months for the participants treated with and without capecitabine. In total, four studies (Kang 2009; Li 2016; Ochenduszko 2015; Van Cutsem 2015) were included in this comparison with a total of 647 participants, demonstrating an overall HR of progression-free survival of 0.98 (95\% Cl 0.77 to 1.23 , very low quality) for participants treated with vs without capecitabine $\left(I^{2}=23 \%, P=0.27\right)$ (Analysis 7.4). The exclusion of studies permitting second-line chemotherapy (Li 2016; Ochenduszko 2015) did not alter the findings (HR 0.94, 95\% Cl 0.58 to 1.53$)$.

\section{Secondary resectability}

This outcome was not reported in these studies.

\section{Toxicity}

Two studies ( $\mathrm{N}=481$ ) reported deaths due to toxicity, where in the capecitabine-containing arm was $5 \%$ in the capecitabinecontaining arm and $2 \%$ in the 5-FU arm (Kang 2009; Van Cutsem 2015) (Analysis 7.5). The pooled OR for treatment related death is 1.88 ( $95 \% \mathrm{Cl} 0.23$ to 15.15 , very low-quality evidence), with substantial heterogeneity $\left(I^{2}=59 \%, P=0.12\right)$. Treatment discontinuation due to toxicity was similar in both arms (18\%) (Kang 2009) (Analysis 7.6).

\section{Quality of life}

Was not reported in these studies.

\section{(8) Chemotherapy with oxaliplatin versus the same regimen including cisplatin}

\section{Overall survival}

Data were available on 1105 participants in five studies (Al Batran 2008; Hironaka 2016; Kim 2014; Popov 2008; Yamada 2015). The HR for overall survival of $0.81(95 \% \mathrm{Cl} 0.67$ to 0.98 , low-quality evidence) show a small, advantage for the regimen with oxaliplatin 
(Analysis 8.1), with a moderate heterogeneity index $\left(\mathrm{I}^{2}=38 \%\right.$, $P=0.17)$. This survival benefit is also reflected in the pooled median overall survival time of 14.0 months versus 11.3 months, respectively.

\section{Secondary outcome measures}

\section{Tumour response}

Data were available on 1081 participants of the five studies (Al Batran 2008; Hironaka 2016; Kim 2014; Popov 2008; Yamada 2015). The response was 54\% in the oxaliplatin-based arms and $47 \%$ in the cisplatin-based arms, with a statistically significant advantage for the oxaliplatin-containing regimen (OR $1.38,95 \% \mathrm{Cl} 1.08$ to 1.76 , moderate-quality evidence), and low heterogeneity between studies $\left(I^{2}=0 \%, P=0.41\right.$ ) (Analysis 8.2 ).

\section{Progression-free survival}

Progression-free survival, rather than time to progression, was reported in the studies by Al Batran 2008, Hironaka 2016, Kim 2014, and Yamada $2015(\mathrm{~N}=1034)$. The pooled hazard ratio of oxaliplatinversus cisplatin-based regimens, was 0.88 (95\% Cl: 0.66 to 1.19$)$ with a high level of heterogeneity between studies $\left(I^{2}=59 \%, P=\right.$ 0.06) (Analysis 8.3).

\section{Secondary resectability}

This outcome was not reported in these studies.

\section{Toxicity}

In Popov 2008, two participants (1.4\%) experienced a toxic death in the cisplatin-containing arms. These two participants suffered from febrile neutropenia, developed sepsis, and died of septic shock despite antimicrobial therapy. No participant died of toxicity in the oxaliplatin-containing arm (Popov 2008). One treatment-related death occurred in each arm in Kim 2014. Al Batran 2008 observed no treatment-related deaths. Overall, the pooled occurrence of treatment-related deaths (Al Batran 2008; Hironaka 2016; Kim 2014; Popov 2008; Yamada 2015) ( $\mathrm{N}=1132)$ in both arms were $0.9 \%$ and $2.0 \%$ in the oxaliplatin- and cisplatin-containing arms, respectively (OR $0.47,95 \% \mathrm{Cl} 0.17$ to 1.30 , low-quality evidence), with a relatively stable effect across studies $\left(I^{2}=0 \%, P=0.74\right)$ (Analysis 8.4). Data on treatment discontinuation due to toxicity (Al Batran 2008; Hironaka 2016;Yamada 2015) ( $N=970)$ were $8 \%$ and $10 \%$ in the oxaliplatin and cisplatin arms, respectively (OR $0.97,95 \% \mathrm{Cl} 0.44$ to 2.13 , very low-quality evidence), with substantial between-study heterogeneity $\left(\mathrm{I}^{2}=60 \%, \mathrm{P}=0.08\right)$ (Analysis 8.5 ).

\section{Quality of life}

This was not reported in these studies.

\section{(9) Taxane-platinum-fluoropyrimidine combinations versus taxane-platinum (without fluoropyrimidine)}

\section{Overall survival}

The results for this comparison are based on 482 randomised participants in three studies (Ajani 2005; Roth 2007; Van Cutsem 2015). The HR for overall survival of $0.86(95 \% \mathrm{Cl} 0.71$ to 1.06 , very low-quality evidence) favours the regimen with fluoropyrimidine $\left(I^{2}\right.$ $=0 \%, P=0.47$ ), but does not reach statistical significance (Analysis 9.1). The corresponding pooled median survival times are 11.7 versus 10.0 months with a small benefit for participants treated with fluoropyrimidines. Allocation concealment was adequate in the studies included in this comparison.

\section{Secondary outcome measures}

\section{Tumour response}

Data were available all participants in the above mentioned three studies. The objective response rate was $38 \%$ in the 5 FU-containing regimen and $23 \%$ in the arm without 5-FU. This corresponds to an OR of $2.08(95 \% \mathrm{Cl} 1.37$ to 3.15 , low-quality evidence) with an advantage for the 5-FU-containing regimen. Low heterogeneity $\left(I^{2}=0 \%, P=0.89\right)$ between studies was observed.

\section{Time to progression}

All three studies reported progression-free survival instead of time to progression. Data from the included studies showed a benefit (HR $0.7495 \% \mathrm{Cl} 0.59$ to 0.93 , moderate-quality evidence) for the participants treated with 5-FU (Analysis 9.3), and low heterogeneity between studies $\left(I^{2}=0 \%, P=0.83\right)$.

\section{Secondary resectability}

This outcome was not reported in these studies.

\section{Toxicity numbers}

In three studies ( $\mathrm{N}=482)$, treatment-related deaths were $6.2 \%$ and $2.6 \%$ in the 5-FU-containing arms and non-FU-containing arms respectively (OR $1.95,95 \% \mathrm{Cl} 0.73$ to 5.17 , very lowquality evidence) $\left(I^{2}=0 \%, P=0.88\right)$ (Analysis 9.4). Treatment discontinuation due to toxicity was more frequent for the participants treated with $5-\mathrm{FU}(16.7 \%$ versus $10.5 \%)$, corresponding to an OR of 1.71 (95\% Cl 0.79 to 3.69 , very low-quality evidence) and results between studies were not different $\left(I^{2}=0 \%, P=0.93\right)$ (Analysis 9.5).

\section{Quality of life}

This was assessed in only one of these studies (Roth 2007). Treatment burden increased over time in both treatment arms.

\section{(10) S-1 versus 5-FU-containing regimens}

\section{Overall survival}

This meta-analysis was based on 1793 participants in four randomised studies (Ajani 2010; Boku 2009; Chen 2015; Li 2015). The resulting HR for overall survival of $0.91(95 \% \mathrm{Cl} 0.83$ to 1.00 , high-quality evidence) demonstrates a borderline statistically significant benefit with low heterogeneity $\left(I^{2}=0 \%, P=0.50\right)$ with overall survival in favour of S-1 (Analysis 10.1). The corresponding pooled median survival times were 9.6 and 9.1 months with a clinically negligible benefit for participants treated with S-1. Allocation concealment was adequate in Ajani 2010 and Boku 2009.

\section{Secondary outcome measures}

\section{Tumour response}

Data were available in 1753 participants in seven studies (Ajani 2010; Boku 2009; Chen 2015; Dong 2014; Huang 2013; Li 2015; Li 2014). The objective response rate was $32 \%$ with S-1 and $26 \%$ in the 5-FU arm. This corresponds to an OR of $1.73(95 \% \mathrm{Cl} 1.01$ to 2.94 , very low-quality evidence) (Analysis 10.2). However, considering the statistically significant heterogeneity $\left(I^{2}=77 \%, P=0.0002\right)$, the results of this comparison have to be evaluated cautiously. 


\section{Time to progression}

Four studies (Ajani 2010; Boku 2009; Huang 2013; Li 2015) ( $N=1942$ ) reported progression-free survival, with a small non-significant benefit for participants treated with S-1 (HR $0.85,95 \% \mathrm{Cl} 0.70$ to 1.04 , low-quality evidence) (Analysis 10.3) and with substantial heterogeneity $\left(I^{2}=70 \%, P=0.02\right)$.

Three studies (Ajani 2010; Boku 2009; Huang 2013) reported time to treatment failure (TTF) with a HR of $0.84(95 \% \mathrm{Cl} 0.69$ to 1.02$)$ in favour of S-1. With the inclusion of Li 2014 and Chen 2015, who reported the time to progression, into the meta-analysis of TTF (Analysis 10.4), ( $\mathrm{N}=1818)$, the pooled HR was 0.88 (95\% $\mathrm{Cl} 0.76$ to 1.01. low-quality evidence), indicating a slight but statistically nonsignificant benefit of S-1.

\section{Secondary resectability}

This outcome was not reported in these studies.

\section{Toxicity}

Rates of treatment-related deaths were less frequent in the S-1containing arm (1.5\%) compared to $2.7 \%$ in the 5 -FU-containing arm (OR $0.56,95 \% \mathrm{Cl} 0.30$ to 1.06 , moderate-quality evidence) ( $I^{2}$ $=0 \%, P=0.52$ ) (Analysis 10.5). Treatment discontinuation due to toxicity was slightly less frequent for the participants treated with S-1 $(11.1 \%$ versus $12.8 \%$, corresponding to an OR of $0.85(95 \% \mathrm{Cl}$ 0.63 to 1.13 , high-quality evidence) $\left(I^{2}=11 \%, P=0.32\right)$ (Analysis 10.6).

\section{Quality of life}

Health-related quality of life was reported by Ajani 2010. There was an advantage of CS compared to CF in terms of the Physical WellBeing (PWB; $51.7 \%$ versus $45.1 \%, P=0.044$ ) component of the FACT$\mathrm{Ga}$, longer time to worsening of PWB scores (median duration; 4.5 versus 3.0 months, $P=0.014$ ), and Chemotherapy Convenience and Chemotherapy Concerns scores.

\section{DISCUSSION}

\section{Summary of main results}

Only randomised controlled studies were included in this metaanalysis. An exhaustive search for unpublished or ongoing material was performed to minimise publication bias. Sixty studies, with a total of 11,698 participants, have been included in the meta-analysis of overall survival. The meta-analyses of comparisons 1 (three studies, 184 participants) and 2 (23 studies involving 4447 participants) provide evidence for significant benefits in overall survival for first-line chemotherapy versus best supportive care (BSC), as well as a smaller benefit for combination versus single-agent chemotherapy. Overall, regimens containing irinotecan demonstrated improved results for overall survival in the substitutive comparison (i.e. where another chemotherapy was substituted by irinotecan) of irinotecan versus non-irinotecancontaining regimens (six studies with 826 participants, HR 0.87 , $95 \% \mathrm{Cl} 0.75$ to 1.00 , high-quality evidence), but not in the additive comparison (i.e. where irinotecan was added to another chemotherapy; HR $0.88,95 \% \mathrm{Cl} 0.76$ to 1.03 , three studies with 500 participants, low-quality evidence). In contrast, the meta-analysis of all irinotecan-containing versus non-irinotecancontaining regimens demonstrates a small, but significant survival benefit in favour of the people treated with irinotecan. Of note, both treatment-related deaths and treatment-discontinuation due to toxicity were not increased for people treated with irinotecan.

Furthermore, regimens in which docetaxel was added to a twodrug platinum-fluoropyrimidine combination showed a significant survival benefit (four studies with 1466 participants (HR 0.80, $95 \% \mathrm{Cl} 0.71$ to 0.91 , moderate-quality evidence). In contrast, substituting another chemotherapy (e.g. 5-FU (Ridwelski 2008), epirubicin (Roth 2007), or both epirubicin and 5-FU (Thuss-Patience 2005)) by docetaxel provides no advantage - either in survival, or in secondary outcomes (three studies involving 479 participants, HR $1.05 ; 0.87$ to 1.27 , moderate-quality evidence). However, the addition of docetaxel to a two-drug chemotherapy regimen in first-line therapy slightly increases both the risk of treatmentrelated deaths and treatment discontinuation due to toxicity. The comparison of regimens including capecitabine versus 5-FU showed non-significant advantages in terms of overall survival for the oral 5-FU prodrug capecitabine (732 participants in five studies, $0.94,95 \% \mathrm{Cl} 0.79$ to 1.11 , moderate-quality evidence).

The comparison of regimens including oxaliplatin versus cisplatin (comparison 8), and S-1 versus 5-FU (comparison 10), however demonstrated the superior efficacy of oxaliplatin (1105 participants from five studies, $\mathrm{HR} 0.81,95 \% \mathrm{Cl} 0.67$ to 0.98 , low-quality evidence) and S-1 (1793 participants in four studies, HR 0.91, 95\% $\mathrm{Cl} 0.83$ to 1.00 , high-quality evidence), respectively, the latter being statistically non significant. However the magnitude of the benefit in individual populations is unclear due to differences in dosing and treatment schedules, and drug metabolism of S-1 between Asian and Caucasian populations. Of note, the landmark REAL-2 study could not be included in this analysis as it included up to $13 \%$ of people with oesophageal squamous cell carcinoma in the different study arms.

\section{(1) First-line chemotherapy versus best supportive care}

Results for the comparison of first-line chemotherapy versus best supportive care (BSC) convincingly demonstrate a benefit in median survival in favour of chemotherapy ( $\mathrm{HR} 0.37,95 \% \mathrm{Cl} 0.24$ to 0.55 , three studies, 184 participants, moderate-quality evidence), corresponding to 11 versus 4.3 months weighted average survival. The validity of this result was limited by the small number of participants included in this analysis. In two of four studies addressing this question, either the randomisation (Murad 1993) or the study (Pyrhönen 1995) were terminated early. In another one (Glimelius 1997) the conduct of the study was not possible as planned because the research ethics committee requested the provision of chemotherapy upon request in the BSC group. Further studies addressing this comparison cannot be carried out as BSC cannot be considered to be an appropriate control arm for further studies. Exclusion of the studies by Murad and Pyrhönen, both of which have severe methodological limitations as described above, restricts the studies eligible for this analysis to the study by Scheithauer (Scheithauer 1996). This study, which included 103 participants, was the largest of all studies performed for this comparison and demonstrated a survival benefit of 10.2 versus 5.0 months in the chemotherapy versus BSC group ( $P$ $=0.0001$ ), which is statistically significant and in line with the results of the other two studies, although not as large. Another study (Glimelius 1997), which was excluded from the analysis (see above) because of cross-over, provided important insights about the quality of life of participants in the chemotherapy and BSC arms. The average quality-adjusted survival was longer in the 
group of participants randomised to chemotherapy than in the BSC group (median six versus two months). In addition to the benefits in median survival and quality of life, between $10 \%$ and $24 \%$ of all participants in the chemotherapy groups in these three studies were alive after two years. In contrast, only one of 81 participants included in the BSC arms of these studies survived longer than 24 months. Two-year survival rates in chemotherapytreated participants between $5 \%$ and $14 \%$ were confirmed by other authors (Ohkuwa 2000; Waters 1999), confirming the observation that a limited number of people do have a considerably greater survival benefit from chemotherapy. The reason for the difference in pooled median survival between chemotherapy arms in the studies that compared chemotherapy versus BSC (11.0 months) and the combination therapy arms in studies comparing singleagent versus combination chemotherapy ( 7.0 months) remains unclear and cannot be explained by differences in prognostic factors. Considering the small number of participants included in the studies comparing chemotherapy versus BSC, as well as the methodological limitations in two of these three studies, an overestimation of the effect of chemotherapy in these studies is likely.

\section{(2) Single agent versus combination chemotherapy}

Regarding comparison 2, 16 of 23 relevant individual studies $(\mathrm{N}=$ 4447) did not demonstrate a benefit in terms of overall survival for the combination chemotherapy arms. In this context, the results of this meta-analysis demonstrate a statistically significant and consistent benefit for combination versus single-agent therapy in terms of overall survival (HR $0.84,95 \% \mathrm{Cl} 0.79$ to 0.89 , moderate-quality evidence). Furthermore, response rate and time to progression show advantages for the participants treated with combination chemotherapy. The pooled results of these studies represent a generalised estimate of the effectiveness of the combination chemotherapy regimens used in the last 25 years. Therefore, the benefit of a modern two-drug combination, such as 5-FU/irinotecan or 5-FU/oxaliplatin over a single-agent, usually fluoropyrimidine-based chemotherapy regimen is likely to exceed this global result.

Although any potential survival benefit associated with combination chemotherapy is achieved at the price of increased toxicity, the toxicity of the above mentioned combinations of 5FU and irinotecan, and 5-FU and oxaliplatin is well managed by oncologists today. Furthermore, given the known correlation between tumour response and quality of life (Sadighi 2006), and considering that the ability of a chemotherapy to maintain a person's health-related quality of life is correlated to its efficacy (Al-Batran 2010), in the absence of contraindications, modern twodrug combination chemotherapy regimens as discussed above should clearly be the preferred option for first-line treatment of people with advanced gastric cancer.

\section{(3) 5-FU/cisplatin/anthracycline combinations versus 5-FU/ cisplatin (without anthracyclines)}

This comparison was based on 579 participants in four randomised studies and results in a $\mathrm{HR}$ of $0.74(95 \% \mathrm{Cl} 0.61$ to 0.89 , moderatequality evidence) in favour of the three-drug combination. This comparison is limited by a small number of studies and participants. The results of this comparison are predominantly attributable to the study by Ross 2002, which compared ECF versus MCF. The difference between the data included in this review and the final publication is due to the fact that the original publication included people with squamous cell cancer of the oesophagus, which do not correspond to the inclusion criteria of this review. Therefore, data from people with gastric adenocarcinoma only as provided by the authors were included in this review.

Whether these results are still relevant today is questionable for two reasons.

1) Since the publication of the REAL-2 study (Cunningham 2008), which demonstrated a significant survival benefit for the combination of EOX (epirubicin, oxaliplatin, and capecitabine) as compared to ECF (epirubicin, cisplatin, and fluorouracil), cisplatin is frequently replaced by oxaliplatin and 5-FU by capecitabine in clinical practice. The relative contribution of epirubicin to the efficacy of the three-drug regimen of capecitabine, oxaliplatin, and epirubicin must be considered as unclear.

2) All studies included in this comparison were conducted at a time when active drugs for second-line chemotherapy were not available. Thus, the validity of these results in 2017, after the publication of 3 randomised studies comparing second-line therapy versus BSC (Ford 2014; Kang 2012; Thuss-Patience 2011), which all three demonstrated as clinically meaningful, statistically significant, and consistent benefit in survival of about 1.5 months, as well as improvements in clinical symptoms Thuss-Patience 2011 and quality of life Ford 2014, needs to be questioned.

In addition, a recently published, french randomised multicentre phase III study Guimbaud 2014, in which a total of 416 participants were included, is of special interest in this context. This study compared the combination of FOLFIRI, followed by ECX (epirubicin, cisplatin, and capecitabine) with the reverse sequence of the same regimens. It has not been included in this meta-analysis as all participants eligible for second-line chemotherapy were systematically crossed over. The results of this study showed similar results for PFS (5.3 versus 5.8 months) and OS ( 9.5 versus 9.7 months) for both treatment strategies, but a longer timeto treatment-failure for FOLFIRI. Furthermore, the tolerance of FOLFIRI (overall grade III+IV toxicities and haematological adverse events) was better. For these reasons it must be considered as questionable whether the benefit from adding epirubicin to a twodrug regimen including capecitabine and oxaliplatin outweighs its additional toxicity, especially in sequential treatment strategies.

\section{(4) 5-FU/cisplatin/anthracycline-combinations versus 5-FU/ anthracycline combinations (without cisplatin)}

Comparison 4 was based on 1147 participants randomised in seven studies and resulted in a HR of 0.82 (95\% Cl 0.73 to 0.92 ; low-quality evidence, Analysis 4.1) in favour of the three-drug combination. A sensitivity analysis according to the quality score with inclusion of only those studies in which allocation concealment was adequate (Cocconi 1994; Cocconi 2003; Kikuchi 1990; Webb 1997) does not cause a relevant change of the resulting $\mathrm{HR}(0.82,95 \% \mathrm{Cl} 0.73$ to 0.92 , low-quality evidence). Heterogeneity was non-significant in comparison 3 and $4\left(\mathrm{P}=0.71\right.$ and $0.21 ; \mathrm{I}^{2}$ was $0 \%(95 \% \mathrm{Cl} 0 \%$ to $26.5 \%)$ and $28.5 \%(95 \% \mathrm{Cl} 0 \%$ to $69.2 \%)$.

This comparison, which included a greater number of participants and studies compared to comparison $\mathbf{3}$, and is thus much more robust, confirms a statistically significant advantage in overall survival for the addition of cisplatin to the combination of epirubicin and fluorouracil, achieved at the price of increased 
toxicity. Again, all studies included in this comparison were published more than 20 years ago, when second-line therapy was unavailable. Therefore, as discussed above, the benefit of anthracyclines in this three-drug combination today is unclear. In view of the evidence discussed above, combinations of 5-FU/ cisplatin and an anthracycline are no longer considered as a preferred option for the first-line treatment of advanced gastric cancer today.

\section{(5) Irinotecan versus non-irinotecan-containing regimens}

Comparison 5 was based on 2135 participants randomised in 10 studies including six studies in substitutive comparisons, three studies in additive comparison, and two other comparisons. Two treatment arms without irinotecan (5-FU as single-agent and 5-FU/ cisplatin) were compared to FOLFIRI in Bouche 2004. Taking all studies into account, the pooled hazard ratio was 0.87 (95\% Cl 0.80 to 0.95 , high-quality evidence) in favour of irinotecan-containing regimens. In subgroup analyses of overall survival, the pooled HR were 0.87 ( $95 \% \mathrm{Cl} 0.75$ to 1.00 , high-quality evidence) for the substitutive comparison, HR 0.88 ( $95 \% \mathrm{Cl} 0.76$ to 1.03 , low-quality evidence) for the additive comparison, and $\mathrm{HR} 0.87$ (95\% $\mathrm{Cl} 0.76$ to 1.00 , very low-quality evidence) for the other comparisons, Analysis 5.1.

Objective response rates of $38 \%$ versus $30 \%$ were observed in substitutive (OR $1.53,95 \% \mathrm{Cl} 0.93$ to 2.50 , low-quality evidence) and $38 \%$ versus $22 \%$ in additive comparisons (OR $2.18,95 \% \mathrm{Cl}$ 1.25 to 3.80 , low-quality evidence). The pooled HR for progressionfree survival was $0.76(95 \% \mathrm{Cl} 0.69$ to 0.84 , high-quality evidence); and 0.85 (95\% $\mathrm{Cl} 0.72$ to 1.00 , moderate-quality evidence) and 0.74 ( $95 \% \mathrm{Cl} 0.66$ to 0.84 , high-quality evidence) for subgroup analysis of substitutive and other comparisons, respectively. Results for rates of treatment-related deaths and treatment discontinuation due to toxicity showed high heterogeneity between studies.

In view of these results, 5-FU/irinotecan-based two-drug combinations should be considered as a true and at least equally effective alternative to platinum-based combinations in first-line therapy. A further advantage of the irinotecan-based combination is the different toxicity profile with no neurotoxicity (as compared to the platinum derivatives) and no significant renal toxicity. In addition, irinotecan-based regimens can easily be administered in the outpatient setting and avoid the hyperhydration necessary for the treatment with cisplatin. Again, the above mentioned study Guimbaud 2014 clearly demonstrates not only the comparable results of treatment with FOLFIRI in first- versus second-line, but as well the feasibility of second-line chemotherapy in $40 \%$ to $50 \%$ of people and third-line in about $20 \%$ of people in Europe.

\section{(6) Docetaxel versus non-docetaxel-containing regimens}

Comparison 6 was based on 2001 participants randomised in eight studies including three studies in substitutive comparisons, four studies in additive comparison, and one study in other comparisons. Results from one study (Sadighi 2006) are not included in this meta-analysis at present because data for the calculation of the HR were not available. Overall, heterogeneity was not significant in the former two comparisons $\left(I^{2}=0 \%, P=\right.$ 0.99 and 0.82 ). Of special interest is the fact that studies, in which docetaxel was added to a two-drug regimen of a platinum and a fluoropyrimidine (Al-Batran 2013; Wang 2016; Van Cutsem 2006) or S-1 as single-agent (Koizumi 2014) demonstrate a significant benefit not only in terms of survival (HR $0.80 ; 0.71$ to 0.91 , moderate-quality evidence), but also in terms of response rates where the OR was 1.83 ( $95 \% \mathrm{Cl} 1.45$ to 2.32 , high-quality evidence) for the regimens with docetaxel. In contrast, when docetaxel is substituting another chemotherapy, such as 5-FU, no OS benefit of the docetaxel-containing chemotherapy regimen was observed (HR $1.05,95 \% \mathrm{Cl} 0.87$ to 1.27 , moderate-quality evidence). Thus, docetaxel-containing two-drug regimens are less efficient than docetaxel-containing three-drug regimens. This observation is confirmed by the recently published, randomised phase II study by Van Cutsem 2015, where overall survival was 14.59 months (95\% $\mathrm{Cl}: 11.7$ to 21.78 ) for participants treated with docetaxel, oxaliplatin, and 5-FU, as compared to $11.3(95 \% \mathrm{Cl} 8.08$ to 14.03) months. However, survival was only a secondary endpoint of this study, and the study was not powered to detect survival differences. Of note, in the study by Van Cutsem $200632 \%$ and $41 \%$ of participants in both study arms were treated with further chemotherapy lines, while this figure was not given for the study by Al-Batran 2013. The positive effect of the addition of docetaxel to the cisplatin/ fluorouracil combination on survival as well as the time to $5 \%$ deterioration of global health status in the study by Van Cutsem 2006 was unfortunately achieved at the price of significant toxicity, especially haematological toxicity. For this reason, the clinical value of this regimen is regarded as controversial (Ilsen 2007). Of note, grade III to IV infection (related to treatment) was more frequent in elderly people ( $20 \%$ versus $9 \%$ ), and infection was the main cause of treatment-related deaths in both study arms.

Finally, the median age of 55 in the participants included in this study, which was well below the median age of the participants included in other studies (e.g. Al Batran 2008 or Cunningham 2008: 64 and 65 years), needs to be considered when applying these findings to people outside a clinical study. In contrast, the FLOT regimen (5-FU, leucovorin, oxaliplatin, and docetaxel) was developed in an elderly population (median age 69 and 70 years in both treatment groups) (Al-Batran 2013). The primary endpoint of this randomised phase II study, which compared FLOT with FLO (5FU, leucovorin and oxaliplatin) was the tolerability and feasibility, defined as per group differences in toxic effects. While the results of this study show - as expected - higher rates of neutropenia, leukopenia, alopecia, and diarrhoea for the participants treated with FLOT, there were similar rates of complicated neutropenia and serious adverse events in the two treatment arms. However, progression-free and overall survival in people over 70 years was similar for treatment with FLOT and FLO. Thus, although FLOT has shown to be feasible in a population over 65 years old, according to a subgroup analysis of younger participants $(n=68)$ versus equal to or older than 70 years $(n=75)$ in this study, only in participants younger than 70 an improved survival was observed for the three-drug combination (median survival 7.1 versus 10.6 months). However, these data are not more than hypothesis generating based on a subgroup analysis from a randomised phase II study. Nevertheless, although the same limitation is valid, another subgroup analysis from this study, which compared the benefit of FLOT to FLO in people with locally advanced versus metastatic disease raised another interesting hypothesis. According to this subgroup analysis, median survival of people with locally advanced disease $(n=44)$ treated with FLOT versus FLO is 24.2 versus 10.3 months, as compared to 7.3 versus 6.0 months in people with metastatic disease $(n=99)$. Thus, people with locally advanced disease might have a greater benefit from FLOT than people with metastatic disease. 
(7) Regimens including capecitabine versus intravenous 5-FUcontaining regimens

Comparison 7 was based on 732 randomised participants in five studies and resulted in a HR of $0.94(95 \% \mathrm{Cl} 0.79$ to 1.11 ; moderatequality evidence, Analysis 7.1). The finding of these studies are in line with the study by Cunningham 2008, which confirms the non-inferiority of capecitabine as compared to 5-FU although it was not included in this comparison because of differences in the participant population (inclusion of people with squamous cell cancer of the oesophagus). For this reason, people with gastric cancer without dysphagia, with adequate renal function and compliance may be treated with capecitabine (or S-1 - see Analysis 10.1) instead of 5-FU.

\section{(8) Regimens including oxaliplatin versus the same regimen including cisplatin}

Overall survival results for comparison $\mathbf{8}$ are based on 1105 randomised participants in five studies. The HR for overall survival was 0.81 ( $95 \% \mathrm{Cl} 0.67$ to 0.98 , low-quality evidence) showing a statistically significant survival advantage in favour of oxaliplatincontaining regimens (Analysis 8.1). A higher rate of tumour response was also observed in oxaliplatin-containing regimens (54\%) compared to cisplatin-containing regimens (47\%) (OR 1.38, $95 \% \mathrm{Cl} 1.08$ to 1.76 , moderate-quality evidence). Again, although data from the landmark REAL-2 study (Cunningham 2008) were not included in this comparison for reasons specified above, they confirm the non-inferiority of oxaliplatin as compared to cisplatin. It is worth noting that three of these included studies were conducted in Asia (Hironaka 2016; Kim 2014; Yamada 2015), potentially highlighting the applicability of these results to an Asian cohort.

Of special interest in this context is a subgroup analysis of the study by Al Batran 2008, which reports better results for elderly participants treated with oxaliplatin as compared to cisplatin. Therefore, especially when taking into account the higher response rates and lower risk of treatment-related death, oxaliplatin should be preferred to cisplatin in the treatment of gastric cancer.

\section{9) Taxane-platinum-fluoropyrimidine combinations versus taxane-platinum (without fluoropyrimidine)}

This comparison was based on 482 randomised participants in three studies and resulted in a HR for overall survival of 0.86 (95\% $\mathrm{Cl} 0.71$ to 1.06; very low-quality evidence, Analysis 9.1) in favour of the taxane regimen plus fluoropyrimidine, without reaching statistical significance. The potential drawback was the higher rate of treatment-related deaths $(6.2 \%$ versus $2.6 \%$, OR $1.95 ; 95 \% \mathrm{Cl}$ 0.73 to 5.17$)$ and treatment discontinuation due to toxicity (17\% versus $11 \%$, OR $1.71,95 \% \mathrm{Cl} 0.79$ to 3.69 ) in the regimens with fluoropyrimidines. Of note; these results are partially attributable to the docetaxel/oxaliplatin/capecitabine-combination, which due to its clearly inferior therapeutic index as compared to the same combination with 5-FU instead of capecitabine (Van Cutsem 2015) is not recommended. However, objective response rates $(38 \%$ versus $23 \%, 2.08(95 \% \mathrm{Cl} \mathrm{Cl} 1.37$ to 3.15$)$ and progression-free survival ( $\mathrm{HR} 0.74,95 \% \mathrm{Cl} 0.59$ to 0.93 , moderate-quality evidence) were improved in regimens with fluoropyrimidine. Treatment burden increased over time in both treatment arms. Thus, in conclusion, when a docetaxel-containing three-drug combination chemotherapy regimen is chosen as first-line treatment, oxaliplatin should be preferred to cisplatin, and 5-FU should be preferred to capecitabine.

\section{(10) S-1 versus 5-FU-containing regimens}

This comparison was based on 1793 randomised participants in four studies and resulted in a HR for overall survival of 0.91 (95\% $\mathrm{Cl} 0.83$ to 1.00; Analysis 10.1). In addition, a statistically significant advantage in tumour response (OR $1.73,95 \% \mathrm{Cl} 1.01$ to 2.94 , very low-quality evidence), a numerical benefit in progression- freesurvival (HR 0.85, 95\% $\mathrm{Cl} 0.70$ to 1.04 ) and time-to-treatment failure ( $\mathrm{HR} 0.88,95 \% \mathrm{Cl} 0.76$ to 1.01 , both low-quality evidence), less frequent treatment-related deaths $(1.5 \%$ versus $2.7 \%$, OR $0.56,95 \%$ $\mathrm{Cl} 0.30$ to 1.06 ), and treatment discontinuations due to toxicity ( $11.1 \%$ versus $12.8 \%$, OR $0.85,95 \% \mathrm{Cl} 0.63$ to 1.13 ) were observed in the S-1-containing compared to the 5-FU-containing arms.

\section{Overall completeness and applicability of evidence}

In most of these studies, the participants were only in part representative of all people with gastric cancer because they were generally younger than the overall population of people with gastric cancer (Pye 2001). People with co-morbidities, such as renal or cardiac disease, were excluded. For this reason, these findings are only applicable to people who fulfil the inclusion criteria of these studies and cannot be generalised to all people with gastric cancer. The number of studies representing Asian people with gastric cancer in this 2017 updated review has increased considerably, with now a total of 26 studies conducted at least in part in Asia (Boku 2009; Chen 2015; Dong 2014; Hironaka 2016; Huang 2013; Kang 2009; Kikuchi 1990; Kim 2001; Kim 2014; Koizumi 2008; Koizumi 2014; Komatsu 2011; KRGGC 1992; Li 2014; Li 2015; Li 2016; Lu 2014; Narahara 2011; Nishikawa 2012; Ohtsu 2003; Shirao 2013; Sugimoto 2014; Wang 2013; Wu 2015; Yamada 2015; Yamamura 1998). The largest number of Asian people was included in comparison 2. Asian people were clearly underrepresented in comparisons 3, 4, and 6. The example of $\mathrm{S}-1$, which is used in different doses in Caucasian $\left(25 \mathrm{mg} / \mathrm{m}^{2}\right.$ twice daily) and Asian people (40 mg/m $\mathrm{m}^{2}$ twice daily) (Satoh 2014) confirms that chemotherapy regimens need to be tested in Asian and Caucasian populations separately, and that the balance between efficacy and toxicity of a given regimen might be different in different populations due in part to genetic differences (Syn 2015). Results from clinical studies are thus applicable only to those populations where they have been tested. Except for these limitations, the evidence cited above should be regarded as complete and applicable.

\section{Quality of the evidence}

This review included a total of 60 studies and 11,698 participants in the meta-analysis for the primary outcome of overall survival. Seven of the 10 main comparisons for overall survival had low heterogeneity $\left(1^{2}<20 \%\right)$, and even among comparisons with higher levels of inconsistency $\left(\mathrm{I}^{2}>20 \%\right)$, the amount of heterogeneity present was not statistically significant $(P>0.05)$. Hence, the pooled results can be considered to be relatively stable. The majority of studies had low risk of bias in terms of random sequence generation, blinding, incomplete efficacy or safety outcome data, and selective reporting. However, the risk of bias due to lack of independent or blinded radiological review and other sources of bias (see Risk of bias in included studies) are unclear or high in more than $50 \%$ of included studies; hence, these can be considered areas for improvement in future studies. The main reasons for 
downgrading of evidence in the 'Summary of findings' tables are due to lack of precision in pooled effect sizes, risk of bias (particularly, allocation bias), and statistical heterogeneity.

\section{Potential biases in the review process}

For this review, all reasonable effort has been made to reduce and address potential sources of bias, such as inclusion of studies not published in English, searches for unpublished and not fully published studies. Therefore, the likelihood that relevant studies have not been identified is considered as small. One factor with known impact on overall survival after first-line chemotherapy is second-line therapy, which is administered in up to $70 \%$ of some recent studies. However, as second-line therapy is now a standard of care, it should not be considered as a source of bias.

\section{Agreements and disagreements with other studies or reviews}

Another meta-analysis (Okines 2008), which summarised the results from two studies that used capecitabine instead of 5-FU, confirmed a significant survival benefit for the people treated with capecitabine, thus lending further support to the use of capecitabine in people with gastric cancer.

We agree with the following key issues in the review by Garrido 2014: DCF is - in terms of efficacy - one of the most promising regimens in younger people with adequate general health. However, it is counterbalanced by significant toxicity, and other three-drug regimens including docetaxel, 5-FU, and oxaliplatin, such as FLOT or TEF (Van Cutsem 2015) are appropriate alternatives with better tolerability, and that either FOLFIRI or the combination of irinotecan and 5-FU as described by Dank 2008 should also be considered among the most promising regimens on the basis of their significant impact on overall survival, the overall reduced toxicity and time to treatment failure as compared to three-drug regimens (Guimbaud 2014), as well as the absence of cumulative toxicity. However, we would strongly advise not to use IFL (a combination of bolus 5-FU and irinotecan) in view of the higher rate of treatment-related deaths of this regimen in colorectal cancer (Hurwitz 2004). The conclusions of the review by Lordick 2014b "both doublet and triplet drugregimens can be used......but careful consideration of the potential toxic complications, impairment of the person's quality of life, and the relative benefit should be undertaken". Lordick 2014a gives an excellent, more general overview of the current status and challenges in gastric cancer treatment. It addresses not only medical treatment (both chemotherapy and targeted therapies), but also the pathology and surgery. We agree with the main conclusions of the meta-analysis published by the GASTRIC Group 2013 that the addition of experimental chemotherapeutic agents to pre-existing control- or standard regimens have produced a modest improvement in overall survival and progression-free survival, and that none of the regimens emerged as a clear standard. The meta-analysis by Petrelli 2013 compared any two-and three-drug regimens that included CDDP with any regimen containing the same number of agents in which CDDP was replaced by oxaliplatin, CPT-11 or a taxane, We agree with the observation that substitution of cisplatin by modern agents, such as oxaliplatin or irinotecan generally improves outcomes. We also agree with the analysis by (Chen 2013) that DCF has a better response-rate than nontaxane-containing regimens, but disagree with their statement that chemotherapy-related toxicity of DCF regimen is acceptable to some extent.

\section{AUTHORS' CONCLUSIONS}

\section{Implications for practice}

Our review found that people with advanced gastric cancer would benefit from being tested for HER-2 over expression, and in the absence of contraindications receive trastuzumab in combination with cisplatin and 5-FU or capecitabine in case of HER-2 positive disease. For all other people, the use of combination chemotherapy could be considered as standard of care for first-line treatment. The results of this meta-analysis suggest a significant and conclusive survival benefit for chemotherapy versus best supportive care (BSC), as well as a modest survival benefit for combination versus single-agent chemotherapy. As many studies included in this comparison have used combination chemotherapy regimens with suboptimal efficacy, such as 5FU/epirubicin or 5-FU/ cisplatin, the benefit of combination chemotherapy is likely to be underestimated. In the absence of contraindications, the upfront use of a two-drug combination is efficacious. Among the combination chemotherapy regimens, twodrug combinations including a fluoropyrimidine and oxaliplatin is more efficacious than cisplatin-based combinations in view of their survival benefit and reduced risk of treatment-related deaths. 5-FU/irinotecan-based two-drug combinations are an alternative to platinum-based regimens for first-line treatment, which demonstrated superior results for survival, as well as progression-free survival and tumour response, without any negative impact on toxicity as compared to the non-irinotecancontaining combination chemotherapy regimens. Thus, based on both their efficacy and the balance between efficacy and toxicity, two-drug combinations of a fluoropyrimidine and oxaliplatin or 5-FU and irinotecan are superior treatment regimens for first-line treatment of HER-2 negative gastric cancer. Consideration of the side-effect profile of each regimen is essential in the treatment decision for an individual person.

Three-drug combinations are not widely-used in clinical practice, but might be beneficial for individual people: Two major groups of three-drug-combinations need to be discussed:

\section{Docetaxel-based three drug combinations (DCF, FLO-T or TEF).}

In which docetaxel is added to a single-agent or two-drug (platinum/5-FU- combination) show significant advantages in terms of overall survival, progression-free-survival, and response rates. However, these advantages are counterbalanced by increased toxicity, especially hematological and neurotoxicity. Of note, while the DCF regimen has been evaluated in a population with a median age of 55 years (Van Cutsem 2006) with greater toxicity in the elderly people included in this study, it cannot be recommended for elderly people and for this reason FLOT has been shown to be feasible in people over 65 (Al-Batran 2013). However, in this randomised phase II study conducted in Germany, no benefit from treatment with the three-drug combination of docetaxel, 5FU, and oxaliplatin (FLOT) as compared to the two-drug regimen FLO (5-FU, leucovorin, and oxaliplatin) was observed in people aged 70 years or older. In the age of personalised medicine, we should not only ask which regimen is better, but which regimen is better for which people. In the above mentioned study by AlBatran, the benefit from the three-drug combination was limited 
to people under 70 years old and a small group of people with locally advanced (versus metastatic) disease. Although data from a subgroup analysis need to be interpreted with caution and the validity of these findings needs to be confirmed in future studies, this is an intriguing hypothesis. Of note, in the perioperative setting an increased pathological response rate was demonstrated for the use of FLOT - as compared to ECF- in a recent publication (Al-Batran 2016), although survival results are still pending.

\section{Three-drug regimens which include epirubicin.}

Whether the survival benefit for three-drug combinations including cisplatin, 5-FU, and epirubicin - as compared to the same regimen without epirubicin - is still valid when second-line therapy is routinely administered and when cisplatin is replaced by oxaliplatin and 5-FU by capecitabine is questionable.

Furthermore, the magnitude of the observed survival benefits for both groups of three-drug combinations in the palliative setting is not large enough to be clinically meaningful as defined recently by the American Society for Clinical Oncology (ASCO) (Ellis 2014). In contrast to comparisons, in which a survival benefit was observed by adding a third drug to a two-drug regimen at the cost of increased toxicity, the comparison of regimens in which another chemotherapy was replaced by irinotecan was associated with a survival benefit (of borderline statistical significance) without increased toxicity.

Nevertheless, individual people in good performance status and with a large tumour burden might have a greater advantage from three-drug regimens (especially docetaxel-containing three-drug combinations) due to their higher response rate.

The benefit of second-line chemotherapy in terms of symptom relief and survival over BSC has been demonstrated in several well-conducted and randomised studies in both European and Asian populations, in people with good performance status. Routine administration of second-line therapy to all people with good performance status might further limit the benefit of a three-drug combination upfront, as compared to the sequential administration of doublets followed by a single-agent, as recently shown in the study by Guimbaud 2014. According to recent phase III studies, the vascular-endothelial-growth-factor-receptor-targeting antibody ramucirumab (Fuchs 2014; Wilke 2014) as single-agent treatment or in combination with paclitaxel chemotherapy might be considered as an alternative to chemotherapy alone as second line.

According to a randomised study among patients with metastatic, non-small cell lung cancer, early palliative care led to significant improvements in both quality of life and mood. As compared to patients receiving standard care, patients receiving early palliative care had less aggressive care at the end of life, but longer survival (Temel 2010). According to their most recent update, ASCO guidelines on "Integration of palliative care into standard oncology care" (Ferrell 2017) recommend that - for newly diagnosed people with advanced cancer - the specialised palliative care team should be involved within eight weeks of diagnosis. Among people with high symptom burdens, outpatient care programs should deliver palliative care services to complement existing program tools. For elderly people, the use of a minimum dataset including the Charlson Comorbidity Index (Charlson 1987), the G8 geriatric assessment screening tool, and the instrumental activities of daily living should be considered for the assessment of global health status and functional status (Pallis 2011).

Finally, it should be noted that despite all progress in the last decades, advanced gastric cancer remains a disease with a dismal prognosis, and median survival exceeding 12 months only in a small number of randomised studies. Thus, appropriate treatment measure should follow the guidelines of palliative care, defined by WHO (Sepulveda 2002) as "an approach that improves the qualityof-life of people and their families facing the problems associated with life-threatening illness".

\section{Implications for research}

Further research is necessary to develop specific treatment strategies for the different subtypes of gastric cancer (TCGA 2014). This concerns not only the molecular subtypes described above, but also clinically defined subgroups of people, for example people with locally advanced or limited metastatic disease, as well as a radiological response to chemotherapy. Considering systemic treatment alone in all people with locally advanced and metastatic gastric cancer is unlikely to achieve the best results for these subgroups with favourable prognostic factors: People with a radiological response in the REAL-2 study (Cunningham 2008) had one- and two-year survival rates of $70.9 \%$ (95\% Cl 61.8 to 78.3$)$ and $27.9 \%(95 \% \mathrm{Cl} 20.0$ to 36.2$)$. The value of surgery and/or local ablative therapies in people with good performance status, limited metastatic disease, and respond to chemotherapy is controversial (Kataoka 2017). A randomised clinical study (FLOT-5, NCT02578368) addressing the question if surgery further improves survival and quality of life in people with limited metastatic disease after pretreatment with FLOT is currently ongoing.

The question if strategies to reduce treatment burden, such as maintenance therapy, may be integrated in the continuum of care without compromising efficacy needs to be evaluated in further studies (Digklia 2016).

According to preliminary data from the neoadjuvant setting, people with well differentiated tumours have a greater chance to benefit from chemotherapy than others (Al-Batran 2016). Furthermore, not only targeted therapies, but also chemotherapies might not have the same efficacy in different molecular subtypes of gastric caner (Tan 2011; Syn 2016)

Further integration of targeted therapies and development of new treatment approaches, such as immunotherapy, for which promising preliminary results have just been presented (Kang 2017; Muro 2016) is highly warranted. Furthermore, treatment strategies combining different immunotherapeutic agents, or chemotherapy and immunotherapy, or immunotherapy and antiangiogenic therapies need further development. Valid biomarkers, which permit the selection of people with a high chance to respond to the different types of treatments are urgently required.

The role of intraperitoneal chemotherapy, in which cytotoxic agents are infused into the peritoneum, particularly for people with advanced gastric cancer with peritoneal dissemination are being actively investigated (Chan 2017). Randomised studies, including phase III studies, are currently ongoing, and in a future update to this review, it may be worth adding a comparison or subgroup to evaluate the benefits of this mode of chemotherapy administration. 
For Her-2 positive breast cancer, great progress has been made with the introduction of agents like pertuzumab and T-DM1 (Swain 2015; Verma 2012), which showed major benefits in recent phase III studies, and many other molecules targeting this pathway are in clinical development. While a benefit for T-DM1 as second-line treatment could not be demonstrated for HER-2 positive gastric cancer (Kang 2016), phase III-results for pertuzumab in gastric cancer are still pending.

For any new treatment, apart from the assessment of outcomes like overall- and progression-free survival, the balance between relief of tumour-associated symptoms and treatment-associated toxicity needs to be evaluated from the person's perspective to determine the palliative value of new therapy regimens in advanced gastric cancer.

Quality of life assessment deserves adequate methodology. Validated measurement instruments are available: a diseasespecific module to supplement the EORTC core quality of life questionnaire has been published (Vickery 2001), a FACTquestionnaire for people with stomach cancer has been developed concurrently in North America and Asia (Eremenco 2004), and a clinical meaningful benefit may be defined in advance (Norman 2003). Nevertheless, quality of life assessment remains challenging. Therefore, according to a recent statement from the American Society for Clinical Oncology (Ellis 2014), the interest has shifted to person's self reported specific symptom burden.

An ECOG performance status of 0 to 1 versus 2, and the presence of liver metastases and peritoneal metastases have been identified as poor prognostic factors by multivariate analysis (Chau 2004). A prognostic index was constructed dividing people into a good (no risk factor), moderate (one or two risk factors), and poor (three or more risk factors) risk group. This model has been validated in a second data set from the REAL-2 study. This study did also confirm the major prognostic impact of obtaining a radiological response: One- and two-year survival rates for responders were $70.9 \%$ (95\% $\mathrm{Cl} 61.8$ to 78.3$)$ and $27.9 \%(95 \% \mathrm{Cl} 20.0$ to 36.2$)$. Future studies should explicitly address the value of novel therapeutic strategies in different clinical risk groups.

Importantly, not all questions can be answered in randomised clinical studies. Further research on the risks and benefits of chemotherapy in both the elderly people population, as well as people who do not fulfil the inclusion criteria for clinical studies is required. Therefore, large observational cohort studies or registries of people treated with standard treatment outside clinical studies are important, such as the analysis published by Dixon 2016. Of note, both EORTC and ASCO (Pallis 2011; Wildiers 2013) have published recommendations for designing and reporting clinical studies in Geriatric Oncology in the future, which include obligatory reporting of age-related subgroup analysis, obligatory post-marketing studies in vulnerable and frail older people, and obligatory inclusion of a minimum dataset for senior adults in registration studies and post-marketing studies.

In view of the fact that second-line therapy has become a standard of care in the treatment of this disease, endpoints for clinical studies need reconsideration. Thus, in a disease where the sequential use of different treatments is established, overall survival might not be sufficiently sensitive as an endpoint for clinical studies. However, the correlation of progression-free survival with overall survival in advanced/recurrent gastric cancer was not confirmed in a recent meta-analysis (Paoletti 2013).

\section{ACKN OWLEDGEMENTS}

We thank Mrs. Shino Yuo for translations from Japanese and Dr. Yan Pu for translation of Chinese studies, as well as all authors who provided unpublished data. 


\section{R E F E R E N C E S}

\section{References to studies included in this review}

\section{Ajani 2005 \{published data only\}}

Ajani JA, Fodor MB, Tjulandin SA, Moiseyenko VM, Chao Y, Cabral FS, et al. Phase II multi-institutional randomized trial of docetaxel plus cisplatin with or without fluorouracil in patients with untreated, advanced gastric, or gastroesophageal adenocarcinoma. Journal of Clinical Oncology 2005;23(24):5660-7.

\section{Ajani 2010 \{published data only\}}

Ajani JA, Buyse M, Lichinitser M, Gorbunova V, Bodoky G, Douillard JY, et al. Combination of cisplatin/S-1 in the treatment of patients with advanced gastric or gastroesophageal adenocarcinoma: Results of noninferiority and safety analyses compared with cisplatin/5-fluorouracil in the First-Line Advanced Gastric Cancer Study. European Journal of Cancer 2013;49:3616-24.

* Ajani JA, Rodriguez W, Bodoky G, Moiseyenko V, Lichinitser M, Gorbunova V, et al. Multicenter phase III comparison of cisplatin/S-1 with cisplatin/infusional fluorouracil in advanced gastric or gastroesophageal adenocarcinoma study: the FLAGS trial. Journal of Clinical Oncology 2010;28(9):1547-53.

Bodoky G, Carrato A, Ravaioli A, Ajani JA. Quality of life in flags trial a randomized, comparative, open label, multicenter, phase 3 of S-1 + cisplatin (CS) compared to 5 -fu + cisplatin (CF) in untreated advanced gastric cancer (AGC) patients. Annals of Oncology. 2012; Vol. 23 (Supplement 9):ix232-ix233.

Bodoky G, Scheulen ME, Rivera F, Jassem J, Carrato A, Moiseyenko V, et al. Clinical benefit and health-related quality of life assessment in patients treated with cisplatin/S-1 versus cisplatin/5-FU: secondary end point results from the FirstLine Advanced Gastric Cancer Study (FLAGS). Journal of Gastrointestinal Cancer 2015;46(2):109-17.

\section{Al Batran 2008 \{published data only\}}

Al Batran SE, Hartmann JT, Probst S, Schmalenberg H, Hollerbach S, Hofheinz R, et al. Phase III trial in metastatic gastroesophageal adenocarcinoma with fluorouracil, leucovorin plus either oxaliplatin or cisplatin: a study of the Arbeitsgemeinschaft Internistische Onkologie. Journal of Clinical Oncology 2008;26(9):1435-42.

\section{Al-Batran 2013 \{published and unpublished data\}}

* Al-Batran SE, Pauligk C, Homann N, Hartmann JT, Moehler M, Probst S, et al. The feasibility of triple-drug chemotherapy combination in older adult patients with oesophagogastric cancer: a randomised trial of the Arbeitsgemeinschaft Internistische Onkologie (FLOT65+). European Journal of Cancer 2013;49(4):835-42.

Kripp M, Al-Batran S E, Rosowski J, Pauligk C, Homann N, Hartmann JT, et al. Quality of life of older adult patients receiving docetaxel-based chemotherapy triplets for esophagogastric adenocarcinoma: a randomized study of the Arbeitsgemeinschaft Internistische Onkologie (AIO). Gastric Cancer 2014;17:181-7.

\section{Barone 1998 \{published data only\}}

Barone C, Corsi DC, Pozzo C, Cassano A, Fontana T, Noviello MR, et al. Treatment of patients with advanced gastric carcinoma with a 5-fluorouracil-based or a cisplatin-based regimen: two parallel randomized phase II studies. Cancer 1998;82(8):1460-7. [MEDLINE: 12]

\section{Boku 2009 \{unpublished data only\}}

* Boku N, Yamamoto S, Fukuda H, Shirao K, Doi T, Sawaki A, et al. Fluorouracil versus combination of irinotecan plus cisplatin versus S-1 in metastatic gastric cancer: a randomised phase 3 study. Lancet Oncology 2009;10(11):1063-9.

Boku N, Yamamoto S, Shirao K, Doi T, Sawaki A, Koizumi W, et al. Randomized phase III study of 5-fluorouracil (5-FU) alone versus combination of irinotecan and cisplatin (CP) versus S-1 alone in advanced gastric cancer (JCOG9912). Journal of Clinical Oncology, ASCO Annual Meeting Proceedings Part I 2007;25(18S):LBA4513.

\section{Bouche 2004 \{published data only\}}

Bouche O, Raoul JL, Bonnetain F, Giovannini M, Etienne PL, Lledo G, et al. Randomized multicenter phase II trial of biweekly regime of fluorouracil and leucovorin (LV5FU2), LV5FU2 plus cisplatinum, or LV5FU2 plus irinotecan in patients with previously untreated metastatic gastric cancer. Final results of study FFCD 9803. Journal of Clinical Oncology 2004;22:4319-29.

\section{Cascinu 2011 \{published data only\}}

Cascinu S, Galizia E, Labianca R, Ferrau F, Pucci F, Silva RR, et al. Pegylated liposomal doxorubicin, 5-fluorouracil and cisplatin versus mitomycin-C, 5-fluorouracil and cisplatin for advanced gastric cancer: a randomized phase II trial. Cancer Chemotherapy and Pharmacology 2011;68(1):37-43.

\section{Chen 2015 \{published data only\}}

Chen JH, Shen WX, Xia JX, Xu RL, Zhu MQ, Xu M. Comparative study between docetaxel, oxaliplatin plus S-1 and DCF regimen as first-line therapy in patients with advanced gastric cancer. Chinese Journal of Cancer Prevention and Treatment 2015;22(2):134-7.

\section{Cocconi 1994 \{published data only\}}

Cocconi G, Bella M, Zironi S, Algeri R, Di Costanzo F, De Lisi V, et al. Fluorouracil, doxorubicin, and mitomycin combination versus PELF chemotherapy in advanced gastric cancer: a prospective randomized trial of the Italian Oncology Group for Clinical Research. Journal of Clinical Oncology 1994;12(12):2687-93. [MEDLINE: 23]

\section{Cocconi 2003 \{published data only\}}

Cocconi G, Carlini P, Gamboni A, Gasperoni S, Rodino C, Zironi S, et al. Cisplatin, epirubicin, leucovorin and 5-fluorouracil (PELF) is more active than 5-fluorouracil, doxorubicin and methotrexate (FAMTX) in advanced gastric carcinoma. Annals of Oncology 2003;14(8):1258-63. [MEDLINE: 2] 
Colucci 1995 \{published data only\}

Colucci G, Giotta F, Maiello E, Cifarelli RA, Leo S, Giuliani F, et al. Efficacy of the association of folinic acid and 5-

fluorouracil alone versus folinic acid and 5-fluorouracil plus 4epidoxorubicin in the treatment of advanced gastric carcinoma. American Journal of Clinical Oncology 1995;18(6):519-24. [MEDLINE: 24]

\section{Cullinan 1985 \{published data only\}}

Cullinan SA, Moertel CG, Fleming TR, Rubin JR, Krook JE, Everson LK, et al. A comparison of three chemotherapeutic regimens in the treatment of advanced pancreatic and gastric carcinoma: fluorouracil vs fluorouracil and doxorubicin vs fluorouracil, doxorubicin, and mitomycin. JAMA 1985;253:2061-7.

\section{Cullinan 1994 \{published data only\}}

Cullinan SA, Moertel CG, Wieand HS, O'Connell MJ, Poon MA, Krook JE, et al. Controlled evaluation of three drug combination regimens versus fluorouracil alone for the therapy of advanced gastric cancer. North Central Cancer Treatment Group. Journal of Clinical Oncology 1994;12(2):412-6. [MEDLINE: 26]

\section{Dank 2008 \{published data only\}}

Curran D, Pozzo C, Zaluski J, Dank M, Barone C, Valvere V, et al. Quality of life of palliative chemotherapy naive patients with advanced adenocarcinoma of the stomach or esophagogastric junction treated with irinotecan combined with 5-fluorouracil and folinic acid: results of a randomised phase III trial. Quality of Life Research 2009;18:853-61.

* Dank M, Zaluski J, Barone C, Valvere V, Yalcin S, Peschel C, et al. Randomized phase III study comparing irinotecan combined with 5-fluorouracil and folinic acid to cisplatin combined with 5-fluorouracil in chemotherapy naive patients with advanced adenocarcinoma of the stomach or esophagogastric junction. Annals of Oncology 2008;19(8):1450-7.

\section{De Lisi 1986 \{published data only\}}

De Lisi V, Cocconi G, Tonato M. Randomized comparison of 5-FU alone or combined with carmustine, doxorubicin, and mitomycin (BAFMi) in the treatment of advanced gastric cancer: a phase III trial of the Italian Clinical Research Oncology Group (GOIRC). Cancer Treatment Reports 1986;70:481-5.

\section{Dong 2014 \{published data only\}}

Dong L, Li J, Lou XP, Miao JH, Lu P, Chang ZW, et al. Comparison of short-term efficacy and safety of TIROX and DCF regimens for advanced gastric cancer. Journal of International Medical Research 2014;42(3):737-43.

\section{GITSG 1988 \{published data only\}}

Gastrointestinal Tumor Study Group. Triazinate and platinum efficacy in combination with 5-fluorouracil and doxorubicin: results of a three arm randomized trial in metastatic gastric cancer. Journal of the National Cancer Institute 1988;80:1011-5.

* Koizumi W, Kim YH, Fujii M, Kim HK, Imamura H, Lee KH, et al. Addition of docetaxel to $\mathrm{S}-1$ without platinum prolongs survival of patients with gastric cancer: a randomized study
(START). Journal of Cancer Research and Clinical Oncology 2014; 140:319-28.

\section{Hironaka 2016 \{published data only\}}

Hironaka S, Sugimoto N, Yamaguchi K, Moriwaki T, Komatsu Y, Nishina T, et al. S-1 plus leucovorin versus S-1 plus leucovorin and oxaliplatin versus S-1 plus cisplatin in patients with advanced gastric cancer: a randomised, multicentre, openlabel, phase 2 trial. Lancet Oncology 2016;17(1):99-108. [DOI: 10.1016/S1470-2045(15)00410-6]

\section{Huang 2013 \{published data only\}}

Huang D, Ba Y, Xiong Ji, Xu N, Yan Z, Zhuang Z, et al. A multicentre randomised trial comparing weekly paclitaxel +S-1 with weekly paclitaxel+5-fluorouracil for patients with advanced gastric cancer. European Journal of Cancer. England: Department of Gastrointestinal Medical Oncology, Tianjin Medical University Cancer Institute \& Hospital, Tianjin, China., 2013; Vol. 49, issue 14:2995-3002.

Kang 2009 \{published data only\}

Kang YK, Kang WK, Shin DB, Chen J, Xiong J, Wang J, et al. Capecitabine/cisplatin versus 5-fluorouracil/cisplatin as first-line therapy in patients with advanced gastric cancer: a randomised phase III non inferiority trial. Annals of Oncology 2009;20:666-73. [DOI: 10.1093/annonc/mdn717]

\section{Kikuchi 1990 \{published data only\}}

Kikuchi K, Wakui A, Shimizu H, Kunii Y. Randomized controlled study on chemotherapy with 5-FU, ADM plus CDDP in advanced gastric carcinoma. [Japanese]. Gan to Kagaku Ryoho [Japanese Journal of Cancer \& Chemotherapy] 1990;17(4 Pt 1):655-62. [MEDLINE: 55]

\section{Kim 2001 \{published and unpublished data\}}

Kim TW, Choi SJ, Ahn JH, Bang HS, Chang HM, Kang YK, et al. A prospective randomized phase III trial of 5-fluorouracil and cisplatin (FP) versus epirubicin, cisplatin, and 5-fu (ECF) in the treatment of patients with previously untreated advanced gastric cancer (AGC). European Journal of Cancer 2001;37(Suppl 6):314. [MEDLINE: 56]

\section{Kim 2014 \{published data only\}}

Kim YS, Sym SJ, Park SH, Park I, Hong J, Ahn HK, et al. A randomized phase II study of weekly docetaxel/cisplatin versus weekly docetaxel/oxaliplatin as firstline therapy for patients with advanced gastric cancer. Cancer Chemotherapy and Pharmacology 2014;73:163-9.

\section{Koizumi 2008 \{published data only\}}

Koizumi W, Narahara H, Hara T, Takagane A, Akiya T, Takagi M. S-1 plus cisplatin versus S-1 alone for first-line treatment of advanced gastric cancer (SPIRITS trial): a phase III trial. Lancet Oncology 2008;9(3):215-21.

\section{Koizumi 2014 \{published data only\}}

Fujii M. Chemotherapy for advanced gastric cancer: ongoing phase III study of S- 1 alone versus S- 1 and docetaxel combination (JACCRO GC03 study). International Journal of Clinical Oncology 2008;13(3):201-5. 
Fujii M, Kim YH, Satoh T, Hosaka H, Kim T, Tsuji A, et al. Randomized phase III study of S-1 alone versus S-1 plus docetaxel (DOC) in the treatment for advanced gastric cancer (AGC): The START trial update. Journal of Clinical Oncology 2011;29(15 Suppl 1):4016.

Kim YH, Koizumi W, Lee KH, Kishimoto T, Chung HC, et al. Randomized phase III study of S-1 alone versus S-1 plus Docetaxel in the treatment for advanced gastric cancer: The START trial. Journal of Clinical Oncology. 2011; Vol. 29:suppl. 4.

* Koizumi W, Kim YH, Fujii M, Kim HK, Imamura H, Lee KH, et al. Addition of docetaxel to $\mathrm{S}-1$ without platinum prolongs survival of patients with advanced gastric cancer: a randomized study (START). Journal of Cancer Research and Clinical Oncology 2014;140(2):319-28.

\section{Komatsu 2011 \{published data only\}}

Komatsu Y, Takahashi Y, Kimura Y, Oda H, Tajima Y, Tamura S. Randomized phase II trial of first-line treatment with tailored irinotecan and S-1 therapy versus S-1 monotherapy for advanced or recurrent gastric carcinoma (JFMC31-0301). Anticancer drugs 2011;22(6):576-83.

\section{KRGGC 1992 \{published data only\}}

Kyoto Research Group for Chemotherapy of Gastric Cancer. A randomized, comparative study of combination chemotherapies in advanced gastric cancer: 5 -fluorouracil and cisplatin (FP) versus 5-fluorouracil, cisplatin, and 4-epirubicin (FPEPIR). Anticancer Research 1992;12:1983-8.

\section{Levi 1986 \{published and unpublished data\}}

Levi JA, Fox RM, Tattersall MH, Woods RL, Thomson D, Gill G. Analysis of a prospectively randomized comparison of doxorubicin versus 5 -fluorouracil, doxorubicin, and BCNU in advanced gastric cancer: implications for future studies. Journal of Clinical Oncology 1986;4(9):1348-55. [MEDLINE: 70]

\section{Li 2014 \{published data only\}}

Li Y, Zhu D. Comparison between the effect of SOX regimen and FOLFOX4 regimen for advanced gastric cancer. [Chinese] [SOX 方案对比FOLFOX4方案治疗进展期胃癌的临床观察]. Cancer Research and Clinic 2014;26(1):42-51.

\section{Li 2015 \{published data only\}}

Li YH, Qiu MZ, Xu JM, Sun GP, Lu HS, Liu YP, et al. S-1 plus cisplatin versus fluorouracil plus cisplatin in advanced gastric or gastro-esophageal junction adenocarcinoma patients: a pilot study. Oncotarget 2015;6(33):35107-15. [DOI: 10.18632/ oncotarget.5959]

\section{Li 2016 \{published data only\}}

Li JY, Huang CZ, Yuan JH, Chen QH. Comparison of efficacy of modified EOX and FOLFIRI regimens in treatment of metastatic gastric cancer. World Chinese Journal of Digestology 2016;24(12):1866-73.

\section{Loehrer 1994 \{published data only\}}

Loehrer PJ Sr, Harry D, Chlebowski RT. 5-fluorouracil vs. epirubicin vs. 5-fluorouracil plus epirubicin in advanced gastric carcinoma. Investigational New Drugs 1994;12(1):57-63. [MEDLINE: 72]
Lu 2014 \{published data only\}

Lu Y, Liu Z, Zhang J. S-1 plus oxaliplatin vs. S-1 as first-line treatment in patients with previously untreated advanced gastric cancer: a randomized phase II study. Journal of Chemotherapy 2014;26(3):159-64.

\section{Lutz 2007 \{published data only\}}

Lutz MP, Wilke H, Wagener DJ, Vanhoefer U, Jeziorski K, Hegewisch-Becker $S$, et al. Weekly infusional high-dose fluorouracil (HD-FU), HD-FU plus folinic acid (HD-FU/FA), or HD-FU/FA plus biweekly cisplatin in advanced gastric cancer: randomized phase II trial 40953 of the European Organisation for Research and Treatment of Cancer Gastrointestinal Group and the Arbeitsgemeinschaft Internistische Onkologie. Journal of Clinical Oncology 2007;25(18):2580-5.

\section{Moehler 2005 \{published data only\}}

Moehler M, Eimermacher A, Siebler J, Höhler T, Wein A, Menges $\mathrm{M}$, et al. Randomized phase II evaluation of irinotecan plus high-dose 5-fluorouracil and leucovorin (ILF) versus 5-fluorouracil, leucovorin and etoposide (ELF) in untreated metastatic gastric cancer. British Journal of Cancer 2005;92:2122-8.

\section{Moehler 2010 \{published data only\}}

Moehler M, Kanzler S, Geissler M, Raedle J, Ebert MP, et al. A randomized multicenter phase II study comparing capecitabine with irinotecan or cisplatin in metastatic adenocarcinoma of the stomach or esophagogastric junction. Annals of Oncology 2010;21:71-7. [DOI: 10.1093/annonc/mdp269]

\section{Murad 1993 \{published and unpublished data\}}

Murad AM, Santiago FF, Petroianu A, Rocha PR, Rodrigues MA, Rausch M. Modified therapy with 5-fluorouracil, doxorubicin, and methotrexate in advanced gastric cancer. Cancer 1993;72(1):37-41. [MEDLINE: 77]

\section{Narahara 2011 \{published and unpublished data\}}

Chin K, lishi H, Imamura H, Kobayashi O, Imamoto H, Esaki T, et al. Irinotecan plus S-1 (IRIS) versus S-1 alone as first line treatment for advanced gastric cancer: Preliminary results of a randomized phase III study (GC0301/TOP-002). Journal of Clinical Oncology, ASCO Annual Meeting Proceedings Part I 2007;25(18S):4525.

* Narahara H, lishi H, Imamura H, Tsuburaya A, Chin K, Imamoto $\mathrm{H}$, et al. Randomized phase III study comparing the efficacy and safety of irinotecan plus S-1 with S- 1 alone as firstline treatment for advanced gastric cancer (study GC0301/ TOP-002). Gastric Cancer 2011;14(1):72-80.

\section{Nishikawa 2012 \{published data only\}}

Morita S, Baba H, Tsuburaya A, Takiuchi H, Matsui T, Maehara Y, et al. A randomized phase II selection trial in patients with advanced/recurrent gastric cancer: Trial for Advanced Stomach Cancer (TASC). Japanese Journal of Clinical Oncology 2007;37(6):469-72.

* Nishikawa K, Morita S, Matsui T, Kobayashi M, Takeuchi Y,
Takahashi I, et al. A randomized phase-II trial comparing
sequential and concurrent paclitaxel with oral or parenteral 
fluorinated pyrimidines for advanced or metastatic gastric cancer. Gastric Cancer 2012;15(4):363-9.

\section{Ochenduszko 2015 \{published data only\}}

Ochenduszko S, Puskulluoglu M, Konopka K, Fijorek K, Urbanczyk K, Budzynski A, et al. Comparison of efficacy and safety of first-line palliative chemotherapy with EOX and mDCF regimens in patients with locally advanced inoperable or metastatic HER2-negative gastric or gastroesophageal junction adenocarcinoma: a randomized phase 3 trial. Medical Oncology 2015;32(10):242. [DOI: 10.1007/s12032-015-0687-7]

\section{Ocvirk 2012 \{unpublished data only\}}

Ocvirk J, Rebersek M, Skof E. Randomised prospective phase II study of combination chemotherapy epidoxorubicin, cisplatin, 5-FU (ECF) versus epidoxorubicin, cisplatin, capecitabin (ECX) in patients with advanced or metastatic gastric cancer. Journal of Clinical Oncology, ASCO Annual Meeting Proceedings Part I 2007;25(18S):4571.

* Ocvirk J, Rebersek M, Skof E, Hlebanja Z, Boc M. Randomized prospective phase ii study to compare the combination chemotherapy regimen epirubicin, cisplatin, and 5-fluorouracil with epirubicin, cisplatin, and capecitabine in patients with advanced or metastatic gastric cancer. American Journal of Clinical Oncology 2012;35(3):237-41.

\section{Ohtsu 2003 \{published and unpublished data\}}

Ohtsu A, Shimada Y, Shirao K, Bouku N, Hyodo I, Saito H, et al. Randomized phase III trial of fluorouracil alone versus flourouracil plus cisplatin versus uracil and tegafur plus mitomycin in patients with unresectable, advanced gastric cancer: The Japan Clinical Oncology Group Study (JCOG 9205). Journal of Clinical Oncology 2003;21(1):54-9. [MEDLINE: 191]

\section{Popov 2002 \{published and unpublished data\}}

Popov I, Svetislav BJ, Jezdic SD. Bi-weekly 24-hour infusion of high dose 5-fluorouracil versus EAP regimen in advanced gastric cancer: a randomised phase II study. Annals of Oncology. 2002; Vol. 13 (Suppl. 5):188. [MEDLINE: 150]

* Popov IP, Jelic SB, Krivokapic ZV, Jezdic SD, Pesko PM, Micev MT, et al. Bimonthly $24 \mathrm{~h}$ infusion of high-dose 5fluorouracil vs EAP regimen in patients with advanced gastric cancer. A randomized phase II study. Medical Oncology 2008;252(1):73-80.

\section{Popov 2008 \{published data only\}}

Popov I, Radosevic-Jelic L, Jezdic S, Milovic M, Borojevic N, Stojanovic S, et al. Biweekly oxaliplatin, fluorouracil and leucovorin versus cisplatin, fluorouracil and leucovorin in patients with advanced gastric cancer. Journal of the Balkan Union of Oncology 2008;13(4):505-11.

\section{Pyrhönen 1995 \{published data only\}}

Pyrhönen S, Kuitunen T, Nyandoto P, Kouri M. Randomised comparison of fluorouracil, epidoxorubicin and methotrexate (FEMTX) plus supportive care with supportive care alone in patients with non-resectable gastric cancer. British Journal of Cancer 1995;71(3):587-91. [MEDLINE: 92]

\section{Ridwelski 2008 \{unpublished data only\}}

Ridwelski K, Fahlke J, Schmidt C, Kettner E, Keilholz U, Quitzsch D, et al. Docetaxel-cisplatin (DC) versus 5-fluorouracilleucovorin-cisplatin (FLC) as first-line treatment for locally advanced or metastatic gastric cancer: Preliminary results of a phase III study. Journal of Clinical Oncology 2008;26 (May 20 Suppl):Abstract 4512.

\section{Ross 2002 \{published and unpublished data\}}

Ross P, Nicolson M, Cunningham D, Valle J, Seymour M, Harper $\mathrm{P}$, et al. Prospective randomized trial comparing mitomycin, cisplatin, and protracted venous-infusion fluorouracil (PVI 5-FU) with epirubicin, cisplatin, and PVI 5-FU in advanced esophagogastric cancer. Journal of Clinical Oncology 2002;20(8):1996-2004. [MEDLINE: 137]

\section{Roth 1999 \{published data only\}}

Roth A, Kolaric K, Zupanc D, Oresic V, Roth A, Ebling Z. High doses of 5-fluorouracil and epirubicin with or without cisplatin in advanced gastric cancer: a randomized study. Tumori 1999;85(4):234-8. [MEDLINE: 96]

\section{Roth 2007 \{published and unpublished data\}}

Roth AD, Fazio N, Stupp R, Falk S, Bernhard J, Saletti P, et al. Docetaxel, cisplatin, and fluorouracil; docetaxel and cisplatin; and epirubicin, cisplatin and fluorouracil as systemic treatment for advanced gastric carcinoma: a randomized phase II trial of the Swiss Group for Clinical Cancer Research. Journal of Clinical Oncology 2007;25(22):3217-23.

\section{Roy 2012 \{published data only\}}

Roy A, Cunningham D, Hawkins R, Sorbye H, Adenis A, Barcelo JR, et al. Docetaxel combined with irinotecan or 5fluorouracil in patients with advanced oesophago-gastric cancer: a randomised phase II study. British Journal of Cancer 2012;107(3):435-41.

\section{Sadighi 2006 \{published data only\}}

Sadighi S, Mohagheghi MA, Montazeri A, Sadighi Z. Quality of life in patients with advanced gastric cancer: a randomized trial comparing docetaxel, cisplatin, 5-FU (TCF) with epirubicin, cisplatin, 5-FU (ECF). BMC Cancer 2006;6:274.

\section{Scheithauer 1996 \{published and unpublished data\}}

Scheithauer W, Kornek G, Hejna M, Depisch D, Raderer M, Huber H. Palliative chemotherapy versus best supportive care in patients with metastatic gastric cancer: a randomized trial. Annals of Hematology. 1996; Vol. 73 (Suppl 2):A181. [MEDLINE: 107]

\section{Shirao 2013 \{published data only\}}

Shirao K, Boku N, Yamada Y, Yamaguchi K, Doi T, Goto M, et al. Randomized phase III study of 5-Fluorouracil continuous infusion vs. sequential methotrexate and 5-fluorouracil therapy in far advanced gastric cancer with peritoneal metastasis (JCOG 0106). Japanese Journal of Clinical Oncology 2013;43(10):972-80.

\section{Sugimoto 2014 \{published data only\}}

Sugimoto N, Fujitani K, Imamura H, Uedo N, lijima S, Imano M, et al. Randomized phase II trial of S-1 plus irinotecan versus 
S-1 plus paclitaxel as first-line treatment for advanced gastric cancer (OGSG0402). Anticancer Research 2014;34(2):851-7.

\section{Thuss-Patience 2005 \{published data only\}}

Thuss-Patience PC, Kretzschmar A, Repp M, Kingreen D, Henesser D, Micheel S, et al. Docetaxel and continuous infusion fluorouracil versus epirubicin, cisplatin and fluorouracil for advanced gastric adenocarcinoma: a randomized phase II study. Journal of Clinical Oncology 2005;23(3):494-501.

\section{Van Cutsem 2006 \{published data only\}}

Ajani JA, Moiseyenko VM, Tjulandin S, Majlis A, Constenla M, Boni $C$, et al. Clinical benefit with docetaxel plus fluorouracil and cisplatin compared with cisplatin and fluorouracil in a phase III trial of advanced gastric or gastroesophageal cancer adenocarcinoma: the V-325 Study Group. Journal of Clinical Oncology 2007;25:3205-9.

Ajani JA, Moiseyenko VM, Tjulandin S, Majlis A, Constenla M, Boni C, et al. Quality of life with docetaxel plus cisplatin and fluorouracil compared with cisplatin and fluorouracil from a phase III trial for advanced gastric or gastroesophageal adenocarcinoma: the V-325 Study Group. Journal of Clinical Oncology 2007;25:3210-6.

* Van Cutsem E, Moiseyenko VM, Tjulandin S, Majlis A, Constenla M, Boni C, et al. Phase III study of docetaxel and cisplatin plus fluorouracil compared with cisplatin and fluorouracil as first-line therapy for advanced gastric cancer: a report of the V325 Study Group. Journal of Clinical Oncology 2006;24(31):4991-7.

\section{Van Cutsem 2015 \{published data only\}}

Van Cutsem E, Boni C, Tabernero J, Massuti B, Middleton G, Dane F, et al. Docetaxel plus oxaliplatin with or without fluorouracil pr capecitabine in metastatic or locally recurrent gastric cancer: a randomized phase II study. Annals of Oncology 2015;26(1):149-56

\section{Wang 2013 \{published data only}

Wang X, Wang ML, Zhou LY, Lu XY, Yang JF, Yu HG. Randomized phase II study comparing paclitaxel with S-1 vs. S-1 as first-line treatment in patients with advanced gastric cancer. Clinical and Translational Oncology. Springer Milan (Via Podgora 4, Milan I-20122, Italy), 2013; Vol. 15, issue 10:836-42.

\section{Wang 2016 \{published data only\}}

Wang J, Xu R, Li J, Bai Y, Liu T, Jiao S, et al. Randomized multicenter phase III study of a modified docetaxel and cisplatin plus fluorouracil regimen compared with cisplatin and fluorouracil as first-line therapy for advanced or locally recurrent gastric cancer. Gastric Cancer 2016;19(1):234-44.

\section{Webb 1997 \{published and unpublished data\}}

Webb A, Cunningham D, Scarffe JH, Harper P, Norman A, Joffe JK, et al. Randomized trial comparing epirubicin, cisplatin, and fluouracil versus fluouracil, doxorubicin, and methotrexate in advanced esophagogastric cancer. Journal of Clinical Oncology 1997;15(1):261-7. [MEDLINE: 148]

\section{Wu 2015 \{published data only\}}

Wu D, Li X, Tong J, Sun L, Zheng H, Gao C, et al. S-1 combined with cisplatin versus cisplatin alone for the treatment of advanced gastric cancer: a pilot randomized-controlled trial. Anticancer Drugs 2015;26(7):774-8. [DOI: 10.1097/ CAD.0000000000000242]

\section{Yamada 2015 \{published data only\}}

Yamada Y, Higuchi K, Nishikawa K, Gotoh M, Fuse N, Sugimoto N, et al. Phase III study comparing oxaliplatin plus S-1 with cisplatin plus S-1 in chemotherapy-naive patients with advanced gastric cancer. Annals of Oncology 2015;26:141-8.

\section{Yamamura 1998 \{published and unpublished data\}}

Yamamura Y, Miyazaki I, Ogawa M, Yonemura Y, Tanemura H, Kito $T$, et al. A randomized controlled trial with methotrexate (MTX), 5-fluorouracil (5-FU) and pirarubicin (THP) vs 5-FU alone in advanced or recurrent gastric carcinoma. Tokai Hokuriku THP Study Group. [Japanese]. Gan to Kagaku Ryoho. Cancer \& Chemotherapy 1998;25(10):1543-8. [MEDLINE: 132]

\section{References to studies excluded from this review}

\section{Ahn 2002 \{published and unpublished data\}}

Ahn JH, Kang YK, Kim TW, Bahng H, Chang HM, Kang WC, et al. Nephrotoxicity of heptaplatin: a randomized comparison with cisplatin in advanced gastric cancer. Cancer Chemotherapy \& Pharmacology 2002;50(2):104-10. [MEDLINE: 2]

\section{Ajani 2002 \{published data only\}}

Ajani JA. Docetaxel in combination for advanced gastric cancer. Gastric Cancer 2002;5(Suppl 1):31-4. [MEDLINE: 5]

\section{Ajani 2006 \{published data only\}}

Ajani JA, Lee F-C, Singh DA, Haller DG, Lenz H-J, Benson Al B III, et al. Multicenter phase II trial of S-1 plus cisplatin in patients with untreated advanced gastric of gastroesophageal junction adenocarcinoma. Journal of Clinical Oncology 2006;24(4):663-7.

\section{Akagi 2010 \{published data only\}}

Akagi J, Baba H. PSK may suppress CD57(+) T cells to improve survival of advanced gastric cancer patients. International Journal of Clinical Oncology 2010;15(2):145-52.

\section{Akazawa 1985 \{published data only\}}

Akazawa S, Nakajima T, Kitagawa H, Nakagawa T, Kanda Y, Futatsuki K, et al. Therapeutic effect of sequential doses of methotrexate (MTX) and 5-fluorouracil (5-FU) in advanced gastric cancer: comparison of intermediate-dose MTX with high-dose MTX. Gan to Kagaku Ryoho. Cancer \& Chemotherapy 1985;12(1):91-8. [MEDLINE: 140]

\section{Andrić 2012 \{published data only\}}

Andrić Z, Randjelović T, Kovčin V, Gutović J, Crevar S, Murtezani Z, et al. Evaluation of the efficacy and toxicity of protocol cisplatin, 5-fluorouracil, leucovorin compared to protocol fluorouracil, doxorubicin and mitomycin C in locally advanced and metastatic gastric cancer. Srpski Arhiv za Celokupno Lekarstvo 2012;140(5-6):305-12. 


\section{Anonymous 1979 \{published data only\}}

Anonymous. Phase II-III chemotherapy studies in advanced gastric cancer. The Gastrointestinal Tumor Study Group. Cancer Treatment Reports 1979;63(11-12):1871-6. [MEDLINE: 3]

\section{Anonymous 1982 \{published data only\}}

* Anonymous. A comparative clinical assessment of combination chemotherapy in the management of advanced gastric carcinoma: The Gastrointestinal Tumour Study Group. Cancer 1982;49(7):1362-6.

O'Connel MJ, O'Fallon Y, Lavin PT, Moertel CG, Bruckner HW, Douglass $\mathrm{HO} \mathrm{Jr}$, et al. A comparative assessment of combination chemotherapy in advanced gastric cancer. Proceedings/ Annual Meeting of the American Society of Clinical Oncology. 1980:Abstract 403. [MEDLINE: 85]

\section{Anonymous 1983 \{published data only\}}

Anonymous. Chemotherapy for advanced stomach cancer a controlled study of AF and MF. [Japanese]. Gan to Kagaku Ryoho [Japanese Journal of Cancer \& Chemotherapy] 1983;10(10):2171-8. [MEDLINE: 5]

\section{Anonymous 1984 \{published data only\}}

* Anonymous. Randomized study of combination chemotherapy in unresectable gastric cancer. The Gastrointestinal Tumor Study Group. Cancer 1984;53(1):13-7.

O'Conell DM, Stablein DM for the Gastrointestinal Tumor Study Group. A prospective clinical trial of 5-fluorouracil/ adriamycin based chemotherapy in unresectable gastric cancer. Proceedings/Annual Meeting of the American Society of Clinical Oncology. 1982; Vol. 2:91. [MEDLINE: 86]

\section{Aoyama 1981 \{published data only\}}

Aoyama M, Hirose H, Adachi N. Comparison of combination therapy of 5-fluorouracil, mitomycin C, and adriamycin (FAM) and mitomycin C, 5-fluorouracil and cytosine arabinoside (MFC) for advanced gastric cancer. [Japanese]. Gan to Kagaku Ryoho. Cancer \& Chemotherapy 1981;8(5):757-62. [MEDLINE: 9]

\section{Bajetta 1998 \{published data only\}}

Bajetta E, Di Bartolomeo M, Carnaghi C, Buzzoni R, Mariani L, Gebbia V, et al. FEP regimen (epidoxorubicin, etoposide and cisplatin) in advanced gastric cancer, with or without low-dose GM-CSF: an Italian Trial in Medical Oncology (ITMO) study. British Journal of Cancer 1998;77(7):1149-54. [MEDLINE: 10]

\section{Baker 1976 \{published data only\}}

Baker LH, Talley RW, Matter R, Lehane DE, Rutter BW, Jones SE, et al. Phase III comparison of the treatment of advanced gastrointestinal cancer with bolus weekly 5-FU vs. methyl-CCNU plus bolus weekly 5-FU. Cancer 1976;38:1-7. [MEDLINE: 163]

\section{Balana 1990 \{published data only\}}

Balana C, Camps C, Diaz Rubio E, Jimeno J, Dorta J, Massuti B, et al. Treatment of advanced gastric cancer (GC) with a fluorouracil (F) or a cisplatin (P) based chemotherapy. A study of the Spanish cooperative group for gastrointestinal tumor therapy (TTD). Annals of Oncology. 1990; Vol. 1 (Suppl):43. [MEDLINE: 11]

\section{Berenberg 1989 \{published data only\}}

Berenberg JL, Goodman PJ, Oishi N, Fleming T, Natale RB, Hutchins LH, et al. [5-Fluorouracil (5-FU) and folinic acid (FA): for the treatment of metastatic gastric cancer]. Proceedings/ Annual Meeting of the American Society of Clinical Oncology. 1989; Vol. 8:101.

\section{Berenberg 1995 \{published data only\}}

Berenberg JL, Tangen C, Macdonald JS, Hutchins LF, Natale RB, Oishi N, et al. Phase II study of 5-fluorouracil and folinic acid in the treatment of patients with advanced gastric cancer. A Southwest Oncology Group Study. Cancer 1995;76(5):715-9. [MEDLINE: 136]

\section{Beretta 1983 \{published data only\}}

Beretta G, Fraschini P, Ravaioli A, Amadori D, Luporini G. FAM/ FAMB Polychemotherapy for advanced carcinoma of the stomach (ACS): a randomized study. Proceedings/Annual Meeting of the American Society of Clinical Oncology. 1983; Vol. 2:131. [MEDLINE: 159]

\section{Beretta 1989 \{published data only\}}

Beretta G, Arnoldi E, Beretta GD, Tedeschi L, Dallavalle G, Bollina $\mathrm{R}$, et al. A randomized study of fluorouracil versus FAM polychemotherapy in gastric carcinoma. Proceedings of the EORTC Symposium on Advances in Gastrointestinal Tract Cancer Research and Treatment. Strasbourg, 1989:P.48. [MEDLINE: 162]

\section{Berglund 2006 \{published data only\}}

Berglund A, Byström P, Pedersen D, Nygren P, Frödin JE, Bergman A, et al. GI-TAC: A randomised phase II study of sequential docetaxel and irinotecan with 5-fluorouracil.folinic acid in patients with metastatic upper abdominal (pancreatic, gastric or biliary) cancer. Annals of Oncology 2006;17(Suppl 9: Abstract 1126P):ix308-ix326.

\section{Bi 2011 \{published data only\}}

Bi F, Li Q, Zhou C, Yu J, Cai X, Qiu M, et al. Preliminary results of a randomized phase II study: Treatment of Chinese patients with advanced gastric cancer with FOLFIRI followed by FOLFOX7 or the reverse sequence. Journal of Clinical Oncology. 2011; Vol. 29 (Supp 1):15.

\section{Bjerkeset 1986 \{published data only\}}

Bjerkeset T, Fjosne HE. Comparison of oral ftorafur and intravenous 5-fluorouracil in patients with advanced cancer of the stomach, colon or rectum. Oncology 1986;43(4):212-5. [MEDLINE: 13]

\section{Bruckner 1986 \{published data only\}}

Bruckner HW, Stablein DM for the Gastrointestinal Tumor Study Group. A randomized study of 5-fluorouracil (F) and doxorubicin (A) with semustine (Me), cis-platinum (P), or triazinate $(T)$ for treatment of advanced gastric cancer. Proceedings/Annual Meeting of the American Society of Clinical Oncology. 1986; Vol. 5:90. [MEDLINE: 164]

\section{Brugarolas 1975 \{published and unpublished data\}}

Brugarolas A, Garcia MM, Lacave AJ. Chemotherapy in advanced gastric cancer. A controlled clinical study. Proceedings /Annual 
Meeting of the American Association for Cancer Research. 1975; Vol. 16(66):169. [MEDLINE: 15]

\section{Bugat 2003 \{published data only\}}

Bugat R. Irinotecan in the treatment of gastric cancer. Annals of Oncology 2003;14(Suppl 2):37-40. [MEDLINE: 13]

\section{Buroker 1979 \{published data only\}}

Buroker T, Kim PN, Groppe C, McCracken J, O'Bryan R, Panettiere F, et al. $5 \mathrm{FU}$ infusion with mitomycin-C vs. $5 \mathrm{FU}$ infusion with methyl-CCNU in the treatment of advanced upper gastrointestinal cancer: a Southwest Oncology Group Study. Cancer 1979;44(4):1215-21. [MEDLINE: 16]

\section{Cai 2011 \{published data only\}}

Cai X, Xue P, Song WF, Hu J, Gu HL, Yang HY, et al. The role of pharmacokinetic monitoring of fluorouracil in improvement of efficacy and reduction of adverse reactions for patients with advanced gastric cancer. Tumor 2011;31(10):930-6.

\section{Cascinu 1994 \{published data only\}}

Cascinu S, Cordella L, Catalano G. Neuroprotective effect of reduced glutathione (GSH) on cisplatin based chemotherapy in advanced gastric cancer: a double blind randomized trial. Proceedings/Annual Meeting of the American Society of Clinical Oncology. 1994; Vol. 13:431. [MEDLINE: 17]

\section{Cascinu 1995 \{published data only\}}

Cascinu S, Cordella L, Del Ferro E, Fronzoni M, Catalano G. Neuroprotective effect of reduced glutathione on cisplatinbased chemotherapy in advanced gastric cancer: a randomized double-blind placebo-controlled trial. Journal of Clinical Oncology 1995;13(1):26-32. [MEDLINE: 18]

\section{Cascinu 1996 \{published data only\}}

Cascinu S, Del Ferro E, Catalano G. Different doses of granulocyte colony stimulating factor to support a weekly chemotherapeutic regimen in advanced gastric cancer: a randomized study. Anti-Cancer Drugs 1996;7(1):43-7. [MEDLINE: 19]

\section{Chau 2013 \{published data only\}}

Chau I, Passalacqua R, Zalcberg JR, Fuchs CS, Liepa AM, Hsu Y, et al. Tolerability and quality-of-life $(\mathrm{Q} O \mathrm{~L})$ results from the phase 3 REGARD study: Ramucirumab versus placebo in patients with previously treated gastric or gastroesophageal junction (GEJ) adenocarcinoma. European Journal of Cancer. Elsevier Ltd, 2013; Vol. 49:S615.

\section{Chen 2011 \{published data only\}}

Chen D, Jia R, Gao S, Feng X, Pan L, Song N, et al. Effect of low-dose gimeracil and oteracil potassium combined with oxaliplatin on aged patients with advanced gastric cardiac adenocarcinoma. Chinese Journal of Clinical Oncology 2011;38(7):396-9.

\section{Chlebowski 1979 \{published data only\}}

Chlebowski RT, Paroly WS, Pugh RP, Weiner JM, Bateman JR. Treatment of advanced gastric carcinoma with 5-fluorouracil: a randomized comparison of two routes of delivery. Cancer Treatment Reports 1979;63(11-12):1979-81. [MEDLINE: 138]

\section{Chlebowski 1985 \{published data only\}}

Chlebowski RT, Weiner JM, Silverberg I, Glass A, Bateman JR. Cyclophosphamide plus 5-FU versus 5-FU alone in advanced gastric carcinoma. Oncology 1985;42(3):141-3. [MEDLINE: 20]

\section{Chu 2006 \{published data only\}}

Chu JH, Zhang Y, Liu DF, Ji HM. Weekly docetaxel combined with cisplatin of fluorouracil for advanced gastric carcinoma [Chinese]. Chinese Journal of Clinical Oncology 2006;11:541-2.

Chung 2011 \{published data only\}

Chung KY, Saito K, Zergebel C, Hollywood E, Segal M, Saltz LB. Phase I study of two schedules of oral S-1 in combination with fixed doses of oxaliplatin and bevacizumab in patients with advanced solid tumors. Oncology 2011;8(2):65-72.

\section{Coates 1984 \{published data only\}}

Coates AS, Tattersall MH, Swanson C, Hedley D, Fox RM, Raghavan D. Combination therapy with methotrexate and 5fluorouracil: a prospective randomized clinical trial of order of administration. Journal of Clinical Oncology 1984;2(7):756-61. [MEDLINE: 21]

\section{Cocconi 1982 \{published data only\}}

Cocconi G, DeLisi V, Di Blasio B. Randomized comparison of 5FU alone or combined with mitomycin and cytarabine (MFC) in the treatment of advanced gastric cancer. Cancer Treatment Reports 1982;66(6):1263-6. [MEDLINE: 22]

\section{Cocconi 1992 \{published data only\}}

Cocconi G, Bella M, Zironi S, Algeri R, Bartolucci R, De Lisi V, et al. A prospective randomized trial comparing FAM combination with PELF combination in advanced gastric carcinoma. Proceedings/Annual Meeting of the American Society of Clinical Oncology. 1992; Vol. 11:163. [MEDLINE: 166]

\section{Colucci 1991 \{published data only\}}

Colucci G, Maiello E, Valori V, Pezzella G, Giuliani F. A randomized study with 5-FU + folinic acid (FA) alone or with epirubicin (E) in advanced gastric carcinoma. European Journal of Cancer. 1991; Vol. 27 Suppl. 2:S81. [MEDLINE: 168]

\section{Constenla 2002 \{published data only\}}

Constenla M, Garcia-Arroyo R, Lorenzo I, Carrete N, Campos B, Palacios P. Docetaxel, 5-fluorouracil, and leucovorin as treatment for advanced gastric cancer: results of a phase II study. Gastric Cancer 2002;5(3):142-7. [MEDLINE: 7]

\section{Coombes 1994 \{published data only\}}

Coombes RC, Chilvers CE, Amadori D, Medi F, Fountzilas G, Rauschecker $\mathrm{H}$, et al. Randomised trial of epirubicin vs fluorouracil in advanced gastric cancer. An International Collaborative Cancer Group (ICCG) study. Annals of Oncology 1994;5:33-6. [MEDLINE: 189]

\section{Cullinan 1993 \{published data only\}}

Cullinan S, Moertel CG, Wieand H, Poon M. A randomized comparison of fluorouracil + adriamycin + cisplatin (FAP); fluorouracil + adriamycin + seumustine ( FAMe), FAME alternating with triazinate $(T)$, and fluorouracil alone in advanced gastric carcinoma. A North Central Cancer Treatment 
Group Study. Proceedings/Annual Meeting of the American Society of Clinical Oncology. 1993; Vol. 12:200. [MEDLINE: 169]

\section{Cunningham 2008 \{published data only\}}

Cunningham D, Starling N, Rao S, Iveson T, Nicolson M, Coxon F, et al. Capecitabine and oxaliplatin for advanced esophagogastric cancer. New England Journal of Medicine 2008;358:36-46.

\section{De Lisi 1985 \{published data only\}}

De Lisi V, Tonato M, Leonardi F, Soldani M, Di Constanzo F, Marinelli G, et al. Randomized comparison of 5-fluorouracil (5$\mathrm{FU}$ ) versus a combination of $\mathrm{BCNU}(\mathrm{B})$, adriamycin (A), 5-FU and mitomycin $\mathrm{C}$ (Mi) (BAFMi) in the treatment of advanced gastric carcinoma. Proceedings/Annual Meeting of the American Association for Cancer Research. 1985; Vol. 26:696. [MEDLINE: 27]

\section{De Lisi 1988 \{published data only\}}

De Lisi V, Cocconi G, Tonato M, Di Costanzo F, Leonardi F, Soldani M. 5-Fluorouracil versus a combination of BCNU, adriamycin, 5-FU and mitomycin $\mathrm{C}$ in advanced gastric cancer: a prospective randomized study of the Italian Clinical Research Oncology Group. Recent Results in Cancer Research 1988;110:212-8. [MEDLINE: 29]

\section{Diaz-Rubio 1991 \{published data only\}}

Diaz-Rubio E, Jimeno J, Cervantes A, Cruz J, Camps C, Massutic B, et al. Treatment of stage IV gastric cancer (GC) with a fluorouracil $(F)$ or a cisplatin $(P)$ based combination chemotherapy. Proceedings/Annual Meeting of the American Society of Clinical Oncology. 1991; Vol. 10:158. [MEDLINE: 171]

\section{Douglass 1983 \{published data only\}}

Douglass HO Jr, Lavin PT, Goudsmit A, Klaassen DJ, Paul AR. Phase II-III evaluation of combinations of methyl-CCNU, mitomycin C, adriamycin, and 5-fluorouracil in advanced measurable gastric cancer. Proceedings/Annual Meeting of the American Society of Clinical Oncology. 1983; Vol. 2:121. [MEDLINE: 161]

\section{Douglass 1984 \{published data only\}}

Douglass HO Jr, Lavin PT, Goudsmit A, Klaassen DJ, Paul AR. An Eastern Cooperative Oncology Group evaluation of combinations of methyl-CCNU, mitomycin C, adriamycin, and 5fluorouracil in advanced measurable gastric cancer (EST 2277). Journal of Clinical Oncology 1984;2(12):1372-81. [MEDLINE: 32]

\section{Duffour 2006 \{published data only\}}

Duffour J, Bouche O, Rougier P, Milan C, Bedenne L, Seitz JF, et al. Safety of cisplatin combined with continuous $5-\mathrm{FU}$ versus bolus 5-FU and leucovorin, in metastatic gastrointestinal cancer (FFCD 9404 randomised trial). Anticancer Research 2006;26(5B):3877-83.

\section{Figoli 1991 \{published data only\}}

Figoli F, Galligioni E, Crivellari D, Frustaci S, Talamini R, Sorio R, et al. Evaluation of two consecutive regimens in advanced gastric cancer. Cancer Investigation 1991;9(3):257-62. [MEDLINE: 34]

\section{Ford 2014 \{published data only\}}

Ford HER, Marshall A, Bridgewater JA, Janowitz T, Coxon FY, Wadsley J, et al. Docetaxel versus active symptom control for refractory oesophagogastric adenocarcinoma (COUGAR-02): an open-label, phase 3 randomised controlled trial. Lancet Oncology 2014;15(1):78-86.

\section{Fuchs 2014 \{published data only\}}

Fuchs CS, Tomasek J, Yong CJ, Dumitru F, Passalacqua R, Goswami C, et al. REGARD Trial Investigators. Ramucirumab monotherapy for previously treated advanced gastric or gastro-oesophageal junction adenocarcinoma (REGARD): an international, randomised, multicentre, placebo-controlled, phase 3 trial[DW11]. Lancet. England: Department of Medical Oncology, Dana-Farber Cancer Institute, Harvard Medical School, Boston, MA, USA. Electronic address: cfuchs@partners.org., 2014; Vol.383, issue 9911:31-9.

\section{Fujii 1983 \{published data only\}}

Fujii M, Murakami N. Single chemotherapy with 5-fluorouracil or ftorafur and combination chemotherapy with mitomycin $\mathrm{C}$ and 5-fluorouracil for inoperable elderly gastric cancers. [Japanese]. Nihon Gan Chiryo Gakkai Shi 1983;18(1):1-4. [MEDLINE: 36]

\section{Furue 1985 \{published data only\}}

Furue H, Uchino H, Orita K, Kimura T, Goto Y, Kondo T, et al. Clinical evaluation of schizophyllan (SPG) in advanced gastric cancer (the second report) - a randomized controlled study. [Japanese]. Gan to Kagaku Ryoho. Cancer \& Chemotherapy 1985;12(6):1272-7. [MEDLINE: 37]

\section{Furukawa 1995 \{published data only\}}

Furukawa H, Iwanaga T, Nakajima T, Okabayashi K, Nakazato H, Hiratsuka M, et al. Randomized study with mitomycin C+ 5fluorouracil+cytosine arabinoside (MFC)+5-fluorouracil, MFC + tegafur and uracil (UFT), and MF+UFT in advanced gastric cancer: Interinstitutional differences in a Multicenter Study in Japan. Journal of Surgical Oncology 1995;60(1):59-64. [MEDLINE: 38]

\section{Gao 2010 \{published data only\}}

Gao H, Ding X, Wei D, Xu T, Cheng P. Docetaxel versus epirubic in combined with cisplatin, leucovorin and fluorouracil for advanced gastric carcinoma as first line therapy: a randomized clinical trial. Chinese Journal of Clinical Oncology 2010;15:529-33.

\section{Gioffre 1984 \{published data only\}}

Gioffre FM, Caputo G, Lucania L. 5-FU + BCNU versus FAM for advanced gastric cancer. [Italian]. Folia Oncologica 1984;7(3):198-203. [MEDLINE: 40]

\section{Glimelius 1994 \{published data only\}}

Glimelius B, Hoffman K, Haglund U. Initial or delayed chemotherapy with best supportive care in advanced gastric cancer. Annals of Oncology 1994;5:189-90. [MEDLINE: 187]

\section{Glimelius 1995 \{published data only\}}

Glimelius B, Hoffman K, Graf W, Haglund U, Nyren O, Pahlman L, et al. Cost-effectiveness of palliative chemotherapy in advanced 
gastrointestinal cancer. Annals of Oncology 1995;6(3):267-74. [MEDLINE: 41]

\section{Glimelius 1997 \{published data only\}}

Glimelius B, Ekstrom K, Hoffman K, Graf W, Sjoden PO, Haglund $U$, et al. Randomized comparison between chemotherapy plus best supportive care with best supportive care in advanced gastric cancer. Annals of Oncology 1997;8(2):1-6. [MEDLINE: 42]

\section{Goseki 1995 \{published data only\}}

Goseki N, Maruyama M, Nagai K, Kando F, Endo M, Shimoju K, et al. Clinical evaluation of anticancer effect of methioninedepleting total parenteral nutrition with 5-fluorouracil and/ or mitomycin C. [Japanese]. Gan to Kagaku Ryoho. Cancer \& Chemotherapy 1995;22(8):1028-35. [MEDLINE: 43]

\section{Grau 1988 \{published data only\}}

Grau JJ, Estapé J, Alcobendas F, Gracía J, Antón A, Cruz JJ, et al. Mitomycin $\mathrm{C}$-ftorafur versus mitomycin $\mathrm{C}$ alone as complementary chemotherapy in locally advanced gastric cancer. Neoplasia 1988;5:179-81. [MEDLINE: 45]

\section{Grieco 1984 \{published data only\}}

Grieco A, Lasorella A, Astone A, Vagliviello L, Bartoloni C, Barone $C$. Chemotherapy of gastrointestinal cancer in the advanced stage with a combination of 5-fluorouracil, adriamycin, mitomycin C (FAM). A non-controlled study [Italian]. Clinica Terapeutica 1984;110(4):353-8. [MEDLINE: 46]

\section{Gubanski 2010 \{published data only\}}

Gubanski M, Johnsson A, Fernebro E, Kadar L, Karlberg I, Flygare $\mathrm{P}$, et al. Randomized phase II study of sequential docetaxel and irinotecan with 5-fluorouracil/folinic acid (leucovorin) in patients with advanced gastric cancer: the GATAC trial. Gastric Cancer 2010;13(3):155-61.

\section{Guimbaud 2014 \{published data only\}}

Guimbaud R, Bouché O, Rebischung C, Bonnetain F, Louvet C, Viret $F$, et al. Planned interim analysis of the intergroup FFCD-GERCOR-FNCLCC-AERO phase III study comparing two sequences of chemotherapy in locally advanced or metastatic gastric cancers. Journal of Clinical Oncology 2009;210(15 suppl):4533.

* Guimbaud R, Louvet C, Ries P, Ychou M, Maillard E, Andre T, et al. Prospective, randomized, multicenter, phase III study of fluorouracil, leucovorin, and irinotecan versus epirubicin, cisplatin, and capecitabine in advanced gastric adenocarcinoma: a French intergroup (Federation Francophone de Cancerologie Digestive, Federation Nationale des Centres de Lutte Contre le Cancer, and Groupe Cooperateur Multidisciplinaire en Oncologie) study. Journal of Clinical Oncology 2014;32:3520-6.

\section{Gupta 1982 \{published data only\}}

Gupta S. Treatment of advanced gastric cancer with 5fluorouracil versus mitomycin C. Journal of Surgical Oncology 1982;21(2):94-6. [MEDLINE: 47]

\section{Haas 1983 \{published data only\}}

Haas C, Oishi N, Mc Donald B, Coltman C, O'Bryan R. Southwest Oncology Group Phase II-III Gastric Cancer Study: 5-fluorouracil, adramycin, and mitomycin-C +/- vincristine (FAM vs. V-FAM) compared to chlorozotozin (CZT), M-AMSA, and dihydroxyanthracenedione (DHAD) with unimpressive differences. Proceedings/Annual Meeting of the American Society of Clinical Oncology. 1983; Vol. 2:122. [MEDLINE: 157]

\section{Hawkins 2003 \{published data only\}}

Hawkins R, Cunningham D, Soerbye H, Adenis A, Canon J-L, Lopez-Vivanco G, et al. Randomized phase II trial of docetaxel plus irinotecan versus docetaxel plus 5-fluorouracil (5FU) in patients with untreated advanced gastric adenocarcinoma (AGAC). Proceedings/Annual Meeting of the American Society of Clinical Oncology. 2003; Vol. 22:257. [MEDLINE: 154]

Hoffman 1998 \{published data only\}

Hoffman K, Glimelius B. Evaluation of clinical benefit of chemotherapy in patients with upper gastrointestinal cancer. Acta Oncologica 1998;37(7-8):651-9. [MEDLINE: 49]

\section{Icli 1993 \{published data only\}}

Icli F, Karaoguz H, Dincol D, Günel N. Comparison of EAP and FAM combination chemotherapies in advanced gastric cancer. Proceedings/Annual Meeting of the American Society of Clinical Oncology. 1993; Vol. 12:207. [MEDLINE: 160]

\section{Imada 1999 \{published data only\}}

Imada T, Sairenji M, Suda T, Yamamoto Y, Amano T, Motohashi H. A combination chemotherapy of 5-fluorouracil and cisplatin against advanced gastric cancer. Hepato-Gastroenterology 1999;46(25):594-600. [MEDLINE: 51]

\section{Inoue 1989 \{published data only\}}

Inoue Y, Nasu H, Nakamura J, Arakawa H, Masamune O, Yamada N, et al. Efficacy of UFT in advanced gastric carcinoma under comparative study of MMC + UFT and MMC + tegafur therapies. [Japanese]. Gan to Kagaku Ryoho. Cancer \& Chemotherapy 1989;16(11):3567-72. [MEDLINE: 52]

\section{Jeung 2011 \{published data only\}}

Jeung HC, Rha SY, Im CK, Shin SJ, Ahn JB, Yang WI, et al. A randomized phase 2 study of docetaxel and S-1 versus docetaxel and cisplatin in advanced gastric cancer with an evaluation of SPARC expression for personalized therapy. Cancer 2011;117(10):2050-7.

\section{Kang 2007 \{unpublished data only\}}

Kang Y, Lee J, Min Y, Lee K, Zang D, Ryoo B, et al. A randomized multi-center phase II trial of capecitabine $(X)$ versus $S-1(S)$ as first-line treatment in elderly patients with metastatic or recurrent unresectable gastric cancer. Journal of Clinical Oncology, ASCO Annual Meeting Proceedings Part I 2007;25(18S):4546.

\section{Kelsen 1990 \{published data only\}}

Kelsen D, Atiq O, Niedzwiecki D. A random assignment trial of fluorouracil (F), methotrexate (MTX) and adriamycin (A) (FAMTX) versus etoposide, $A$, and cisplatin $(P)(E A P)$ in gastric cancer 
(GAST CA). Proceedings/Annual Meeting of the American Society of Clinical Oncology. 1990; Vol. 9:121. [MEDLINE: 172]

\section{Kilickap 2011 \{published data only\}}

Kilickap S, Yalcin S, Ates O, Tekuzman G. The first line systemic chemotherapy in metastatic gastric carcinoma: A comparison of docetaxel, cisplatin and fluorouracil (DCF) versus cisplatin and fluorouracil (CF); versus epirubicin, cisplatin and fluorouracil (ECF) regimens in clinical setting. Hepato-Gastroenterology 2011;58(105):208-12.

\section{Kim 1991 \{published and unpublished data\}}

Kim NK, Park YS, Suh Cl, Kang WK, Kim HT, Heo DS, et al. Phase III randomized comparison of 5-FU vs. FAM (5-FU/Adria/MMC) vs FP (5-FU/Cisplatin) in patients with advanced gastric carcinoma (AGC). Proceedings/Annual Meeting of the American Society of Clinical Oncology. 1991; Vol. 10:144. [MEDLINE: 174]

\section{Kim 1993 \{published and unpublished data\}}

Kim NK, Park YS, Heo DS, Suh C, Kim SY, Park KC, et al. A phase III randomized study of 5-fluorouracil and cisplatin versus 5fluorouracil, doxorubicin, and mitomycin $\mathrm{C}$ versus 5 -fluorouracil alone in the treatment of advanced gastric cancer. Cancer 1993;71(12):3813-8. [MEDLINE: 57]

\section{Kim 2012 \{published data only\}}

Kim GM, Jeung HC, Rha SY, Kim HS, Jung I, Nam BH, et al. A randomized phase II trial of S-1-oxaliplatin versus capecitabineoxaliplatin in advanced gastric cancer. European Journal of Cancer 2012;48(4):518-26.

\section{Kim 2013 \{published data only\}}

Kim HS, Kim HJ, Kim SY, Lee KW, Baek SK, Kim TY, et al. Secondline chemotherapy versus supportive cancer treatment in advanced gastric cancer: A meta-analysis. Annals of Oncology. Oxford University Press (Great Clarendon Street, Oxford OX2 6DP, United Kingdom), 2013; Vol. 24, issue 11:2850-4.

\section{Kitamura 1995 \{published data only\}}

Kitamura S, Ohtani T, Kurihara M, Kosaki G, Akazawa S, Sasaki T, et al. A controlled study of AO-90, a methionine-free intravenous amino acid solution, in combination with 5-fluorouracil and mitomycin $\mathrm{C}$ in advanced gastric cancer patients (internal medicine group evaluation). [Japanese]. Gan to Kagaku Ryoho. Cancer \& Chemotherapy 1995;22(6):765-75. [MEDLINE: 58]

\section{Koizumi 1996 \{published data only\}}

Koizumi W, Kurihara M, Hasegawa K, Chonan A, Kubo Y, Maekawa R. Combination therapy with cisplatin, 5'-deoxy-5fluorouridine (5'-DFUR) and mitomycin (MMC) in patients with inoperable, advanced gastric cancer: a randomized trial comparing two dosage regimens. Oncology Reports 1996;3(2):255-60. [MEDLINE: 62]

\section{Koizumi 2004 \{published data only\}}

Koizumi W, Fukuyama Y, Fukuda T, Akiya T, Hasegawa K, Kojima Y, et al. Randomized phase II study comparing mitomycin, cisplatin plus doxifluridine with cisplatin plus doxifluridine in advanced unresectable gastric cancer. Anticancer Research 2004;24(4):2465-70.

\section{Koizumi 2012 \{published data only\}}

Koizumi W, Nakayama N, Tanabe S, Sasaki T, Higuchi K, Nishimura K, et al. A multicenter phase II study of combined chemotherapy with docetaxel, cisplatin, and S-1 in patients with unresectable or recurrent gastric cancer (KDOG 0601). Cancer Chemotherapy and Pharmacology 2012;69(2):407-11.

\section{Koizumi 2013 \{published data only\}}

Koizumi W, Higuchi K, Shimada K, Hosaka H, Sasaki E, Nakayama N, et al. Biweekly irinotecan plus cisplatin (BIRIP) versus irinotecan alone (IRI) after S-1-based chemotherapy failure in patients with advanced gastric cancer (AGC): Final analysis of a randomised phase III trial (TCOG GI-0801/BIRIP trial). European Journal of Cancer. Elsevier Ltd, 2013; Vol. 49:S616.

\section{Kolaric 1986 \{published data only\}}

Kolaric K, Potrebica V, Stanovnik M. Controlled phase III clinical study of 4-epi-doxorubicin + 5-fluorouracil versus 5-fluorouracil alone in metastatic gastric and rectosigmoid cancer. Oncology 1986;43(2):73-7. [MEDLINE: 149]

\section{Kondo 2000 \{published data only\}}

Kondo K, Sakamoto J, Nakazato H, Koike A, Kitoh T, Hachisuka K, et al. A phase III randomized study comparing doxifluridine and 5-fluorouracil as supportive chemotherapy in advanced and recurrent gastric cancer. Oncology Reports 2000;7(3):485-90. [MEDLINE: 63]

\section{Kono 2002 \{published data only\}}

Kono K, Takahashi A, Ichihara F, Amemiya H, lizuka H, Fujii H, et al. Prognostic significance of adoptive immunotherapy with tumor-associated lymphocytes in patients with advanced gastric cancer: a randomized trial. Clinical Cancer Research 2002;8(6):1767-71. [MEDLINE: 10]

\section{Kornek 2002 \{published data only\}}

Kornek GV, Raderer M, Schull B, Fiebiger W, Gedlicka C, Lenauer $A$, et al. Effective combination chemotherapy with paclitaxel and cisplatin with or without human granulocyte colony-stimulating factor and/or erythropoietin in patients with advanced gastric cancer. British Journal of Cancer 2002;86(12):1858-63. [MEDLINE: 8]

\section{Kosaka 1995 \{published data only\}}

Kosaka T, Sugaya J, Yoshida S, Takano Y, Nakano Y, Akiyama T, et al. A study of chemotherapy for patients with severely advanced gastric cancer--comparison of chemotherapy and route [Japanese]. Gan to Kagaku Ryoho. Cancer \& Chemotherapy 1995;22(11):1582-5. [MEDLINE: 64]

\section{Kovach 1974 \{published data only\}}

Kovach JS, Moertel CG, Schutt AJ, Hahn RG, Reitemeier J. A controlled study of combined 1,3 bis ( 2 chloroethyl) 1 nitrosourea and 5 fluorouracil therapy for advanced gastric and pancreatic cancer. Cancer 1974;33:563. [MEDLINE: 65]

\section{Kuitunen 1991 \{published data only\}}

Kuitunen T, Pyrhönen S. A randomized phase III trial comparing fluouracil, epidoxorubicin and methotrexate (FEMTX) with no 
treatment in nonresectable gastric cancer. European Journal of Cancer. 1991; Vol. 27 Supp. 2:80. [MEDLINE: 180]

Kurihara 1991 \{published data only\}

* Kurihara M, Izumi T, Yoshida S, Ohkubo T, Suga S, Kiyohashi A, et al. A cooperative randomized study on tegafur plus mitomycin $\mathrm{C}$ versus combined tegafur and uracil plus mitomycin $\mathrm{C}$ in the treatment of advanced gastric cancer. Japanese Journal of Cancer Research 1991;82(5):613-20.

Ohkuwa M, Ohtsu A, Boku N, Yoshida S, Miyata Y, Shirao K, et al. Long-term results for patients with unresectable gastric cancer who received chemotherapy in the Japan Clinical Oncology Group (JCOG) trials. Gastric Cancer 2000;3(3):145-50. [MEDLINE: 88]

\section{Kurihara 1995 \{published data only\}}

Kurihara M, Kosaki G, Taguchi T, Akazawa S, Sasaki T, Takahashi $\mathrm{H}$, et al. Quality of life in patients with advanced gastric cancer receiving $\mathrm{AO}-90$, a methionine-free intravenous amino acid solution, with 5-fluorouracil and mitomycin $\mathrm{C}$ [Japanese]. Gan to Kagaku Ryoho. Cancer \& Chemotherapy 1995;22(7):911-23. [MEDLINE: 67]

Kurihara 1995a \{published data only\}

Kurihara M, Hasegawa K, Satoh A, Koizumi W, Saigenji K, Inoue $S$, et al. A randomized trial investigating two cisplatin $(\mathrm{P})$ dosage schedules combined 5 'DFUR (D) and mitomycin C (M) for advanced gastric cancer. Proceedings/Annual Meeting of the American Society of Clinical Oncology. 1995; Vol. 14:214. [MEDLINE: 151]

\section{Lacave 1985 \{published data only\}}

Lacave A, Dalesio O, Bleiberg H, Wils J, Diaz-Rubio E, Vendrik C, et al. A randomized trial of MeFA (methylccnu (Me); 5fluorouracil (F), adriamycin (A)) vs. FA in advanced gastric cancer. Proceedings/Annual Meeting of the American Society of Clinical Oncology. 1985; Vol. 4:78. [MEDLINE: 176]

\section{Lacave 1987 \{published data only\}}

Lacave A, Wils J, Bleiberg H, Diaz-Rubio E, Duez N, Dalesio O. An EORTC Gastrointestinal Group phase III evaluation of combinations of methyl-CCNU, 5-fluorouracil, and adriamycin in advanced gastric cancer. Journal of Clinical Oncology 1987;5(9):1387-93. [MEDLINE: 68]

\section{Lee 2008 \{published data only\}}

Lee JL, Kang YK, Kang HJ, Lee KH, Zang DY, Ryoo BY, et al. A randomised multicentre phase II trial of capecitabine vs S-1 as first-line treatment in elderly patients with metastatic or recurrent unresectable gastric cancer. British Journal of Cancer 2008;99(4):584-90.

\section{Lee 2012 \{published data only\}}

Lee HJ, Park JC, Kim JH, Yoon JY, Cheoi KS, Lee H, et al. The ATP-based doublet chemotherapy response assay for unresectable advanced gastric cancer; a single center, prospective, randomized controlled study. Gastrointestinal Endoscopy 2012;75 (4 Suppl 1):abstr. 236

\section{Levard 1998 \{published data only\}}

Levard H, Pouliquen X, Hay J-M, Fingerhut A, LangloisZantain $\mathrm{O}$, Huguier M, et al. 5 -fluorouracil and cisplatin as palliative treatment of advanced oesophageal squamous cell carcinoma: a multicentre randomised controlled trial. European Journal of Surgery 1998;164:849-57. [MEDLINE: 69]

\section{Li 2002 \{published data only\}}

Li Q, Feng FY, Han J, Sui GJ, Zhu YG, Zhang Y, et al. Phase III clinical study of a new anticancer drug atofluding [Chinese]. Aizheng 2002;21(12):1350-3. [MEDLINE: 6]

\section{Li 2007 \{published data only\}}

Li XQ, Gu HG, Guo JW, Zhu XX. Clinical study of continuous venous infusion of low-dose 5 -Fu and cisplatin combined with weekly docetaxel for treatment of advanced gastric cancer [Chinese]. Modern Oncology 2007;15:659-61.

\section{Li 2011 \{published data only\}}

Li XD, Shen H, Jiang JT, Zhang HZ, Zheng X, Shu YQ, et al. Paclitaxel based vs oxaliplatin based regimens for advanced gastric cancer. World Journal of Gastroenterology 2011;17(8):1082-7.

\section{Li 2013 \{published data only\}}

Li J, Qin S, Xu J, Guo W, Xiong J, Bai Y, et al. Apatinib for chemotherapy-refractory advanced metastatic gastric cancer: results from a randomized, placebo-controlled, parallel-arm, phase II trial. Journal of Clinical Oncology 2013;31(26):3219-25.

\section{Lim 2011 \{published data only\}}

Lim T, Yun J, Lee J, Park S, Park J, Park Y, et al. Updated survival results of the randomized phase II study comparing cisplatin/ capecitabine (CX) with epirubicin plus CX (ECX) in advanced gastric cancer (AGC). Journal of Clinical Oncology 2011;29 (Supp 4):Abstract 46.

\section{Livstone 1977 \{published data only\}}

Livstone EM. A controlled randomized evaluation of combined modality therapy $(5,000 \mathrm{r}+5-\mathrm{FU}+\mathrm{MeCCNU}$ versus combination chemotherapy (5-FU + Me CCNU) in the treatment of locally unresectable gastric carcinoma. Digestion 1977;16:256. [MEDLINE: 71$]$

\section{Lordick 2013 \{published data only\}}

Lordick F, Kang YK, Chung HC, Salman P, Oh SC, Bodoky G, et al. Capecitabine and cisplatin with or without cetuximab for patients with previously untreated advanced gastric cancer (EXPAND): a randomised, open-label phase 3 trial. Lancet Oncology 2013; Vol. 14, issue 6:490-9.

\section{Lorenzen 2007 \{published data only\}}

Lorenzen S, Hentrich M, Haberl C, Heinemann V, Schuster T, Seroneit T, et al. Split-dose docetaxel, cisplatin and leucovorin/ fluorouracil as first-line therapy in advanced gastric cancer and adenocarcinoma of the gastroesophageal junction: results of a phase II trial. Annals of Oncology 2007;18(10):1673-9.

\section{Luelmo 2006 \{published data only\}}

Luelmo S, Polee M, Van Bochove A, Pruijt H, Ouwerkerk J, Sleeboom H, et al. Randomized phase II study of cisplatin and 
highdose 5-fluorouracil/leucovorin or paclitaxel and high-dose 5-fluorouracil/leucovorinin locally advanced or metastatic gastric cancer and adenocarcinomas of the gastrooesophageal junction. Annals of Oncology 2006;17(Suppl 9: Abstract 530):ix308-ix326.

\section{Malik 1990 \{published data only\}}

Malik STA, Talbot D, Clarke PI, Osborne R, Reznek R, Wrigley PFM. Phase II trial of UFT in advanced colorectal and gastric cancer. British Journal of Cancer 1990;62(6):1023-5. [MEDLINE: 73]

\section{Maruta 2007 \{published data only\}}

Maruta F, Ishizone S, Hiraguri M, Fujimori Y, Shimizu F, Kumeda S, et al. A clinical study of docetaxel with or without 5'DFUR as a second-line chemotherapy for advanced gastric cancer. Medical Oncology 2007;24(1):71-5.

\section{Massuti 1994 \{published data only\}}

Massuti B, Cervantes A, Anton A, Aranda E, Diaz-Rubio E, Abad A, et al. A phase III multicenter randomized study in advanced gastric cancer (GC): fluorouracil + leucovorin + epirubicin + cisplatin (FLEP) versus fluorouracil + adriamycin + methotrexate + leucovorin (FAMTX): toxicity report. Annals of Oncology 1994;5(Suppl 8):76. [MEDLINE: 139]

\section{Massuti 1995 \{published data only\}}

Massuti B, Cervantes A, Aranda E, Abad A, Anton A, Jara C, et al. Myelotoxicity: the limiting side-effect of second-generation chemotherapy in gastric cancer: comparative analysis of fluorouracil + leucovorin + epirubicin + cisplatin (FLEP) and fluorouracil + adriamycin + methotrexate + leucovorin (FAMTX). Proceedings/Annual Meeting of the American Society of Clinical Oncology. 1995; Vol. 14:212. [MEDLINE: 177]

\section{Mochiki 2012 \{published data only\}}

Mochiki E, Ogata K, Ohno T, Toyomasu Y, Haga N, Fukai Y, et al. Phase II multi-institutional prospective randomised trial comparing S-1paclitaxel with S-1cisplatin in patients with unresectable and/or recurrent advanced gastric cancer. British Journal of Cancer 2012;107(1):31-6.

\section{Moertel 1976 \{published data only\}}

Moertel CG, Mittelman JA, Bakemeier RF, Engstrom P, Hanley J. Sequential and combination chemotherapy of advanced gastric cancer. Cancer 1976;38(2):678-82. [MEDLINE: 74]

\section{Moertel 1979 \{published data only\}}

Moertel CG, Engstrom P, Lavin PT, Gelber RD, Carbone PP. Chemotherapy of gastric and pancreatic carcinoma: a controlled evaluation of combinations of 5-fluorouracil with nitrosoureas and "lactones". Surgery 1979;85(5):509-13. [MEDLINE: 75]

\section{Moertel 1979a \{published data only\}}

Moertel CG, Lavin PT. Phase II-III chemotherapy studies in advanced gastric cancer. Eastern Cooperative Oncology Group. Cancer Treatment Reports 1979;63(11-12):1863-9. [MEDLINE: 76]
Moore 2005 \{published data only\}

Moore MJ. Three-armed trial to study new regimens for advanced gastric/esophageal cancer. Oncology Report 2005;SPRING:121-2.

\section{Mustacchi 1997 \{published data only\}}

Mustacchi G, Ceccherini R, Milani S, Sandri P, Leita ML, Carbonara T. Efficacy of sequential administration of G-CSF and GM-CSF after antitumor chemotherapy in patients with advanced cancer: Results of a randomized study. [Italian]. Tumori 1997;83(Suppl 5):S13-6. [MEDLINE: 78]

Nakajima 1984 \{published data only\} Nakajima T, Takahashi T, Takagi K, Kuno K, Kajitani T. Comparison of 5-fluorouracil with ftorafur in adjuvant chemotherapies with combined inductive and maintenance therapies for gastric cancer. Journal of Clinical Oncology 1984;2(12):1366-71. [MEDLINE: 79]

Nakao 1983 \{published data only\}

Nakao I, Uchino H, Orita K, Kaido I, Kimura T, Goto Y, et al. Clinical evaluation of schizophyllan (SPG) in advanced gastric cancer--a randomized comparative study by an envelope method. [Japanese]. Gan to Kagaku Ryoho. Cancer \& Chemotherapy 1983;10(4 Pt 2):1146-59. [MEDLINE: 80]

Nakashima 2008 \{published data only\}

Nakashima K, Hironaka S, Boku N, Onozawa Y, Fukutomi A, Yamazaki K, et al. Irinotecan plus cisplatin therapy and S-1 plus cisplatin therapy for advanced or recurrent gastric cancer in a single institution. Japanese Journal of Clinical Oncology 2008;38(12):810-5.

\section{Niitani 1987 \{published data only\}}

Niitani H, Kurihara M, Hasegawa K, Hatta Y, Suwa T, Tsuboi E, et al. Randomized comparison of continuous and intermittent oral administration of 5'-deoxy-5-fluorouridine in the treatment of advanced gastric cancer: a phase II trial by the multiinstitutional cooperative study group. [Japanese]. Japanese Journal of Cancer \& Chemotherapy 1987;14(12):3345-50. [MEDLINE: 81]

\section{Nordin 2001 \{published data only\}}

Nordin K, Steel J, Hoffman K, Glimelius B. Alternative methods of interpreting quality of life data in advanced gastrointestinal cancer patients. British Journal of Cancer 2001;85(9):1265-72. [MEDLINE: 83]

\section{Novik 1999 \{published data only\}}

Novik Y, Ryan LM, Haller DG, Asbury R, Dutcher JP, Schutt A. Phase II protocol for the evaluation of new treatments in patients with advanced gastric carcinoma: results of ECOG 5282. Medical Oncology 1999;16(4):261-6. [MEDLINE: 84]

\section{Ohtsu 2011 \{published data only\}}

Ohtsu A, Shah MA, Van Cutsem E, Rha SY, Sawaki A, Park SR, et al. Bevacizumab in combination with chemotherapy as firstline therapy in advanced gastric cancer: a randomized, doubleblind, placebo-controlled phase III study. Journal of Clinical Oncology 2011;29:3968-76. 


\section{Okines 2010 \{published data only\}}

Okines AFC, Asghar U, Cunningham D, Ashley S, Ashton J, Jackson K, et al. Rechallenge with platinum plus fluoropyrimidine + /- epirubicin in patients with oesophagogastric cancer. Oncology 2010;79(1-2):150-8.

\section{Osawa 1996 \{published data only\}}

Osawa S, Shiroto H, Kondo Y, Nakanishi Y, Fujisawa J, Miyakawa K, et al. Randomized controlled study on adjuvant immunochemotherapy with carmofur (HCFU) for noncuratively resected and unresected gastric cancer. [Japanese]. Gan to Kagaku Ryoho. Cancer \& Chemotherapy 1996;23(3):327-31. [MEDLINE: 89]

\section{Pannettiere 1984 \{published data only\}}

Pannettiere FJ, Haas C, McDonald B, Costanzi JJ, Talley RW, Athens $\mathrm{J}$, et al. Drug combinations in the treatment of gastric adenocarcinoma: a randomized Southwest Oncology Group study. Journal of Clinical Oncology 1984;2(5):420-4. [MEDLINE: 141]

\section{Park 2004 \{published data only\}}

Park SH, Kim MJ, Chung M, Lee WK, Bang SM, Cho EK, et al. Interim analysis from a prospective randomized trial of taxanes plus 5-FU in advanced gastric cancer. Proceedings/Annual Meeting of the American Society of Clinical Oncology. 2004; Vol. 23:360.

\section{Park 2006 \{published data only\}}

Park SH, Lee WK, Chung M, Lee Y, Han SH, Bang SM, et al. Paclitaxel versus docetaxel for advanced gastric cancer: a randomized phase II trial in combination with infusional 5fluorouracil. Anti-Cancer Drugs 2006;17(2):225-9.

\section{Park 2008 \{published data only\}}

Park SH, Nam E, Park J, Cho EK, Shin DB, Lee JH, et al. Randomized phase II study of irinotecan, leucovorin and 5fluorouracil (ILF) versus cisplatin plus ILF (PILF) combination chemotherapy for advanced gastric cancer. Annals of Oncology 2008;19(4):729-33.

\section{Popliela 1982 \{published data only\}}

Popliela T, Zembala M, Oszacki J, Jedrychowski W. A followup study on chemoimmunotherapy (5-fluorouracil and BCG) in advances gastric cancer [abstract]. Cancer Immunology, Immunotherapy 1982;13:182-4. [MEDLINE: 90]

\section{Popov 1999 \{published data only\}}

Popov I, Jelic S, Radosavljevic D, Nicolic-Tomasevic Z. Eighthour infusion versus bolus injection of doxorubicin in EAP regimen in patients with advanced gastric cancer (AGC): a prospective randomised trial. European Journal of Cancer 1999;35(Suppl 4):139. [MEDLINE: 178]

\section{Popov 2000 \{published and unpublished data\}}

Popov I, Jelic S, Radulovic S, Radosavljevic D, Nikolic TZ. Eighthour infusion versus bolus injection of doxorubicin in the EAP regimen in patients with advanced gastric cancer: a prospective randomised trial. Annals of Oncology 2000;11(3):343-8. [MEDLINE: 91]
Pozzo 2004 \{published data only\}

Pozzo C, Barone C, Szanto J, Padi E, Peschel C, Bukki J, et al. Irinotecan in combination with 5-fluorouracil and folinic acid or with cisplatin in patients with advanced gastric or esophagealgastric junction adenocarcinoma: results of a randomized phase II study. Annals of Oncology 2004;15(12):1773-81.

Pyrhonen 1992 \{published data only\}

Pyrhönen S, Kuitunen T, Kouri M. A randomized phase III trial comparing fluouracil, epidoxorubicin and methotrexate (FEMTX) with best supportive care in non-resectable gastric cancer. Annals of Oncology 1992; Vol. 3, issue Suppl 5:47. [MEDLINE: 179]

\section{Queisser 1984 \{published data only\}}

* Queisser W, Schnitzler G, Heim ME, Konig H, Katz R, Fritze $\mathrm{D}$, et al. Prospective randomized study in advanced stomach cancer. Comparison between combinations of 5fluorouracil and carmustine without and with adriamycin [Prospektiv randomisierte studie beim fortgeschrittenen magenkarzinom]. Deutsche Medizinische Wochenschrift (1946) 1984;109(25):976-80.

Schnitzler G, Queißer W, Heim ME, König HJ, Fritze D, Herrmann R, et al. Comparison of 5-FU-BCNU (FB) and 5-FU/ adriamycin/BCNU (FAB) in advanced gastric cancer [Vergleich von 5-Fluorouracil-BCNU (FB) mit 5-Fluorouracil-AdriamycinBCNU (FAB) beim fortgeschrittenen Magenkarzinom]. Verhandlungen der Deutschen Gesellschaft fur Innere Medizin 1983;89:105-4.

\section{Rake 1979 \{published data only\}}

Rake MO, Mallinson CN, Cocking JB, Cwynarski MT, Fox CA, Wass VJ, et al. Chemotherapy in advanced gastric cancer: a controlled, prospective, randomised multi-centre study. Gut 1979;20(9):797-801. [MEDLINE: 94]

\section{Roth 1994 \{published data only\}}

Roth A, Kolaric K, Zupanc D. High doses of epirubicin and 5fluorouracil with or without cisplatin in advanced gastric cancer - a preliminary report of a randomized study. Libri Oncologici 1994;23:187-93. [MEDLINE: 95]

\section{Roth 1995 \{published data only\}}

Roth A, Kolaric K, Zupanc D. High doses of epirubicin and 5fluouracil with or without cisplatin in advanced gastric cancer. European Journal of Cancer. 1995; Vol. 31A (Suppl 5). [MEDLINE: 182]

\section{Roth 1997 \{published data only\}}

Roth A, Zupanc D. Randomised clinical study (phase III) FE versus FEP in advanced gastric cancer. European Journal of Cancer. 1997; Vol. 33 (Suppl 8):275. [MEDLINE: 181]

\section{Sakata 1982 \{published data only\}}

Sakata Y, Yoshida Y, Komatsu Y, Sugawara K, Nishimura S, Kikuchi K. MQF-OK therapy in advanced terminal stomach cancer-with special reference to a comparison with MFC therapy. [Japanese]. Gan to Kagaku Ryoho. Cancer \& Chemotherapy 1982;9(1):109-15. [MEDLINE: 97] 


\section{Sakata 1988 \{published data only\}}

Sakata Y, Munakata A, Baba T, Saitoh S, Itoh T, Tamura Y, et al. Controlled study of MQF-OK therapy with FT and with UFT on various advanced gastrointestinal cancers. Hirosaki Cooperative Study Group of Cancer Chemotherapy. [Japanese]. Gan to Kagaku Ryoho. Cancer \& Chemotherapy 1988;15(7):2065-71. [MEDLINE: 98]

\section{Sakata 1992 \{published data only\}}

Sakata Y, Chiba Y, Sato T, Kimura M, Fukushi G, Matsukawa M, et al. Comparative study of UFT plus mitomycin C and UFT plus doxorubicin in adenocarcinoma. Hirosaki Cooperative Group of Cancer Chemotherapy. [Japanese]. Gan to Kagaku Ryoho. Cancer \& Chemotherapy 1992;19(2):195-201. [MEDLINE: 99]

\section{Sasagawa 1994 \{published data only\}}

Sasagawa T, Ho N, Endo T, Sekine T, Sugiyama K, Tomidokoro T, et al. Randomized controlled trial of MMC + UFT and MMC + 5-FU therapy in advanced gastric cancer. [Japanese]. Gan to Kagaku Ryoho [Japanese Journal of Cancer \& Chemotherapy] 1994;21(8):1179-85. [MEDLINE: 100]

\section{Sasaki 1989 \{published data only\}}

Sasaki T, Ota K, Ibayashi J, Sakata Y, Matsuoka T, Ishikawa M. Randomized multicenter trial of sequential methotrexate and 5-fluorouracil versus 5-fluorouracil alone in advanced gastric cancer. [Japanese]. Gan to Kagaku Ryoho. Cancer \& Chemotherapy 1989;16(8 Pt 1):2545-55. [MEDLINE: 102]

\section{Sasaki 1990 \{published data only\}}

Sasaki T, Ota K, Sakata Y, Matsuoka T, Wakui A, Akazawa S, et al. High-dose leucovorin and 5-fluorouracil in advanced gastric and colorectal cancer. High-Dose Leucovorin and 5-FU Study Group. [Japanese]. Gan to Kagaku Ryoho. Cancer \& Chemotherapy 1990;17(12):2361-8. [MEDLINE: 103]

\section{Sasaki 1992 \{published data only\}}

Sasaki T. High-dose leucovorin and 5-FU. Gan to Kagaku Ryoho. Cancer \& Chemotherapy 1992;19(7):954-62. [MEDLINE: 101]

\section{Sasaki 1995 \{published data only\}}

Sasaki T. Clinical evaluation of leucovorin and 5-fluorouracil. [Japanese]. Gan to Kagaku Ryoho. Cancer \& Chemotherapy 1995;22(8):1001-8. [MEDLINE: 104]

\section{Sato 1991 \{published data only\}}

Sato H, Wakui A, Hoshi M, Kurihara M, Yokoyama M, Shimizu H. Randomized controlled trial of induced hypertension chemotherapy (IHC) using angiotensin II human (TY-10721) in advanced gastric carcinoma (TY-10721 IHC Study Group Report). [Japanese]. Gan to Kagaku Ryoho [Japanese Journal of Cancer \& Chemotherapy] 1991;18(3):451-60. [MEDLINE: 105]

\section{Sato 1995 \{published data only\}}

Sato H, Sugiyama K, Hoshi M, Urushiyama M, Ishizuka K. Angiotensin II (All) induced hypertension chemotherapy (IHC) for unresectable gastric cancer: with reference to resection after down staging. World Journal of Surgery 1995;19(6):836-42. [MEDLINE: 106]
Satoh 2013 \{published data only\}

Satoh T, Doi T, Tsuji A, Omuro Y, Miwa H, Nishina T, et al. A Japanese subgroup analysis of the lapatinib for gastric cancer (TyTAN) study. Annals of Oncology. Oxford University Press, 2013; Vol. 24:ix6.

\section{Satoh 2014 \{published data only\}}

Satoh T, Xu RH, Chung HC, Sun GP, Doi T, Xu JM, et al. Lapatinib plus paclitaxel versus paclitaxel alone in the second-line treatment of HER2-amplified advanced gastric cancer in Asian populations: TyTAN--a randomized, phase III study. Journal of Clinical Oncology 2014;32:2039-49.

Schmid 2003 \{published data only\}

Schmid KE, Kornek GV, Schull B, Raderer M, Lenauer A, Depisch D, et al. Second-line treatment of advanced gastric cancer with oxaliplatin plus raltitrexed. Onkologie 2003;26(3):255-8. [MEDLINE: 1]

\section{Shen 2009 \{published data only\}}

Shen YC, Chu JH. Observation of weekly dose of docetaxel combined with small doses of cisplatin, 5-fluorouracil continuous intravenous infusion treatment of advanced gastric cancer [Chinese]. Journal of Basic and Clinical Oncology 2009;22(4):318-20

\section{Shin 2007 \{unpublished data only\}}

Shin D, Lee S, Park S, Park J, Cho E, Lee J, et al. Randomized phase II trial of irinotecan, leucovorin and 5-fluorouracil (ILF) versus cisplatin plus ILF (PILF) for advanced gastric cancer. Journal of Clinical Oncology, ASCO Annual Meeting Proceedings Part I 2007;25(18S):4580.

Shinoda 1995 \{published data only\}

Shinoda M, Morise K, Kusugami K, Iwase H, Ina K, Kaneko H. Combination chemotherapy with FP versus FEP in patients with advanced gastric cancer. Research group of gastric cancer chemotherapy. [Japanese]. Gan to Kagaku Ryoho. Cancer \& Chemotherapy 1995;22(4):515-20. [MEDLINE: 109]

\section{Shu 1999 \{published data only\}}

Sun H, Qun Z, Guifang L. Clinical study of 68 advanced gastric cancer cases treated by DELF project. Zhejiang Oncology 1999;5:85-6. [MEDLINE: 110]

\section{Shudong 1996 \{published data only\}}

Shudong X, Dehua L, Dezong Z. ACNU and methyl-CCNU in combination chemotherapy for advanced gastric cancer: a randomized comparative study. Shanghai ACNU Collaborative Study Group. [Chinese]. Chung-Hua Chung Liu Tsa Chih [Chinese Journal of Oncology] 1996;18(1):30-3. [MEDLINE: 129]

\section{Smith 1983 \{published data only\}}

Smith BJ, Ashford RF, Bakowski M, Hellman K, Newton K, Phillips $\mathrm{R}$, et al. A trial of high-dose 5-fluorouracil with razoxane or adriamycin in the treatment of advanced adenocarcinoma of the gastrointestinal tract. American Journal of Clinical Oncology 1983;6(4):481-4. [MEDLINE: 111] 
Sun 2004 \{published data only\}

Sun W, Whittington R, Gallagher M, O'Dwyer P, Giantonio B, Metz J, et al. Concurrent RT with 5-FU/epirubicin and cisplatin or irinotecan for locally advanced upper $\mathrm{Gl}$ adenocarcinoma. Oncology (Williston Park) 2004;18(14 (Suppl 14)):39-42.

\section{Sym 2013 \{published data only\}}

Sym SJ, Hong J, Park J, Cho EK, Lee JH, Park YH, et al. A randomized phase II study of biweekly irinotecan monotherapy or a combination of irinotecan plus 5-fluorouracil/leucovorin ( $\mathrm{mFOLFIRI)} \mathrm{in} \mathrm{patients} \mathrm{with} \mathrm{metastatic} \mathrm{gastric} \mathrm{adenocarcinoma}$ refractory to or progressive after first-line chemotherapy. Cancer Chemotherapy and Pharmacology 2013; Vol. 71, issue 2:481-8.

\section{Taal 1990 \{published data only\}}

Taal BG, ten Bokkel Huinink WW, Simonetti G, Franklin H, McVie JG. A phase II trial of sequential MTx and 5-FU alternated with 4-epidoxorubicin and cisplatin in advanced gastric cancer. Cancer Investigation 1990;8(5):501-4. [MEDLINE: 112]

\section{Taguchi 1985 \{published data only\}}

Taguchi T, Furue H, Kimura T, Kondo T, Hattori T, Itoh I, et al. Results of phase III study of lentinan. [Japanese]. Gan to Kagaku Ryoho. Cancer \& Chemotherapy 1985;12(2):366-78. [MEDLINE: 113]

\section{Takahashi 1991 \{published data only\}}

Takahashi N. 5-FU concentration in the tissue of gastric cancer, and evaluation of cancer chemotherapy with angiotensinII. [Japanese]. Nihon Geka Gakkai Zasshi 1991;92(7):775-84. [MEDLINE: 114]

\section{Tebbutt 2002 \{published data only\}}

Tebbutt NC, Norman A, Cunningham D, Iveson T, Seymour M, Hickish T, et al. A multicentre, randomised phase III trial comparing protracted venous infusion (PVI) 5-fluorouracil (5-FU) with PVI 5-FU plus mitomycin C in patients with inoperable oesophago-gastric cancer. Annals of Oncology 2002;13(10):1568-75. [MEDLINE: 115]

\section{Tebbutt 2007 \{unpublished data only\}}

Tebbutt N, Sourjina T, Strickland A, Van Hazel G, Ganju V, Gibbs D, et al. ATTAX: Randomised phase II study evaluating weekly docetaxel-based chemotherapy combinations in advanced esophago- gastric cancer, final results of an AGITG trial. Journal of Clinical Oncology, ASCO Annual Meeting Proceedings Part / 2007;25(18S):4528.

\section{Tebbutt 2010 \{published data only\}}

Tebbutt NC, Cummins MM, Sourjina T, Strickland A, Van Hazel G, Ganju V, et al. Randomised, non-comparative phase II study of weekly docetaxel with cisplatin and 5-fluorouracil or with capecitabine in oesophagogastric cancer: the AGITG ATTAX trial. British Journal of Cancer 2010;102:475-81.

\section{Thuss-Patience 2011 \{published data only\}}

* Thuss-Patience PC, Kretzschmar A, Bichev D, Deist T, Hinke A, Breithaupt $\mathrm{K}$, et al. Survival advantage for irinotecan versus best supportive care as second-line chemotherapy in gastric cancer-a randomised phase III study of the Arbeitsgemeinschaft
Internistische Onkologie (AIO). European Journal of Cancer 2011;47(15):2306-14.

Thuss-Patience PC, Kretzschmar A, Deist T, Hinke A, Bichev D, Lebedinzew $B$, et al. Irinotecan versus best supportive care (BSC) as second-line therapy in gastric cancer: a randomized phase III study of the Arbeitsgemeinschaft Internistische Onkologie (AIO). Journal of Clinical Oncology 2009;27(15s):abstr 4540.

\section{Tsushima 1991 \{published data only\}}

Tsushima K, Sakata Y, Suzuki H, Saitoh S, Sugimoto N, Itoh T, et al. A randomized controlled study of 5-fluorouracil/doxorubicin/ mitomycin C/OK-432 (FAM-OK) therapy and 4-fluorouracil/ epirubicin/mitomycin C/OK-432 (FEM-OK) therapy in advanced gastric cancer. Journal of Japan Society for Cancer Therapy 1991;26(7):1317-24. [MEDLINE: 118]

\section{Van Cutsem 2009 \{published data only\}}

Van Cutsem E, Kang Y, Chung H, Shen L, Sawaki L, Lordick F, et al. Efficacy results from the ToGA trial: a phase III study of trastuzumab added to standard chemotherapy (CT) in firstline human epidermal growth factor receptor 2 (HER2)-positive advanced gastric cancer (GC). Journal of Clinical Oncology Supplement 2009;27:abstr LBA4509.

\section{Vanhoefer 2000 \{published data only\}}

* Vanhoefer Uk, Rougier P, Wilke H, Ducreux MP, Lacave AJ, Van Cutsem E, et al. Final results of a randomized phase III trial of sequential high-dose methotrexate, fluorouracil, and doxorubicin versus etoposide, leucovorin, and fluorouracil versus infusional fluorouracil and cisplatin in advanced gastric cancer: A trial of the European Organization for Research and Treatment of Cancer Gastrointestinal Tract Cancer Cooperative Group. Journal of Clinical Oncology 2000;18(14):2648-57.

Wilke H, Wils J, Rougier P, Lacave A, Van Cutsem E, Vanhoefer U, et al. Preliminary analysis of a randomized phase III trial of FAMTX versus ELF versus cisplatin/5-FU in advanced gastric cancer (GC): a trial of the EORTC Gastrointestinal Tract Cancer Cooperative Group and the AIO (Arbeitsgemeinschaft Internsitische Onkologie). Proceedings/Annual Meeting of the American Society of Clinical Oncology. 1995; Vol. 14:206. [MEDLINE: 184]

\section{Vaughn 1980 \{published data only\}}

Vaughn CB, Brady P, Chinn BJ. Combination chemotherapy in advanced gastrointestinal malignancy (with 1 color plate). Oncology 1980;37(1):57-61. [MEDLINE: 120]

\section{Vestlev 1990 \{published data only\}}

Vestlev PM, Pedersen H. Doxorubicin and 5-fluorouracil versus doxorubicin and oral ftorafur in the treatment of advanced gastric cancer - a phase II and III trial. Acta Oncologica 1990;29(7):945-6. [MEDLINE: 121]

\section{Villar 1987 \{published data only\}}

Villar A, Asensio F, Candel M, Delgado F, Garcia J, Lledo S, et al. Chemotherapy of advanced gastric carcinoma (stage IV): a randomized study of FAM versus 5-FU plus BCNU. Chemioterapia 1987;6(1):57-62. [MEDLINE: 122] 


\section{Voznyi 1978 \{published data only\}}

Voznyi EK, Borisov VI, Perevodchikova NI, Babaian LA, Vaarik KhM. Comparative assessment of the effectiveness of the preparations CCNU, 5-fluorouracil, ftorafur and their combinations in inoperable stomach cancer [Russian]. Vestnik Akademii Meditsinskikh Nauk SSSR 1978;9:83-7. [MEDLINE: 123]

\section{Wadler 2002 \{published data only\}}

Wadler S, Brain C, Catalano P, Einzig Al, Cella D, Benson AB, III. Randomized phase II trial of either fluorouracil, parenteral hydroxyurea, interferon-alpha-2a, and filgrastim or doxorubicin/docetaxel in patients with advanced gastric cancer with quality-of-life assessment: Eastern Cooperative Oncology Group Study E6296. Cancer Journal 2002;8(3):282-6. [MEDLINE: 9]

\section{Wakui 1983 \{published data only\}}

Wakui A, Takahashi K, Sato Y, Sato K, Matsuoka T, Saito T. Clinical evaluation of chemoimmunotherapy for advanced gastrointestinal cancer using a combined regimen of 5fluorouracil, adriamycin and levamisole. [Japanese]. Gan to Kagaku Ryoho [Japanese Journal of Cancer \& Chemotherapy] 1983;10(2):218-26. [MEDLINE: 124]

\section{Wakui 1983a \{published data only\}}

Wakui A, Kikuchi K, Yokoyama M, Takahashi K, Yoshida Y, Kaito I, et al. Phase III multi-center study of levamisole (LMS)-a randomized evaluation in advanced gastrointestinal cancer, with special reference to stomach cancer. [Japanese]. Gan to Kagaku Ryoho. Cancer \& Chemotherapy 1983;10(7):1610-23. [MEDLINE: 125]

\section{Wakui 1986 \{published data only\}}

Wakui A, Kasai M, Konno K, Abe R, Kanamaru R, Takahashi K, et al. Randomized study of lentinan on patients with advanced gastric and colorectal cancer. Tohoku Lentinan Study Group. [Japanese]. Gan to Kagaku Ryoho. Cancer \& Chemotherapy 1986;13 (4 part 1):1050-9. [MEDLINE: 126]

\section{Wang 2007 \{published data only\}}

Wang ZH, Chen Z, Li CZ, Zhou DG, Sheng LJ, Liu B, et al. Comparative study of continuous intravenous infusional tegafur or 5-fluorouracil combined with oxaliplatin in the treatment of advanced gastric cancer. Chinese Journal of Cancer Prevention and Treatment 2007;14(2):136-9.

\section{Waters 1999 \{published data only\}}

Waters JS, Norman A, Cunningham D, Scarffe JH, Webb A, Harper $\mathrm{P}$, et al. Long-term survival after epirubicin, cisplatin and fluorouracil for gastric cancer: results of a randomized trial. British Journal of Cancer 1999;80(1-2):269-72. [MEDLINE: 127]

\section{Wilke 2014 \{published data only\}}

Wilke H, Muro K, Van Cutsem E, Oh SC, Bodoky G, Shimada Y, et al. Ramucirumab plus paclitaxel versus placebo plus paclitaxel in patients with previously treated advanced gastric or gastro-oesophageal junction adenocarcinoma (RAINBOW): a double-blind, randomised phase 3 trial. Lancet Oncology 2014;15:1224-35.
Wils 1991 \{published data only\}

Klein HO, Buyse M, Wils JA. Prospective randomized trial using 5-fluorouracil, adriamycin and methotrexate (FAMTX) versus FAM for treatment of advanced gastric cancer. Onkologie 1992;15(5):364-7. [MEDLINE: 61]

Wils J, Klein H, Bleiberg H, Buyse M, Wagener DTh, Diaz-Rubio E, et al. EORTC 40851: A Gastrointestinal Group (GI) randomized evaluation of the toxicity of sequential high-dose methotrexate (MTX) and 5-fluouracil (F) combined with adriamycin (A) (FAMTX) versus $F, A$ and mitomycin C (M) (FAM) in advanced gastric cancer. Proceedings/Annual Meeting of the American Society of Clinical Oncology. 1987; Vol. 6:73. [MEDLINE: 190]

Wils J, Klein HO, Bleiberg H, Buyse M, Wagener DJ, Conroy T, et al. EORTC 40851: Sequential high dose methotrexate (MTX) and 5-fluorouracil (F) combined with adriamycin (A) (FAMTX versus $F, A$, and mitomycin C (M) (FAM) in advanced gastric cancer. Proceedings/Annual Meeting of the American Society of Clinical Oncology. 1989; Vol. 8:109. [MEDLINE: 186]

Wils J, Klein HO, Bleiberg H, Buyse M, Wagener DJTh, Conroy T, et al. FAMTX (5-FU, adriamycin (A) and methotrexate (MTX)): a step ahead in the treatment of advanced gastric cancer. Proceedings/Annual Meeting of the American Society of Clinical Oncology. 1990; Vol. 9, issue 102. [MEDLINE: 175]

* Wils JA, Klein HO, Wagener DJ, Bleiberg H, Reis H, Korsten F, et al. Sequential high-dose methotrexate and fluorouracil combined with doxorubicin - a step ahead in the treatment of advanced gastric cancer: a trial of the European Organization for Research and Treatment of Cancer Gastrointestinal Tract Cooperative Group. Journal of Clinical Oncology 1991;9(5):827-31.

\section{Wils 1994 \{published data only\}}

Wils J, Wagener DJT, Coombes RC, Fountzilas G, Bliss JM, Law M, et al. Phase III trial of fluorouracil, methotrexate and epirubicin (FEMTX) versus FEMTX plus cisplatin (FEMTX-P) in advanced gastric cancer. Annals of Oncology. 1994; Vol. 5 (Suppl 8). [MEDLINE: 144$]$

\section{Xu 2013 \{published data only\}}

Xu R, Ma N, Wang F, Ma L, Chen R, Chen R, et al. Results of a randomized and controlled clinical trial evaluating the efficacy and safety of combination therapy with Endostar and S-1 combined with oxaliplatin in advanced gastric cancer. OncoTargets and Therapy 2013;6:925-9.

\section{Yamada 1994 \{published data only\}}

Yamada Y, Tsushima K, Sakata Y, Saito S, Ito T, Sugimoto N, et al. Sequential methotrexate/5-fluorouracil therapy with 5'-deoxy-5-fluorouridine against advanced gastric cancer: comparison between bolus injection and drip infusion of 5fluorouracil administration. Hirosaki Cooperative Study Group for Cancer Chemotherapy. [Japanese]. Gan to Kagaku Ryoho. Cancer \& Chemotherapy 1994;21(7):1029-32. [MEDLINE: 130]

\section{Yin 1996 \{published data only\}}

Yin Zheng-Min, Zhang Y, Xie Zhong. Elemene plus fluorouracil in the treatment of advanced gastric cancer. [Chinese]. Chinese Journal of Clinical Oncology 1996;23(11):810-12. [MEDLINE: 134] 
Yoshida 2003 \{published data only\}

Yoshida K, Tanabe K, Ueno H, Ohta K, Hihara J, Toge T, et al. Future prospects of personalized chemotherapy in gastric cancer patients: results of a prospective randomized pilot study. Gastric Cancer 2003;6(Suppl 1):82-9. [MEDLINE: 3]

Yoshikawa 2011 \{published data only\} Yoshikawa T, Tsuburaya A, Saze Z, Aoyama T, Hasegawa S, Kanemoto A, et al. [Randomized phase II trial to compare S-1 and S-1/PSK for advanced or recurrent gastric cancerlessons from the results]. Gan to Kagaku Ryoho. Cancer \& Chemotherapy 2011; Vol. 38, issue 12:1909-11.

\section{Yoshino 2007 \{published data only\}}

Yoshino S, Oka M. Randomized phase III study of S-1 alone versus S-1 plus lentinan in advanced or recurrent gastric cancer. Biotherapy 2007;21(5):315-21.

Yun 2010 \{published data only\}

Yun J, Park SH, Park JO, Park YS, Ho YL, Kang WK. A randomised phase II study of combination chemotherapy with epirubicin, cisplatin and capecitabine (ECX) or cisplatin and capecitabine (CX) in advanced gastric cancer. European Journal of Cancer 2010;46:885-91.

\section{Zhao 2009 \{published data only\}}

Zhao F, Wang Q, Zhang JW, Hang M, Chen SB. Therapeutic evaluation of docetaxel-combined chemotherapy for advanced gastric carcinoma [Chinese]. Acta Universitatis Medicinalis NanJing (Natural Science) 2009;29:237-9.

\section{Zironi 1992 \{published data only\}}

Zironi S, Cocconi G, Bella M, Algeri R, Bartolucci R, De Lisi V, et al. A prospective randomized trial comparing FAM combination in advanced gastric carcinoma. Annals of Oncology. 1992; Vol. 3 (Suppl 5):13. [MEDLINE: 165]

\section{References to ongoing studies}

\section{Elsaid 2005 \{unpublished data only\}}

Elsaid AA, Elkerm Y. Final results of a randomized phase III trial of docetaxel, carboplatin and 5FU versus epirubicin, cisplatin and 5FU for locally advanced gastric cancer. Journal of Clinical Oncology, ASCO Annual Meeting Proceedings 2005;23(16S):4014.

\section{Higuchi 2012 \{published data only\}}

Higuche K, Koizumi W, Yamada Y, Nishikawa K, Gotoh M. Randomized phase III study of S-1 plus oxaliplatin versus S-1 plus cisplatin for first-line treatment of advanced gastric cancer. Journal of Clinical Oncology. 2012; Vol. 30 (suppl. 34):abstr 60.

\section{Kurihara \{unpublished data only\}} Isovorin: Phase III study. Ongoing study - .

\section{Maiello 2011 \{published data only\}}

Maiello E, De Vita F, Gebbia V, Lorusso S, Cinieri S, Giuliani F, et al. Epirubicin (E) in combination with cisplatin (CDDP) and capecitabine (C) versus docetaxel (D) combined with 5-fluorouracil (5-FU) by continuous infusion as front-line therapy in patients with advanced gastric cancer (AGC):
Preliminary results of a randomized phase II trial of the Gruppo Oncologico Dell'Italia Meridionale. Journal of Clinical Oncology 2011;29(suppl 1):97.

\section{NCT01498289 \{published data only\}}

NCT01498289. S1201: Combination chemo for oatients w/advanced or metastatic esophageal, gastric, or gastroesophageal junction cancer. clinicaltrials.gov/ct2/show/ NCT01498289 Dat first received: 22 December 2011.

NCT01558947 \{published data only\}

NCT01558947. Peri-operative chemotherapy with ECX or XP in the treatment of advanced gastric cancer. clinicaltrials.gov/ct2/ show/NCT01558947 Date first received: 7 March 2012.

\section{NCT01967875 \{published data only\}}

NCT01967875. A phase 2 trial of optimizing platinum-based chemotherapy based on ERCC1 expression as first-line treatment in patients with locally advanced or metastatic gastric cancer. clinicaltrials.gov/ct2/show/NCT01967875 Date first received: 15 October 2013.

\section{NCT02076594 \{published data only\}}

NCT02076594. Low-Tox vs Eox in patients with locally advanced unresectable or metastatic gastric cancer. clinicaltrials.gov/ct2/ show/NCT02076594 Date first received: 20 August 2013.

\section{NCT02114359 \{published data only\}}

NCT02114359. Chemotherapy options for the first line chemotherapy in elderly patient with advanced gastric cancer. clinicaltrials.gov/ct2/show/NCT02114359 Date first received: 9 April 2014.

\section{NCT02289378 \{published data only\}}

NCT02289378. Dose-dense biweekly docetaxel, oxaliplatin and 5 -fluorouracil as first-line treatment in advanced gastric cancer (DaeMon-Plus). clinicaltrials.gov/ct2/show/NCT02289378 Date first received: 7 November 2014.

\section{NCT02289547 \{published data only\}}

NCT02289547. Phase 3 study of Xelox followed by maintenance capecitabine in the advanced gastric cancer. clinicaltrials.gov/ ct2/show/NCT02289547 Date first received: 30 October 2014.

NCT02549911 \{published data only\}

NCT02549911. HIPEC, intravenous chemotherapy and surgery for the treatment of advanced GC with peritoneal metastasis. clinicaltrials.gov/ct2/show/NCT02549911 Date first received: 7 September 2015

\section{NCT02583659 \{published data only\}}

NCT02583659. The first-line combined chemotherapy for advanced gastric cancer: a prospective observational clinical study. clinicaltrials.gov/ct2/show/NCT02583659 Date first received: 19 October 2015.

NCT02855788 \{published data only\}

NCT02855788. Metronomic chemotherapy in advanced gastric cancer. clinicaltrials.gov/ct2/show/NCT02855788 Date first received: 2 August 2016. 


\section{NCT03006432 \{published data only\}}

NCT03006432. Phase iii randomised trial to evaluate folfox with or without docetaxel (TFOX) as 1st line chemotherapy for locally advanced or metastatic oesophago-gastric carcinoma (GASTFOX). clinicaltrials.gov/ct2/show/NCT03006432 Date first received: 27 December 2016.

\section{Tsuburaya 2012 \{published data only\}}

Tsuburaya A, Morita S, Kodera Y, Kobayashi M, Shitara K, Yamaguchi $\mathrm{K}$, et al. A randomized phase II trial to elucidate the efficacy of capecitabine plus cisplatin (XP) and S-1 plus cisplatin (SP) as a first-line treatment for advanced gastric cancer: XP ascertainment vs. SP randomized PII trial (XParTS II). BMC Cancer 2012;12:307.

\section{Additional references}

\section{Abrams 2013}

Abrams JA, Gonsalves L, Neugut Al. Diverging trends in the Incidence of reflux-related and Helicobacter pylori-related gastric cardia cancer. Journal of Clinical Gastroenterology 2013;47(4):322-7.

\section{Ajani 2007}

Ajani JA, Moiseyenko VM, Tjulandin S, Majlis A, Constenla M, Boni $C$, et al. Clinical benefit with docetaxel plus fluorouracil and cisplatin compared with cisplatin and fluorouracil in a phase III trial of advanced gastric or gastroesophageal cancer adenocarcinoma: the V-325 Study Group. Journal of Clinical Oncology 2007;25:3205-9.

\section{Ajani 2007a}

Ajani JA, Moiseyenko VM, Tjulandin S, Majlis A, Constenla M, Boni C, et al. Quality of life with docetaxel plus cisplatin and fluorouracil compared with cisplatin and fluorouracil from a phase III trial for advanced gastric or gastroesophageal adenocarcinoma: the V-325 Study Group. Journal of Clinical Oncology 2007;25:3210-6.

\section{Al-Batran 2010}

Al-Batran SE, Ajani JA. Impact of chemotherapy on quality of life in patients with metastatic esophagogastric cancer. Cancer 2010;116(11):2511-8.

\section{Al-Batran 2016}

Al-Batran SE, Hofheinz RD, Pauligk C, Kopp HG, Haag GM, Luley KB, et al. Histopathological regression after neoadjuvant docetaxel, oxaliplatin, fluorouracil, and leucovorin versus epirubicin, cisplatin, and fluorouracil or capecitabine in patients with resectable gastric or gastro-oesophageal junction adenocarcinoma (FLOT4-AIO): results from the phase 2 part of a multicentre, open-label, randomised phase $2 / 3$ trial. Lancet Oncology 2016;17(12):1697-708.

\section{Altman 2001}

Altman DG. Systematic reviews of evaluations of prognostic variables. In: Egger M, et al. editor(s). Systematic Reviews in Health Care. 2nd Edition. London: BMJ, 2001:228-47.

\section{Bang 2010}

Bang YJ, Van Cutsem E, Feyereislova A, Chung HC, Shen L, Sawaki A, et al. Trastuzumab in combination with chemotherapy versus chemotherapy alone for treatment of HER2-positive advanced gastric or gastro-oesophageal junction cancer (ToGA): a phase 3, open-label, randomised controlled trial. Lancet 2010;376(9742):687-97.

\section{Bang 2012}

Bang YJ, Kim YW, Yang HK, Chung HC, Park YK, Lee KH, et al. Adjuvant capecitabine and oxaliplatin for gastric cancer after D2 gastrectomy (CLASSIC): a phase 3 open-label, randomised controlled trial. Lancet. 2012/01/10 2012; Vol. 379, issue 9813:315-21. [0140-6736]

\section{Bonenkamp 1999}

Bonenkamp JJ, Hermanns J, Sasako M. Extended lymph-node dissection for gastric cancer. New England Journal of Medicine 1999;340:908-14

\section{Bosman 2010}

Bosman FT, Carneiro F, Hruban RH, Theise ND. WHO Classification of Tumours of the Digestive System. 4th Edition. Lyon (France): IARC Press, 2010. [9283224329]

\section{Chan 2017}

Chan DY, Syn NL, Yap R, Phua JN, Soh TI, Chee CE, et al. Conversion surgery post-intraperitoneal paclitaxel and systemic chemotherapy for gastric cancer carcinomatosis peritonei. Are we ready?. Journal of Gastrointestinal Surgery 2017;21(3):425-33. [DOI: 10.1007/s11605-016-3336-3; NCT01739894]

\section{Charlson 1987}

Charlson ME, Pompei P, Ales KL, MacKenzie CR. A new method of classifying prognostic comorbidity in longitudinal studies: development and validation. Journal of Chronic Diseases 1987;40(5):373-83.

\section{Chau 2004}

Chau I, Norman AR, Cunningham D, Waters JS, Oates J, Ross PJ. Multivariate prognostic factor analysis in locally advanced and metastatic esophago-gastric cancer - pooled analysis from three multicenter, randomized, controlled trials using individual patient data. Journal of Clinical Oncology 2004;22(12):2395-403.

\section{Chen 2013}

Chen XL, Chen XZ, Yang C, Liao YB, Li H, Wang L, et al. Docetaxel, cisplatin and fluorouracil (DCF) regimen compared with non-taxane-containing palliative chemotherapy for gastric carcinoma: a systematic review and meta-analysis. PLOS One 2013;8:e60320.

\section{Correa 1996}

Correa P. Helicobacter pylori and gastric cancer: state of the art. Cancer Epidemiology, Biomarkers \& Prevention 1996;5:477-81.

\section{Crew 2004}

Crew CD, Neugut Al. Epidemiology of upper gastrointestinal malignancies. Seminars in Oncology 2004;31(4):450-61. 


\section{Cunningham 2006}

Cunningham D, Allum WH, Stenning SP, Thompson JN, Van de Velde CJ, Nicolson M, et al. Perioperative chemotherapy versus surgery alone for resectable gastroesophageal cancer. New England Journal of Medicine 2006;355(1):11-20.

\section{Curran 2009}

Curran D, Pozzo C, Zaluski J, Dank M, Barone C, Valvere V, et al. Quality of life of palliative chemotherapy naive patients with advanced adenocarcinoma of the stomach or esophagogastric junction treated with irinotecan combined with 5-fluorouracil and folinic acid: results of a randomised phase III trial. Quality of Life Research 2009;18:853-61.

\section{Digklia 2016}

Digklia A, Wagner AD. Advanced gastric cancer: Current treatment landscape and future perspectives. World Journal of Gastroenterology 2016;22(8):2403-14.

\section{Dixon 2016}

Dixon M, Mahar AL, Helyer LK, Vasilevska-Ristovska J, Law C, Coburn NG. Prognostic factors in metastatic gastric cancer: results of a population-based, retrospective cohort study in Ontario. Gastric Cancer 2016;19(1):150-9.

\section{Ellis 2014}

Ellis LM, Bernstein DS, Voest EE, Berlin JD, Sargent D, Cortazar P, et al. American Society of Clinical Oncology perspective: Raising the bar for clinical trials by defining clinically meaningful outcomes. Journal of Clinical Oncology 2014;32:1277-80.

\section{Eremenco 2004}

Eremenco SL, Cashy J, Webster K, Ohashi Y, Locker GY, Pelletier G, et al. FACT-Gastric: a new international measure of QOL in gastric cancer. Proceedings/Annual Meeting of the American Society of Clinical Oncology. 2004; Vol. 23.

\section{Ferrell 2017}

Ferrell BR, Temel JS, Temin S, Alesi ER, Balboni TA, Basch EM, et al. Integration of palliative care into standard oncology care: American Society of Clinical Oncology clinical practice guideline update. Journal of Clinical Oncology 2017;35(1):96-112.

\section{Ferro 2014}

Ferro A, Peleteiro B, Malvezzi M, Bosetti C, Bertuccio P, Levi F, et al. Worldwide trends in gastric cancer mortality (1980-2011), with predictions to 2015, and incidence by subtype. European Journal of Cancer 2014;50(7):1330-44.

\section{Garrido 2014}

Garrido M, Fonseca PJ, Vieitez JM, Frunza M, Lacave AJ. Challenges in first line chemotherapy and targeted therapy in advanced gastric cancer. Expert Review of Anticancer Therapy 2014;14(8):887-900.

\section{GASTRIC Group 2013}

GASTRIC Group, Oba K, Paoletti X, Bang YJ, Bleiberg H, Burzykowski T, et al. Role of chemotherapy for advanced/ recurrent gastric cancer: an individual-patient-data metaanalysis. European Journal of Cancer 2013;49(7):1565-77.

\section{GBD Cancer Collaboration 2017}

Global Burden of Disease Cancer Collaboration. Global, Regional, and National Cancer Incidence, Mortality, Years of Life Lost, Years Lived With Disability, and Disability-Adjusted Life-years for 32 Cancer Groups, 1990 to 2015: A Systematic Analysis for the Global Burden of Disease Study. JAMA Oncology 2017;3(4):524-48.

\section{Higgins 2003}

Higgings JPT, Thompson SG, Deeks JJ, Altman DG. Measuring inconsistency in meta-analyses. BMJ 2003;327(7414):557-60.

\section{Higgins 2008}

Higgins JPT, Green S (editors). Cochrane Handbook for Systematic Reviews of Interventions Version 5.0.2 [updated September 2009]. The Cochrane Collaboration, 2008. Available from www.cochrane-handbook.org.

\section{Higgins 2011}

Higgins JPT, Green S (editors). Cochrane Handbook for Systematic Reviews of Interventions Version 5.1.0 [updated March 2011]. The Cochrane Collaboration, 2011. Available from www.cochrane-handbook.org.

\section{Hurwitz 2004}

Hurwitz H, Fehrenbacher L, Novotny W, Cartwright T, Hainsworth J, Heim W, et al. Bevacizumab plus irinotecan, fluorouracil, and leucovorin for metastatic colorectal cancer. New England Journal of Medicine 2004;350(23):2335-42.

\section{Ilsen 2007}

Ilson DH. Docetaxel, cisplatin and fluouracil in gastric cancer: does the punishment fit the crime?. Journal of Clinical Oncology 2007;25(22):3188-90.

\section{Jadad 1996}

Jadad AR, Moore A, Carroll D. Assessing the quality of reports of randomized clinical trials: Is blinding necessary?. Controlled Clinical Trials 1996;17:1-12.

\section{Kang 2012}

Kang JH, Lee SI, Lim DH, Park K-W, Oh SY, Kwon H-C, et al. Salvage chemotherapy for pretreated gastric cancer: a randomized phase III trial comparing chemotherapy plus best supportive care with best supportive care alone. Journal of Clinical Oncology 2012; Vol. 30, issue 13:1513-8. [0732-183X]

\section{Kang 2016}

Kang Y-K, Shah MA, Ohtsu A, Van Custem E, Ajani JA, van der Horst $\mathrm{T}$, et al. A randomized, open-label, multicenter, adaptive phase $2 / 3$ study of trastuzumab emtansine ( $T$ DM1) versus a taxane (TAX) in patients (pts) with previously treated HER2-positive locally advanced or metastatic gastric/ gastroesophageal junction adenocarcinoma (LA/MGC/ GEJC). Journal of Clinical Oncology 2016;4S:abstr 5. [http:// meetinglibrary.asco.org/record/120278/abstract]

\section{Kang 2017}

Kang Y-K, Satoh T, Ryu M-H, Chao Y, Kato K, Chung HC, et al. Nivolumab (ONO-4538/BMS-936558) as salvage treatment after second or later-line chemotherapy for advanced gastric 
or gastro-esophageal junction cancer (AGC): A double-blinded, randomized, phase III trial. Journal of Clinical Oncology 2017;35(4S):abstract 2. [http://meetinglibrary.asco.org/ record/139096/abstract]

\section{Kataoka 2017}

Kataoka K, Kinoshita T, Moehler M, Mauer M, Shitara K, Wagner A $D$, et al. Current management of liver metastases from gastric cancer: what is common practice? New challenge of EORTC and JCOG. Gastric Cancer 2017;1 February:Epub ahead of print.

\section{Kelley 2003}

Kelley JR, Duggan JM. Gastric cancer epidemiology and risk factors. Journal of Clinical Epidemiology 2003;56:1-9.

\section{Kripp 2014}

Kripp M, Al-Batran S E, Rosowski J, Pauligk C, Homann N, Hartmann JT, et al. Quality of life of older adult patients receiving docetaxel-based chemotherapy triplets for esophagogastric adenocarcinoma: a randomized study of the Arbeitsgemeinschaft Internistische Onkologie (AIO). Gastric Cancer 2014;17:181-7.

\section{Lauren 1965}

Lauren P. The two histological main types of gastric carcinoma: an attempt at a histological classification. Acta Pathologica Microbiologica Scandinavia 1965;64:31-49.

\section{Leichman 1991}

Leichman L, Berry BT. Cisplatin therapy for adenocarcinoma of the stomach. Seminars in Oncology 1991;18 (1 Suppl 3):25-33.

\section{Lordick 2014a}

Lordick F, Allum W, Carneiro F, Mitry E, Tabernero J, Tan P, et al. Unmet needs and challenges in gastric cancer: the way forward. Cancer Treatment Reviews 2014;40:692-700.

\section{Lordick 2014b}

Lordick F, Lorenzen S, Yamada Y, Ilson D. Optimal chemotherapy for advanced gastric cancer: is there a global consensus? Gastric Cancer 2014;17:213-25.

\section{MacDonald 1992}

MacDonald JS, Havlin KA. Etoposide in gastric cancer. Seminars in Oncology 1992;19 (6 Suppl 13):59-62.

\section{MacDonald 2001a}

MacDonald JS. Gastric cancer. Educational Book. ASCO, 2001:77-80.

\section{MacDonald 2001b}

MacDonald JS, Smalley SR, Benedetti J. Chemoradiotherapy after surgery compared with surgery alone for adenocarcinoma of the stomach or gastroesophageal junction. New England Journal of Medicine 2001;345:725-30.

\section{Machin 1997}

Machin D, Stenning SP, Parmar MKP. Thirty years of Medical Research Council randomized trials in solid tumors. Journal of Clinical Oncology 1997;9:100-14.

\section{Moher 2009}

Moher D, Liberati A, Tetzlaff J, Altman DG, the PRISMA Group. Preferred reporting items for systematic reviews and metaanalyses: the PRISMA statement. PLOS Medicine 2009;6(7):1-6.

\section{Munoz 1968}

Munoz N, Correa P, Cuello C. Histological types of gastric carcinoma in high and low risk areas. International Journal of Cancer 1968;3:809-18.

\section{Muro 2016}

Muro K, Chung H C, Shankaran V, Geva R, Catenacci D, Gupta S, et al. Pembrolizumab for patients with PD-L1-positive advanced gastric cancer (KEYNOTE-012): a multicentre, open-label, phase 1b trial. Lancet Oncology 2016;17(6):717-26.

\section{Norman 2003}

Norman GR, Sloan J, Wyrwich KW. Interpretation of changes in health-related quality of life: the remarkable universality of half a standard deviation. Medical Care 2003;41(5):582-92.

\section{Ohkuwa 2000}

Ohkuwa M, Ohtsu A, Boku N, Yoshida S, Miyata Y, Shirao K, et al. Long-term results for patients with unresectable gastric cancer who received chemotherapy in the Japan Clinical Oncology Group (JCOG) trials. Gastric Cancer 2000;3(3):145-50. [MEDLINE: 88]

\section{Ohtsu 2013}

Ohtsu A, Ajani JA, Bai YX, Bang YJ, Chung HC, Pan HM, et al. Everolimus for previously treated advanced gastric cancer: results of the randomized, double-blind, phase III GRANITE-1 study. Journal of Clinical Oncology. 2013/09/18 2013; Vol. 31, issue 31:3935-43. [0732-183x]

\section{Okines 2008}

Okines A, Chau I, Cunningham D. Capecitabine in gastric cancer. Drugs of Today 2008;44(8):629-40.

\section{Pallis 2011}

Pallis AG, Ring A, Fortpied C, Penninckx B, Van Nes MC, Wedding U, et al. EORTC workshop on clinical trial methodology in older individuals with a diagnosis of solid tumors. Annals of Oncology 2011;22(8):1922-6.

\section{Paoletti 2013}

Paoletti X, Oba K, Bang YJ, Bleiberg H, Boku N, Bouche O, et al. Progression-free survival as a surrogate for overall survival in advanced/recurrent gastric cancer trials: a meta-analysis. Journal of the National Cancer Institute 2013;105(21):1667-70.

\section{Parmar 1998}

Parmar MKB, Torri V, Steward L. Extracting summary statistics to perform meta-analysis of the published literature for survival endpoints. Statistics in Medicine 1998;17:2815-34.

\section{Peleteiro 2012}

Peleteiro B, La Vecchia C, Lunet N. The role of Helicobacter pylori infection in the web of gastric cancer causation. European Journal of Cancer Prevention 2012;21(2):118-25. 


\section{Petrelli 2013}

Petrelli F, Zaniboni A, Coinu A, Cabiddu M, Ghilardi M, Sgroi G, et al. Cisplatin or not in advanced gastric cancer: a systematic review and meta-analysis. PLOS One 2013;8:e83022.

\section{Preusser 1988}

Preusser P, Achterrath W, Wilke H, Lenaz L, Fink U, Heinicke A, et al. Chemotherapy of gastric cancer. Cancer Treatment Reviews 1988;15:257-77.

\section{Pye 2001}

Pye JK, Crumplin MK, Charles J. One-year survey of carcinoma of the esophagus and stomach in Wales. British Journal of Surgery 2001;88:278-85.

\section{RevMan [Computer program]}

Nordic Cochrane Centre, The Cochrane Collaboration. Review Manager (RevMan). Version 5.3. Copenhagen: Nordic Cochrane Centre, The Cochrane Collaboration, 2014.

\section{Rusch 2004}

Rusch VW. Are cancers of the esophagus, gastroesophageal junction, and cardia one disease, two, or several?. Seminars in Oncology 2004;31(4):444-9.

\section{Sakuramoto 2007}

Sakuramoto S, Sasako M, Yamaguchi T, Kinoshita T, Fujii M, Nashimoto A, et al. ACTS-GC Group. Adjuvant chemotherapy for gastric cancer with S-1, an oral fluoropyrimidine. New England Journal of Medicine 2007;357(18):1810-20.

\section{Sepulveda 2002}

Sepulveda C, Marlin A, Yoshida T, Ulrich A. Palliative care: the World Health Organization's global perspective. Journal of Pain and Symptom Management 2002;24(2):91-6.

\section{Sharma 2003}

Sharma P. Cancer of the esophagogastric junction: epidemiology and pathogenesis. Journal of Gastrointestinal Surgery 2003;6:516-7.

\section{Song 2016}

Song H, Zhu J, Lu D. Molecular-targeted first-line therapy for advanced gastric cancer. Cochrane Database of Systematic Reviews 2016, Issue 7. [DOI: 10.1002/14651858.CD011461.pub2]

\section{Songun 2010}

Songun I, Putter H, Kranenbarg EM, Sasako M, van de Velde CJ. Surgical treatment of gastric cancer: 15-year follow-up results of the randomised nationwide Dutch D1D2 trial. Lancet Oncology 2010;11:439-49.

\section{Swain 2015}

Swain SM, Baselga J, Kim SB, Ro J, Semiglazov V, Campone M, et al. Pertuzumab, trastuzumab, and docetaxel in HER2-positive metastatic breast cancer. New England Journal of Medicine 2015;372(8):724-34

\section{Syn 2015}

Syn NL, Yong WP, Lee SC, Goh BC. Genetic factors affecting drug disposition in Asian cancer patients. Expert Opinion on
Drug Metabolism \& Toxicology 2015;11(12):1879-92. [DOI: $10.1517 / 17425255.2015 .1108964]$

\section{Syn 2016}

Syn NL, Yong WP, Goh BC, Lee SC. Evolving landscape of tumor molecular profiling for personalized cancer therapy: a comprehensive review. Expert Opinion on Drug Metabolism \& Toxicology 2016;12(8):911-22. [DOI: 10.1080/17425255.2016.1196187]

\section{Tan 2011}

Tan IB, Ivanova T, Lim KH, Ong CW, Deng N, Lee J, et al. Intrinsic subtypes of gastric cancer, based on gene expression pattern, predict survival and respond differently to chemotherapy. Gastroenterology 2011;141:476-85, e1-11.

\section{TCGA 2014}

Cancer Genome Atlas Research Network. Comprehensive molecular characterization of gastric adenocarcinoma. Nature 2014;513:202-9.

\section{Temel 2010}

Temel JS, Greer JA, Muzikansky A, Gallagher ER, Admane S, Jackson VA, et al. Early palliative care for patients with metastatic non-small-cell lung cancer. New England Journal of Medicine 2010;363(8):733-42.

\section{Thompson 2002}

Thompson SG, Higgins JB. How should meta-regression analysis be undertaken and interpreted?. Statistics in Medicine 2002;21(11):1559-73.

\section{Tierney 2007}

Tierney JF, Stewart L, Ghersi D, Burdett S, Sydes MR. Practical methods for incorporating summary time-to-event data into meta-analysis. Trials 2007;8:16.

\section{Verma 2012}

Verma S, Miles D, Gianni L, Krop IE, Welslau M, Baselga J, et al. Trastuzumab emtansine for HER2-positive advanced breast cancer. New England Journal of Medicine 2012;367(19):1783-91.

\section{Vickery 2001}

Vickery CW, Blazeby JM, Conroy T, Arraras J, Sezer O, Koller M, et al. Development of an EORTC disease-specific quality of life module for use in patients with gastric cancer. European Journal of Cancer 2001;37(8):966-71.

\section{Wadhwa 2013}

Wadhwa R, Song S, Lee JS, Yao Y, Wei Q, Ajani JA. Gastric cancermolecular and clinical dimensions. Nature Reviews. Clinical Oncology 2013;10(11):643-55.

\section{Wildiers 2013}

Wildiers H, Mauer M, Pallis A, Hurria A, Mohile SG, Luciani A, et al. End points and trial design in geriatric oncology research: a joint European organisation for research and treatment of cancer--Alliance for Clinical Trials in Oncology--International Society Of Geriatric Oncology position article. Journal of Clinical Oncology 2013;31(29):3711-8. 


\section{Wu 2001}

Wu AH, Wan P, Bernstein L. A multiethnic populationbased study of smoking, alcohol and body size and risk of adenocarcinomas of the stomach and esophagus (United States). Cancer Causes \& Control 2001;12:721-32.

\section{Wu-Williams 1990}

Wu-Williams AH, Yu MC, Mack TM. Lifestyle, the workplace and stomach cancer by subsite in young men of Los Angeles County. Cancer Research 1990;50:2569-76.

\section{Ychou 2011}

Ychou M, Boige V, Pignon JP, Conroy T, Bouche O, Lebreton G, et al. Perioperative chemotherapy compared with surgery alone for resectable gastroesophageal adenocarcinoma: an FNCLCC and FFCD multicenter phase III trial. Journal of Clinical Oncology. 2011/03/30 2011; Vol. 29, issue 13:1715-21. [0732-183x]

\section{References to other published versions of this review \\ Wagner 2002}

Wagner AD, Grothe W, Behl S, Kleber G, Grothey A, Haerting J, et al. Chemotherapy for advanced gastric cancer. Cochrane

\section{CHARACTERISTICS OF STUDIES}

Characteristics of included studies [ordered by study ID]
Database of Systematic Reviews 2002, Issue 4. [DOI: 10.1002/14651858.CD004064]

\section{Wagner 2005}

Wagner ADW, Grothe W, Behl S, Kleber G, Grothey A, Haerting J, et al. Chemotherapy for advanced gastric cancer. Cochrane Database of Systematic Reviews 2005, Issue 2. [DOI: 10.1002/14651858.CD004064.pub2]

\section{Wagner 2006}

Wagner AD, Grothe W, Haerting J, Kleber G, Grothey A, Fleig WE, et al. Chemotherapy in advanced gastric cancer: a systematic review and meta-analysis based on aggregate data. Journal of Clinical Oncology 2006;24:2903-6.

\section{Wagner 2010}

Wagner AD, Unverzagt S, Grothe W, Kleber G, Grothey A, Haerting J, et al. Chemotherapy for advanced gastric cancer. Cochrane Database of Systematic Reviews 2010, Issue 3. [DOI: 10.1002/14651858.CD004064.pub3]

* Indicates the major publication for the study

Ajani 2005

\begin{tabular}{|c|c|}
\hline Methods & $\begin{array}{l}\text { Multicentre RCT } \\
2 \text { arms } \\
\text { Quality score: D }\end{array}$ \\
\hline Participants & $\begin{array}{l}\mathrm{n}=158 \text { ( } 68 \% \text { with tumour location in the stomach; and } 32 \% \text { with tumour location at the GE-junction) } \\
\text { Median age: } 57 \text { years } \\
\text { ECOG 2-3: } 0 \% \text { (Karnofsky performance status KPS was } \geq 70 \% \text { for all patients) } \\
\text { Metastatic disease: } 95 \%\end{array}$ \\
\hline Interventions & $\begin{array}{l}\text { DCF: docetaxel }\left(75 \mathrm{mg} / \mathrm{m}^{2} \mathrm{~d} 1\right)+\text { cisplatin }\left(75 \mathrm{mg} / \mathrm{m}^{2} \mathrm{~d} 1\right)+\mathrm{FU}\left(750 \mathrm{mg} / \mathrm{m}^{2} / \mathrm{d} \mathrm{d} 1-5\right) \text {, repeated at d } 21 \\
\text { versus } \\
\text { DC: docetaxel }\left(85 \mathrm{mg} / \mathrm{m}^{2}\right)+\text { cisplatin }\left(75 \mathrm{mg} / \mathrm{m}^{2}\right) \mathrm{d} 1 \text {, repeated at } \mathrm{d} 21\end{array}$ \\
\hline Outcomes & $\begin{array}{l}\text { Response rates } \\
\text { Time to progression } \\
\text { Overall survival } \\
\text { Toxicities }\end{array}$ \\
\hline Notes & $\begin{array}{l}\text { This is the phase II to chose the investigational arm in Van Cutsem 2006. A similar proportion of pa- } \\
\text { tients received second-line chemotherapy (DCF 39\%; DC 45\%). }\end{array}$ \\
\hline
\end{tabular}


Ajani 2005 (Continued)

Risk of bias

\begin{tabular}{|c|c|c|}
\hline Bias & Authors' judgement & Support for judgement \\
\hline $\begin{array}{l}\text { Random sequence genera- } \\
\text { tion (selection bias) }\end{array}$ & Low risk & $\begin{array}{l}\text { Randomisation was centralised (Aventis, Antony, France) and was stratified for } \\
\text { centre, liver and/or peritoneal metastases, prior gastrectomy, and measurable } \\
\text { versus assessable disease. }\end{array}$ \\
\hline $\begin{array}{l}\text { Allocation concealment } \\
\text { (selection bias) }\end{array}$ & Low risk & Randomisation was centralised (Aventis, Antony, France) \\
\hline $\begin{array}{l}\text { Incomplete outcome data } \\
\text { (attrition bias) } \\
\text { efficacy }\end{array}$ & Low risk & Modified ITT (randomised and treated patients) \\
\hline $\begin{array}{l}\text { Incomplete outcome data } \\
\text { (attrition bias) } \\
\text { safety }\end{array}$ & Low risk & Modified ITT \\
\hline \multirow{2}{*}{$\begin{array}{l}\text { Selective reporting (re- } \\
\text { porting bias) }\end{array}$} & Unclear risk & All treated patients were included in the safety analyses. \\
\hline & & $\begin{array}{l}\text { The primary efficacy end point was initially the CR rate in the per-protocol } \\
\text { population. However, because CRs were infrequent in this study, the IDMC } \\
\text { based its decision regarding treatment selection on the best ORR. }\end{array}$ \\
\hline \multirow[t]{2}{*}{ Other bias } & Unclear risk & Number of diffuse adenocarcinoma is lower in the DC arm (22\% vs. $38 \%)$. \\
\hline & & $\begin{array}{l}\text { The protocol required that the IDMC review data on at least } 70 \text { patients (mini- } \\
\text { mum of } 60 \text { assessable patients) to make their decision; however, by the time } \\
\text { mature data on } 70 \text { patients were verified, the study had accrued } 158 \text { patients }\end{array}$ \\
\hline $\begin{array}{l}\text { Blinded review of } \mathrm{CT} / \mathrm{MRI}- \\
\text { scans? }\end{array}$ & Low risk & $\begin{array}{l}\text { All pertinent imaging studies (except for those of four patients) were reviewed } \\
\text { by an External Response Review Committee (ERRC) }\end{array}$ \\
\hline
\end{tabular}

Ajani 2010

\begin{tabular}{|c|c|}
\hline Methods & $\begin{array}{l}\text { Multicentre RCT } \\
2 \text { arms } \\
\text { Quality score: A }\end{array}$ \\
\hline Participants & $\begin{array}{l}\mathrm{n}=1053 \\
\text { Median age: } 59 \text { years } \\
\text { ECOG 2-3: } 0 \% \\
\text { Metastatic disease: } 96 \%\end{array}$ \\
\hline Interventions & $\begin{array}{l}\text { S-1+Cisplatin: S-1 }\left(50 \mathrm{mg} / \mathrm{m}^{2}\right) \text { in two daily doses d1-21orally + cisplatin }\left(75 \mathrm{mg} / \mathrm{m}^{2}\right) \text { repeated at d } 28 \\
\text { versus } \\
\text { FU+Cisplatin: fluorouracil }\left(1000 \mathrm{mg} / \mathrm{m}^{2} / 24 \text { hrs as } 120 \text {-hour infusion }\right)+\text { cisplatin }\left(100 \mathrm{mg} / \mathrm{m}^{2}\right) \text {, repeated } \\
\text { at d } 28\end{array}$ \\
\hline
\end{tabular}


Ajani 2010 (Continued)

Cisplatin was discontinued after 6 cycles; provision to continue S-1 or FU until progression of disease or unacceptable toxicities

\begin{tabular}{|c|c|c|}
\hline \multirow[t]{5}{*}{ Outcomes } & \multicolumn{2}{|l|}{ Overall survival } \\
\hline & \multicolumn{2}{|c|}{ Progression-free survival } \\
\hline & \multicolumn{2}{|c|}{ Time to treatment failure } \\
\hline & \multicolumn{2}{|l|}{ Tumour response } \\
\hline & \multicolumn{2}{|l|}{ Toxicity } \\
\hline Notes & \multicolumn{2}{|c|}{ Second-line therapy in $31.4 \%$ of patients, most frequently with fluoropyrimidine } \\
\hline \multicolumn{3}{|l|}{ Risk of bias } \\
\hline Bias & Authors' judgement & Support for judgement \\
\hline $\begin{array}{l}\text { Random sequence genera- } \\
\text { tion (selection bias) }\end{array}$ & Low risk & Computer-generated dynamic randomisation \\
\hline $\begin{array}{l}\text { Allocation concealment } \\
\text { (selection bias) }\end{array}$ & Low risk & Centralised randomisation \\
\hline $\begin{array}{l}\text { Incomplete outcome data } \\
\text { (attrition bias) } \\
\text { efficacy }\end{array}$ & Low risk & $\begin{array}{l}\text { Full analysis set of all treated patients }(98.8 \% \text { in S-1+cisplatin arm and } 94.6 \% \\
\text { in FU+cisplatin arm) }\end{array}$ \\
\hline $\begin{array}{l}\text { Incomplete outcome data } \\
\text { (attrition bias) } \\
\text { safety }\end{array}$ & Low risk & Full analysis set of all treated patients \\
\hline Selective reporting (re- & Low risk & PEP: OS \\
\hline poting Nias) & & SEP: ORR, PFS, TTF, safety \\
\hline Other bias & Low risk & None \\
\hline $\begin{array}{l}\text { Blinded review of } \mathrm{CT} / \mathrm{MRI}- \\
\text { scans? }\end{array}$ & Low risk & $\begin{array}{l}\text { Radiographic evidence of response to treatment was also independently re- } \\
\text { viewed. An independent data monitoring committee oversaw the safety and } \\
\text { efficacy data along with other aspects of the conduct of the study. }\end{array}$ \\
\hline
\end{tabular}

Al Batran 2008

\begin{tabular}{ll}
\hline Methods & Multicentre RCT \\
& 2 arms \\
& Quality score: $\mathrm{D}$ \\
\hline Participants & $\mathrm{n}=220$ \\
& Median age: 64 years \\
& ECOG 2-3: $9 \%$ \\
& Metastatic disease: $94 \%$ \\
\hline Interventions & FLO: oxaliplatin $85 \mathrm{mg} / \mathrm{m}^{2}$; leucovorin $200 \mathrm{mg} / \mathrm{m}^{2}$ and $\mathrm{FU} 2.600 \mathrm{mg} / \mathrm{m}^{2}$ as 24 -hour continuous infusion \\
& every 14 days
\end{tabular}


Al Batran 2008 (Continued)

FLP: cisplatin $50 \mathrm{mg} / \mathrm{m}^{2}$; leucovorin $200 \mathrm{mg} / \mathrm{m}^{2}$; FU $2.000 \mathrm{mg} / \mathrm{m}^{2}$ weekly for 6 weeks followed by a 2week rest

\begin{tabular}{ll}
\hline Outcomes & $\begin{array}{l}\text { Median overall survival } \\
\text { Tumour response } \\
\text { Toxicity }\end{array}$ \\
\hline Notes & $\begin{array}{l}\text { A pre-planned interim analysis of toxicity and response was conducted after } 80 \text { patients were included } \\
\text { in the study }\end{array}$
\end{tabular}

\section{Risk of bias}

\begin{tabular}{|c|c|c|}
\hline Bias & Authors' judgement & Support for judgement \\
\hline $\begin{array}{l}\text { Random sequence genera- } \\
\text { tion (selection bias) }\end{array}$ & Unclear risk & Not stated \\
\hline $\begin{array}{l}\text { Allocation concealment } \\
\text { (selection bias) }\end{array}$ & Unclear risk & Not stated \\
\hline $\begin{array}{l}\text { Incomplete outcome data } \\
\text { (attrition bias) } \\
\text { efficacy }\end{array}$ & Low risk & ITT analysis of all randomised patients $(n=220)$ \\
\hline $\begin{array}{l}\text { Incomplete outcome data } \\
\text { (attrition bias) } \\
\text { safety }\end{array}$ & Low risk & Analysis of all treated patients $(n=214)$ \\
\hline $\begin{array}{l}\text { Selective reporting (re- } \\
\text { porting bias) }\end{array}$ & Unclear risk & Report includes all expected outcomes (OS, RR and toxicity) \\
\hline Other bias & High risk & $\begin{array}{l}\text { Differences in baseline distribution of sex ( } 42.9 \% \text { versus } 25 \% \text { female) and } \\
\text { metastatic disease }(97.3 \% \text { versus } 90.7 \%) \text {. Preplanned interim analysis. }\end{array}$ \\
\hline $\begin{array}{l}\text { Blinded review of CT/MRI- } \\
\text { scans? }\end{array}$ & Unclear risk & Not stated \\
\hline
\end{tabular}

\begin{tabular}{|c|c|}
\hline Methods & $\begin{array}{l}\text { Multicentre RCT } \\
2 \text { arms } \\
\text { Quality score: B }\end{array}$ \\
\hline Participants & $\begin{array}{l}\mathrm{n}=143 \\
\text { Median age: } 70 \text { years } \\
\text { ECOG: } 7.7 \% \\
\text { Metastatic disease: } 69 \%\end{array}$ \\
\hline Interventions & $\begin{array}{l}\text { FLOT: oxaliplatin } 85 \mathrm{mg} / \mathrm{m}^{2}+\text { leucovorin } 200 \mathrm{mg} / \mathrm{m}^{2}+\text { docetaxel } 50 \mathrm{mg} / \mathrm{m}^{2} \text {, followed by } 5 \text {-FU } 2600 \mathrm{mg} / \\
\mathrm{m}^{2} \text { as a } 24 \text {-hour continuous infusion d } 1 \text {, repeated at } 2 \text { weeks } \\
\text { FLO: oxaliplatin } 85 \mathrm{mg} / \mathrm{m}^{2}+\text { leucovorin } 200 \mathrm{mg} / \mathrm{m}^{2} \text {, each as infusion followed by } 5 \text {-FU } 2600 \mathrm{mg} / \mathrm{m}^{2} \text { as a } \\
\text { 24-hour continuous infusion d } 1 \text {, repeated at } 2 \text { weeks until disease progression, or for a total of } 8 \text {, maxi- } \\
\text { mum } 12 \text { cycles }\end{array}$ \\
\hline
\end{tabular}


Al-Batran 2013 (Continued)

Outcomes
Tolerabiliby and feasibility, defined as per group differences in toxicity, serious adverse events, treatment duration, treatment withdrawal, discontinuation for toxicity or patient's request, proportion of patients with $a \geq 10$ point change of QoL global health status (EORTC QLQ C-30 questionnaires) at eight weeks, compared to baseline

Response rates

Overall survival

Progression-free survival FLO: $42.7 \%$ )

Notes

\section{Risk of bias}

\begin{tabular}{lll}
\hline Bias & Authors' judgement & Support for judgement \\
\hline $\begin{array}{l}\text { Random sequence genera- } \\
\text { tion (selection bias) }\end{array}$ & Low risk & Computer random generator \\
\hline $\begin{array}{l}\text { Allocation concealment } \\
\text { (selection bias) }\end{array}$ & Low risk & Centralised randomisation \\
\hline $\begin{array}{l}\text { Incomplete outcome data } \\
\text { (attrition bias) } \\
\text { efficacy }\end{array}$ & Low risk & $\begin{array}{l}\text { All 143 patients (FLOT, 72; FLO, 71) were eligible for the efficacy analysis on an } \\
\text { ITT basis }\end{array}$ \\
\hline $\begin{array}{l}\text { Incomplete outcome data } \\
\text { (attrition bias) } \\
\text { safety }\end{array}$ & Low risk & $\begin{array}{l}\text { Only 1 patient was excluded from the safety analysis because of consent with- } \\
\text { drawal before study treatment }\end{array}$ \\
\hline $\begin{array}{l}\text { Selective reporting (re- } \\
\text { porting bias) }\end{array}$ & Low risk & $\begin{array}{l}\text { ITT analysis } \\
\text { Expected endpoints (ORR, OS, PFS, safety by NCI-CTC etc) were included. QoL } \\
\text { also assessed }\end{array}$ \\
\hline $\begin{array}{l}\text { Other bias } \\
\text { Blinded review of CT/MRI- }\end{array}$ & High risk & \begin{tabular}{l} 
The treatment arms were well balanced for pretreatment characteristics \\
\hline
\end{tabular} \\
\hline
\end{tabular}

\section{Barone 1998}

\begin{tabular}{ll}
\hline Methods & $\begin{array}{l}\text { Multicentre RCT } \\
2 \text { arms } \\
\text { Quality score: } \mathrm{B}\end{array}$ \\
\hline Participants & $\mathrm{n}=72$ \\
& Median age: 58 years \\
& ECOG 2-3: $22 \%$
\end{tabular}


Barone 1998 (Continued)

$\begin{array}{ll}\text { Outcomes } & \text { Median survival } \\ & \text { 1and 2-year survival rates } \\ & \text { Response rates } \\ & \text { Symptom control } \\ & \text { Toxicity }\end{array}$

Notes No standard error can be assessed for TTP

\section{Risk of bias}

Bias Authors' judgement Support for judgement

Random sequence genera- Low risk tion (selection bias)

Patients were randomised by a sealed envelope method, using random permutated blocks unknown to the clinicians, to receive either the 5-FU/6S-LV (Study A) or EEP-L combination (Study B). Patients also were stratified into four groups based on a resected or nonresected primary tumor and an ECOG PS $\leq 1$ or $>1$.

\begin{tabular}{ll}
\hline $\begin{array}{l}\text { Allocation concealment } \\
\text { (selection bias) }\end{array}$ & Low risk
\end{tabular}

\begin{tabular}{ll}
\hline $\begin{array}{l}\text { Incomplete outcome data } \\
\text { (attrition bias) }\end{array}$ & Oow risk \\
efficacy & from the response analysis, but not from the tolerance and survival analysis. \\
& Two patients refused chemotherapy after randomisation and were excluded \\
completely from the analysis.
\end{tabular}

\begin{tabular}{ll}
\hline $\begin{array}{l}\text { Incomplete outcome data } \\
\text { (attrition bias) }\end{array}$ & Low risk \\
safety & $\begin{array}{l}\text { One patient refused further treatment after the first cycle and was excluded } \\
\text { from the response analysis, but not from the tolerance and survival analysis. }\end{array}$ \\
& $\begin{array}{l}\text { Two patients refused chemotherapy after randomisation and were excluded } \\
\text { completely from the analysis. }\end{array}$ \\
\hline
\end{tabular}

\begin{tabular}{lll}
\hline $\begin{array}{l}\text { Selective reporting (re- } \\
\text { porting bias) }\end{array}$ & Low risk & Report includes all expected outcomes \\
\hline Other bias & High risk & $\begin{array}{l}1 \text { participant who died after the second cycle of therapy has not been included } \\
\text { in the survival analysis = no ITT }\end{array}$ \\
\hline
\end{tabular}

Blinded review of CT/MRI- High risk High risk. Likely unblinded

scans?

\section{Boku 2009}

\begin{tabular}{ll}
\hline Methods & Multicentre RCT \\
& 3 arms \\
& Quality score: A \\
\hline
\end{tabular}

\begin{tabular}{ll}
\hline Participants & $\mathrm{n}=704$ \\
& Median age: 63.5 years
\end{tabular}

ECOG 2-3: $1.4 \%$

The study was conducted in Japan.

Interventions $5-\mathrm{FU}: 800 \mathrm{mg} / \mathrm{m}^{2} / \mathrm{d}, \mathrm{ci}, \mathrm{d} 1-5$, repeated at $4 \mathrm{w}$


Boku 2009 (Continued)

\author{
versus \\ IP: irinotecan $70 \mathrm{mg} / \mathrm{m}^{2} \mathrm{~d} 1+15+$ cisplatin $80 \mathrm{mg} / \mathrm{m}^{2} \mathrm{~d} 1$, repeated at $4 \mathrm{w}$ \\ versus \\ $\mathrm{S}-1: 40 \mathrm{mg} / \mathrm{m}^{2}$ twice a day, $\mathrm{d} 1-28$, repeated at $6 \mathrm{w}$
}

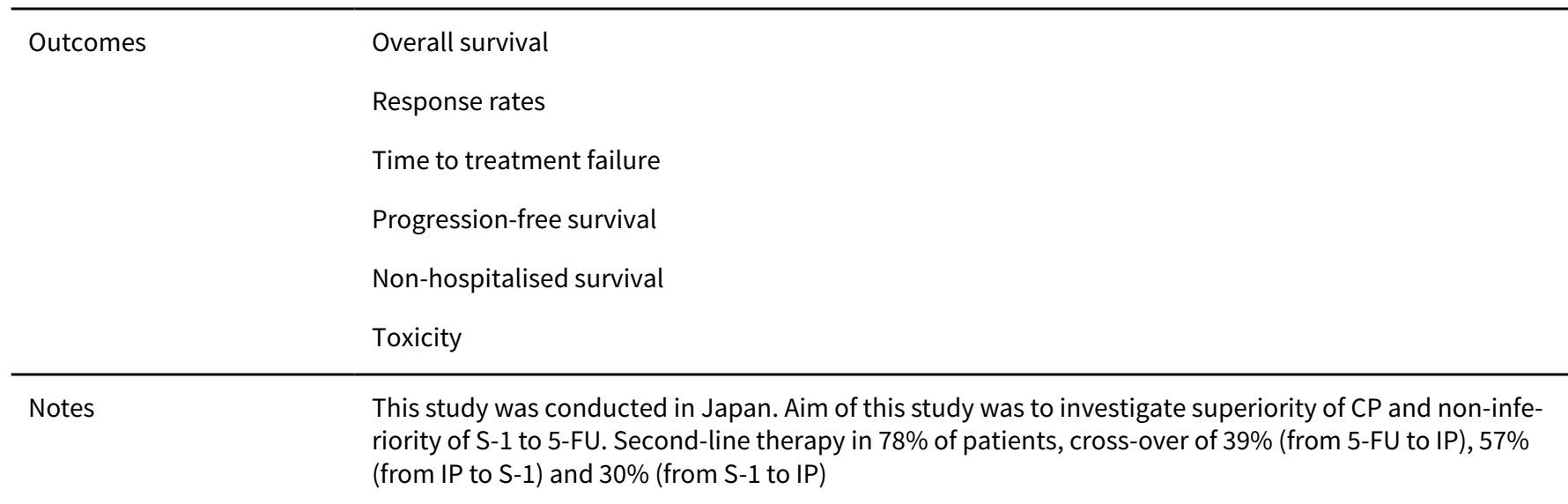

\title{
Risk of bias
}

\begin{tabular}{|c|c|c|}
\hline Bias & Authors' judgement & Support for judgement \\
\hline $\begin{array}{l}\text { Random sequence genera- } \\
\text { tion (selection bias) }\end{array}$ & Low risk & Minimisation method \\
\hline $\begin{array}{l}\text { Allocation concealment } \\
\text { (selection bias) }\end{array}$ & Low risk & Central allocation \\
\hline $\begin{array}{l}\text { Incomplete outcome data } \\
\text { (attrition bias) } \\
\text { efficacy }\end{array}$ & Low risk & Extremely low rate of withdrawals \\
\hline $\begin{array}{l}\text { Incomplete outcome data } \\
\text { (attrition bias) } \\
\text { safety }\end{array}$ & Low risk & Extremely low rate of withdrawals \\
\hline $\begin{array}{l}\text { Selective reporting (re- } \\
\text { porting bias) }\end{array}$ & Low risk & All expected endpoints reported \\
\hline Other bias & Low risk & None \\
\hline $\begin{array}{l}\text { Blinded review of } \mathrm{CT} / \mathrm{MRI}- \\
\text { scans? }\end{array}$ & Low risk & $\begin{array}{l}\text { Reviewed centrally at a trial group meeting; reviewers were unaware of treat- } \\
\text { ment allocations at this time }\end{array}$ \\
\hline
\end{tabular}

Bouche 2004

\begin{tabular}{ll}
\hline Methods & Multicentre RCT \\
& 3 arms \\
& Quality score: $\mathrm{D}$ \\
\hline Participants & $\mathrm{n}=134$ \\
& Median age: 65 years \\
\hline
\end{tabular}


Bouche 2004 (Continued)

Metastatic disease: $100 \%$

Interventions LV5FU2: LV $200 \mathrm{mg} / \mathrm{m}^{2}$; FU $400 \mathrm{mg} / \mathrm{m}^{2}$ bolus; FU $600 \mathrm{mg} / \mathrm{m}^{2} \mathrm{~d} 1+2$, repeated at $15 \mathrm{~d}$

LV5FU2-cisplatin: cisplatin $50 \mathrm{mg} / \mathrm{m}^{2} \mathrm{~d}$ 1+ 2+ LV5FU2, repeated at d 15

LV5FU2-irinotecan: irinotecan $180 \mathrm{mg} / \mathrm{m}^{2} \mathrm{~d} 1+\mathrm{LV} 5 \mathrm{FU} 2$, repeated at $\mathrm{d} 15$

\begin{tabular}{ll}
\hline Outcomes & Tumour response \\
& Median overall survival \\
1 year survival rates \\
Quality of life \\
Toxicity
\end{tabular}

\section{Risk of bias}

\begin{tabular}{|c|c|c|}
\hline Bias & Authors' judgement & Support for judgement \\
\hline $\begin{array}{l}\text { Random sequence genera- } \\
\text { tion (selection bias) }\end{array}$ & Unclear risk & Not stated \\
\hline $\begin{array}{l}\text { Allocation concealment } \\
\text { (selection bias) }\end{array}$ & Low risk & Central allocation \\
\hline $\begin{array}{l}\text { Incomplete outcome data } \\
\text { (attrition bias) } \\
\text { efficacy }\end{array}$ & Low risk & $\begin{array}{l}\text { One hundred thirty-six patients were enrolled between January } 1999 \text { and Oc- } \\
\text { tober } 2001 \text { in } 41 \text { centres in France. Two patients were considered ineligible; } \\
\text { one had a lymphoma and the other had no metastatic disease. No arm was } \\
\text { closed after the two interim analyses. Thus, the analyses were carried out on } \\
\text { an ITT basis with the remaining } 134 \text { enrolled patients. }\end{array}$ \\
\hline $\begin{array}{l}\text { Incomplete outcome data } \\
\text { (attrition bias) } \\
\text { safety }\end{array}$ & Low risk & $\begin{array}{l}\text { One hundred thirty-six patients were enrolled between January } 1999 \text { and Oc- } \\
\text { tober } 2001 \text { in } 41 \text { centres in France. Two patients were considered ineligible; } \\
\text { one had a lymphoma and the other had no metastatic disease. No arm was } \\
\text { closed after the two interim analyses. Thus, the analyses were carried out on } \\
\text { an ITT basis with the remaining } 134 \text { enrolled patients. }\end{array}$ \\
\hline $\begin{array}{l}\text { Selective reporting (re- } \\
\text { porting bias) }\end{array}$ & Low risk & Report includes all expected outcomes \\
\hline Other bias & Unclear risk & $\begin{array}{l}\text { Low QoL response }(41 \%(n=22) \text { and } 48 \%(n=29) \text { at the third evaluation in } \\
\text { arms } A \text { and C can bias longitudinal } Q \circ L \text { analysis. Prior chemotherapy and ra- } \\
\text { diotherapy were allowed under certain circumstances. }\end{array}$ \\
\hline $\begin{array}{l}\text { Blinded review of } \mathrm{CT} / \mathrm{MRI}- \\
\text { scans? }\end{array}$ & Unclear risk & $\begin{array}{l}\text { All objective tumor responses and cases of disease stabilisation were reviewed } \\
\text { retrospectively }\end{array}$ \\
\hline
\end{tabular}

Cascinu 2011

\begin{tabular}{ll}
\hline Methods & $\begin{array}{l}\text { Multicentre RCT } \\
2 \text { arms } \\
\text { Quality score: } \mathrm{A}\end{array}$ \\
\hline Participants & $\mathrm{n}=78$ \\
\hline
\end{tabular}


Cascinu 2011 (Continued)

Median age: 63 years

ECOG 2-3: $6.3 \%$

Metastatic disease: $89.7 \%$

Interventions

Arm A (LdCF): 5-FU ( $400 \mathrm{mg} / \mathrm{m}^{2}$ bolus $+600 \mathrm{mg} / \mathrm{m}^{2} 22 \mathrm{~h}$ continuous infusion $\left.\mathrm{d} 1-2\right)+$ cisplatin $(50 \mathrm{mg} /$ $\left.\mathrm{m}^{2} \mathrm{~d} 1\right)+$ pegylated liposomal doxorubicin $\left(20 \mathrm{mg} / \mathrm{m}^{2} \mathrm{~d} 1\right)$, repeated at $\mathrm{d} 14$

versus

Arm B (MCF) : 5 -FU $\left(400 \mathrm{mg} / \mathrm{m}^{2}\right.$ bolus $+600 \mathrm{mg} / \mathrm{m}^{2} 22 \mathrm{~h}$ continuous infusion d $\left.1-2\right)+$ cisplatin $\left(50 \mathrm{mg} / \mathrm{m}^{2}\right.$ $\mathrm{d} 1$, repeated at $\mathrm{d} 15)+$ mitomycin-C $\left(7 \mathrm{mg} / \mathrm{m}^{2}\right.$, repeated at $\left.\mathrm{d} 42\right)$

\begin{tabular}{|c|c|c|}
\hline \multirow[t]{4}{*}{ Outcomes } & \multicolumn{2}{|l|}{ Response rates } \\
\hline & \multicolumn{2}{|l|}{ Time to progression } \\
\hline & \multicolumn{2}{|l|}{ Overall survival } \\
\hline & \multicolumn{2}{|l|}{ Toxicity } \\
\hline Notes & \multicolumn{2}{|c|}{ second-line treatment in $38.5 \%$ and $25.6 \%$ of patients } \\
\hline \multicolumn{3}{|l|}{ Risk of bias } \\
\hline Bias & Authors' judgement & Support for judgement \\
\hline $\begin{array}{l}\text { Random sequence genera- } \\
\text { tion (selection bias) }\end{array}$ & Low risk & Random sequence generated by a computer programme \\
\hline $\begin{array}{l}\text { Allocation concealment } \\
\text { (selection bias) }\end{array}$ & Low risk & Central allocation \\
\hline $\begin{array}{l}\text { Incomplete outcome data } \\
\text { (attrition bias) } \\
\text { efficacy }\end{array}$ & Low risk & $\begin{array}{l}\text { Seventy-seven of } 78 \text { patients were assessable for response; one patient in arm } \\
\text { B was not assessable but was included in the ITT analysis and kept in the de- } \\
\text { nominator of the response rate. }\end{array}$ \\
\hline $\begin{array}{l}\text { Incomplete outcome data } \\
\text { (attrition bias) } \\
\text { safety }\end{array}$ & Low risk & $\begin{array}{l}\text { Seventy-seven of } 78 \text { patients were assessable for response; one patient in arm } \\
\text { B was not assessable but was included in the ITT analysis and kept in the de- } \\
\text { nominator of the response rate. }\end{array}$ \\
\hline $\begin{array}{l}\text { Selective reporting (re- } \\
\text { porting bias) }\end{array}$ & Low risk & Expected endpoints reported \\
\hline Other bias & Low risk & Patients characteristics resulted well balanced between the treatment groups \\
\hline $\begin{array}{l}\text { Blinded review of } \mathrm{CT} / \mathrm{MRI}- \\
\text { scans? }\end{array}$ & Low risk & $\begin{array}{l}\text { Tumour response was assessed by an independent radiologist as central re- } \\
\text { viewer. }\end{array}$ \\
\hline
\end{tabular}

Chen 2015

\begin{tabular}{ll}
\hline Methods & 60 AGC participants randomly divided into 2 groups by "random number table" - 30 vs 30 \\
\hline Participants & Age range 18-75 years \\
& Males:Females ratio was 18:12 in the DSOX group and 14:16 in the DCF group \\
\hline
\end{tabular}


Chen 2015 (Continued)

Interventions Docetaxel plus S1 plus oxaliplatin (DSOX) vs Docetaxel plus fluorouracil plus cisplatin (DCF)

\begin{tabular}{ll}
\hline Outcomes & OS \\
TTP \\
Tumour response \\
\hline
\end{tabular}

Notes

\section{Risk of bias}

\begin{tabular}{lll}
\hline Bias & Authors' judgement & Support for judgement \\
\hline $\begin{array}{l}\text { Random sequence genera- } \\
\text { tion (selection bias) }\end{array}$ & Low risk & "Random number table" \\
\hline $\begin{array}{l}\text { Allocation concealment } \\
\text { (selection bias) }\end{array}$ & Unclear risk & Not stated \\
\hline $\begin{array}{l}\text { Incomplete outcome data } \\
\text { (attrition bias) } \\
\text { efficacy }\end{array}$ & Unclear risk & 2 patients lost to follow-up, reasons not stated \\
\hline $\begin{array}{l}\text { Incomplete outcome data } \\
\text { (attrition bias) } \\
\text { safety }\end{array}$ & Unclear risk & 2 patients lost to follow-up, reasons not stated \\
\hline $\begin{array}{l}\text { Selective reporting (re- } \\
\text { porting bias) }\end{array}$ & Unclear risk & $\begin{array}{l}\text { Not clear how many were screened for eligibility and randomised. Only the } \\
\text { number of evaluable patients are provided. }\end{array}$ \\
\hline $\begin{array}{l}\text { Other bias } \\
\begin{array}{l}\text { Blinded review of CT/MRI- } \\
\text { scans? }\end{array}\end{array}$ & Unclear risk & Nothing to comment on \\
\hline
\end{tabular}

\section{Cocconi 1994}

\begin{tabular}{ll}
\hline Methods & Multicentre RCT \\
& 2 arms \\
& Quality score: A \\
\hline Participants & $\mathrm{n}=130$ \\
& Metastatic disease: $88 \%$ \\
& ECOG 2-3: $7 \%$ \\
\hline Interventions & FAM: 5 -FU $600 \mathrm{mg} / \mathrm{m}^{2} \mathrm{~d} 1,8,29,36 ;$ adriamycin $30 \mathrm{mg} / \mathrm{m}^{2} \mathrm{~d} 1,29$ and mitomycin $10 \mathrm{mg} / \mathrm{m}^{2} \mathrm{~d} 1, \mathrm{repeat}-$ \\
& ed at d 57 \\
& versus \\
& PELF: cisplatin $40 \mathrm{mg} / \mathrm{m}^{2} \mathrm{~d} 1,5 ;$ etoposide $30 \mathrm{mg} / \mathrm{m}^{2} \mathrm{~d} 1,5 ; \mathrm{Lv} 200 \mathrm{mg} / \mathrm{m}^{2} \mathrm{~d} 1-4+5-\mathrm{FU} \mathrm{300} \mathrm{mg} / \mathrm{m}^{2} \mathrm{~d}$ \\
& $1-4$, repeated at d 22 \\
\hline Outcomes & Median survival \\
& Response rates \\
& Time to progression \\
& Toxicity \\
\hline \hline
\end{tabular}


Cocconi 1994 (Continued)

Notes

\section{Risk of bias}

\begin{tabular}{lll}
\hline Bias & Authors' judgement & Support for judgement \\
\hline $\begin{array}{l}\text { Random sequence genera- } \\
\text { tion (selection bias) }\end{array}$ & Unclear risk & Not stated \\
\hline $\begin{array}{l}\text { Allocation concealment } \\
\text { (selection bias) }\end{array}$ & Low risk & Centralised \\
\hline $\begin{array}{l}\text { Incomplete outcome data } \\
\text { (attrition bias) } \\
\text { efficacy }\end{array}$ & Low risk & All eligible pts include din survival evaluation \\
\hline $\begin{array}{l}\text { Incomplete outcome data } \\
\text { (attrition bias) } \\
\text { safety }\end{array}$ & Low risk & All eligible pts included \\
\hline $\begin{array}{l}\text { Selective reporting (re- } \\
\text { porting bias) }\end{array}$ & Low risk & Report includes all expected outcomes \\
\hline $\begin{array}{l}\text { Other bias } \\
\text { Blinded review of CT/MRI- } \\
\text { scans? }\end{array}$ & Low risk & Baseline characteristics well-balanced \\
\hline
\end{tabular}

\section{Cocconi 2003}

\begin{tabular}{|c|c|}
\hline Methods & $\begin{array}{l}\text { Multicentre RCT } \\
2 \text { arms } \\
\text { Quality score: A }\end{array}$ \\
\hline Participants & $\begin{array}{l}n=200 \\
\text { Metastatic disease: } 85 \%\end{array}$ \\
\hline Interventions & $\begin{array}{l}\text { FAMTX: MTX } 1500 \mathrm{mg} / \mathrm{m}^{2} \mathrm{~d} 1 ; 5-\mathrm{FU} 1500 \mathrm{mg} / \mathrm{m}^{2} ; \mathrm{Lv} 7.5 \mathrm{mg} / \mathrm{m}^{2} \text { p.o. every } 6 \text { hrs d 1-3, adriamycin } 30 \mathrm{mg} / \\
\mathrm{m}^{2} \mathrm{~d} 15 \text {, repeated at d } 29 \\
\text { versus } \\
\text { PELF: cisplatin } 40 \mathrm{mg} / \mathrm{m}^{2} \mathrm{~d} 1,5 \text {, etoposide } 30 \mathrm{mg} / \mathrm{m}^{2} \mathrm{~d} 1,5 ; \mathrm{Lv} 100 \mathrm{mg} / \mathrm{m}^{2} \mathrm{~d} 1-4,5-\mathrm{FU} 300 \mathrm{mg} / \mathrm{m}^{2} \mathrm{~d} 1-4 \text {, } \\
\text { repeated at d } 22\end{array}$ \\
\hline Outcomes & $\begin{array}{l}\text { Median survival } \\
\text { Response rates } \\
\text { Time to progression } \\
\text { Toxicity }\end{array}$ \\
\hline Notes & - \\
\hline
\end{tabular}

\section{Risk of bias}

Bias Authors' judgement Support for judgement


Cocconi 2003 (Continued)

Random sequence genera- Unclear risk $\quad$ Not stated
tion (selection bias)

\begin{tabular}{ll}
\hline $\begin{array}{l}\text { Allocation concealment } \\
\text { (selection bias) }\end{array}$ & Low risk
\end{tabular}$\quad \begin{aligned} & \text { Eligible patients were centrally randomised by the operational office of GOIRC } \\
& \text { (Parma, Italy) }\end{aligned}$

\section{Incomplete outcome data Unclear risk} (attrition bias)

efficacy

Thirteen of the 200 randomised patients (six in the PELF and seven in the FAMTX group) did not begin the assigned chemotherapy and were not evaluated for toxicity. Reasons were not provided, and it is possible that this proportion could have an impact on analysis.

The response of 15 patients in the PELF group and 14 in the FAMTX group were unevaluable or not evaluated for the following reasons: the treatment was never started (five versus five), protocol violations (zero versus one), insufficient treatment due to early death (five versus three), refusal (four versus two), early discontinuation due to toxicity (zero versus three) or severe medical events (one versus zero)

$\begin{array}{ll}\begin{array}{l}\text { Incomplete outcome data } \\ \text { (attrition bias) }\end{array} & \text { Unclear risk } \\ \text { safety } & \begin{array}{l}\text { Thirteen of the } 200 \text { randomised patients (six in the PELF and seven in the } \\ \text { FAMT group) did not begin the assigned chemotherapy and were not evaluat- } \\ \text { ed for toxicity. Reasons were not provided, and it is possible that this propor- } \\ \text { tion could have an impact on analysis. }\end{array}\end{array}$

\begin{tabular}{lll}
\hline $\begin{array}{l}\text { Selective reporting (re- } \\
\text { porting bias) }\end{array}$ & Unclear risk & $\begin{array}{l}\text { Toxicity was evaluated in all of the patients receiving at least one dose of } \\
\text { chemotherapy whether they were eligible or not }\end{array}$ \\
\hline Other bias & Unclear risk & N/A \\
\hline $\begin{array}{l}\text { Blinded review of CT/MRI- } \\
\text { scans? }\end{array}$ & Unclear risk & $\begin{array}{l}\text { Response was assessed by the clinical investigators at each participating } \\
\text { unit, and centrally reviewed in the case of CR, PR, no change for more than } 6 \\
\text { months, or in the case of patients who underwent gastric resection at the end } \\
\text { of the chemotherapy programme. }\end{array}$ \\
\hline
\end{tabular}

Colucci 1995

\begin{tabular}{ll}
\hline Methods & $\begin{array}{l}\text { Multicentre RCT } \\
2 \text { arms } \\
\text { Quality score: } \mathrm{D}\end{array}$ \\
\hline Participants & $\mathrm{n}=71$ \\
& Median age: 60 years \\
\hline Interventions & $\begin{array}{l}5-\mathrm{FU} / \mathrm{Lv} \text { : Lv } 200 \mathrm{mg} / \mathrm{m}^{2} ; 5-\mathrm{FU} 375 \mathrm{mg} / \mathrm{m}^{2} \mathrm{~d} 1-5 \text {, repeated at d } 22 \\
\text { versus } \\
\text { 5-FU/Lv+E: Lv } 200 \mathrm{mg} / \mathrm{m}^{2} ; 5-\mathrm{FU} 375 \mathrm{mg} / \mathrm{m}^{2} \mathrm{~d} 1-5 \text {, repeated at d 22; epirubicin } 60 \mathrm{mg} / \mathrm{m}^{2} \mathrm{~d} 1, \text { repeated } \\
\text { at d 22 }\end{array}$ \\
\hline Outcomes & $\begin{array}{l}\text { Median survival } \\
\text { Response rates } \\
\text { Secondary resectability }\end{array}$ \\
\hline Notes & -
\end{tabular}

\section{Risk of bias}

Bias Authors' judgement Support for judgement

Chemotherapy for advanced gastric cancer (Review) 
Colucci 1995 (Continued)

\begin{tabular}{|c|c|c|}
\hline $\begin{array}{l}\text { Random sequence genera- } \\
\text { tion (selection bias) }\end{array}$ & Unclear risk & Not stated \\
\hline $\begin{array}{l}\text { Allocation concealment } \\
\text { (selection bias) }\end{array}$ & Unclear risk & Not stated \\
\hline $\begin{array}{l}\text { Incomplete outcome data } \\
\text { (attrition bias) } \\
\text { efficacy }\end{array}$ & Low risk & Reasons for exclusion clearly documented and valid \\
\hline $\begin{array}{l}\text { Incomplete outcome data } \\
\text { (attrition bias) } \\
\text { safety }\end{array}$ & Low risk & Reasons for exclusion clearly documented and valid \\
\hline $\begin{array}{l}\text { Selective reporting (re- } \\
\text { porting bias) }\end{array}$ & Low risk & Report includes all expected outcomes \\
\hline Other bias & Unclear risk & $\begin{array}{l}\text { No ITT, missing information about type and schedule of follow-up between } \\
\text { groups }\end{array}$ \\
\hline $\begin{array}{l}\text { Blinded review of CT/MRI- } \\
\text { scans? }\end{array}$ & High risk & Not stated, likely unblinded/by investigators \\
\hline
\end{tabular}

Cullinan 1985

\begin{tabular}{ll}
\hline Methods & $\begin{array}{l}\text { Multicentre RCT } \\
\text { arms } \\
\text { Quality score: } \mathrm{D}\end{array}$ \\
\hline Participants & $\mathrm{n}=151$ \\
& Metastatic disease: $62 \%$ \\
\hline Interventions & 5-FU included 5-FU $500 \mathrm{mg} / \mathrm{m}^{2}$ on days $1-5$, repeated at 4 weeks, 8 weeks and every 5 weeks thereafter \\
& $\begin{array}{l}\text { FAM included } 5-\mathrm{FU} \text { at } 600 \mathrm{mg} / \mathrm{m}^{2} \text { on days } 1,8,29 \text { and } 36 \text {; doxorubicin } 30 \mathrm{mg} / \mathrm{m}^{2} \text { on days } 1 \text { and } 29, \text { and } \\
\text { mitomycin } 10 \mathrm{mg} / \mathrm{m}^{2} \text { on day } 1\end{array}$ \\
& FA included 5-FU $400 \mathrm{mg} / \mathrm{m}^{2}$ with 40 mg of doxorubicin on day 1 every 4 weeks \\
\hline Outcomes & Overall survival, response rates, toxicity (not classified according to WHO or CTC) \\
\hline Notes & $\begin{array}{l}\text { Study included participants with pancreatic and gastric cancer. Patients were stratified within institu- } \\
\text { tion according to the primary tumour. Separate results were given for participants with gastric cancer. } \\
\text { Results only for participants with gastric cancer are included in this analysis. }\end{array}$
\end{tabular}

\section{Risk of bias}

\begin{tabular}{lll}
\hline Bias & Authors' judgement & Support for judgement \\
\hline $\begin{array}{l}\text { Random sequence genera- } \\
\text { tion (selection bias) }\end{array}$ & Unclear risk & Not stated \\
\hline $\begin{array}{l}\text { Allocation concealment } \\
\text { (selection bias) }\end{array}$ & Unclear risk & Not stated \\
\hline
\end{tabular}


Cullinan 1985 (Continued)

Incomplete outcome data Low risk
(attrition bias)

efficacy

Incomplete outcome data Low risk ITT analysis
(attrition bias)
safety

\begin{tabular}{lll}
\hline $\begin{array}{l}\text { Selective reporting (re- } \\
\text { porting bias) }\end{array}$ & Low risk & Report includes all expected outcomes \\
\hline Other bias & High risk & 5-FU/doxorubicin(FA) and FAM arm will be combined in the analysis \\
\hline $\begin{array}{l}\text { Blinded review of CT/MRI- } \\
\text { scans? }\end{array}$ & High risk & High risk - likely unblinded \\
\hline
\end{tabular}

Cullinan 1994

\begin{tabular}{|c|c|}
\hline Methods & $\begin{array}{l}\text { Multicentre RCT } \\
4 \text { arms } \\
\text { Quality score: D }\end{array}$ \\
\hline Participants & $\begin{array}{l}\mathrm{n}=252 \\
\text { Median age: } 62 \text { years } \\
\text { ECOG 2-3: } 30 \%\end{array}$ \\
\hline Interventions & 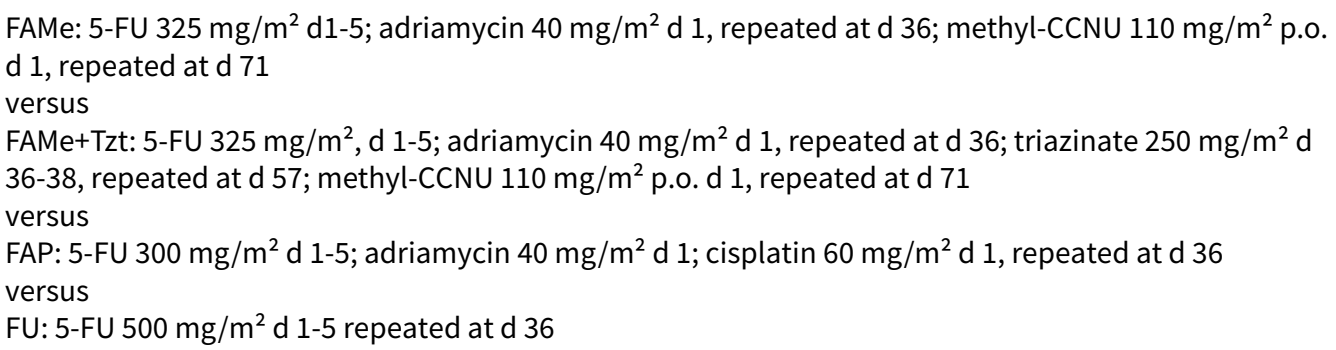 \\
\hline
\end{tabular}

\begin{tabular}{ll}
\hline Outcomes & $\begin{array}{l}\text { Median survival } \\
\text { Toxicity } \\
\text { Effects on performance status and weight gain }\end{array}$ \\
\hline Notes & $\begin{array}{l}\text { Three combination chemotherapy arms combined in the analysis. The single-agent 5-FU arm was } \\
\text { opened after } 56 \text { participants were randomised. FAMe and FAP were closed after a planned interim } \\
\text { analysis because of slightly higher death rate. }\end{array}$
\end{tabular}

\section{Risk of bias}

\begin{tabular}{lll}
\hline Bias & Authors' judgement & Support for judgement \\
\hline $\begin{array}{l}\text { Random sequence genera- } \\
\text { tion (selection bias) }\end{array}$ & Unclear risk & Not stated \\
\hline $\begin{array}{l}\text { Allocation concealment } \\
\text { (selection bias) }\end{array}$ & Unclear risk & Not stated \\
\hline $\begin{array}{l}\text { Incomplete outcome data } \\
\text { (attrition bias) }\end{array}$ & Low risk & $\begin{array}{l}\text { Low attrition rate with long follow-up (only 7 of 252 patients remain alive at } \\
\text { the time of analysis) }\end{array}$ \\
\hline
\end{tabular}


Cullinan 1994 (Continued)

efficacy

Incomplete outcome data Low risk $\quad \mathrm{n}=69+51+53+79$
(attrition bias)
safety

\begin{tabular}{lll}
\hline $\begin{array}{l}\text { Selective reporting (re- } \\
\text { porting bias) }\end{array}$ & Unclear risk & $\begin{array}{l}\text { Missing response rates } \\
\text { only a small minority of patients had measurable disease so regression rate } \\
\text { was not used as a study endpoint }\end{array}$ \\
\hline Other bias & High risk & $\begin{array}{l}\text { Missing information to type and follow-up in the treatment groups, combina- } \\
\text { tion of } 3 \text { combination treatment arms in the analysis, } 2 \text { arms were closed after } \\
\text { a planned interim analysis }\end{array}$
\end{tabular}

Blinded review of CT/MRI- Unclear risk $\quad$ Not stated
scans?

\begin{tabular}{ll} 
Dank 2008 & \\
\hline Methods & $\begin{array}{l}\text { Multicentre RCT } \\
2 \text { arms } \\
\text { Quality score: D }\end{array}$ \\
\hline Participants & $\begin{array}{l}\mathrm{n}=337 \\
\text { Median age: } 59 \text { years } \\
\text { Metastatic disease: } 95.5 \%\end{array}$ \\
\hline Interventions & $\begin{array}{l}\text { IF: irinotecan } 80 \mathrm{mg} / \mathrm{m}^{2} \text { i.v.; FA } 500 \mathrm{mg} / \mathrm{m}^{2} \text { i.v.; } 5 \text {-FU } 2000 \mathrm{mg} / \mathrm{m}^{2} \text { as a 22-hour continuous infusion on d } \\
1 \text { weekly for } 6 \text { weeks, followed by } 1 \mathrm{week} \text { rest } \\
\text { versus } \\
\text { CF: cisplatin } 100 \mathrm{mg} / \mathrm{m}^{2} \text { i.v. } \mathrm{d} 1 ; 5 \text {-FU } 1000 \mathrm{mg} / \mathrm{m}^{2} / \mathrm{day} \text { as } 24 \text {-hour continuous infusion d } 1-5 \text {, repeated } \\
\text { at } 4 \text { weeks }\end{array}$ \\
\hline Outcomes & $\begin{array}{l}\text { Hazard ratios and median survival for overall survival and time to progression, tumour response, toxic- } \\
\text { ity, QoL }\end{array}$ \\
\hline Notes & $\begin{array}{l}\text { The trial was planned to establish superiority or non-inferiority of IF over CF. Patients have finished pri- } \\
\text { or radiotherapy and surgery } 6 \text { and } 3 \text { weeks, respectively, before randomisation. Previous adjuvant or } \\
\text { neo-adjuvant chemotherapy was allowed if completed } 12 \text { months before first relapse. }\end{array}$
\end{tabular}

\section{Risk of bias}

\begin{tabular}{lll}
\hline Bias & Authors' judgement & Support for judgement \\
\hline $\begin{array}{l}\text { Random sequence genera- } \\
\text { tion (selection bias) }\end{array}$ & Low risk & Biased coin method \\
\hline $\begin{array}{l}\text { Allocation concealment } \\
\text { (selection bias) }\end{array}$ & Unclear risk & Not stated \\
\hline $\begin{array}{l}\text { Incomplete outcome data } \\
\text { (attrition bias) } \\
\text { efficacy }\end{array}$ & Low risk & Analysis of the full-analysis population of treated patients \\
\hline $\begin{array}{l}\text { Incomplete outcome data } \\
\text { (attrition bias) }\end{array}$ & Low risk & Analysis of the full-analysis population of treated patients \\
\hline
\end{tabular}


Dank 2008 (Continued)

safety

\begin{tabular}{ll}
\hline $\begin{array}{l}\text { Selective reporting (re- } \\
\text { porting bias) }\end{array}$ & Low risk
\end{tabular}

porting bias)

\begin{tabular}{lll}
\hline Other bias & High risk & $\begin{array}{l}\text { Rate of non-evaluable response was imbalanced between arms (IF 9.4\% ver- } \\
\text { sus CF } 16.8 \%), \text { largely due to the higher rate of early discontinuations for toxi- } \\
\text { city in the CF arm. This difference may result from closer follow-up in IF. Prior } \\
\text { radiotherapy and chemotherapy were allowed under certain circumstances. }\end{array}$ \\
\hline $\begin{array}{l}\text { Blinded review of CT/MRI- } \\
\text { scans? }\end{array}$ & Low risk & $\begin{array}{l}\text { An External Radiological Review Committee (ERRC), blinded to treatment arm, } \\
\text { reviewed all disease assessments and determined evaluability for response } \\
\text { and date of progression. }\end{array}$
\end{tabular}

\section{De Lisi 1986}

\begin{tabular}{ll}
\hline Methods & $\begin{array}{l}\text { Multicentre RCT } \\
2 \text { arms } \\
\text { Quality score: } \mathrm{B}\end{array}$ \\
\hline Participants & $\begin{array}{l}\mathrm{n}=85 \\
\text { Median age: } 64 \text { years }\end{array}$ \\
\hline Interventions & Arm A: 5 -FU $13.5 \mathrm{mg} / \mathrm{kg} /$ day for 5 days, every 5 weeks \\
& $\begin{array}{l}\text { Arm B: carmustine } 50 \mathrm{mg} / \mathrm{m}^{2} \text { on days } 1 \text { and } 29 ; \text { doxorubicine } 25 \mathrm{mg} / \mathrm{m}^{2} \text { on days } 1,8,15,29 \text { and } 36 \text { and } \\
\text { mitomycin } 10 \mathrm{mg} / \mathrm{m}^{2} \text { on day } 15\end{array}$ \\
\hline Outcomes & Overall survival, response rate, haematological toxicity \\
\hline Notes & -
\end{tabular}

\section{Risk of bias}

\begin{tabular}{lll}
\hline Bias & Authors' judgement & Support for judgement \\
\hline $\begin{array}{l}\text { Random sequence genera- } \\
\text { tion (selection bias) }\end{array}$ & Unclear risk & Not stated \\
\hline $\begin{array}{l}\text { Allocation concealment } \\
\text { (selection bias) }\end{array}$ & Low risk & Centralised \\
\hline $\begin{array}{l}\text { Incomplete outcome data } \\
\text { (attrition bias) } \\
\text { efficacy }\end{array}$ & Low risk & ITT \\
\hline $\begin{array}{l}\text { Incomplete outcome data } \\
\text { (attrition bias) } \\
\text { safety }\end{array}$ & Low risk & $\mathrm{n}=82$ \\
\hline $\begin{array}{l}\text { Selective reporting (re- } \\
\text { porting bias) }\end{array}$ & Low risk & $\begin{array}{l}\text { Only haematological toxicity given (in table format - but nonhaematologic side } \\
\text { effects were also mentioned) }\end{array}$ \\
\hline \begin{tabular}{l} 
Other bias \\
\hline
\end{tabular} & Unclear risk & N/A \\
\hline
\end{tabular}


De Lisi 1986 (Continued)

Blinded review of $\mathrm{CT} / \mathrm{MRI}-\quad$ High risk High risk
scans?

Dong 2014

\begin{tabular}{ll}
\hline Methods & Single-centre, randomised \\
\hline Participants & Total of 60 patients: 30 each received TIROX or DCF \\
& "Included patients: (i) gastric cancer diagnosed by pathology; (ii) patients not currently receiving \\
& chemotherapy (i.e. chemotherapy-naïve) or those who had stopped chemotherapy $\geq 1$ month prior to \\
enrolment" & Enrolled "consecutive patients with recurrent or metastatic gastric cancer" \\
& 21 and 20 pts in the TIROX and DCR group are 60 years or older
\end{tabular}

Interventions
"In the TIROX group, patients received $40 \mathrm{mg} / \mathrm{m} 2 \mathrm{~S}-1$ orally twice daily after a meal on days $1-14 ; 150$
fused over $2 \mathrm{~h}$ on the first day. This treatment regimen was repeated every 21 days and a 21 -day treat-
ment period was defined as one chemotherapy cycle. In the DCF group, patients received $75 \mathrm{mg} / \mathrm{m} 2$
docetaxel i.v. and $75 \mathrm{mg} / \mathrm{m} 2$ cisplatin i.v. on the first day; $750 \mathrm{mg} / \mathrm{m} 25$-FU via continuous i.v. infusion
once a day from the first day to the fifth day."

\begin{tabular}{ll}
\hline Outcomes & $\begin{array}{l}\text { Response rates } \\
\text { Safety }\end{array}$ \\
\hline Notes & $\begin{array}{l}\text { No registration number found but "All of the study methods were approved by the Ethics Committee of } \\
\text { the First Affiliated Hospital of Zhengzhou University (no. 2010-003854)" }\end{array}$ \\
\hline
\end{tabular}

\section{Risk of bias}

\begin{tabular}{lll}
\hline Bias & Authors' judgement & Support for judgement \\
\hline $\begin{array}{l}\text { Random sequence genera- } \\
\text { tion (selection bias) }\end{array}$ & Low risk & $\begin{array}{l}\text { Low } \\
\text { "computer-generated randomization schedule" }\end{array}$ \\
\hline $\begin{array}{l}\text { Allocation concealment } \\
\text { (selection bias) }\end{array}$ & Unclear risk & None stated \\
\hline $\begin{array}{l}\text { Incomplete outcome data } \\
\text { (attrition bias) } \\
\text { efficacy }\end{array}$ & Unclear risk & $\begin{array}{l}\text { Number screened for eligibility and excluded not provided. Only number of } \\
\text { evaluable patients stated. }\end{array}$ \\
\hline $\begin{array}{l}\text { Incomplete outcome data } \\
\text { (attrition bias) } \\
\text { safety }\end{array}$ & Unclear risk & $\begin{array}{l}\text { Number screened for eligibility and excluded not provided. Only number of } \\
\text { evaluable patients stated. }\end{array}$ \\
\hline $\begin{array}{l}\text { Selective reporting (re- } \\
\text { porting bias) }\end{array}$ & High risk & $\begin{array}{l}\text { Only response rates and certain safety data were presented. "The rates of } \\
\text { long-term progression-free survival and overall survival were not measured". } \\
\text { Not clear if any of these endpoints were prespecified. }\end{array}$ \\
\hline $\begin{array}{l}\text { Other bias } \\
\begin{array}{l}\text { Blinded review of CT/MRI- } \\
\text { scans? }\end{array}\end{array}$ & Unclear risk & N/A \\
\hline & Not stated \\
\hline
\end{tabular}


GITSG 1988

\begin{tabular}{ll}
\hline Methods & $\begin{array}{l}\text { Multicentre RCT } \\
3 \text { arms } \\
\text { Quality score: } \mathrm{D}\end{array}$ \\
\hline Participants & $\mathrm{n}=249$ \\
& Median age: 61 \\
& ECOG 2-3: $34 \%$
\end{tabular}

\section{Risk of bias}

\begin{tabular}{lll}
\hline Bias & Authors' judgement & Support for judgement \\
\hline $\begin{array}{l}\text { Random sequence genera- } \\
\text { tion (selection bias) }\end{array}$ & Unclear risk & Not stated \\
\hline $\begin{array}{l}\text { Allocation concealment } \\
\text { (selection bias) }\end{array}$ & Unclear risk & Not stated \\
\hline $\begin{array}{l}\text { Incomplete outcome data } \\
\text { (attrition bias) } \\
\text { efficacy }\end{array}$ & Unclear risk & Not clear how many screened for eligibility and excluded \\
\hline $\begin{array}{l}\text { Incomplete outcome data } \\
\text { (attrition bias) } \\
\text { safety }\end{array}$ & Unclear risk & Not clear how many screened for eligibility and excluded \\
\hline $\begin{array}{l}\text { Selective reporting (re- } \\
\text { porting bias) }\end{array}$ & Unclear risk & Toxicity not classified according to WHO or NCl \\
\hline $\begin{array}{l}\text { Other bias } \\
\text { Blinded review of CT/MRI- } \\
\text { scans? }\end{array}$ & Unclear risk & Not stated \\
\hline
\end{tabular}

Hironaka 2016

\begin{tabular}{ll}
\hline Methods & Multicentre, randomised, open-label, 3-armed, phase 2 trial \\
\hline Participants & Median (IQR) age in the 3 arms was 65 (60-70), 65 (58-71), 65 (59-69) years \\
\hline Interventions & $\begin{array}{l}\text { S-1 plus leucovorin (S-1 } 40-60 \mathrm{mg} \text { orally plus oral leucovorin } 25 \mathrm{mg} \text { twice a day for } 1 \text { week, every } 2 \\
\text { weeks), S-1 plus leucovorin and oxaliplatin (S-1 plus leucovorin and intravenous oxaliplatin } 85 \mathrm{mg} / \mathrm{m}^{2}\end{array}$
\end{tabular}


Hironaka 2016 (Continued)

on day 1 , every 2 weeks), or S-1 plus cisplatin (S-1 40-60 mg orally twice a day for 3 weeks, plus intravenous cisplatin $60 \mathrm{mg} / \mathrm{m}^{2}$ on day 8 , every 5 weeks)

49 patients were randomly assigned to the S-1 plus leucovorin group, 47 to the S-1 plus leucovorin and oxaliplatin group, and 49 to the S-1 plus cisplatin group

Outcomes

Primary endpoint was overall response as assessed by an independent review committee, defined as a confirmed complete response or partial response. Secondary endpoints were overall survival, progression-free survival, time to treatment failure, disease control, duration of response, and toxic effects

\section{Notes}

\section{Risk of bias}

\begin{tabular}{|c|c|c|}
\hline Bias & Authors' judgement & Support for judgement \\
\hline $\begin{array}{l}\text { Random sequence genera- } \\
\text { tion (selection bias) }\end{array}$ & Low risk & $\begin{array}{l}\text { Randomisation was done centrally with the minimisation method using per- } \\
\text { formance status ( } 0 \text { vs } 1 \text { ) and tumour stage (stage IV vs recurrent) as stratifica- } \\
\text { tion factors }\end{array}$ \\
\hline $\begin{array}{l}\text { Allocation concealment } \\
\text { (selection bias) }\end{array}$ & Low risk & $\begin{array}{l}\text { Randomisation sequence was generated by EPS Corporation (Tokyo, Japan) } \\
\text { independently from the study sponsor }\end{array}$ \\
\hline $\begin{array}{l}\text { Incomplete outcome data } \\
\text { (attrition bias) } \\
\text { efficacy }\end{array}$ & Low risk & $\begin{array}{l}\text { After randomisation, one patient did not receive treatment because of aspi- } \\
\text { ration pneumonia. } † \text { Two patients who were judged to have no measurable le- } \\
\text { sions by the independent review committee after enrolment were excluded } \\
\text { from the efficacy analyses }\end{array}$ \\
\hline $\begin{array}{l}\text { Incomplete outcome data } \\
\text { (attrition bias) } \\
\text { safety }\end{array}$ & Low risk & $\begin{array}{l}\text { After randomisation, one patient did not receive treatment because of aspi- } \\
\text { ration pneumonia. †Two patients who were judged to have no measurable le- } \\
\text { sions by the independent review committee after enrolment were excluded } \\
\text { from the efficacy analyses }\end{array}$ \\
\hline $\begin{array}{l}\text { Selective reporting (re- } \\
\text { porting bias) }\end{array}$ & Low risk & All prespecified outcomes were reported \\
\hline Other bias & Unclear risk & $\mathrm{N} / \mathrm{A}$ \\
\hline $\begin{array}{l}\text { Blinded review of } \mathrm{CT} / \mathrm{MRI}- \\
\text { scans? }\end{array}$ & Low risk & $\begin{array}{l}\text { independent data monitoring committee (but not stated review committee } \\
\text { was blinded) }\end{array}$ \\
\hline
\end{tabular}

Huang 2013

\begin{tabular}{|c|c|}
\hline Methods & $\begin{array}{l}\text { Multicentre RCT } \\
2 \text { arms } \\
\text { Quality score: D }\end{array}$ \\
\hline Participants & $\begin{array}{l}\mathrm{n}=240 \\
\text { Median age: } 55 \text { years } \\
\text { Metastatic disease: } 93 \%\end{array}$ \\
\hline Interventions & $\begin{array}{l}\text { Paclitaxel+S-1: Paclitaxel } 60 \mathrm{mg} / \mathrm{m}^{2} \mathrm{~d} 1,8,15, \mathrm{~S}-1 \text { depending on body surface area (BSA }<1.25 \mathrm{~m}^{2}: 80 \\
\mathrm{mg} / \mathrm{d} ; \mathrm{BSA} 1.25 \text { to }<1.5 \mathrm{~m}^{2}: 100 \mathrm{mg} / \mathrm{d} ; \mathrm{BSA}>1.5 \mathrm{~m}^{2}, 120 \mathrm{mg} / \mathrm{d} \text { twice daily) twice daily } \mathrm{d} 1-14 \text {, repeated at } \\
\mathrm{d} 29 \\
\text { versus }\end{array}$ \\
\hline
\end{tabular}


Huang 2013 (Continued)

Paclitaxel+5-FU: Paclitaxel $60 \mathrm{mg} / \mathrm{m}^{2} \mathrm{~d}$ 1,8,15, 5-FU 500mg/m² d 1-5, leucovorin $20 \mathrm{mg} / \mathrm{m}^{2} \mathrm{~d} 1-5$ repeated at $d 29$

\begin{tabular}{|c|c|c|}
\hline \multirow[t]{4}{*}{ Outcomes } & \multicolumn{2}{|l|}{ Response rates } \\
\hline & \multicolumn{2}{|c|}{ Progression-free survival } \\
\hline & \multicolumn{2}{|c|}{ Time to treatment failure } \\
\hline & \multicolumn{2}{|l|}{ Toxicity } \\
\hline Notes & \multicolumn{2}{|c|}{$6 \%$ of patients had no adenocarconoma } \\
\hline \multicolumn{3}{|l|}{ Risk of bias } \\
\hline Bias & Authors' judgement & Support for judgement \\
\hline $\begin{array}{l}\text { Random sequence genera- } \\
\text { tion (selection bias) }\end{array}$ & Unclear risk & Not mentioned \\
\hline $\begin{array}{l}\text { Allocation concealment } \\
\text { (selection bias) }\end{array}$ & Low risk & Central randomisation \\
\hline $\begin{array}{l}\text { Incomplete outcome data } \\
\text { (attrition bias) } \\
\text { efficacy }\end{array}$ & Low risk & $\begin{array}{l}229 / 240 \text { included in full analysis set: One patient was not eligible for the cur- } \\
\text { rent analysis due to a lack of measurable lesions, } 11 \text { patients withdrew in- } \\
\text { formed consent }\end{array}$ \\
\hline $\begin{array}{l}\text { Incomplete outcome data } \\
\text { (attrition bias) } \\
\text { safety }\end{array}$ & Low risk & $\begin{array}{l}229 / 240 \text { included in full analysis set: One patient was not eligible for the cur- } \\
\text { rent analysis due to a lack of measurable lesions, } 11 \text { patients withdrew in- } \\
\text { formed consent }\end{array}$ \\
\hline $\begin{array}{l}\text { Selective reporting (re- } \\
\text { porting bias) }\end{array}$ & Low risk & All expected outcomes except OS analysed \\
\hline Other bias & Unclear risk & OS not analysed \\
\hline $\begin{array}{l}\text { Blinded review of } \mathrm{CT} / \mathrm{MRI}- \\
\text { scans? }\end{array}$ & Unclear risk & Not stated \\
\hline
\end{tabular}

Kang 2009

\begin{tabular}{ll}
\hline Methods & $\begin{array}{l}\text { Multicentre RCT } \\
2 \text { arms } \\
\text { Quality score: } \mathrm{D}\end{array}$ \\
\hline Participants & $\mathrm{n}=316$ \\
& Median age: 56 years \\
\hline Interventions & $\begin{array}{l}\text { XP: capecitabine } 1000 \mathrm{mg} / \mathrm{m}^{2} \text { twice daily d } 1-14 \text {; cisplatin } 80 \mathrm{mg} / \mathrm{m}^{2} \mathrm{~d} 1 \text { every } 3 \text { weeks } \\
\text { versus } \\
\text { FP: } 5 \text {-FU } 800 \mathrm{mg} / \mathrm{m}^{2} / \mathrm{d} \text { as continuous infusion } \mathrm{d} 1-5 \text { every } 3 \text { weeks; cisplatin } 80 \mathrm{mg} / \mathrm{m}^{2} \mathrm{~d} 1 \text { every } 3 \\
\text { weeks }\end{array}$ \\
\hline Outcomes & $\begin{array}{l}\text { Progression-free-survival, overall survival } \\
\text { Tumour response } \\
\text { Toxicity }\end{array}$ \\
\hline
\end{tabular}


Kang 2009 (Continued)

Notes

\section{Risk of bias}

\begin{tabular}{|c|c|c|}
\hline Bias & Authors' judgement & Support for judgement \\
\hline $\begin{array}{l}\text { Random sequence genera- } \\
\text { tion (selection bias) }\end{array}$ & Low risk & Random permuted block design \\
\hline $\begin{array}{l}\text { Allocation concealment } \\
\text { (selection bias) }\end{array}$ & Unclear risk & Not stated \\
\hline $\begin{array}{l}\text { Incomplete outcome data } \\
\text { (attrition bias) } \\
\text { efficacy }\end{array}$ & Low risk & Analysis of ITT population $(n=316)$ \\
\hline $\begin{array}{l}\text { Incomplete outcome data } \\
\text { (attrition bias) } \\
\text { safety }\end{array}$ & Low risk & Analysis of all treated patients $(n=311)$ \\
\hline $\begin{array}{l}\text { Selective reporting (re- } \\
\text { porting bias) }\end{array}$ & Low risk & Report includes all expected outcomes \\
\hline Other bias & Low risk & $\begin{array}{l}\text { Patients followed up for OS till end of study regardless of withdrawal + ITT vs } \\
\text { PP, and unadjusted vs adjusted analyses performed }\end{array}$ \\
\hline $\begin{array}{l}\text { Blinded review of } \mathrm{CT} / \mathrm{MRI}- \\
\text { scans? }\end{array}$ & Low risk & $\begin{array}{l}\text { An independent review committee (IRC) reviewed patients' radiological im- } \\
\text { ages and assessed tumour responses without knowledge of treatment assign- } \\
\text { ment }\end{array}$ \\
\hline
\end{tabular}

Kikuchi 1990

\begin{tabular}{ll}
\hline Methods & Multicentre RCT \\
& 2 arms \\
& Quality score: B
\end{tabular}

\begin{tabular}{ll}
\hline Participants & $n=77$ \\
& Metastatic disease: $46 \%$ \\
& ECOG 2-3: $88 \%$
\end{tabular}

Interventions FA: 5-FU 270 to $300 \mathrm{mg} / \mathrm{m}^{2} \mathrm{Cl} \mathrm{d} \mathrm{1-5;} \mathrm{adriamycin} 25 \mathrm{mg} / \mathrm{m}^{2} \mathrm{~d}$ 5, repeated at d 22 versus

FAP: 5-FU 270 to $300 \mathrm{mg} / \mathrm{m}^{2} \mathrm{Cl}$ d 1- 5; adriamycin $25 \mathrm{mg} / \mathrm{m}^{2} \mathrm{~d}$ 5; cisplatin $70 \mathrm{mg} / \mathrm{m}^{2} \mathrm{~d}$ 1, repeated at d 22

\begin{tabular}{ll}
\hline Outcomes & $\begin{array}{l}\text { Median survival } \\
\text { Response rates }\end{array}$ \\
\hline Notes & Translated from Japanese \\
\hline
\end{tabular}

\section{Risk of bias}

Bias Authors' judgement Support for judgement


Kikuchi 1990 (Continued)

\begin{tabular}{lll}
$\begin{array}{l}\text { Random sequence genera- } \\
\text { tion (selection bias) }\end{array}$ & Unclear risk & Not stated \\
\hline $\begin{array}{l}\text { Allocation concealment } \\
\text { (selection bias) }\end{array}$ & Low risk & Sequential opaque envelopes \\
\hline $\begin{array}{l}\text { Incomplete outcome data } \\
\text { (attrition bias) } \\
\text { efficacy }\end{array}$ & Low risk & All evaluable pts analysed \\
\hline $\begin{array}{l}\text { Incomplete outcome data } \\
\text { (attrition bias) } \\
\text { safety }\end{array}$ & Low risk & All evaluable pts analysed \\
\hline $\begin{array}{l}\text { Selective reporting (re- } \\
\text { porting bias) }\end{array}$ & Low risk & Report includes all expected outcomes \\
\hline $\begin{array}{l}\text { Other bias } \\
\begin{array}{l}\text { Blinded review of CT/MRI- } \\
\text { scans? }\end{array}\end{array}$ High risk & Enclear risk & \\
\hline
\end{tabular}

Kim 2001

\begin{tabular}{ll}
\hline Methods & $\begin{array}{l}\text { Single-centre RCT } \\
2 \text { arms } \\
\text { Quality score: } \mathrm{B}\end{array}$ \\
\hline Participants & $\mathrm{n}=121$ \\
& Metastatic disease: $90 \%$ \\
& ECOG 2 -3: $12 \%$ \\
\hline Interventions & FP: 5 -FU $1000 \mathrm{mg} / \mathrm{m}^{2}$ over 6 hours d $1-5 ;$ cisplatin $60 \mathrm{mg} / \mathrm{m}^{2} \mathrm{~d} 1$, repeated at $\mathrm{d} 29$ versus \\
& ECF: epirubicine $50 \mathrm{mg} / \mathrm{m}^{2} \mathrm{~d} 1 ;$ cisplatin $60 \mathrm{mg} / \mathrm{m}^{2} \mathrm{~d} 1,5-\mathrm{FU}: 1000 \mathrm{mg} / \mathrm{m}^{2} \mathrm{~d} 1-5$, repeated at $\mathrm{d} 29$ \\
\hline Outcomes & $\begin{array}{l}\text { Median survival } \\
\text { 1- and 2-year survival rates } \\
\text { Response rates } \\
\text { Toxicity }\end{array}$ \\
\hline Notes & Study currently published as abstract only. Final results were provided by the first author.
\end{tabular}

\section{Risk of bias}

\begin{tabular}{lll}
\hline Bias & Authors' judgement & Support for judgement \\
\hline $\begin{array}{l}\text { Random sequence genera- } \\
\text { tion (selection bias) }\end{array}$ & Unclear risk & Abstract / supplement only \\
\hline $\begin{array}{l}\text { Allocation concealment } \\
\text { (selection bias) }\end{array}$ & Unclear risk & Abstract / supplement only \\
\hline $\begin{array}{l}\text { Incomplete outcome data } \\
\text { (attrition bias) } \\
\text { efficacy }\end{array}$ & Unclear risk & Abstract / supplement only \\
\hline
\end{tabular}


Kim 2001 (Continued)
Incomplete outcome data
Unclear risk
Abstract / supplement only
(attrition bias)
safety

Selective reporting (re- Low risk $\quad$ Report includes all expected outcomes
porting bias)

\begin{tabular}{lll}
\hline Other bias & Unclear risk & Abstract / supplement only \\
\hline $\begin{array}{l}\text { Blinded review of CT/MRI- } \\
\text { scans? }\end{array}$ & High risk & Per first author \\
\hline
\end{tabular}

Kim 2014

\begin{tabular}{ll}
\hline Methods & $\begin{array}{l}\text { Single-centre RCT } \\
2 \text { arms } \\
\text { Quality score: } \mathrm{D}\end{array}$ \\
\hline Participants & $\mathrm{n}=77$ \\
& Median age: 57 years \\
& Metastatic disease: $62 \%$ \\
& ECOG 2-3: $13 \%$
\end{tabular}

Interventions

WDP: docetaxel $\left(35 \mathrm{mg} / \mathrm{m}^{2}\right) \mathrm{d} 1,8$, cisplatin

$\left(60 \mathrm{mg} / \mathrm{m}^{2}\right) \mathrm{d} 1$ repeated at $\mathrm{d} 22$

versus

wDO: docetaxel $\left(35 \mathrm{mg} / \mathrm{m}^{2}\right) \mathrm{d} 1,8$, oxaliplatin

$\left(120 \mathrm{mg} / \mathrm{m}^{2}\right) \mathrm{d} 1$ repeated at $\mathrm{d} 22$

\begin{tabular}{|c|c|c|}
\hline \multirow[t]{4}{*}{ Outcomes } & \\
\hline & \multicolumn{2}{|l|}{ Overall survival } \\
\hline & \multicolumn{2}{|c|}{ Progression-free survival } \\
\hline & \multicolumn{2}{|l|}{ Toxicity } \\
\hline Notes & \multicolumn{2}{|c|}{$\begin{array}{l}\text { Second-line treatment in } 63 \%(\mathrm{wDP}) \text { and } 77 \% \text { (wDO): irinotecan monotherapy or irinotecan plus 5-flu- } \\
\text { orouracil/ leucovorin in } 67 \% \text { and } 70 \% \text { of the wDP and wDO arms }\end{array}$} \\
\hline \multicolumn{3}{|l|}{ Risk of bias } \\
\hline Bias & Authors' judgement & Support for judgement \\
\hline $\begin{array}{l}\text { Random sequence genera- } \\
\text { tion (selection bias) }\end{array}$ & Unclear risk & Not stated \\
\hline $\begin{array}{l}\text { Allocation concealment } \\
\text { (selection bias) }\end{array}$ & Unclear risk & Not stated \\
\hline $\begin{array}{l}\text { Incomplete outcome data } \\
\text { (attrition bias) } \\
\text { efficacy }\end{array}$ & Low risk & ITT analysis \\
\hline
\end{tabular}


Kim 2014 (Continued)

Incomplete outcome data Low risk ITT analysis
(attrition bias)
safety

\begin{tabular}{lll}
\hline $\begin{array}{l}\text { Selective reporting (re- } \\
\text { porting bias) }\end{array}$ & Low risk & All expected endpoints included \\
\hline Other bias & Low risk & $\begin{array}{l}\text { Patients in the wDP arm received } 85 \% \text { and } 82 \% \text { of the planned dose intensi- } \\
\text { ties of docetaxel and cisplatin, respectively. In the wDO arm, the mean relative } \\
\text { dose intensity was } 83 \% \text { for docetaxel and } 80 \% \text { for oxaliplatin. }\end{array}$ \\
\hline
\end{tabular}

Blinded review of CT/MRI- Unclear risk Not stated

scans?

Koizumi 2008

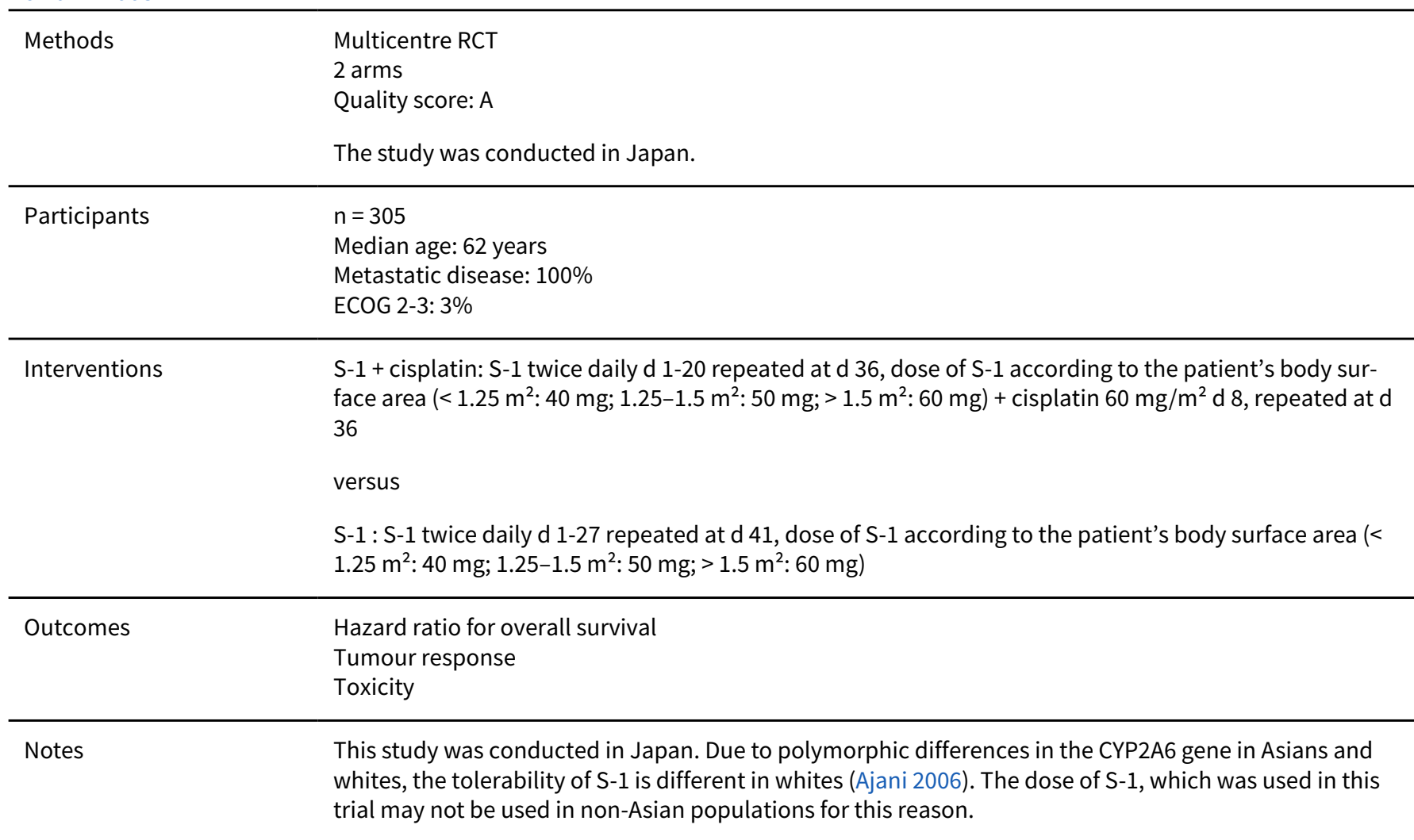

\section{Risk of bias}

\begin{tabular}{lll}
\hline Bias & Authors' judgement & Support for judgement \\
\hline $\begin{array}{l}\text { Random sequence genera- } \\
\text { tion (selection bias) }\end{array}$ & Low risk & Minimisation by use of biased coin method \\
\hline $\begin{array}{l}\text { Allocation concealment } \\
\text { (selection bias) }\end{array}$ & Low risk & Central allocation \\
\hline $\begin{array}{l}\text { Incomplete outcome data } \\
\text { (attrition bias) }\end{array}$ & Low risk & $298 / 305$ patients included in analysis. \\
\end{tabular}


Koizumi 2008 (Continued)

efficacy

Incomplete outcome data Low risk 298/305 patients included in analysis.
(attrition bias)

safety

\begin{tabular}{lll}
\hline $\begin{array}{l}\text { Selective reporting (re- } \\
\text { porting bias) }\end{array}$ & Low risk & Report includes all expected outcomes \\
\hline Other bias & Low risk & $\begin{array}{l}\text { If second-line treatment was started without progressive disease (i.e. due to } \\
\text { adverse events), patients were censored }\end{array}$
\end{tabular}

Blinded review of CT/MRI- Low risk Images were assessed by an extramural review committee

scans?

Koizumi 2014

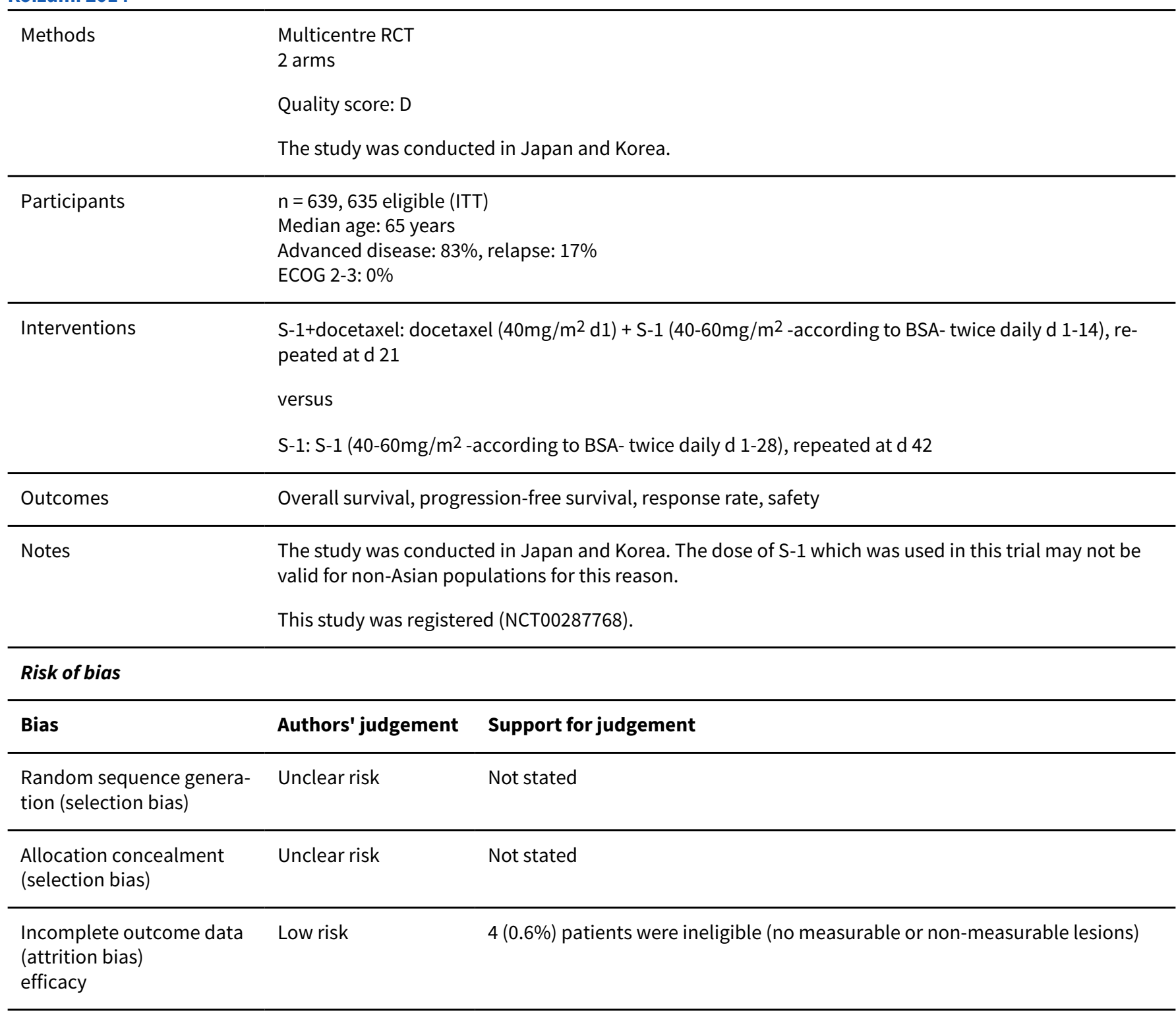


Koizumi 2014 (Continued)
Incomplete outcome data
Low risk
All treated patients were included (98\%)
(attrition bias)
safety

Selective reporting (re- Low risk $\quad$ Report includes all expected outcomes
porting bias)

\begin{tabular}{lll}
\hline Other bias & High risk & $\begin{array}{l}\text { Second-line treatment was given to 69.7\% of patients in the S-1+docetaxel } \\
\text { group and 76\% in the S-1 group, planned interim analysis }\end{array}$ \\
\hline $\begin{array}{l}\text { Blinded review of CT/MRI- } \\
\text { scans? }\end{array}$ & Unclear risk & Images were reviewed by a central review board. \\
\hline
\end{tabular}

\section{Komatsu 2011}

\begin{tabular}{|c|c|}
\hline Methods & $\begin{array}{l}\text { Multicentre RCT } \\
2 \text { arms } \\
\text { Quality score: D }\end{array}$ \\
\hline Participants & $\begin{array}{l}\mathrm{n}=95 \\
\text { Median age: } 66 \text { years } \\
\text { ECOG 2-3: } 0 \%\end{array}$ \\
\hline Interventions & $\begin{array}{l}\text { irinotecan/S-1: irinotecan } 75 \mathrm{mg} / \mathrm{m}^{2} \text { as iv infusion d } 1,15 \text { repeated at } \mathrm{d} 29+\mathrm{S}-1 \text { initial } 40-60 \mathrm{mg} / \mathrm{m}^{2} \\
\text { orally twice daily d 1-14, repeated at } 4 \text { weeks } \\
\text { versus } \\
\text { S-1: S-1 initial } 40-60 \mathrm{mg} / \mathrm{m}^{2} \text { orally twice daily d } 1-28 \text {, repeated at } 6 \text { weeks } \\
\text { In subsequent cycles doses were varied according to the most severe adverse events during the pre- } \\
\text { ceding cycle }\end{array}$ \\
\hline Outcomes & $\begin{array}{l}\text { Response rates } \\
\text { Time to treatment failure } \\
\text { Time to progression } \\
\text { Overall survival } \\
\text { Toxicity }\end{array}$ \\
\hline Notes & This study was conducted in Japan. \\
\hline
\end{tabular}

\section{Risk of bias}

\begin{tabular}{lll}
\hline Bias & Authors' judgement & Support for judgement \\
\hline $\begin{array}{l}\text { Random sequence genera- } \\
\text { tion (selection bias) }\end{array}$ & Low risk & Minimization \\
\hline $\begin{array}{l}\text { Allocation concealment } \\
\text { (selection bias) }\end{array}$ & Unclear risk & Not stated \\
\hline $\begin{array}{l}\text { Incomplete outcome data } \\
\text { (attrition bias) }\end{array}$ & Unclear risk & 16.7 versus 9.4\% were not evaluable for tumour response (RECIST)
\end{tabular}


Komatsu 2011 (Continued) efficacy

\begin{tabular}{lll}
\hline $\begin{array}{l}\text { Incomplete outcome data } \\
\text { (attrition bias) } \\
\text { safety }\end{array}$ & Low risk & Two untreated patients who were excluded from safety evaluation \\
\hline $\begin{array}{l}\text { Selective reporting (re- } \\
\text { porting bias) }\end{array}$ & Low risk & Response rates \\
& Time to treatment failure \\
& Time to progression \\
& Overall survival \\
\hline Other bias & Toxicity \\
& High risk & $\begin{array}{l}\text { Patients aged over } 70 \text { years were more frequent in the group treated with } \\
\text { irinotecan and S-1: 45.8\% (irinotecan/S-1) vs. 14.9\% (S-1). Median age was 70 } \\
\text { years for patients treated with irinotecan/S-1 and 63 years for patients treated } \\
\text { with S-1 alone. }\end{array}$ \\
\hline $\begin{array}{l}\text { Blinded review of CT/MRI- } \\
\text { scans? }\end{array}$ & High risk & High risk \\
\hline
\end{tabular}

\section{KRGGC 1992}

\begin{tabular}{ll}
\hline Methods & Multicentre RCT \\
& 2 arms \\
\hline Participants & $\mathrm{n}=60$ \\
& Inoperable or metastatic gastric adenocarcinoma \\
\hline Interventions & FP: cisplatin $50 \mathrm{mg} / \mathrm{m}^{2} ; 5-\mathrm{FU} 250 \mathrm{mg} / \mathrm{m}^{2}$ on day $1 ; 5-\mathrm{FU} 250 \mathrm{mg} / \mathrm{m}^{2}$ days $2-5$ \\
& FPEPIR: cisplatin $50 \mathrm{mg} / \mathrm{m}^{2} ; 5-\mathrm{FU} 250 \mathrm{mg} / \mathrm{m}^{2}$ days $2-5 ;$ epirubicin $30 \mathrm{mg} / \mathrm{m}^{2}$ day 2 \\
\hline Outcomes & $\begin{array}{l}\text { Response rates } \\
\text { Overall survival }\end{array}$ \\
& Toxicity \\
\hline Notes & -
\end{tabular}

\section{Risk of bias}

\begin{tabular}{lll}
\hline Bias & Authors' judgement & Support for judgement \\
\hline $\begin{array}{l}\text { Random sequence genera- } \\
\text { tion (selection bias) }\end{array}$ & Unclear risk & Not stated \\
\hline $\begin{array}{l}\text { Allocation concealment } \\
\text { (selection bias) }\end{array}$ & Low risk & Sealed envelopes \\
\hline $\begin{array}{l}\text { Incomplete outcome data } \\
\text { (attrition bias) } \\
\text { efficacy }\end{array}$ & High risk & $\begin{array}{l}\text { 5 patients not evaluated: 3 death from PD with 4 weeks of treatment, 1 due to } \\
\text { relocation, } 1 \text { due to absence of follow-up exam }\end{array}$ \\
\hline
\end{tabular}


KRGGC 1992 (Continued)

$\begin{aligned} & \text { Incomplete outcome data } \\ & \begin{array}{l}\text { (attrition bias) } \\ \text { safety }\end{array}\end{aligned}$
$\begin{aligned} & \text { treatment" grading } \\ & \text { toxic reactions classified by "standardization of reporting of results of cancer }\end{aligned}$

\begin{tabular}{lll}
\hline $\begin{array}{l}\text { Selective reporting (re- } \\
\text { porting bias) }\end{array}$ & Low risk & RR, OS, toxicity (but not CTCAE/WHO) \\
\hline Other bias & Unclear risk & N/A \\
\hline $\begin{array}{l}\text { Blinded review of CT/MRI- } \\
\text { scans? }\end{array}$ & Unclear risk & Not stated \\
\hline
\end{tabular}

Levi 1986

\begin{tabular}{ll}
\hline Methods & Multicentre RCT \\
& 2 arms \\
& Quality score: $\mathrm{B}$ \\
\hline Participants & $\mathrm{n}=203$ \\
& Median age: 60 years \\
& ECOG 2-3: $22 \%$
\end{tabular}

\begin{tabular}{ll}
\hline Interventions & $\begin{array}{l}\text { A: adriamycin } 60 \mathrm{mg} / \mathrm{m}^{2} \mathrm{~d} 1 \text {, repeated at } \mathrm{d} 22 \\
\text { versus } \\
\\
\text { FAB: } 5 \text {-FU } 600 \mathrm{mg} / \mathrm{m}^{2}, \mathrm{~d} 1,8 ; \text { adriamycin } 40 \mathrm{mg} / \mathrm{m}^{2} \mathrm{~d} 1 \text {, repeated at d } 28 \\
\text { BCNU } 100 \mathrm{mg} / \mathrm{m}^{2} \mathrm{~d} 1 \text {, repeated at d } 56\end{array}$ \\
\hline Outcomes & $\begin{array}{l}\text { Median survival } \\
\text { 1- and 2-year survival rates } \\
\text { Response rates } \\
\text { Toxicity }\end{array}$ \\
\hline Notes & -
\end{tabular}

\section{Risk of bias}

\begin{tabular}{lll}
\hline Bias & Authors' judgement & Support for judgement \\
\hline $\begin{array}{l}\text { Random sequence genera- } \\
\text { tion (selection bias) }\end{array}$ & Unclear risk & Not stated \\
\hline $\begin{array}{l}\text { Allocation concealment } \\
\text { (selection bias) }\end{array}$ & Low risk & Central \\
\hline $\begin{array}{l}\text { Incomplete outcome data } \\
\text { (attrition bias) } \\
\text { efficacy }\end{array}$ & High risk & $\begin{array}{l}\text { 16 patients not included because of ?inadequate follow-up, 3 = treatment can- } \\
\text { cellation, 2 = protocol violation }\end{array}$ \\
\hline $\begin{array}{l}\text { Incomplete outcome data } \\
\text { (attrition bias) } \\
\text { safety }\end{array}$ & High risk & Not ITT \\
\hline $\begin{array}{l}\text { Selective reporting (re- } \\
\text { porting bias) }\end{array}$ & Low risk & Report includes all expected outcomes \\
\hline
\end{tabular}


Levi 1986 (Continued)

\begin{tabular}{lll} 
Other bias & Unclear risk & No information about type and schedule of follow-up in the treatment groups \\
\hline $\begin{array}{l}\text { Blinded review of CT/MRI- } \\
\text { scans? }\end{array}$ & Unclear risk & Not stated \\
\hline
\end{tabular}

Li 2014

\begin{tabular}{|c|c|}
\hline Methods & Single-centre \\
\hline Participants & $\begin{array}{l}n=16 \text { vs } 16 \\
\text { Average age }=45.7 \text { (range } 30-65) \text { in the FOLFOX } 4 \text { group, and } 42.1 \text { (range } 26-70) \text { in the SOX group. }\end{array}$ \\
\hline Interventions & $\begin{array}{l}\text { "Total of } 32 \text { patients with advanced gastric cancer proved pathologically were randomly divided into } \\
2 \text { groups: } 16 \text { patients received SOX regimen [oxaliplatin } 1.30 \mathrm{mg} / \mathrm{m} 2 \text { as a } 2 \text {-hour infusion on day } 1 \text {, S-1 } \\
\text { capsules } 80 \mathrm{mg} / \mathrm{m} 2 \cdot \mathrm{d} \text { ) twice a day per oral from day } 1 \text { to day } 14 \text { every } 3 \text { weeks], the other } 16 \text { patients re- } \\
\text { ceived FOLFOX4 regimen [oxaliplatin } 85 \mathrm{mg} / \mathrm{m} 2 \text { as a } 2 \text { hour infusion on day } 1 \text { and a } 2 \text { hour infusion of LV } \\
200 /(\mathrm{m} 2 \cdot \mathrm{d}) \text { followed by a } 5 \text {-Fu bolus } 400 /(\mathrm{m} 2 \cdot \mathrm{d}) \text { and } 22 \text { hour infusion } 600 /(\mathrm{m} 2 \cdot \mathrm{d}) \text { for } 2 \text { consecutive days } \\
\text { every } 2 \text { weeks]. Efficacy was evaluated at least } 2 \text { cycles" }\end{array}$ \\
\hline
\end{tabular}

\begin{tabular}{ll}
\hline Outcomes & Response rates \\
& Disease control rates \\
& PFS \\
OS & Safety
\end{tabular}

Notes

PFS and OS were not analysed using Kaplan-Meier methods. HR for PFS could be estimated from summary data but HR for OS could not.

\section{Risk of bias}

\begin{tabular}{lll}
\hline Bias & Authors' judgement & Support for judgement \\
\hline $\begin{array}{l}\text { Random sequence genera- } \\
\text { tion (selection bias) }\end{array}$ & Low risk & Simple random assignment \\
\hline $\begin{array}{l}\text { Allocation concealment } \\
\text { (selection bias) }\end{array}$ & Unclear risk & Not described \\
\hline $\begin{array}{l}\text { Incomplete outcome data } \\
\text { (attrition bias) } \\
\text { efficacy }\end{array}$ & High risk & Time-to-event analysed not analysed using Kaplan-Meier methods. \\
\hline $\begin{array}{l}\text { Incomplete outcome data } \\
\text { (attrition bias) }\end{array}$ & High risk & \\
safety & & $\begin{array}{l}\text { Quantitative comparison only made for grade 3 or higher haematological toxi- } \\
\text { Selective reporting (re- }\end{array}$ \\
porting bias) & Unclear risk & N/A \\
\hline $\begin{array}{l}\text { Other bias } \\
\text { Blinded review of CT/MRI- } \\
\text { scans? }\end{array}$ & Unclear risk & Not stated \\
\hline
\end{tabular}




\begin{tabular}{ll}
\hline Methods & "prospectively recruited AGC patients all over China" (did not state number of centres involved) \\
& 2 arms: "randomly assigned in a 1:1 ratio to receive S1 plus cisplatin (CS group) or fluorouracil plus cis- \\
& platin (CF group)"
\end{tabular}

\begin{tabular}{l} 
Participants \\
$\begin{array}{l}\text { Mean age: CS group - } 53.3 \text { years, CF group - } 55 \text { years } \\
\text { "About } 50 \% \text { of the patients had low differentiated cancer. Approximately } 85 \% \text { of the patients had more } \\
\text { than one site of metastasis and over half of the patients received previous gastrectomy" }\end{array}$ \\
\hline $\begin{array}{l}\text { "S- } 1 \text { was given as } 40 \mathrm{mg} / \mathrm{m} 2 \text { twice daily on day } 1-21 \text { and cisplatin was } 20 \mathrm{mg} / \mathrm{m} 2 \mathrm{iv} \text { drip on day } 1-4, \mathrm{re}- \\
\text { peated every } 5 \text { weeks in the CS group. In the CF group, } 5 \text {-Fu was given as } 800 \mathrm{mg} / \mathrm{m} 2 / \mathrm{d} \mathrm{Cl} 120 \mathrm{~h} \text {, and the } \\
\text { dosage of cisplatin was } 20 \mathrm{mg} / \mathrm{m} 2 \text { iv on day } 1-4 \text {, repeated every } 4 \text { weeks" }\end{array}$ \\
\hline
\end{tabular}

Outcomes PFS (although TTP was stated as the primary endpoint, the definition they used is more consistent with
PFS)

OS

Safety

Notes "As a pilot study, there is no need for sample size calculation. We planned to enroll 270 patients"

\section{Risk of bias}

\begin{tabular}{|c|c|c|}
\hline Bias & Authors' judgement & Support for judgement \\
\hline $\begin{array}{l}\text { Random sequence genera- } \\
\text { tion (selection bias) }\end{array}$ & Unclear risk & $\begin{array}{l}\text { "Randomized grouping information for each patient was generated by central } \\
\text { randomization system. At randomization, patients were stratified by ECOG PS } \\
\text { (0-1 vs. 2), numbers of metastasis sites ( } 1 \text { vs. }>1 \text { ) and gastrectomy (yes vs no)" }\end{array}$ \\
\hline $\begin{array}{l}\text { Allocation concealment } \\
\text { (selection bias) }\end{array}$ & High risk & $\begin{array}{l}\text { "Neither patients nor investigators were masked to treatment assignment in } \\
\text { this open-label study" }\end{array}$ \\
\hline $\begin{array}{l}\text { Incomplete outcome data } \\
\text { (attrition bias) } \\
\text { efficacy }\end{array}$ & Unclear risk & Low rate of attrition but reasons not specified \\
\hline $\begin{array}{l}\text { Incomplete outcome data } \\
\text { (attrition bias) } \\
\text { safety }\end{array}$ & Unclear risk & Low rate of attrition but reasons not specified \\
\hline $\begin{array}{l}\text { Selective reporting (re- } \\
\text { porting bias) }\end{array}$ & Unclear risk & $\mathrm{N} / \mathrm{A}$ \\
\hline Other bias & High risk & $\begin{array}{l}\text { "As a pilot study, there is no need for sample size calculation. We planned to } \\
\text { enroll } 270 \text { patients" }\end{array}$ \\
\hline $\begin{array}{l}\text { Blinded review of } \mathrm{CT} / \mathrm{MRI}- \\
\text { scans? }\end{array}$ & High risk & "Investigators assessed tumor response and progression" \\
\hline
\end{tabular}

Methods SIngle-centre


Li 2016 (Continued)

Non-inferiority comparison of mEOX vs FOLFIRI

RCT

2 arms: modified EOX vs FOLFIRI

\begin{tabular}{ll}
\hline Participants & 105 patients (55 received EOX, 50 received FOLFIRI) \\
\hline Interventions & $\begin{array}{l}\text { "The EOX group was given epirubicin } 50 \mathrm{mg} / \mathrm{m} 2 \text { iv on day one, oxaliplatin } 85 \mathrm{mg} / \mathrm{m} 2 \mathrm{iv} \text { on day } 1 \text { and } \\
\text { capecitabine at a twice-daily dose of } 625 \mathrm{mg} / \mathrm{m} 2 \text { po for } 2 \mathrm{wk} \text {, which was repeated every } 3 \mathrm{wk}\end{array}$
\end{tabular}

Outcomes

OS

PFS (separately for both first- and second-line)

Objective response rate

Disease control rate

Adverse events

Notes Second-line chemo allowed

\section{Risk of bias}

\begin{tabular}{lll}
\hline Bias & Authors' judgement & Support for judgement \\
\hline $\begin{array}{l}\text { Random sequence genera- } \\
\text { tion (selection bias) }\end{array}$ & Unclear risk & Not specified \\
\hline $\begin{array}{l}\text { Allocation concealment } \\
\text { (selection bias) }\end{array}$ & Unclear risk & Not mentioned \\
\hline $\begin{array}{l}\text { Incomplete outcome data } \\
\text { (attrition bias) } \\
\text { efficacy }\end{array}$ & Unclear risk & $\begin{array}{l}\text { Patient disposition/CONSORT flow diagram not provided; unclear how many } \\
\text { were screened and excluded, and for what reasons }\end{array}$ \\
\hline $\begin{array}{l}\text { Incomplete outcome data } \\
\text { (attrition bias) } \\
\text { safety }\end{array}$ & Unclear risk & $\begin{array}{l}\text { Patient disposition/CONSORT flow diagram not provided; unclear how many } \\
\text { were screened and excluded, and for what reasons }\end{array}$ \\
\hline $\begin{array}{l}\text { Selective reporting (re- } \\
\text { porting bias) }\end{array}$ & Unclear risk & Adverse effects (NCI-CTC) categorised and analysed as grades 1-4 and 3-4 \\
\hline $\begin{array}{l}\text { Other bias } \\
\begin{array}{l}\text { Blinded review of CT/MRI- } \\
\text { Scans? }\end{array}\end{array}$ Unclear risk & Not mentioned \\
\hline
\end{tabular}

Loehrer 1994

\begin{tabular}{ll}
\hline Methods & Multicentre RCT \\
& 3 arms \\
& Quality score: $\mathrm{B}$ \\
\hline Participants & $\mathrm{n}=165$ \\
& Median age: 60 years \\
& Metastatic disease: $63 \%$ \\
\hline
\end{tabular}


Loehrer 1994 (Continued)

\section{ECOG 2-3: $27 \%$}

\begin{tabular}{|c|c|}
\hline Interventions & $\begin{array}{l}\text { 5-FU: } 5 \text {-FU } 500 \mathrm{mg} / \mathrm{m}^{2} \mathrm{~d} 1-5 \text { repeated at d } 29 \\
\text { versus } \\
\text { E: epirubicin } 90 \mathrm{mg} / \mathrm{m}^{2} \mathrm{~d} 1 \text {, repeated at d } 29 \text { versus } \\
5 \text {-FU+E: } 5 \text {-FU } 400 \mathrm{mg} / \mathrm{m}^{2} \mathrm{~d} \text { 1-5; epirubicin } 90 \mathrm{mg} / \mathrm{m}^{2} \mathrm{~d} 1 \text {, repeated at d } 29\end{array}$ \\
\hline
\end{tabular}

\begin{tabular}{ll}
\hline Outcomes & Median survival \\
Toxicity
\end{tabular}

Notes -

\section{Risk of bias}

\begin{tabular}{lll}
\hline Bias & Authors' judgement & Support for judgement \\
\hline $\begin{array}{l}\text { Random sequence genera- } \\
\text { tion (selection bias) }\end{array}$ & Low risk & Random number tables \\
\hline $\begin{array}{l}\text { Allocation concealment } \\
\text { (selection bias) }\end{array}$ & Low risk & Central allocation \\
\hline $\begin{array}{l}\text { Incomplete outcome data } \\
\text { (attrition bias) } \\
\text { efficacy }\end{array}$ & High risk & Analysis for all randomised and screened patients \\
\hline $\begin{array}{l}\text { Incomplete outcome data } \\
\text { (attrition bias) } \\
\text { safety }\end{array}$ & Unclear risk & Analysis for all randomised, screened and treated patients \\
\hline $\begin{array}{l}\text { Selective reporting (re- } \\
\text { porting bias) }\end{array}$ & High risk & No response rates are given \\
\hline $\begin{array}{l}\text { Other bias } \\
\begin{array}{l}\text { Blinded review of CT/MRI- } \\
\text { scans? }\end{array}\end{array}$ High risk & N/A \\
\hline
\end{tabular}

Lu 2014

\begin{tabular}{ll}
\hline Methods & "randomized phase II clinical trial conducted at Guizhou Cancer Hospital, China" \\
\hline Participants & "a total of 94 consecutive patients were enrolled to Guizhou Cancer Hospital and randomly divided into \\
two arms: OXS group (47 cases) and S-1 group (47 cases)" & In both arms, about 3/4 of participants were males \\
& Median age was 63 and 65 years in the OXS and S-1 groups \\
\hline Interventions & "Advanced gastric cancer patients were treated with S-1 daily for first 2 weeks of a 3-week cycle, or S-1 \\
daily for first 2 weeks plus $130 \mathrm{mg} / \mathrm{m} 2$ of oxaliplatin administered as a 2-hour intravenous infusion on \\
day 1 of a 3-week cycle. S-1 was orally administered in a fixed quantity according to body surface area \\
(BSA) as follows: BSA less than $1.25 \mathrm{~m} 2,40$ mg two times daily; 1.25,BSA,1.5 m2, 50 mg two times daily; \\
and BSA more than $1.5 \mathrm{~m} 2,60 \mathrm{mg}$ two times daily"
\end{tabular}


Lu 2014 (Continued)

Outcomes

"The primary endpoint was OS, defined as time from date of randomization to date of death from any cause. The secondary endpoints included PFS, RR, and safety profile."

Notes

\section{Risk of bias}

\begin{tabular}{lll}
\hline Bias & Authors' judgement & Support for judgement \\
\hline $\begin{array}{l}\text { Random sequence genera- } \\
\text { tion (selection bias) }\end{array}$ & Low risk & $\begin{array}{l}\text { "Randomization was generated using a computer-generated random se- } \\
\text { quence concealed in consecutively numbered opaque sealed envelopes" }\end{array}$ \\
\hline $\begin{array}{l}\text { Allocation concealment } \\
\text { (selection bias) }\end{array}$ & Low risk & $\begin{array}{l}\text { "Randomization was generated using a computer-generated random se- } \\
\text { quence concealed in consecutively numbered opaque sealed envelopes" }\end{array}$ \\
\hline $\begin{array}{l}\text { Incomplete outcome data } \\
\text { (attrition bias) } \\
\text { efficacy }\end{array}$ & Low risk & No patient was lost to follow-up \\
\hline $\begin{array}{l}\text { Incomplete outcome data } \\
\begin{array}{l}\text { (attrition bias) } \\
\text { safety }\end{array}\end{array}$ & Low risk & No patient was lost to follow-up \\
\hline $\begin{array}{l}\text { Selective reporting (re- } \\
\text { porting bias) }\end{array}$ & Unclear risk & $\begin{array}{l}\text { OS, PFS, RR and safety included; possible loss of information because of the } \\
\text { way the adverse events were categorised and analysed }\end{array}$ \\
\hline $\begin{array}{l}\text { Other bias } \\
\begin{array}{l}\text { Blinded review of CT/MRI- } \\
\text { scans? }\end{array}\end{array}$ & Unclear risk & N/A \\
\hline
\end{tabular}

Lutz 2007

\begin{tabular}{|c|c|}
\hline Methods & $\begin{array}{l}\text { Multicentre RCT } \\
3 \text { arms } \\
\text { Quality score: A }\end{array}$ \\
\hline Participants & $\begin{array}{l}\mathrm{n}=90 \\
\text { Median age: } 62 \text { years } \\
\text { Metastatic disease: } 78 \% \text { (HD-FU), 89\% (HD-FU/FA); 88\% (HD-FU/FA/Cis) } \\
\text { ECOG 2-3: } 8 \% \text { (HD-FU), 8\% (HD-FU/FA), 4\% (HD-FU/FA/Cis) }\end{array}$ \\
\hline Interventions & $\begin{array}{l}\text { HD-FU: weekly FU } 3.000 \mathrm{mg} / \mathrm{m}^{2} \text { as } 24 \text {-hour infusion } \\
\text { versus } \\
\text { HD-FU/FA: weeks } d l \text {-FA } 500 \mathrm{mg} / \mathrm{m}^{2} / 2 \text { hours or } l \text {-FA } 250 \mathrm{mg} / \mathrm{m}^{2} / 2 \text { hours }+\mathrm{FU} 2.600 \mathrm{mg} / \mathrm{m}^{2} \text { as } 24 \text {-hour in- } \\
\text { fusion } \\
\text { versus } \\
\text { HD-FU/FA/Cis: cisplatin } 50 \mathrm{mg} / \mathrm{m}^{2} / \text { hour on days } 1,15,29 ; \mathrm{dl} \text {-FA } 500 \mathrm{mg} / \mathrm{m}^{2} / 2 \text { hours or } l \text {-FA } 250 \mathrm{mg} / \mathrm{m}^{2} / 2 \\
\text { hours; FU } 2.000 \mathrm{mg} / \mathrm{m}^{2} / 24-\text { hour continuous infusion on } \mathrm{d} 1,8,15,22,29,36 \text {. In all } 3 \text { arms, chemothera- } \\
\text { py was administered weekly in } 6 \text { subsequent weeks, followed by } 1 \text { week rest. }\end{array}$ \\
\hline Outcomes & $\begin{array}{l}\text { Tumour response } \\
\text { Median and 1-year overall survival rates } \\
\text { Toxicity }\end{array}$ \\
\hline
\end{tabular}


Lutz 2007 (Continued)

Notes
After stage 1 (21 patients in each arm) of the trial, the HD-FU (single agent-arm) arm was closed because only 2 responses had been observed. Total number of patients in this arm was 37 because inclusion was not interrupted before interim analysis. The results of the 2 combination arms were combined in the analysis.

\section{Risk of bias}

\begin{tabular}{|c|c|c|}
\hline Bias & Authors' judgement & Support for judgement \\
\hline $\begin{array}{l}\text { Random sequence genera- } \\
\text { tion (selection bias) }\end{array}$ & Low risk & Minimisation technique \\
\hline $\begin{array}{l}\text { Allocation concealment } \\
\text { (selection bias) }\end{array}$ & Low risk & Central randomisation at the EORTC data centre \\
\hline $\begin{array}{l}\text { Incomplete outcome data } \\
\text { (attrition bias) } \\
\text { efficacy }\end{array}$ & Low risk & $127 / 145$ eligible, reasons for exclusions provided and valid \\
\hline $\begin{array}{l}\text { Incomplete outcome data } \\
\text { (attrition bias) } \\
\text { safety }\end{array}$ & Low risk & $127 / 145$ eligible, reasons for exclusions provided and valid \\
\hline $\begin{array}{l}\text { Selective reporting (re- } \\
\text { porting bias) }\end{array}$ & Low risk & Report includes all expected outcomes \\
\hline Other bias & High risk & $\begin{array}{l}\text { Single-therapy arm was closed earlier (Simon 2-stage minimax design). The re- } \\
\text { sults of the } 2 \text { combination arms were combined in the analysis. }\end{array}$ \\
\hline $\begin{array}{l}\text { Blinded review of } \mathrm{CT} / \mathrm{MRI}- \\
\text { scans? }\end{array}$ & High risk & $\begin{array}{l}\text { Computed tomography scans were reviewed centrally by the study co-ordina- } \\
\text { tors. }\end{array}$ \\
\hline
\end{tabular}

\section{Moehler 2005}

\begin{tabular}{ll}
\hline Methods & Multicentre RCT \\
& $\begin{array}{l}2 \text { arms } \\
\text { Quality score: } \mathrm{D}\end{array}$ \\
\hline Participants & $\mathrm{n}=120$ \\
& Median age: 62 years \\
& Metastatic disease: $100 \%$ \\
\hline Interventions & ILF: irinotecan $80 \mathrm{mg} / \mathrm{m}^{2}+\mathrm{LV} 500 \mathrm{mg} / \mathrm{m}^{2}+5-\mathrm{FU} 2000 \mathrm{mg} / \mathrm{m}^{2}$ days $1,8,15,22,29,36$, repeated at 8 \\
& $\begin{array}{l}\text { weeks } \\
\text { ELF: etoposide } 120 \mathrm{mg} / \mathrm{m}^{2}+\mathrm{LV} 300 \mathrm{mg} / \mathrm{m}^{2}+5-\mathrm{FU} 500 \mathrm{mg} / \mathrm{m}^{2} \mathrm{~d} 1-3, \text { repeated at d 22 }\end{array}$ \\
\hline Outcomes & Tumour response \\
& Median overall survival \\
& Hazard ratio \\
\hline Notes & - \\
\hline
\end{tabular}

\section{Risk of bias}

\section{Authors' judgement Support for judgement}


Moehler 2005 (Continued)

\begin{tabular}{lll}
$\begin{array}{l}\text { Random sequence genera- } \\
\text { tion (selection bias) }\end{array}$ & Unclear risk & Not stated \\
\hline $\begin{array}{l}\text { Allocation concealment } \\
\text { (selection bias) }\end{array}$ & Low risk & Central allocation by the Co-ordination Centre for Clinical trials Mainz \\
\hline $\begin{array}{l}\text { Incomplete outcome data } \\
\text { (attrition bias) } \\
\text { efficacy }\end{array}$ & Low risk & Analysis of the full-analysis set of all treated patients \\
\hline $\begin{array}{l}\text { Incomplete outcome data } \\
\text { (attrition bias) } \\
\text { safety }\end{array}$ & Low risk & Analysis of the full-analysis set of all treated patients \\
\hline $\begin{array}{l}\text { Selective reporting (re- } \\
\text { porting bias) }\end{array}$ & Low risk & Report includes all expected outcomes \\
\hline $\begin{array}{l}\text { Other bias } \\
\begin{array}{l}\text { Blinded review of CT/MRI- } \\
\text { scans? }\end{array}\end{array}$ Unclear risk & Not stated \\
\hline
\end{tabular}

\section{Moehler 2010}

\begin{tabular}{|c|c|c|}
\hline Methods & \multicolumn{2}{|l|}{$\begin{array}{l}\text { Multicentre RCT } \\
2 \text { arms } \\
\text { Quality score: D }\end{array}$} \\
\hline Participants & \multicolumn{2}{|c|}{$\begin{array}{l}\mathrm{n}=118 \\
\text { Median age: } 62.5 \text { years } \\
\text { Metastatic disease: } 100 \%\end{array}$} \\
\hline Interventions & \multicolumn{2}{|c|}{$\begin{array}{l}\text { XI: capecitabine } 1000 \mathrm{mg} / \mathrm{m}^{2} \text { twice daily d } 1-14+\text { irinotecan } 250 \mathrm{mg} / \mathrm{m}^{2} \mathrm{~d} 1 \text {, repeated at d } 22 \\
\text { versus } \\
\text { XP: capecitabine } 1000 \mathrm{mg} / \mathrm{m}^{2} \text { twice daily d } 1-14+\text { cisplatin } 80 \mathrm{mg} / \mathrm{m}^{2} \mathrm{~d} 1 \text {, repeated at d } 22\end{array}$} \\
\hline Outcomes & \multicolumn{2}{|l|}{$\begin{array}{l}\text { Median overall survival } \\
\text { 1- and 2-year rate of OS } \\
\text { Tumour response } \\
\text { Toxicity }\end{array}$} \\
\hline Notes & \multicolumn{2}{|c|}{ The reported results are from the first stage of the study (design with adaptive interim analysis) } \\
\hline \multicolumn{3}{|l|}{ Risk of bias } \\
\hline Bias & Authors' judgement & Support for judgement \\
\hline $\begin{array}{l}\text { Random sequence genera- } \\
\text { tion (selection bias) }\end{array}$ & Unclear risk & Not stated \\
\hline $\begin{array}{l}\text { Allocation concealment } \\
\text { (selection bias) }\end{array}$ & Low risk & Central allocation \\
\hline $\begin{array}{l}\text { Incomplete outcome data } \\
\text { (attrition bias) }\end{array}$ & Low risk & $\begin{array}{l}\text { Analysis of the full-analysis set of all treated patients with at least one } \\
\text { assessment }\end{array}$ \\
\hline
\end{tabular}


Moehler 2010 (Continued)

efficacy

Incomplete outcome data Low risk $\quad$ Analysis of the full-analysis set of all treated patients
(attrition bias)

safety

\begin{tabular}{ll}
\hline Selective reporting (re- $\quad$ Low risk & Report includes all expected outcomes \\
porting bias)
\end{tabular}
porting bias)

$\begin{array}{ll}\text { Other bias } \quad \text { High risk } & \begin{array}{l}\text { Results are from the first stage of the study (design with adaptive interim } \\ \text { analysis) }\end{array}\end{array}$

Blinded review of CT/MRI- Unclear risk Not stated

scans?

\section{Murad 1993}

\begin{tabular}{ll}
\hline Methods & $\begin{array}{l}\text { Single-centre RCT } \\
2 \text { arms } \\
\text { Quality score: not applicable }\end{array}$ \\
\hline Participants & $\begin{array}{l}\mathrm{n}=41 \\
\text { Metastatic disease: } 68 \% \\
\end{array}$ \\
\hline ECOG $2-3: 30 \%$
\end{tabular}

\section{Risk of bias}

\begin{tabular}{lll}
\hline Bias & Authors' judgement & Support for judgement \\
\hline $\begin{array}{l}\text { Random sequence genera- } \\
\text { tion (selection bias) }\end{array}$ & Unclear risk & Not stated \\
\hline $\begin{array}{l}\text { Allocation concealment } \\
\text { (selection bias) }\end{array}$ & Unclear risk & Not stated \\
\hline $\begin{array}{l}\text { Incomplete outcome data } \\
\begin{array}{l}\text { (attrition bias) } \\
\text { efficacy }\end{array}\end{array}$ & High risk & No ITT \\
\hline $\begin{array}{l}\text { Incomplete outcome data } \\
\text { (attrition bias) } \\
\text { safety }\end{array}$ & Unclear risk & No ITT \\
\hline
\end{tabular}


Murad 1993 (Continued)

Selective reporting (re- Low risk $\quad$ Report includes all expected outcomes
porting bias)

\begin{tabular}{lll}
\hline Other bias & Unclear risk & $\begin{array}{l}\text { After 21 participants were randomised, further participants were directly as- } \\
\text { signed to the chemotherapy arm because of "strong evidence for benefit in the } \\
\text { treated participants" }\end{array}$ \\
\hline $\begin{array}{l}\text { Blinded review of CT/MRI- } \\
\text { scans? }\end{array}$ & Unclear risk & Not stated \\
\hline
\end{tabular}

Narahara 2011

\begin{tabular}{ll}
\hline Methods & Multicentre RCT \\
2 arms \\
Quality score: D \\
The study was conducted in Japan.
\end{tabular}

\begin{tabular}{ll}
\hline Participants & $\mathrm{n}=326$ \\
& Median age: 63 years \\
& Metastatic disease: $20 \%$ \\
& ECOG 2-3: $3 \%$ \\
\hline
\end{tabular}

Interventions

S-1: oral S-1 $80 \mathrm{mg} / \mathrm{m}^{2} /$ day d 1-28, repeated at 6 weeks

S-1 + irinotecan: oral S- $180 \mathrm{mg} / \mathrm{m}^{2} / \mathrm{d} \mathrm{d} 1-21+$ irinotecan iv $80 \mathrm{mg} / \mathrm{m}^{2} \mathrm{~d} 1+15$, repeated at 6 weeks

\begin{tabular}{ll}
\hline Outcomes & Overall survival \\
& Time to treatment failure \\
& Response rates \\
& Toxicity \\
\hline Notes & This study was conducted in Japan. Pre-planned follow-up of $\geq 1.5$ years after registration of all pa- \\
tients was continued to 2.5 years because of a unexpectedly high survival rate of $22 \%$ at the cut-off date \\
after a follow-up of 1.5 years. Second-line chemotherapy was administered to $76 \%$ of patients.
\end{tabular}

\section{Risk of bias}

\begin{tabular}{lll}
\hline Bias & Authors' judgement & Support for judgement \\
\hline $\begin{array}{l}\text { Random sequence genera- } \\
\text { tion (selection bias) }\end{array}$ & Low risk & Centralised dynamic allocation \\
\hline $\begin{array}{l}\text { Allocation concealment } \\
\text { (selection bias) }\end{array}$ & Low risk & Centralised dynamic allocation \\
\hline $\begin{array}{l}\text { Incomplete outcome data } \\
\text { (attrition bias) } \\
\text { efficacy }\end{array}$ & Low risk & Full analysis set \\
\hline $\begin{array}{l}\text { Incomplete outcome data } \\
\text { (attrition bias) }\end{array}$ & Unclear risk & $\begin{array}{l}\text { 4 patients found to be ineligible after starting treatment were excluded from } \\
\text { safety analysis - ?per-protocol analysis }\end{array}$ \\
\hline
\end{tabular}


Narahara 2011 (Continued)

safety

Selective reporting (re- Low risk Expected endpoints reported
porting bias)

Other bias High risk Second-line chemotherapy was administered to a total of $76 \%$ of patients. This is likely to dilute the effect of both treatments on overall survival, but not on progression-free-survival.

Blinded review of CT/MRI- Unclear risk Extramural review is described (does not neccessarily mean blinded)
scans?

Nishikawa 2012

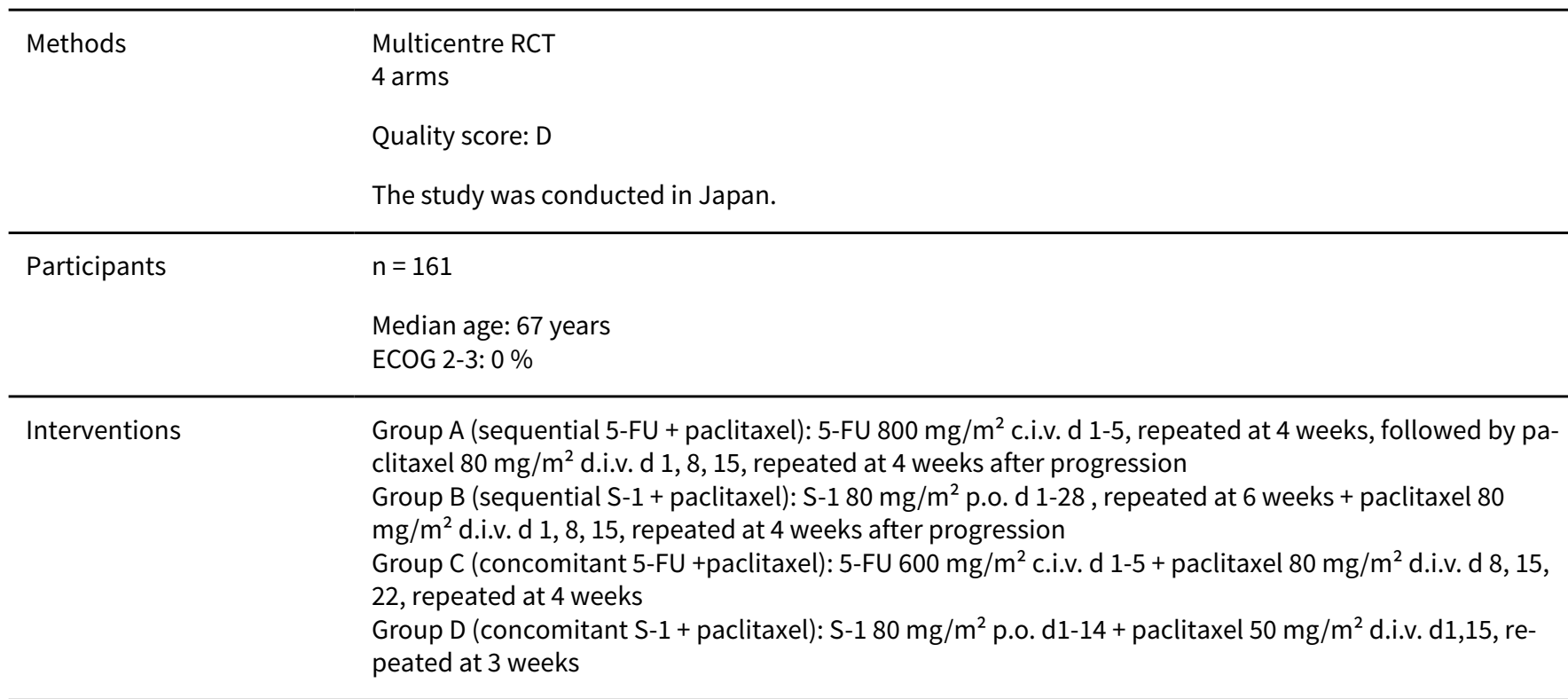

\begin{tabular}{ll}
\hline Outcomes & Overall survival (10 months overall survival rate) \\
Progression-free survival \\
Time to treatment failure \\
Response rates \\
Toxicity \\
This study was conducted in Japan. After publication of the results of the SPIRITS trial (Koizumi 2008) \\
candidates for accrual were informed about the new treatment standard in Japan and they were of- \\
fered the alternative to receive the combination therapy instead of participating in the trial.
\end{tabular}

\section{Risk of bias}

\begin{tabular}{lll}
\hline Bias & Authors' judgement & Support for judgement \\
\hline $\begin{array}{l}\text { Random sequence genera- } \\
\text { tion (selection bias) }\end{array}$ & Low risk & Centralised dynamic randomisation \\
\hline $\begin{array}{l}\text { Allocation concealment } \\
\text { (selection bias) }\end{array}$ & Low risk & Centralised dynamic randomisation \\
\hline \hline
\end{tabular}


Nishikawa 2012 (Continued)

$\begin{array}{ll}\text { Incomplete outcome data Low risk } & \text { Only two patients in arm A and two in arm C declined therapies before the } \\ \text { (attrition bias) } & \text { start of the assigned treatment }\end{array}$
efficacy

\begin{tabular}{|c|c|c|}
\hline $\begin{array}{l}\text { Incomplete outcome data } \\
\text { (attrition bias) } \\
\text { safety }\end{array}$ & Low risk & $\begin{array}{l}\text { Only two patients in arm } \mathrm{A} \text { and two in arm } \mathrm{C} \text { declined therapies before the } \\
\text { start of the assigned treatment }\end{array}$ \\
\hline
\end{tabular}

\begin{tabular}{lll}
\hline $\begin{array}{l}\text { Selective reporting (re- } \\
\text { porting bias) }\end{array}$ & Low risk & Expected endpoints are reported \\
\hline Other bias & Unclear risk & $\begin{array}{l}\text { An irinotecan-containing regimen was recommended for use in case if further } \\
\text { lines of treatment were given. No information about the percentage of pa- } \\
\text { tients receiving second line treatment is provided. }\end{array}$ \\
\hline $\begin{array}{l}\text { Blinded review of CT/MRI- } \\
\text { scans? }\end{array}$ & Unclear risk & not stated \\
\hline
\end{tabular}

Ochenduszko 2015

\begin{tabular}{|c|c|}
\hline Methods & Randomised, single-centre phase 3 study \\
\hline Participants & $\begin{array}{l}\text { "Most patients had metastatic disease and more than } 50 \% \text { of patients in each arm have undergone } \\
\text { gastrectomy (primary tumor resection) as part of curative or palliative treatment. Significantly more } \\
\text { patients in the mDCF arm presented with metastases in the liver ( } 48.1 \text { vs. } 17.2 \% ; p=0.029) "\end{array}$ \\
\hline Interventions & $\begin{array}{l}\text { "The EOX regimen was given every } 3 \text { weeks, initially for a maximum of eight cycles ( } 24 \text { weeks of treat- } \\
\text { ment). It consisted of epirubicin } 50 \mathrm{mg} / \mathrm{m}^{2} \text { (intravenous bolus), followed by oxaliplatin } 130 \mathrm{mg} / \mathrm{m}^{2}(2- \\
\text { h intravenous infusion); capecitabine was administered orally, twice daily at the dose of } 625 \mathrm{mg} / \mathrm{m}^{2} \text { for } \\
21 \text { days. The } \mathrm{mDCF} \text { regimen was administered every } 2 \text { weeks, initially for a maximum of } 12 \mathrm{cycles} \text { ( } 24 \\
\text { weeks of treatment), docetaxel } 40 \mathrm{mg} / \mathrm{m}^{2} \text { (intravenous infusion over } 60 \mathrm{~min} \text { ) on day } 1 \text {, followed by leu- } \\
\text { covorin } 400 \mathrm{mg} / \mathrm{m}^{2} \text { (intravenous infusion over } 120 \mathrm{~min} \text { ) on day } 1 \text {, followed by } 5 \text {-fluorouracil } 400 \mathrm{mg} / \mathrm{m}^{2} \\
\text { (intravenous bolus) on day } 1 \text {, and then } 5 \text {-fluorouracil } 1000 \mathrm{mg} / \mathrm{m}^{2} / \text { day continuous intravenous infusion } \\
\text { on day } 1 \text { and day 2, followed by cisplatin } 40 \mathrm{mg} / \mathrm{m}^{2} \text { (intravenous infusion over } 60 \text { min) on day 3." }\end{array}$ \\
\hline
\end{tabular}

\begin{tabular}{ll}
\hline Outcomes & OS \\
& PFS - the definition of PFS was not clearly stated \\
& Safety
\end{tabular}

\section{Notes}

\section{Risk of bias}

\begin{tabular}{lll}
\hline Bias & Authors' judgement & Support for judgement \\
\hline $\begin{array}{l}\text { Random sequence genera- } \\
\text { tion (selection bias) }\end{array}$ & Unclear risk & Not stated \\
\hline $\begin{array}{l}\text { Allocation concealment } \\
\text { (selection bias) }\end{array}$ & Unclear risk & Not stated \\
\hline $\begin{array}{l}\text { Incomplete outcome data } \\
\text { (attrition bias) }\end{array}$ & Low risk & No loss to follow-up \\
\end{tabular}


Ochenduszko 2015 (Continued) efficacy

Incomplete outcome data Low risk Only one patient from mDCF arm excluded due to rapid disease progression
(attrition bias)
safety

\begin{tabular}{lll}
\hline $\begin{array}{l}\text { Selective reporting (re- } \\
\text { porting bias) }\end{array}$ & Unclear risk & RR not provided \\
\hline Other bias & High risk & $\begin{array}{l}\text { "Significantly more patients in the mDCF arm presented with metastases in } \\
\text { the liver }(48.1 \text { vs. } 17.2 \% ; \mathrm{p}=0.029) \text { " - no statistical adjustment was made for } \\
\text { baseline imbalance }\end{array}$ \\
& $\begin{array}{l}\text { CT scans every 8-12 weeks; and disease progression could also be evaluated } \\
\text { based on clinical symptoms and urgent CT was requested whenever needed }\end{array}$ \\
\hline $\begin{array}{l}\text { Blinded review of CT/MRI- } \\
\text { scans? }\end{array}$ & Unclear risk & Not stated \\
\hline
\end{tabular}

\section{Ocvirk 2012}

\begin{tabular}{|c|c|}
\hline Methods & $\begin{array}{l}\text { Single-centre RCT } \\
2 \text { arms } \\
\text { Quality score: D }\end{array}$ \\
\hline Participants & $\begin{array}{l}\mathrm{n}=85 \\
\text { Median age: } 55 \text { years } \\
\text { Metastatic disease: } 85 \% \\
\text { ECOG 2-3: } 6 \%\end{array}$ \\
\hline Interventions & $\begin{array}{l}\text { ECF: epirubicin } 50 \mathrm{mg} / \mathrm{m}^{2} \text { i.v. } \mathrm{d} 1+\text { cisplatin } 60 \mathrm{mg} / \mathrm{m}^{2} \text { i.v. } \mathrm{d} 1 \text { i.v. }+5 \text { - FU } 200 \mathrm{mg} / \mathrm{m}^{2} / \text { day continuous infu- } \\
\text { sion d 1-14, repeated at d } 22 \\
\text { ECX: epirubicin } 50 \mathrm{mg} / \mathrm{m}^{2} \text { i.v. d1+ cisplatin } 60 \mathrm{mg} / \mathrm{m}^{2} \text { i.v. d } 1+\text { capecitabine } 825 \mathrm{mg} / \mathrm{m}^{2} \text { orally twice daily } \\
\text { d 1-14, repeated at d } 22 \\
\text { Treatment was discontinued in case of disease progression, unacceptable toxicity, or if the patient re- } \\
\text { fused further treatment }\end{array}$ \\
\hline Outcomes & $\begin{array}{l}\text { Overall survival } \\
\text { Response rates } \\
\text { Time to progression } \\
\text { Toxicity }\end{array}$ \\
\hline
\end{tabular}

\section{Notes}

\section{Risk of bias}

\begin{tabular}{lll} 
Bias & Authors' judgement & Support for judgement \\
\hline $\begin{array}{l}\text { Random sequence genera- } \\
\text { tion (selection bias) }\end{array}$ & Unclear risk & The method of sequence generation is not described \\
\hline
\end{tabular}


Ocvirk 2012 (Continued)

\begin{tabular}{lll}
$\begin{array}{l}\text { Allocation concealment } \\
\text { (selection bias) }\end{array}$ & Low risk & "Randomisation and allocation were done by a registration center" \\
\hline $\begin{array}{l}\text { Incomplete outcome data } \\
\text { (attrition bias) } \\
\text { efficacy }\end{array}$ & Low risk & All randomised patients were included in the ITT analysis \\
\hline
\end{tabular}

\begin{tabular}{lll}
\hline $\begin{array}{l}\text { Incomplete outcome data } \\
\text { (attrition bias) } \\
\text { safety }\end{array}$ & Low risk & All randomised patients were included in the ITT analysis \\
\hline $\begin{array}{l}\text { Selective reporting (re- } \\
\text { porting bias) }\end{array}$ & Low risk & N/A - except that TTP rather than PFS reported \\
\hline $\begin{array}{l}\text { Other bias } \\
\text { High risk }\end{array}$ & High risk & $\begin{array}{l}\text { Response assessment was done by abdominal ultrasound and/or abdominal } \\
\text { CT (not CT of the thorax and abdomen). Both methods are insufficient. }\end{array}$ \\
\hline \begin{tabular}{l} 
scans? \\
\hline
\end{tabular} & $\begin{array}{l}\text { Response assessment was done by abdominal ultrasound and/or abdominal } \\
\mathrm{CT} \text { (not CT of the thorax and abdomen). Both methods are insufficient. }\end{array}$
\end{tabular}

\section{Ohtsu 2003}

\begin{tabular}{ll}
\hline Methods & Multicentre RCT \\
& 3 arms \\
& Quality score: A \\
\hline Participants & $\mathrm{n}=280$ \\
& Median age: 62 years \\
& Metastatic disease: $86 \%$ \\
& ECOG 2-3: $17 \%$
\end{tabular}

\begin{tabular}{ll}
\hline Interventions & FU: 5 -FU $800 \mathrm{mg} / \mathrm{m}^{2} \mathrm{Cl} \mathrm{d} 1-5$, repeated at d 29 \\
& versus \\
& FP: 5 -FU $800 \mathrm{mg} / \mathrm{m}^{2} \mathrm{Cl}$ d 1-5; cisplatin $20 \mathrm{mg} / \mathrm{m}^{2} \mathrm{~d} 1-5$, repeated at d 29 \\
& versus \\
& UFTM: UFT (uracil/tegafur) $375 \mathrm{mg} / \mathrm{m}^{2}$ twice daily p.o., mitomycin $5 \mathrm{mg} / \mathrm{m}^{2} \mathrm{~d} 1$, repeated at d 8 \\
\hline Outcomes & Median survival \\
& Response rates \\
& Toxicity \\
\hline Notes & $\begin{array}{l}\text { Full information about second-line therapy given: } 51 \% \text { of participants in the combination therapy arms } \\
\text { and 57\% of participants in the single-agent 5-FU arm received a second-line therapy }\end{array}$
\end{tabular}

\section{Risk of bias}

\begin{tabular}{lll}
\hline Bias & Authors' judgement & Support for judgement \\
\hline $\begin{array}{l}\text { Random sequence genera- } \\
\text { tion (selection bias) }\end{array}$ & Low risk & Minimisation \\
\hline $\begin{array}{l}\text { Allocation concealment } \\
\text { (selection bias) }\end{array}$ & Low risk & JCOG data centre \\
\hline $\begin{array}{l}\text { Incomplete outcome data } \\
\text { (attrition bias) }\end{array}$ & Low risk & ITT \\
\hline
\end{tabular}


Ohtsu 2003 (Continued)

efficacy

\begin{tabular}{|c|c|}
\hline $\begin{array}{l}\text { Incomplete outcome data } \\
\text { (attrition bias) }\end{array}$ & Low risk \\
\hline
\end{tabular}

safety

\begin{tabular}{lll}
\hline $\begin{array}{l}\text { Selective reporting (re- } \\
\text { porting bias) }\end{array}$ & Low risk & Report includes all expected outcomes \\
\hline Other bias & Low risk & $\begin{array}{l}\text { Both combination chemotherapy arms (FP and UFTM) were combined in the } \\
\text { analysis. High rates of second-line therapy. }\end{array}$ \\
\hline
\end{tabular}

Blinded review of CT/MRI- Unclear risk "objective responses confirmed by central review at regular group meetings" scans?

\section{Popov 2002}

\begin{tabular}{|c|c|}
\hline Methods & $\begin{array}{l}\text { Single-centre RCT } \\
2 \text { arms } \\
\text { Quality score: D }\end{array}$ \\
\hline Participants & $\begin{array}{l}\mathrm{n}=60 \\
\text { Median age: } 56 \text { years } \\
\text { Metastatic disease: } 82 \% \\
\text { ECOG 2-3: } 17 \%\end{array}$ \\
\hline Interventions & $\begin{array}{l}5 \text {-FU } 2600 \mathrm{mg} / \mathrm{m}^{2} \text { over } 24 \text { hours } \mathrm{d} 1 \text {, repeated at d } 15 \\
\text { versus } \\
\text { EAP: etoposide } 120 \mathrm{mg} / \mathrm{m}^{2} \mathrm{~d} 4-6 \text {; adriamycin } 20 \mathrm{mg} / \mathrm{m}^{2} \mathrm{~d} 1,7 ; \text { cisplatin } 40 \mathrm{mg} / \mathrm{m}^{2} \mathrm{~d} 2,8 \text {, repeated at d } \\
29\end{array}$ \\
\hline Outcomes & $\begin{array}{l}\text { Median survival } \\
\text { Time to progression } \\
\text { Response rates } \\
\text { Toxicity }\end{array}$ \\
\hline Notes & $\begin{array}{l}\text { Study published as abstract, information on final results provided by first author (Popov 2002). Final } \\
\text { publication in Medical Oncology } 2008 .\end{array}$ \\
\hline
\end{tabular}

\section{Risk of bias}

\begin{tabular}{lll}
\hline Bias & Authors' judgement & Support for judgement \\
\hline $\begin{array}{l}\text { Random sequence genera- } \\
\text { tion (selection bias) }\end{array}$ & Low risk & Method of random numbers \\
\hline $\begin{array}{l}\text { Allocation concealment } \\
\text { (selection bias) }\end{array}$ & Unclear risk & Not stated \\
\hline $\begin{array}{l}\text { Incomplete outcome data } \\
\text { (attrition bias) } \\
\text { efficacy }\end{array}$ & Low risk & No excluded patients \\
\hline $\begin{array}{l}\text { Incomplete outcome data } \\
\text { (attrition bias) }\end{array}$ & Low risk & No excluded patients \\
safety & & \\
\hline \hline
\end{tabular}


Popov 2002 (Continued)

Selective reporting (re- Low risk $\quad$ Report includes all expected outcomes
porting bias)

\begin{tabular}{lll}
\hline Other bias & Unclear risk & N/A \\
\hline $\begin{array}{l}\text { Blinded review of CT/MRI- } \\
\text { scans? }\end{array}$ & Low risk & $\begin{array}{l}\text { Independent response review was performed by a joint interdisciplinary com- } \\
\text { mittee not involved in the study }\end{array}$ \\
\hline
\end{tabular}

\section{Popov 2008}

\begin{tabular}{ll}
\hline Methods & RCT \\
& 2 arms \\
& Quality score: $\mathrm{D}$ \\
\hline Participants & $\mathrm{n}=72$ \\
& Median age: 56 years \\
& ECOG 2-3: $29 \%$
\end{tabular}

\section{Risk of bias}

\begin{tabular}{lll}
\hline Bias & Authors' judgement & Support for judgement \\
\hline $\begin{array}{l}\text { Random sequence genera- } \\
\text { tion (selection bias) }\end{array}$ & Unclear risk & Not stated \\
\hline $\begin{array}{l}\text { Allocation concealment } \\
\text { (selection bias) }\end{array}$ & Unclear risk & Not stated \\
\hline $\begin{array}{l}\text { Incomplete outcome data } \\
\text { (attrition bias) } \\
\text { efficacy }\end{array}$ & High risk & Patients receiving 4 or more cycles were evaluable for efficacy \\
\hline $\begin{array}{l}\text { Incomplete outcome data } \\
\text { (attrition bias) } \\
\text { safety }\end{array}$ & Low risk & Patients receiving 1 cycle were evaluable for toxicity \\
\hline $\begin{array}{l}\text { Selective reporting (re- } \\
\text { porting bias) }\end{array}$ & Low risk & Report includes all expected outcomes \\
\hline
\end{tabular}


Popov 2008 (Continued)

\begin{tabular}{|c|c|c|}
\hline Other bias & Unclear risk & $\mathrm{N} / \mathrm{A}$ \\
\hline $\begin{array}{l}\text { Blinded review of CT/MRI- } \\
\text { scans? }\end{array}$ & Low risk & $\begin{array}{l}\text { "Independent response review was performed by members (surgeon, med- } \\
\text { ical oncologist, radiologist and pathologist) of the joint interdisciplinary com- } \\
\text { mittee for gastrointestinal tumors of the Institute and the University Clinic for } \\
\text { gastrointestinal diseases. The committee members were not involved in the } \\
\text { study" }\end{array}$ \\
\hline
\end{tabular}

Pyrhönen 1995

\begin{tabular}{ll}
\hline Methods & $\begin{array}{l}\text { RCT } \\
2 \text { arms } \\
\text { Quality score: } \mathrm{B}\end{array}$ \\
\hline Participants & $\mathrm{n}=41$ \\
& Metastatic disease: $71 \%$ \\
\hline Interventions & FEMTX: methotrexate $1500 \mathrm{mg} / \mathrm{m}^{2} \mathrm{~d} 1,5-\mathrm{FU} 1500 \mathrm{mg} / \mathrm{m}^{2} \mathrm{~d} 1, \mathrm{Lv} 30 \mathrm{mg}$ p.o. every 6 hours $\mathrm{d} 1,2$, epiru- \\
& $\begin{array}{l}\text { bicin } 60 \mathrm{mg} / \mathrm{m}^{2} \mathrm{~d} 15, \text { repeated at } \mathrm{d} 29 \\
\text { versus } \\
\text { BSC }\end{array}$ \\
\hline Outcomes & Median survival \\
& $\begin{array}{l}\text { 1-and } 2 \text {-year survival rates } \\
\text { Response rates } \\
\text { Toxicity } \\
\text { Palliative measures }\end{array}$ \\
& $\begin{array}{l}\text { Study terminated after } 6 \text { years when } 41 \text { participants were randomised because of slow patient accrual } \\
\text { and "conspicuous difference in survival" }\end{array}$ \\
\hline Notes &
\end{tabular}

\section{Risk of bias}

\begin{tabular}{lll}
\hline Bias & Authors' judgement & Support for judgement \\
\hline $\begin{array}{l}\text { Random sequence genera- } \\
\text { tion (selection bias) }\end{array}$ & Low risk & $\begin{array}{l}\text { Random permutated blocks (length 10) were used. The block was not known } \\
\text { by clinicians. }\end{array}$ \\
\hline $\begin{array}{l}\text { Allocation concealment } \\
\text { (selection bias) }\end{array}$ & Low risk & $\begin{array}{l}\text { Sealed envelopes, Random permutated blocks (length 10) were used. The } \\
\text { block was not known by clinicians. }\end{array}$ \\
\hline $\begin{array}{l}\text { Incomplete outcome data } \\
\text { (attrition bias) } \\
\text { efficacy }\end{array}$ & Low risk & Only 1 patient in treatment group did not receive at least one course of chemo \\
\hline $\begin{array}{l}\text { Incomplete outcome data } \\
\text { (attrition bias) } \\
\text { safety }\end{array}$ & Low risk & Only 1 patient in treatment group did not receive at least one course of chemo \\
\hline $\begin{array}{l}\text { Selective reporting (re- } \\
\text { porting bias) }\end{array}$ & Low risk & Report includes all expected outcomes \\
\hline \begin{tabular}{l} 
Other bias \\
\hline
\end{tabular} & High risk & Early termination of the study \\
\hline
\end{tabular}


Pyrhönen 1995 (Continued)

Blinded review of $\mathrm{CT} / \mathrm{MRI}-\quad$ High risk High risk
scans?

scans?

Ridwelski 2008

\begin{tabular}{ll}
\hline Methods & Multicentre RCT \\
& 2 arms \\
& Quality score: B \\
\hline
\end{tabular}

\begin{tabular}{ll}
\hline Participants & $\mathrm{n}=273$ \\
& Median age: 62 years \\
& Metastatic disease: $90 \%$
\end{tabular}

Interventions $\quad$ DC: docetaxel $75 \mathrm{mg} / \mathrm{m}^{2}+$ cisplatin $75 \mathrm{mg} / \mathrm{m}^{2} \mathrm{~d}$ 1, repeated at $3 \mathrm{w}$

FLC: 5-FU $2000 \mathrm{mg} / \mathrm{m}^{2}+$ leucovorin $500 \mathrm{mg} / \mathrm{m}^{2} \mathrm{~d} \mathrm{1}, 8,15,22,29,36$, repeated at $7 \mathrm{w}+$ cisplatin $50 \mathrm{mg} /$ $\mathrm{m}^{2} \mathrm{~d} 1,15,29$, repeated at $7 \mathrm{w}$ (cisplatin omitted in FLC in cycle 4)

\begin{tabular}{|c|c|c|}
\hline Outcomes & \multicolumn{2}{|c|}{$\begin{array}{l}\text { Median overall and hazard ratios for survival and time to progression } \\
\text { 1-year survival } \\
\text { Tumour response } \\
\text { Toxicity }\end{array}$} \\
\hline Notes & \multicolumn{2}{|c|}{ Study currently published as abstract only. Information on final results provided by first author. } \\
\hline \multicolumn{3}{|l|}{ Risk of bias } \\
\hline Bias & Authors' judgement & Support for judgement \\
\hline $\begin{array}{l}\text { Random sequence genera- } \\
\text { tion (selection bias) }\end{array}$ & Low risk & Random number tables \\
\hline $\begin{array}{l}\text { Allocation concealment } \\
\text { (selection bias) }\end{array}$ & Low risk & Central \\
\hline $\begin{array}{l}\text { Incomplete outcome data } \\
\text { (attrition bias) } \\
\text { efficacy }\end{array}$ & Low risk & Analysis for all randomised and screened patients \\
\hline $\begin{array}{l}\text { Incomplete outcome data } \\
\text { (attrition bias) } \\
\text { safety }\end{array}$ & Low risk & Analysis for all randomised, screened and treated patients \\
\hline $\begin{array}{l}\text { Selective reporting (re- } \\
\text { porting bias) }\end{array}$ & Low risk & Report includes all expected outcomes \\
\hline Other bias & Unclear risk & $\mathrm{N} / \mathrm{A}$ \\
\hline $\begin{array}{l}\text { Blinded review of CT/MRI- } \\
\text { scans? }\end{array}$ & High risk & Per first author \\
\hline
\end{tabular}

Ross 2002

Methods Multicentre RCT


Ross 2002 (Continued)

2 arms

Quality score: B

\begin{tabular}{|c|c|}
\hline Participants & $\begin{array}{l}\mathrm{n}=334 \text { participants with adenocarcinoma of the stomach or gastro-oesophageal junction } \\
\text { Median age: } 55 \text { years } \\
\text { Metastatic disease: } 68 \% \\
\text { ECOG 2-3: } 18 \%\end{array}$ \\
\hline Interventions & $\begin{array}{l}\text { ECF: epirubicin } 50 \mathrm{mg} / \mathrm{m}^{2} \mathrm{~d} 1 \text {, repeated at d 22; cisplatin } 60 \mathrm{mg} / \mathrm{m}^{2} \mathrm{~d} 1 \text {, repeated at d } 22,5-\mathrm{FU} \mathrm{Cl} 300 \\
\mathrm{mg} / \mathrm{m}^{2} \text { continuously } \\
\text { versus } \\
\text { MCF: mitomycin } 7 \mathrm{mg} / \mathrm{m}^{2} \mathrm{~d} 1 \text {, repeated at d } 43 \text {; cisplatin } 60 \mathrm{mg} / \mathrm{m}^{2} \mathrm{~d} 1 \text {, repeated at d } 22,5-\mathrm{FU} \mathrm{Cl} 300 \\
\mathrm{mg} / \mathrm{m}^{2} \text { continuously }\end{array}$ \\
\hline Outcomes & $\begin{array}{l}\text { Median survival } \\
\text { Response rates } \\
\text { Quality of life } \\
\text { Toxicity }\end{array}$ \\
\hline Notes & $\begin{array}{l}\text { The original study included } 580 \text { participants with inoperable adenocarcinoma, squamous cell carcino- } \\
\text { ma, or undifferentiated carcinoma of the oesophagus, oesophagogastric junction or stomach. Informa- } \\
\text { tion on participants with gastric and gastro-oesophageal junction adenocarcinoma only was provided } \\
\text { by the first author and is included in the meta-analysis. }\end{array}$ \\
\hline
\end{tabular}

\section{Risk of bias}

\begin{tabular}{lll}
\hline Bias & Authors' judgement & Support for judgement \\
\hline $\begin{array}{l}\text { Random sequence genera- } \\
\text { tion (selection bias) }\end{array}$ & Unclear risk & Query (correspondence) to first author was not answered \\
\hline $\begin{array}{l}\text { Allocation concealment } \\
\text { (selection bias) }\end{array}$ & Unclear risk & Query (correspondence) to first author was not answered \\
\hline $\begin{array}{l}\text { Incomplete outcome data } \\
\text { (attrition bias) } \\
\text { efficacy }\end{array}$ & Low risk & ITT \\
\hline $\begin{array}{l}\text { Incomplete outcome data } \\
\text { (attrition bias) }\end{array}$ & Low risk & ITT \\
safety & Low risk & Report includes all expected outcomes \\
\hline $\begin{array}{l}\text { Selective reporting (re- } \\
\text { porting bias) }\end{array}$ & Unclear risk & N/A \\
\hline $\begin{array}{l}\text { Other bias } \\
\begin{array}{l}\text { Blinded review of CT/MRI- } \\
\text { scans? }\end{array}\end{array}$ High risk & Not done per first author correspondence \\
\hline
\end{tabular}

Roth 1999

\begin{tabular}{ll}
\hline Methods & Single-centre RCT \\
& 2 arms \\
& Quality score: D \\
\hline
\end{tabular}


Roth 1999 (Continued)

$\begin{array}{ll}\text { Participants } & \mathrm{n}=122 \\ & \text { Median age: } 55 \text { years } \\ & \text { Metastatic disease: } 67 \% \\ & \text { ECOG 2-3: } 48 \%\end{array}$

\begin{tabular}{|c|c|}
\hline Interventions & $\begin{array}{l}\text { FE: 5-FU } 1000 \mathrm{mg} / \mathrm{m}^{2} \mathrm{Cl} \text { d 1-5, repeated at d 29; epirubicin } 120 \mathrm{mg} / \mathrm{m}^{2} \mathrm{~d} 1 \text {, repeated at d } 29 \\
\text { versus } \\
\text { FEP: } 5 \text {-FU } 1000 \mathrm{mg} / \mathrm{m}^{2} \mathrm{Cl} \text { d 1-5, repeated at d 29, epirubicin } 120 \mathrm{mg} / \mathrm{m}^{2} \mathrm{~d} 1 \text {, repeated at d } 29, \mathrm{P} 30 \mathrm{mg} / \\
\mathrm{m}^{2} \mathrm{~d} 2,4 \text {, repeated at d } 29\end{array}$ \\
\hline Outcomes & $\begin{array}{l}\text { Median survival } \\
\text { Response rates } \\
\text { Toxicity }\end{array}$ \\
\hline Notes & - \\
\hline
\end{tabular}

\section{Risk of bias}

\begin{tabular}{lll}
\hline Bias & Authors' judgement & Support for judgement \\
\hline $\begin{array}{l}\text { Random sequence genera- } \\
\text { tion (selection bias) }\end{array}$ & Unclear risk & Not stated \\
\hline $\begin{array}{l}\text { Allocation concealment } \\
\text { (selection bias) }\end{array}$ & Unclear risk & Not stated \\
\hline $\begin{array}{l}\text { Incomplete outcome data } \\
\text { (attrition bias) } \\
\text { efficacy }\end{array}$ & Low risk & $110 / 122$ received treatment and were assessable \\
\hline $\begin{array}{l}\text { Incomplete outcome data } \\
\text { (attrition bias) } \\
\text { safety }\end{array}$ & Low risk & $110 / 122$ received treatment and were assessable \\
\hline $\begin{array}{l}\text { Selective reporting (re- } \\
\text { porting bias) }\end{array}$ & Low risk & All expected outcomes available \\
\hline $\begin{array}{l}\text { Other bias } \\
\text { Blinded review of CT/MRI- }\end{array}$ & High risk & No information about type and schedule of follow-up \\
\hline scans? & High risk \\
\hline
\end{tabular}

\section{Roth 2007}

\begin{tabular}{ll}
\hline Methods & Multicentre RCT \\
& $\begin{array}{l}3 \text { arms } \\
\text { Quality score: } \mathrm{A}\end{array}$ \\
\hline Participants & $\mathrm{n}=121$ \\
& Median age: 59 years \\
& Metastatic disease: $86 \%$ \\
\hline Interventions & ECF: epirubicin $50 \mathrm{mg} / \mathrm{m}^{2} \mathrm{~d} 1+$ cisplatin $60 \mathrm{mg} / \mathrm{m}^{2} \mathrm{~d} 1+\mathrm{FU} 200 \mathrm{mg} / \mathrm{m}^{2} / \mathrm{d}$ as 24 -hour continuous infu- \\
& sion on days $1-21$, repeated at d 22 \\
& TC: docetaxel $85 \mathrm{mg} / \mathrm{m}^{2} \mathrm{~d} 1+$ cisplatin $75 \mathrm{mg} / \mathrm{m}^{2} \mathrm{~d} 1$, repeated at d 22 \\
\hline
\end{tabular}


Roth 2007 (Continued)

TCF: TC + FU $300 \mathrm{mg} / \mathrm{m}^{2} / \mathrm{d}$ as a 24-hour continuous infusion d 1-14, repeated at $\mathrm{d} 22$ for up to 8 cycles

\begin{tabular}{|c|c|c|}
\hline Outcomes & \multicolumn{2}{|c|}{$\begin{array}{l}\text { Tumour response } \\
\text { Median overall survival and time to progression } \\
\text { Toxicity } \\
\text { Quality of life }\end{array}$} \\
\hline Notes & \multicolumn{2}{|c|}{$\begin{array}{l}\text { Because of the toxicity of this regimen, the dose of docetaxel was reduced to } 75 \mathrm{mg} / \mathrm{m}^{2} \text { later in the tri- } \\
\text { al. The results of two docetaxel arms were combined in the analysis. Second-line therapy after disease } \\
\text { progression in } 56 \% \text { of patients with docetaxel and } 48 \% \text { of patients without docetaxel. }\end{array}$} \\
\hline \multicolumn{3}{|l|}{ Risk of bias } \\
\hline Bias & Authors' judgement & Support for judgement \\
\hline $\begin{array}{l}\text { Random sequence genera- } \\
\text { tion (selection bias) }\end{array}$ & Unclear risk & Not stated \\
\hline $\begin{array}{l}\text { Allocation concealment } \\
\text { (selection bias) }\end{array}$ & Low risk & Central randomisation at the SAKK Co-ordinating Center \\
\hline $\begin{array}{l}\text { Incomplete outcome data } \\
\text { (attrition bias) } \\
\text { efficacy }\end{array}$ & Low risk & $\begin{array}{l}\text { "Of } 121 \text { patients randomly assigned between September } 1999 \text { and July } 2003 \text {, } \\
\text { two were not treated (renal failure, } n=1 \text {; and ineligibility, } n=1 \text { ) and were ex- } \\
\text { cluded. Another patient received two cycles of TCF before being considered in- } \\
\text { eligible but was included in the analyses." }\end{array}$ \\
\hline $\begin{array}{l}\text { Incomplete outcome data } \\
\text { (attrition bias) } \\
\text { safety }\end{array}$ & Low risk & $\begin{array}{l}\text { "Of } 121 \text { patients randomly assigned between September } 1999 \text { and July } 2003 \text {, } \\
\text { two were not treated (renal failure, } n=1 \text {; and ineligibility, } n=1 \text { ) and were ex- } \\
\text { cluded. Another patient received two cycles of TCF before being considered in- } \\
\text { eligible but was included in the analyses." }\end{array}$ \\
\hline $\begin{array}{l}\text { Selective reporting (re- } \\
\text { porting bias) }\end{array}$ & Low risk & Report includes all expected outcomes \\
\hline Other bias & Unclear risk & $\mathrm{N} / \mathrm{A}$ \\
\hline $\begin{array}{l}\text { Blinded review of } \mathrm{CT} / \mathrm{MRI}- \\
\text { scans? }\end{array}$ & Low risk & $\begin{array}{l}\text { All responses were confirmed by an independent panel of radiologists and an } \\
\text { oncologist }\end{array}$ \\
\hline
\end{tabular}

Roy 2012

\begin{tabular}{ll}
\hline Methods & Multicentre RCT \\
& $\begin{array}{l}2 \text { arms } \\
\text { Quality score: } \mathrm{D}\end{array}$ \\
\hline Participants & $\mathrm{n}=86$ \\
& Median age: 61 years \\
& Metastatic disease: $94 \%$ \\
& ECOG 2-3: $0 \%$ (Karnofsky performance status KPS was $\geq 70 \%$ for all patients) \\
\hline Interventions & DI: docetaxel $60 \mathrm{mg} / \mathrm{m}^{2}+$ irinotecan $250 \mathrm{mg} / \mathrm{m}^{2} \mathrm{~d} 1$, repeated at d 22 \\
& DF: docetaxel $85 \mathrm{mg} / \mathrm{m}^{2} \mathrm{~d} 1+5$-FU $750 \mathrm{mg} / \mathrm{m}^{2} \mathrm{~d} 1-5$, repeated at d 22 \\
\hline Outcomes & Response rates \\
& Time to progression \\
\hline
\end{tabular}


Roy 2012 (Continued)

Time to treatment failure

Duration of response

Overall survival

Toxicities

Clinical benefit (time to definitive worsening of KPS, time to definitive weight loss, time to definitive worsening of appetite and pain-free survival)

Notes $\quad 43 \%$ patients in the DI group and $49 \%$ patients in the DF group received second-line chemotherapy (mostly a platinum containing regimen)

\section{Risk of bias}

\begin{tabular}{|c|c|c|}
\hline Bias & Authors' judgement & Support for judgement \\
\hline $\begin{array}{l}\text { Random sequence genera- } \\
\text { tion (selection bias) }\end{array}$ & Unclear risk & Not stated \\
\hline $\begin{array}{l}\text { Allocation concealment } \\
\text { (selection bias) }\end{array}$ & Unclear risk & Not stated \\
\hline $\begin{array}{l}\text { Incomplete outcome data } \\
\text { (attrition bias) } \\
\text { efficacy }\end{array}$ & Low risk & ITT analysis with only 1 excluded because of jaundice in the DI group \\
\hline $\begin{array}{l}\text { Incomplete outcome data } \\
\text { (attrition bias) } \\
\text { safety }\end{array}$ & Low risk & ITT analysis with only 1 excluded because of jaundice in the DI group \\
\hline $\begin{array}{l}\text { Selective reporting (re- } \\
\text { porting bias) }\end{array}$ & Low risk & All expected endpoints included \\
\hline Other bias & Unclear risk & $\mathrm{N} / \mathrm{A}$ \\
\hline $\begin{array}{l}\text { Blinded review of } \mathrm{CT} / \mathrm{MRI}- \\
\text { scans? }\end{array}$ & Unclear risk & Assessed by external response review committee \\
\hline
\end{tabular}

Sadighi 2006

\begin{tabular}{|c|c|}
\hline Methods & $\begin{array}{l}\text { Single-centre RCT } \\
2 \text { arms } \\
\text { Quality score: D }\end{array}$ \\
\hline Participants & $\begin{array}{l}\mathrm{n}=86 \\
\text { Mean age: } 56 \text { years } \\
\text { Metastatic disease: } 100 \%\end{array}$ \\
\hline Interventions & $\begin{array}{l}\text { ECF: epirubicin } 60 \mathrm{mg} / \mathrm{m}^{2}+\text { cisplatin } 60 \mathrm{mg} / \mathrm{m}^{2}+5-\mathrm{FU} 750 \mathrm{mg} / \mathrm{m}^{2} / \text { day as } 5 \text { days continuous infusion; } \\
\text { repeated at d } 22 \text { for } 6 \text { cycles } \\
\text { TCF: docetaxel } 60 \mathrm{mg} / \mathrm{m}^{2}+\text { cisplatin } 60 \mathrm{mg} / \mathrm{m}^{2}+5 \text {-FU } 750 \mathrm{mg} / \mathrm{m}^{2} \text { as } 5 \text { days continuous infusion; repeat- } \\
\text { ed at d } 22 \text { for } 6 \text { cycles }\end{array}$ \\
\hline Outcomes & $\begin{array}{l}\text { Response rate } \\
\text { Quality of life }\end{array}$ \\
\hline
\end{tabular}


Sadighi 2006 (Continued)

Overall survival

Progression-free survival

\begin{tabular}{|c|c|c|}
\hline Notes & \multicolumn{2}{|c|}{ Extensive analysis of QoL data } \\
\hline \multicolumn{3}{|l|}{ Risk of bias } \\
\hline Bias & Authors' judgement & Support for judgement \\
\hline $\begin{array}{l}\text { Random sequence genera- } \\
\text { tion (selection bias) }\end{array}$ & Unclear risk & Not stated \\
\hline $\begin{array}{l}\text { Allocation concealment } \\
\text { (selection bias) }\end{array}$ & Unclear risk & Not stated \\
\hline $\begin{array}{l}\text { Incomplete outcome data } \\
\text { (attrition bias) } \\
\text { efficacy }\end{array}$ & Unclear risk & $\begin{array}{l}\text { No information regarding numbers of patients beside response rates (primary } \\
\text { endpoint) }\end{array}$ \\
\hline $\begin{array}{l}\text { Incomplete outcome data } \\
\text { (attrition bias) } \\
\text { safety }\end{array}$ & High risk & $\begin{array}{l}\text { For QoL evaluation, only } 71 \text { patients were included in the comparative analysis } \\
\text { because } 15 \text { patients did not complete the QoL measurements at the beginning } \\
\text { of the study }\end{array}$ \\
\hline $\begin{array}{l}\text { Selective reporting (re- } \\
\text { porting bias) }\end{array}$ & High risk & Missing information regarding PFS as secondary endpoint \\
\hline Other bias & Unclear risk & $\mathrm{N} / \mathrm{A}$ \\
\hline $\begin{array}{l}\text { Blinded review of CT/MRI- } \\
\text { scans? }\end{array}$ & Unclear risk & Not stated \\
\hline
\end{tabular}

Scheithauer 1996

\begin{tabular}{ll}
\hline Methods & Multicentre RCT \\
& 2 arms \\
& Quality score: B
\end{tabular}

\begin{tabular}{ll}
\hline Participants & $\mathrm{n}=103$ \\
& $\begin{array}{l}\text { Metastatic disease: } 63 \% \\
\text { ECOG 2-3: } 29 \%\end{array}$ \\
\hline Interventions & $\begin{array}{l}\text { FE: } 5 \text {-FU } 400 \mathrm{mg} / \mathrm{m}^{2} \mathrm{~d} 1-5 ; \mathrm{Lv} 200 \mathrm{mg} / \mathrm{m}^{2} \mathrm{~d} \text { 1-5; epirubicin } 50 \mathrm{mg} / \mathrm{m}^{2} \mathrm{~d} \text { 1, repeated at d 29 } \\
\text { versus } \\
\text { BSC }\end{array}$ \\
\hline Outcomes & $\begin{array}{l}\text { Median survival } \\
\text { Response rates } \\
\text { 1- and 2-year survival rates } \\
\text { Quality of life } \\
\text { Toxicity }\end{array}$ \\
\hline Notes & Study published as abstract only; additional information provided by first author \\
\hline
\end{tabular}

\section{Risk of bias}


Scheithauer 1996 (Continued)

Random sequence genera- Low risk tion (selection bias)

\begin{tabular}{lll}
\hline $\begin{array}{l}\text { Allocation concealment } \\
\text { (selection bias) }\end{array}$ & Low risk & Adequate \\
\hline $\begin{array}{l}\text { Incomplete outcome data } \\
\text { (attrition bias) } \\
\text { efficacy }\end{array}$ & Low risk & \\
\hline $\begin{array}{l}\text { Incomplete outcome data } \\
\text { (attrition bias) } \\
\text { safety }\end{array}$ & Low risk \\
\hline $\begin{array}{l}\text { Selective reporting (re- } \\
\text { porting bias) }\end{array}$ & Low risk \\
\hline $\begin{array}{l}\text { Other bias } \\
\text { Blinded review of CT/MRI- }\end{array}$ & High risk & High risk \\
scans? & \\
\hline
\end{tabular}

Shirao 2013

\begin{tabular}{ll}
\hline Methods & Multicentre RCT \\
2 arms \\
Quality score: B \\
The study was conducted in Japan .
\end{tabular}

\begin{tabular}{ll}
\hline Participants & $\mathrm{n}=237$ \\
& Median age: 60 years \\
& Metastatic disease: $100 \%$ (all patients had peritoneal metastasis), confirmed by imaging and/or ascites \\
& ECOG 2-3: $3.4 \%$
\end{tabular}

\begin{tabular}{ll}
\hline Interventions & 5-FU: 5 -FU $800 \mathrm{mg} / \mathrm{m}^{2} \mathrm{~d} 1-5$, repeated at d 29 \\
& versus \\
& MF: methotrexate $100 \mathrm{mg} / \mathrm{m}^{2} \mathrm{~d} 1+5$-FU $600 \mathrm{mg} / \mathrm{m}^{2} \mathrm{~d} 1+$ leucovorin rescue (leucovorin $\left.10 \mathrm{mg} / \mathrm{m}^{2} \times 6\right) \mathrm{d}$ \\
& 1, repeated at $\mathrm{d} 8$
\end{tabular}

\begin{tabular}{ll}
\hline Outcomes & $\begin{array}{l}\text { Overall survival, ingestion-possible survival (=surviving days free from nutrition support in patients } \\
\text { with sufficient ingestion aat baseline, ingestive improvement in patients without sufficient ingestion at } \\
\text { baseline), safety }\end{array}$
\end{tabular}

Notes

The study was registered as NCT00149201 and UMIN-CTR number C000000123.

\section{Risk of bias}

\begin{tabular}{lll}
\hline Bias & Authors' judgement & Support for judgement \\
\hline $\begin{array}{l}\text { Random sequence genera- } \\
\text { tion (selection bias) }\end{array}$ & Low risk & Minimization \\
\hline $\begin{array}{l}\text { Allocation concealment } \\
\text { (selection bias) }\end{array}$ & Low risk & Algorithm concealed to investigators \\
\hline
\end{tabular}


Shirao 2013 (Continued)
Incomplete outcome data Low risk
2 non-treated patients were excluded in each group.
(attrition bias)

efficacy

Incomplete outcome data Low risk 2 non-treated patients were excluded in each group.
(attrition bias)
safety

\begin{tabular}{lll}
\hline $\begin{array}{l}\text { Selective reporting (re- } \\
\text { porting bias) }\end{array}$ & High risk & No response and PFS reported \\
\hline Other bias & High risk & $\begin{array}{l}\text { Second-line treatment was given to 80.7\% of patients in the 5-FU group and } \\
72.9 \text { in the MF group, planned interim analysis }\end{array}$ \\
\hline $\begin{array}{ll}\text { Blinded review of CT/MRI- } \\
\text { scans? }\end{array}$ & Unclear risk & N/A (no response and PFS reported) \\
\hline
\end{tabular}

\section{Sugimoto 2014}

Multicentre, randomised phase 2
"Before randomization, patients were stratified according to unresectable advanced cancer/recurrent
cancer with adjuvant chemotherapy /recurrent cancer without adjuvant chemotherapy and ECOG PS
$0 / 1 / 2 "$

Participants
Median age: 64 (SIri) and 62 (SPac)
Advanced/recurrent ratio: $40 / 11$ in both arms
"no prior chemotherapy, except adjuvant chemotherapy completed four weeks or more before entry"
Schedule of S-1 was not similar in both arms
Arm A: SIri: Irinotecan (i.v.) over $1.5 \mathrm{~h}$ at $80 \mathrm{mg} / \mathrm{m}^{2}$ on day 1 and 15 , while $40 \mathrm{mg} / \mathrm{m}^{2} \mathrm{~S}-1$ (Taiho Pharma-
ceutical, Tokyo, Japan) was orally administered twice daily for three weeks from days $1-21$ followed by
a two-week pause.
Arm B: SPac: Paclitaxel was administered i.v. over 1 h at a dose of $50 \mathrm{mg} / \mathrm{m}^{2}$ on day 1 and 8 , while 40
mg/m $/ \mathrm{m}^{2}$ S-1 was orally administered at twice-daily for two weeks from dayl-14 followed by a one-week
pause.

\begin{tabular}{ll}
\hline Outcomes & Primary endpoint: Overall response rate \\
Secondary endpoints: Progression-free survival, overall survival and safety
\end{tabular}

\section{Notes}

\section{Risk of bias}

\begin{tabular}{lll}
\hline Bias & Authors' judgement & Support for judgement \\
\hline $\begin{array}{l}\text { Random sequence genera- } \\
\text { tion (selection bias) }\end{array}$ & Unclear risk & Not stated \\
\hline $\begin{array}{l}\text { Allocation concealment } \\
\text { (selection bias) }\end{array}$ & Unclear risk & Not stated \\
\hline $\begin{array}{l}\text { Incomplete outcome data } \\
\text { (attrition bias) }\end{array}$ & Low risk & (All outcomes analysed for all patients) \\
\hline
\end{tabular}


Sugimoto 2014 (Continued)

efficacy

\begin{tabular}{|c|c|c|}
\hline $\begin{array}{l}\text { Incomplete outcome data } \\
\text { (attrition bias) } \\
\text { safety }\end{array}$ & Low risk & (All outcomes analysed for all patients) \\
\hline $\begin{array}{l}\text { Selective reporting (re- } \\
\text { porting bias) }\end{array}$ & Low risk & Expected endpoints included in reporting \\
\hline Other bias & High risk & $\begin{array}{l}\text { High risk } \\
\text { Schedule of S-1 not similar in two arms }\end{array}$ \\
\hline $\begin{array}{l}\text { Blinded review of } \mathrm{CT} / \mathrm{MRI}- \\
\text { scans? }\end{array}$ & Low risk & ("All radiological assessments were confirmed by extratumoral review") \\
\hline
\end{tabular}

\section{Thuss-Patience 2005}

\begin{tabular}{|c|c|}
\hline Methods & $\begin{array}{l}\text { Multicentre RCT } \\
2 \text { arms } \\
\text { Quality score: A }\end{array}$ \\
\hline Participants & $\begin{array}{l}\mathrm{n}=90 \\
\text { Median age: } 62.5 \text { years } \\
\text { Metastatic disease: } 98 \% \\
\text { ECOG 2-3: } 3 \%\end{array}$ \\
\hline Interventions & $\begin{array}{l}\text { DF: docetaxel } 75 \mathrm{mg} / \mathrm{m}^{2} \mathrm{~d} 1+\mathrm{FU} 200 \mathrm{mg} / \mathrm{m}^{2} / \text { day as a } 24 \text {-hour continuous infusion } \mathrm{d} 1-21 \text {, repeated at d } \\
22 \\
\text { versus } \\
\text { ECF: epirubicin } 50 \mathrm{mg} / \mathrm{m}^{2} \mathrm{~d} 1+\text { cisplatin } 60 \mathrm{mg} / \mathrm{m}^{2} \mathrm{~d} 1+\mathrm{FU} 200 \mathrm{mg} / \mathrm{m}^{2} / \text { as a } 24 \text {-hour continuous infu- } \\
\text { sion d 1-21, repeated at d } 22\end{array}$ \\
\hline Outcomes & $\begin{array}{l}\text { Tumour response } \\
\text { Median survival } \\
\text { Median time to progression } \\
\text { Toxicity }\end{array}$ \\
\hline Notes & $\begin{array}{l}\text { Phase II study } \\
\text { The trial was not intended and not statistically powered to perform a head-to-head comparison of re- } \\
\text { sponse rate and toxicity of the } 2 \text { treatment arms. ECF serves as an internal control arm to avoid selec- } \\
\text { tion bias. }\end{array}$ \\
\hline
\end{tabular}

\section{Risk of bias}

\begin{tabular}{lll}
\hline Bias & Authors' judgement & Support for judgement \\
\hline $\begin{array}{l}\text { Random sequence genera- } \\
\text { tion (selection bias) }\end{array}$ & Low risk & Random numbers \\
\hline $\begin{array}{l}\text { Allocation concealment } \\
\text { (selection bias) }\end{array}$ & Low risk & Central allocation \\
\hline $\begin{array}{l}\text { Incomplete outcome data } \\
\text { (attrition bias) } \\
\text { efficacy }\end{array}$ & Low risk & Analysis of the full analysis set \\
\hline
\end{tabular}


Thuss-Patience 2005 (Continued)

Incomplete outcome data Low risk Analysis of the full analysis set
(attrition bias)
safety

\begin{tabular}{lll}
\hline $\begin{array}{l}\text { Selective reporting (re- } \\
\text { porting bias) }\end{array}$ & Low risk & Report includes all expected outcomes \\
\hline Other bias & High risk & $\begin{array}{l}\text { The trial was not intended and not statistically powered to perform a head-to- } \\
\text { head comparison of response rate and toxicity of the 2 treatment arms, ECF } \\
\text { serves as an internal control arm to avoid selection bias. }\end{array}$ \\
\hline $\begin{array}{l}\text { Blinded review of CT/MRI- } \\
\text { scans? }\end{array}$ & Low risk & Tumour response was assessed together with an independent radiologist \\
\hline
\end{tabular}

Van Cutsem 2006

\begin{tabular}{|c|c|}
\hline Methods & $\begin{array}{l}\text { Multicentre RCT } \\
2 \text { arms } \\
\text { Quality score: D }\end{array}$ \\
\hline Participants & $\begin{array}{l}\mathrm{n}=445 \\
\text { Median age: } 55 \text { years } \\
\text { Metastatic disease: } 96.5 \%\end{array}$ \\
\hline Interventions & $\begin{array}{l}\text { DCF: docetaxel } 75 \mathrm{mg} / \mathrm{m}^{2}+\text { cisplatin } 75 \mathrm{mg} / \mathrm{m}^{2} \mathrm{~d} 1+5-\mathrm{FU} 750 \mathrm{mg} / \mathrm{m}^{2} / \mathrm{d} \text { as a } 24 \text {-hour continuous infu- } \\
\text { sion d } 1-5 \text {, repeated at d } 22 \\
\text { versus } \\
\text { CF: cisplatin } 100 \mathrm{mg} / \mathrm{m}^{2} \mathrm{~d} 1+5 \text {-FU } 1.000 \mathrm{mg} / \mathrm{m}^{2} / \mathrm{d} \text { as a } 24 \text {-hour continuous infusion on d } 1-5 \text {, repeated } \\
\text { at d } 29\end{array}$ \\
\hline Outcomes & $\begin{array}{l}\text { Median overall survival and time to progression } \\
\text { Tumour response } \\
\text { Toxicity } \\
\text { Quality of life }\end{array}$ \\
\hline Notes & - \\
\hline
\end{tabular}

\section{Risk of bias}

\begin{tabular}{lll}
\hline Bias & Authors' judgement & Support for judgement \\
\hline $\begin{array}{l}\text { Random sequence genera- } \\
\text { tion (selection bias) }\end{array}$ & Unclear risk & Not stated \\
\hline $\begin{array}{l}\text { Allocation concealment } \\
\text { (selection bias) }\end{array}$ & Low risk & Central allocation \\
\hline $\begin{array}{l}\text { Incomplete outcome data } \\
\text { (attrition bias) } \\
\text { efficacy }\end{array}$ & Low risk & Analysis of the full-analysis set \\
\hline $\begin{array}{l}\text { Incomplete outcome data } \\
\text { (attrition bias) }\end{array}$ & Low risk & Analysis of the full-analysis set \\
safety & & \\
\hline
\end{tabular}


Van Cutsem 2006 (Continued)

\begin{tabular}{lll}
$\begin{array}{l}\text { Selective reporting (re- } \\
\text { porting bias) }\end{array}$ & Low risk & Report includes all expected outcomes \\
\hline Other bias & Unclear risk & N/A \\
\hline $\begin{array}{l}\text { Blinded review of CT/MRI- } \\
\text { scans? }\end{array}$ & Low risk & $\begin{array}{l}\text { All radiologic assessments were reviewed by an external response review com- } \\
\text { mittee and were assessed by WHO criteria }\end{array}$
\end{tabular}

\section{Van Cutsem 2015}

\begin{tabular}{ll}
\hline Methods & Prospective, multinational, randomised, phase II study \\
& Fifty-two sites in the USA and 11 countries in Europe screened and randomised patients \\
\hline Participants & The majority (69\%) of patients were male; mean age was 59 years \\
\hline Interventions & $\begin{array}{l}\text { 3-arm study: docetaxel/oxaliplatin (TE), docetaxel/oxaliplatin/5-FU (TEF), and docetaxel/oxali- } \\
\text { platin/capecitabine (TEX) }\end{array}$ \\
\hline Outcomes & PFS \\
& OS \\
& Safety \\
\hline "Tumour response was evaluated every 8 weeks and classified according to best overall response \\
(World Health Organization criteria). Responses were confirmed by two evaluations conducted $\geq 4$ \\
weeks apart"
\end{tabular}

\section{Risk of bias}

\begin{tabular}{lll}
\hline Bias & Authors' judgement & Support for judgement \\
\hline $\begin{array}{l}\text { Random sequence genera- } \\
\text { tion (selection bias) }\end{array}$ & Unclear risk & Not clear what method \\
\hline $\begin{array}{l}\text { Allocation concealment } \\
\text { (selection bias) }\end{array}$ & Low risk & RandomiSed centrally using an interactive voice response system \\
\hline $\begin{array}{l}\text { Incomplete outcome data } \\
\text { (attrition bias) } \\
\text { efficacy }\end{array}$ & Low risk & "primary efficacy population was the full analysis population (FAP: all random- \\
& $\begin{array}{l}\text { ized and treated patients analysed in the arm to which they were randomized), } \\
\text { with supportive analyses conducted using the intent-to-treat (ITT: all random- } \\
\text { ized patients) and per protocol (PP: assessable patients [received study treat- } \\
\text { ment and had } \geq 1 \text { post-baseline tumour assessment] without any major proto- } \\
\text { col violation) populations" }\end{array}$ \\
\hline $\begin{array}{l}\text { Incomplete outcome data } \\
\text { (attrition bias) } \\
\text { safety }\end{array}$ & Low risk & $\begin{array}{l}\text { "primary efficacy population was the full analysis population (FAP: all random- } \\
\text { ized and treated patients analysed in the arm to which they were randomized), } \\
\text { with supportive analyses conducted using the intent-to-treat (ITT: all random- } \\
\text { ized patients) and per protocol (PP: assessable patients [received study treat- } \\
\text { ment and had } \geq 1 \text { post-baseline tumour assessment] without any major proto- } \\
\text { col violation) populations" }\end{array}$ \\
\hline
\end{tabular}


Van Cutsem 2015 (Continued)

\begin{tabular}{lll}
$\begin{array}{l}\text { Selective reporting (re- } \\
\text { porting bias) }\end{array}$ & Low risk & PFS, OS, ORR, safety \\
\hline Other bias & Unclear risk & N/A \\
\hline $\begin{array}{l}\text { Blinded review of CT/MRI- } \\
\text { scans? }\end{array}$ & Unclear risk & Not stated \\
\hline
\end{tabular}

Wang 2013

\begin{tabular}{|c|c|}
\hline Methods & $\begin{array}{l}\text { Single-centre RCT } \\
2 \text { arms } \\
\text { Quality score: B }\end{array}$ \\
\hline Participants & $\begin{array}{l}n=82 \text { participants with metastatic or locally recurrent gastric cancer } \\
\text { ECOG 2: } 8.5 \%\end{array}$ \\
\hline Interventions & $\begin{array}{l}\text { S-1 +paclitaxel: S-1 depending on body surface area (BSA }<1.25 \mathrm{~m}^{2}: 80 \mathrm{mg} / \mathrm{d} ; \text { BSA } 1.25 \text { to }<1.5 \mathrm{~m} 2: 100 \\
\mathrm{mg} / \mathrm{d} ; \mathrm{BSA}>1.5 \mathrm{~m}^{2}, 120 \mathrm{mg} / \mathrm{d} \text { twice daily) d 1-14, paclitaxel } 60 \mathrm{mg} / \mathrm{m}^{2} \mathrm{~d} 1,8,15 \text {, repeated at d } 29 \\
\text { versus S-1: S-1 depending on body surface area (BSA }<1.25 \mathrm{~m}^{2}: 80 \mathrm{mg} / \mathrm{d} ; \mathrm{BSA} 1.25 \text { to }<1.5 \mathrm{~m}^{2}: 100 \mathrm{mg} / \mathrm{d} \text {; } \\
\text { BSA }>1.5 \mathrm{~m}^{2}, 120 \mathrm{mg} / \mathrm{d} \text { twice daily) d 1-14, repeated at d } 29\end{array}$ \\
\hline Outcomes & $\begin{array}{l}\text { Overall survival } \\
\text { Progression-free survival } \\
\text { Response rate } \\
\text { Toxicity }\end{array}$ \\
\hline Notes & Second-line therapy with cisplatin or irinotecan in more than half of the patients \\
\hline
\end{tabular}

\section{Risk of bias}

\begin{tabular}{lll}
\hline Bias & Authors' judgement & Support for judgement \\
\hline $\begin{array}{l}\text { Random sequence genera- } \\
\text { tion (selection bias) }\end{array}$ & Low risk & Computer-generated, random sequence \\
\hline $\begin{array}{l}\text { Allocation concealment } \\
\text { (selection bias) }\end{array}$ & Low risk & Consecutively numbered opaque sealed envelopes \\
\hline $\begin{array}{l}\text { Incomplete outcome data } \\
\text { (attrition bias) } \\
\text { efficacy }\end{array}$ & Low risk & No patients lost to follow-up and all outcomes could be confirmed \\
\hline $\begin{array}{l}\text { Incomplete outcome data } \\
\text { (attrition bias) } \\
\text { safety }\end{array}$ & Low risk & No patients lost to follow up and all outcomes could be confirmed \\
\hline $\begin{array}{l}\text { Selective reporting (re- } \\
\text { porting bias) }\end{array}$ & Low risk & OS, PFS, ORR, safety \\
\hline
\end{tabular}


Wang 2013 (Continued)

\begin{tabular}{lll} 
Other bias & Unclear risk & N/A \\
\hline $\begin{array}{l}\text { Blinded review of CT/MRI- } \\
\text { scans? }\end{array}$ & High risk & $\begin{array}{l}\text { Tumor assessment was undertaken with CT or MRI consistently every } 2 \\
\text { months by principal investigators }\end{array}$
\end{tabular}

\section{Wang 2016}

\begin{tabular}{ll}
\hline Methods & Multicentre, prospective, randomised, open-label, phase III trial \\
\hline Participants & Histo: $15 \%$ Signet ring, $3 \%$ Others \\
\hline Interventions & $\begin{array}{l}\text { "Untreated advanced gastric cancer patients randomly received docetaxel and cisplatin at } 60 \mathrm{mg} / \mathrm{m} 2 \\
\text { (day } 1 \text { ) followed by fluorouracil at } 600 \mathrm{mg} / \mathrm{m} 2 / \text { day (days } 1-5 ; \text { mDCF regimen) or cisplatin at } 75 \mathrm{mg} / \mathrm{m} 2 \\
\text { (day } 1 \text { ) followed by fluorouracil at } 600 \mathrm{mg} / \mathrm{m} 2 / \text { day (days } 1-5 ; \text { CF) every } 3 \text { weeks" }\end{array}$ \\
\hline Outcomes & "The primary end point was progression-free survival (PFS). The secondary end points were OS, overall \\
response rate (ORR), time-to-treatment failure (TTF), and safety"
\end{tabular}

\section{Risk of bias}

\begin{tabular}{lll} 
Bias & Authors' judgement & Support for judgement \\
\hline $\begin{array}{l}\text { Random sequence genera- } \\
\text { tion (selection bias) }\end{array}$ & Unclear risk & $\begin{array}{l}\text { Not stated what method was used. "Random assignment was centralized and } \\
\text { stratified for center, liver metastases, prior gastrectomy, Karnofsky perfor- } \\
\text { mance status (KPS) (80 or above vs below } 80), \text { and weight loss during the pre- } \\
\text { vious 3 months (5\% or less vs more than 5 \%)" }\end{array}$ \\
& & \\
\hline
\end{tabular}

\begin{tabular}{lll}
\hline $\begin{array}{l}\text { Allocation concealment } \\
\text { (selection bias) }\end{array}$ & Low risk & Random assignment was centralised \\
\hline $\begin{array}{l}\text { Incomplete outcome data } \\
\text { (attrition bias) } \\
\text { efficacy }\end{array}$ & Low risk & All patients who received treatment were included in full analysis set \\
\hline $\begin{array}{l}\text { Incomplete outcome data } \\
\text { (attrition bias) } \\
\text { safety }\end{array}$ & Low risk & All patients who received treatment were included in full analysis set \\
\hline $\begin{array}{l}\text { Selective reporting (re- } \\
\text { porting bias) }\end{array}$ & Low risk & Endpoints were all reported \\
\hline $\begin{array}{l}\text { Other bias } \\
\text { Blinded review of CT/MRI- }\end{array}$ & High risk & N/A \\
\hline scans? & $\begin{array}{l}\text { "Tumor response and PFS were evaluated by investigators, and although } \\
\text { much effort has been done to limit the bias in the evaluation of these parame- } \\
\text { ters..." }\end{array}$ \\
\hline
\end{tabular}

\section{Webb 1997}

\begin{tabular}{ll}
\hline Methods & Multicentre RCT \\
& 2 arms
\end{tabular}


Webb 1997 (Continued)

\section{Quality score: B}

Participants $\mathrm{n}=199$ participants with adenocarcinoma of the stomach or gastro-oesophageal junction
Metastatic disease: $85 \%$
ECOG 2-3: $26 \%$

Interventions

ECF: epirubicin $50 \mathrm{mg} / \mathrm{m}^{2} \mathrm{~d}$ 1, repeated at d 22; cisplatin $60 \mathrm{mg} / \mathrm{m}^{2} \mathrm{~d}$ 1, repeated at d 22, 5-FU Cl 200 $\mathrm{mg} / \mathrm{m}^{2} \mathrm{~d} 1-21$, repeated at $\mathrm{d} 22$

versus

FAMTX: methotrexate $1500 \mathrm{mg} / \mathrm{m}^{2} \mathrm{~d}$ 1; 5-FU $1500 \mathrm{mg} / \mathrm{m}^{2} \mathrm{~d}$ 1; Lv $30 \mathrm{mg}$ p.o. every 6 hours d 2, 3; adriamycin $30 \mathrm{mg} / \mathrm{m}^{2} \mathrm{~d} 15$, repeated at $\mathrm{d} 28$

\begin{tabular}{ll}
\hline Outcomes & $\begin{array}{l}\text { Median survival } \\
\text { Response rates } \\
\text { Toxicity } \\
\text { Quality of life }\end{array}$ \\
\hline Notes & $\begin{array}{l}\text { The entire study included } 274 \text { participants with inoperable adenocarcinoma or undifferentiated carci- } \\
\text { noma of the oesophagus, oesophagogastric junction or stomach. Results for participants with adeno- } \\
\text { carcinoma of the stomach or gastro-oesophageal junction only were provided by the corresponding } \\
\text { author and included in the meta-analysis. }\end{array}$
\end{tabular}

\section{Risk of bias}

\begin{tabular}{lll}
\hline Bias & Authors' judgement & Support for judgement \\
\hline $\begin{array}{l}\text { Random sequence genera- } \\
\text { tion (selection bias) }\end{array}$ & Unclear risk & Query to first author was not answered \\
\hline $\begin{array}{l}\text { Allocation concealment } \\
\text { (selection bias) }\end{array}$ & Unclear risk & Query to first author was not answered \\
\hline $\begin{array}{l}\text { Incomplete outcome data } \\
\text { (attrition bias) } \\
\text { efficacy }\end{array}$ & Low risk & ITT per correspondence \\
\hline $\begin{array}{l}\text { Incomplete outcome data } \\
\text { (attrition bias) } \\
\text { safety }\end{array}$ & Low risk & ITT per correspondence \\
\hline $\begin{array}{l}\text { Selective reporting (re- } \\
\text { porting bias) }\end{array}$ & Low risk & Report includes all expected outcomes \\
\hline $\begin{array}{l}\text { Other bias } \\
\text { Blinded review of CT/MRI- }\end{array}$ & High risk & N/A \\
\hline \begin{tabular}{l} 
scans? \\
\hline
\end{tabular} & Not done according to correspondence \\
\hline
\end{tabular}

\section{Wu 2015}

\begin{tabular}{ll}
\hline Methods & Pilot randomiSed-controlled study \\
\hline Participants & $\begin{array}{l}\text { "158 participants were initially screened, of whom } 86 \text { were excluded. Of these } 86 \text { patients, } 73 \text { did not } \\
\text { fulfill the study criteria and } 13 \text { declined to participate. The remaining } 72 \text { patients (36 treated with SC } \\
\text { and } 36 \text { treated with C) were entered into the study" }\end{array}$
\end{tabular}


Wu 2015 (Continued)

"The mean age of the patients was 64.1 years in the SC group and 62.7 years in the $\mathrm{C}$ group. The performance status was 0 for $41.7 \%$ of patients treated with SC and $44.4 \%$ of patients treated with $\mathrm{C}$ and it was 1 for $58.3 \%$ of patients treated with SC and $44.4 \%$ of patients treated with C. The primary lesion was $55.6 \%$ in the SC group and $50.0 \%$ in the C group. Histological types were intestinal $(58.3 \%$ in the SC group and $61.1 \%$ in the C group), diffuse (36.1\% in the SC group and $30.6 \%$ in the C group), and others (5.6\% in the SC group and $8.3 \%$ in the C group). The diagnosis was AGC (86.1\% in the SC group and $83.3 \%$ in the C group) and relapse gastric cancer (13.9\% in the SC group and $16.7 \%$ in the C group)."

Interventions

"Patients in the $C$ group received cisplatin $75 \mathrm{mg} / \mathrm{m} 2$ intravenously over $1-3 \mathrm{~h}$ on day 1 and then at 4week intervals. In addition to receiving the same intervention as the $\mathrm{C}$ group, patients in the SC group were also administered S-1 on days 1-14 of a 21-day cycle. The daily dose of S-1 was assigned according to the body surface area as follows: less than $1.25 \mathrm{~m} 2,40 \mathrm{mg}$ two times daily; more than or equal to $1.25 \mathrm{~m} 2$ and less than $1.5 \mathrm{~m} 2,50 \mathrm{mg}$ two times daily; and more than or equal to $1.5 \mathrm{~m} 2,60 \mathrm{mg}$ two times daily."

\begin{tabular}{ll}
\hline Outcomes & OS \\
PFS \\
Adverse events \\
\hline
\end{tabular}

Notes

Risk of bias

\begin{tabular}{lll}
\hline Bias & Authors' judgement & Support for judgement \\
\hline $\begin{array}{l}\text { Random sequence genera- } \\
\text { tion (selection bias) }\end{array}$ & Low risk & $\begin{array}{l}\text { "Patients were stratified using the block randomization method of the SAS } \\
\text { package (version 8.2; SAS Institute Inc., Cary, North Carolina, USA) by a statisti- } \\
\text { cian with no clinical involvement in this study" }\end{array}$ \\
\hline
\end{tabular}

\begin{tabular}{ll}
\hline $\begin{array}{l}\text { Allocation concealment } \\
\text { (selection bias) }\end{array}$ & Low risk \\
& $\begin{array}{l}\text { "The allocation was concealed in sequentially numbered, opaque, sealed en- } \\
\text { velopes containing the randomization assignments" }\end{array}$
\end{tabular}

Incomplete outcome data Low risk All participants could undergo evaluations for efficacy and safety.
(attrition bias)
efficacy

Incomplete outcome data Low risk All participants could undergo evaluations for efficacy and safety.
(attrition bias)
safety

Selective reporting (re- High risk
porting bias)

Overall response rates were compared although it did not appear to be prespecified. Furthermore, details of how response was assessed were not provided.

Other bias High risk
was calculated on the basis of an expected $15 \%$ difference between the two groups, with $80 \%$ power and a two-sided [alpha] value of $0.05 "$

Comments from statistician BCT:The paper is not clear about how the sample size is being estimated. In particular, we do not have information on the HR or the survival probability of the control group. I assume the $15 \%$ difference refers to absolute difference. I try to work out this difference from the KM curve of Fig 2. If we assume a 1 year estimate, then the survival probability is approx. $25 \%$ vs $40 \%$ (HR approx. 0.66). If we assume a 0.5 year estimate, then the survival probability is $75 \%$ vs $90 \%$ (HR approx. 0.37 ). This corresponds to a total sample size of about 300 and 200 respectively, assuming a two-sided test at $5 \%$ level and a power of $80 \%$. If we estimate the HR from the median OS that 
Wu 2015 (Continued)

is reported, the HR is approx. 0.8 , and so we would expect an even larger sample size.

Blinded review of CT/MRI- Unclear risk Not stated
scans?

Yamada 2015

\begin{tabular}{|c|c|}
\hline Methods & Randomised, open-label, multicentre phase III study \\
\hline Participants & 685 patients were enrolled; 343 and 342 patients were randomly assigned to SOX or CS \\
\hline Interventions & $\begin{array}{l}\text { "In CS, S- } 1 \text { was given orally twice daily for the first } 3 \text { weeks of a } 5 \text {-week cycle. The dose was } 80 \mathrm{mg} / \text { day } \\
\text { for body surface area }(B S A)<1.25 \mathrm{~m}^{2}, 100 \mathrm{mg} / \text { day for BSA } \geq 1.25 \text { to }<1.5 \mathrm{~m}^{2} \text {, and } 120 \mathrm{mg} / \text { day for BSA } \\
\geq 1.5 \mathrm{~m}^{2} \text {. Cisplatin was administered at } 60 \mathrm{mg} / \mathrm{m}^{2}\end{array}$ \\
\hline & $\begin{array}{l}\text { as an i.v. infusion with adequate hydration on day } 8 \text { of each cycle [9]. In SOX, S-1 was given as the same } \\
\text { way for the first } 2 \text { weeks of a 3-week cycle. Oxaliplatin at } 100 \mathrm{mg} / \mathrm{m}^{2} \text { was infused for } 2 \text { h i.v. on day } 1 \text { of } \\
\text { each cycle" }\end{array}$ \\
\hline
\end{tabular}

Outcomes

The primary end points were noninferiority in progression-free survival (PFS) and relative efficacy in overall survival (OS) for SOX using adjusted hazard ratios (HRs)

\section{Notes}

\section{Risk of bias}

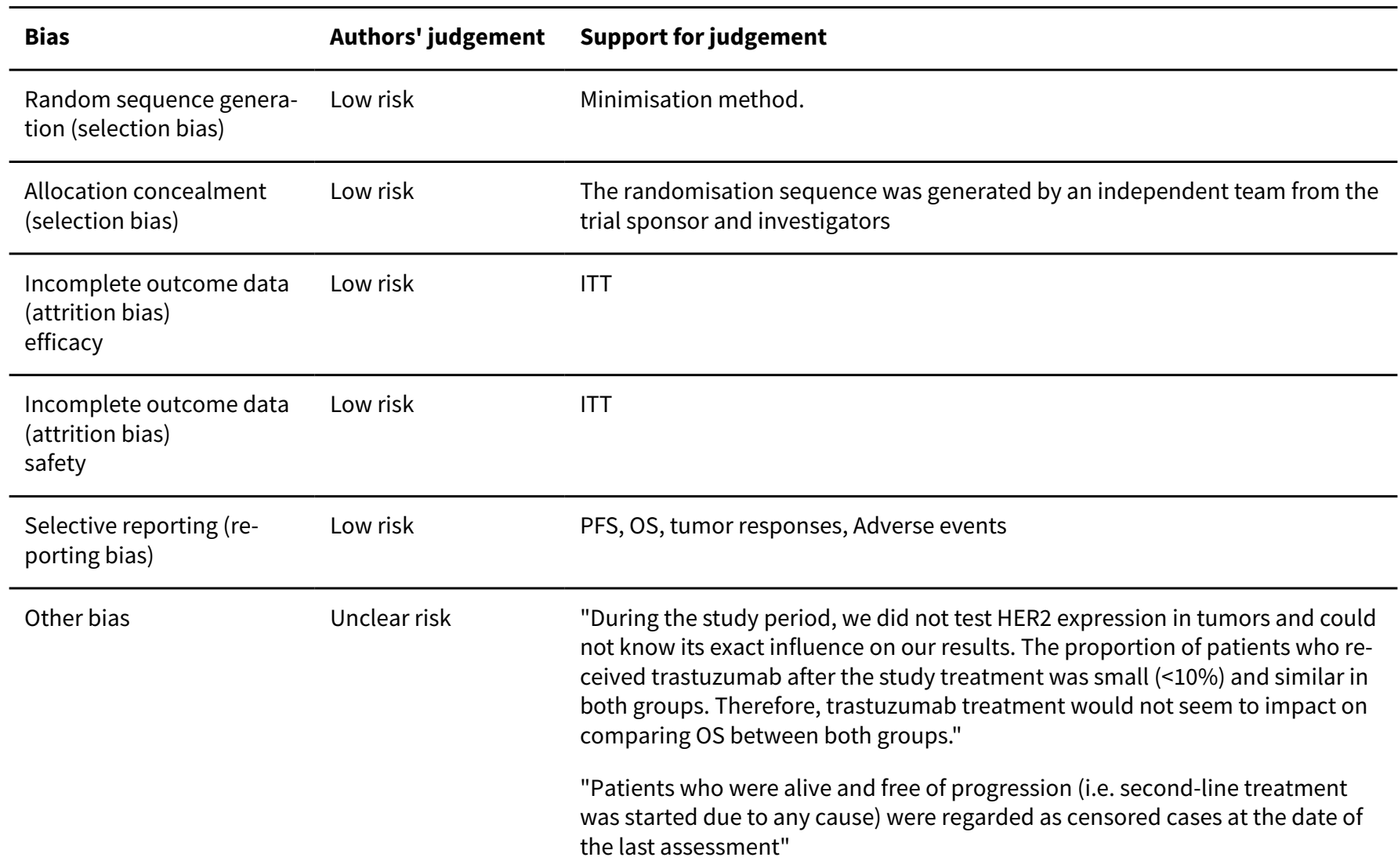


Yamada 2015 (Continued)

"In February 2011, it appeared to be difficult to achieve the required number of events within the preplanned timetable, and the target number of patients was revised to 680 according to the predefined procedure in the protocol"

$\begin{array}{ll}\begin{array}{l}\text { Blinded review of CT/MRI- } \\ \text { scans? }\end{array} & \text { Low risk } \\ & \begin{array}{l}\text { review committee, according to the Response Evaluation Criteria In Solid Tu- } \\ \text { mors (RECIST) version 1.0" }\end{array}\end{array}$

Yamamura 1998

\begin{tabular}{ll}
\hline Methods & $\begin{array}{l}\text { Multicentre RCT } \\
2 \text { arms } \\
\text { Quality score: } \mathrm{C}\end{array}$ \\
\hline Participants & $\mathrm{n}=71$ \\
\hline Interventions & $\begin{array}{l}\text { MTX/5-FU/THP: methotrexate } 50 \mathrm{mg} / \mathrm{m}^{2}, 5 \text {-FU } 650 \mathrm{mg} / \mathrm{m}^{2}, \text { pirarubicin } 20 \mathrm{mg} / \mathrm{m}^{2} \mathrm{~d} 1, \mathrm{repeated} \text { at d } 15 \\
\text { versus } \\
\text { 5-FU: } 5 \text {-FU } 650 \mathrm{mg} / \mathrm{m}^{2} \mathrm{~d} 1, \text { repeated at d } 15\end{array}$ \\
\hline Outcomes & $\begin{array}{l}\text { Median survival } \\
\text { Toxicity }\end{array}$ \\
\hline Notes & Study translated from Japanese \\
\hline
\end{tabular}

\section{Risk of bias}

\begin{tabular}{lll}
\hline Bias & Authors' judgement & Support for judgement \\
\hline $\begin{array}{l}\text { Random sequence genera- } \\
\text { tion (selection bias) }\end{array}$ & Unclear risk & Not stated \\
\hline $\begin{array}{l}\text { Allocation concealment } \\
\text { (selection bias) }\end{array}$ & Low risk & Centralised. Phone call \\
\hline $\begin{array}{l}\text { Incomplete outcome data } \\
\text { (attrition bias) } \\
\text { efficacy }\end{array}$ & Low risk & $71 / 74$ evaluable \\
\hline $\begin{array}{l}\text { Incomplete outcome data } \\
\text { (attrition bias) } \\
\text { safety }\end{array}$ & Low risk & $71 / 74$ evaluable \\
\hline $\begin{array}{l}\text { Selective reporting (re- } \\
\text { porting bias) }\end{array}$ & High risk & No response rates available \\
\hline $\begin{array}{l}\text { Other bias } \\
\text { Blinded review of CT/MRI- }\end{array}$ & Unclear risk & JCOG criteria for toxicity \\
\hline scans? & Unclear risk & Study translated from Japanese \\
\hline
\end{tabular}

\section{Abbreviations:}

BSA: body surface area

BSC: best supportive care

$\mathrm{Cl}$ : continuous infusion 
CT: computed tomography

d: day

dFUR: 5-Deoxyfluouridine

ECOG: Eastern Cooperative Oncology Group

5-FU: 5-Fluorouracil

FA: folinic acid

h: hour

IQR: interquartile range

ITT: intention-to-treat

i.v.: intravenous

KI: Karnofsky-Index

KPS: Karnofsky performance status

Lv: leucovorin

NCl-CTC: National Cancer Institute Common Toxicity Criteria

OS: overall survival

p.o.: per os (orally)

PFS: progression-free survival

QoL: quality of life

$\mathrm{RCT}$ : randomised controlled trial

RR: response rate

TTP: time to progression

UFT: uracil/ftorafur

W: week

WHO: World Health Organization

If not stated differently, all drugs were given as intravenous bolus or short infusion (duration max. 2 hours)

\section{Characteristics of excluded studies [ordered by study ID]}

\begin{tabular}{|c|c|}
\hline Study & Reason for exclusion \\
\hline Ahn 2002 & $\begin{array}{l}\text { According to information provided by the first author about } 2 / 3 \text { of included participants had under- } \\
\text { gone gastric resection and were treated in adjuvant/additive intention. }\end{array}$ \\
\hline Ajani 2002 & Article about study published elsewhere (Van Cutsem 2006). \\
\hline Ajani 2006 & Non-randomised phase II study. \\
\hline Akagi 2010 & Other indication (patients underwent macroscopically curative resection). \\
\hline Akazawa 1985 & Study not randomised. \\
\hline Andrić 2012 & Interventions not relevant for any of the comparisons specified. \\
\hline Anonymous 1979 & $\begin{array}{l}\text { Not all participants were randomised (some were directly assigned to } 1 \text { treatment arm according to } \\
\text { their prior chemotherapy). Systematic cross-over between treatment arms. }\end{array}$ \\
\hline Anonymous 1982 & $\begin{array}{l}\text { Study began as three-arm comparison of FAMe, FAMi and FIMe regimens. FMe was added to ran- } \\
\text { domization later. ICRF-159=dexrazoxaneL None of the possible permutations between these regi- } \\
\text { mens fit our study comparisons }\end{array}$ \\
\hline Anonymous 1983 & 18 of 82 included participants were crossed over (<10\%) \\
\hline Anonymous 1984 & $\begin{array}{l}\text { Compared FA, FAMe, and FAMi. None of the possible permutations between these regimens fit our } \\
\text { study comparisons. }\end{array}$ \\
\hline Aoyama 1981 & Study not randomised \\
\hline
\end{tabular}




\begin{tabular}{|c|c|}
\hline Study & Reason for exclusion \\
\hline Bajetta 1998 & $\begin{array}{l}\text { Participants not randomised to different chemotherapy regimens, but to one regimen (FEP) with or } \\
\text { without GM-CSF }\end{array}$ \\
\hline Baker 1976 & $\begin{array}{l}\text { Participants with different advanced gastrointestinal cancers were included in the study. No sepa- } \\
\text { rate results given for gastric cancer participants. }\end{array}$ \\
\hline Balana 1990 & Preliminary publication. \\
\hline Berenberg 1989 & Final publication: Berenberg 1995 (excluded). \\
\hline Berenberg 1995 & Compares different single-agent chemotherapy regimens. \\
\hline Beretta 1983 & Published as abstract only. No further information obtained by contacting the first author. \\
\hline Beretta 1989 & Published as abstract only. No further information obtained by contacting the first author. \\
\hline Berglund 2006 & Other indications. \\
\hline Bi 2011 & Cross-over study. \\
\hline Bjerkeset 1986 & $\begin{array}{l}\text { Study included participants with different advanced gastrointestinal cancers. No separate results } \\
\text { given for gastric cancer participants. }\end{array}$ \\
\hline Bruckner 1986 & Preliminary publication. \\
\hline Brugarolas 1975 & $\begin{array}{l}\text { Study published as abstract only with insufficient data available. According to information provid- } \\
\text { ed by the first author no further analysis was performed as the study was terminated early due to } \\
\text { slow accrual. }\end{array}$ \\
\hline Bugat 2003 & Secondary publication. \\
\hline Buroker 1979 & $\begin{array}{l}\text { Does not compare different intravenous combination chemotherapy regimens but } 1 \text { intravenous } \\
\text { regimen with or without an additional oral chemotherapy (methyl-CCNU). }\end{array}$ \\
\hline Cai 2011 & Not an RCT, retrospective analysis of an RCT. \\
\hline Cascinu 1994 & Final publication: Cascinu 1995 (excluded). \\
\hline Cascinu 1995 & $\begin{array}{l}\text { Participants not randomised to different chemotherapy regimens but to reduced glutathione or } \\
\text { placebo to prevent cisplatin-induced neurotoxicity. }\end{array}$ \\
\hline Cascinu 1996 & $\begin{array}{l}\text { Participants not randomised to different chemotherapy regimens but to different doses of G-CSF as } \\
\text { supportive therapy. }\end{array}$ \\
\hline Chau 2013 & Testing VEGF inhibitor (ramucirumab) as second-line therapy. \\
\hline Chen 2011 & $\begin{array}{l}\text { Gimeracil + oteracil, neither contains a 5-FU prodrug nor is equivalent to S-1. So this combination } \\
\text { does not fit any comparison. }\end{array}$ \\
\hline Chlebowski 1979 & One study arm was treated with oral 5-FU. \\
\hline Chlebowski 1985 & Insufficient information for calculation of HRs given in the publication or provided by the author. \\
\hline Chu 2006 & Missing information to calculate HRs for OS \\
\hline
\end{tabular}




\begin{tabular}{|c|c|}
\hline Study & Reason for exclusion \\
\hline Chung 2011 & Not an RCT. \\
\hline Coates 1984 & Included 108 participants with advanced cancer (only 5 gastric cancer patients). \\
\hline Cocconi 1982 & Systematic cross-over between study groups (< $10 \%$ of included participants). \\
\hline Cocconi 1992 & Final publication: Cocconi 1994 (included). \\
\hline Colucci 1991 & Final publication: Colucci 1995 (included). \\
\hline Constenla 2002 & Study not randomised. \\
\hline Coombes 1994 & Compares different single agents. \\
\hline Cullinan 1993 & Final publication: Cullinan 1994 (included). \\
\hline Cunningham 2008 & Wider indication (inclusion of patients with squamous cell carcinoma of the oesophagus as well). \\
\hline De Lisi 1985 & Final publication: De Lisi 1986 (included). \\
\hline De Lisi 1988 & Second publication to De Lisi 1986 (included). \\
\hline Diaz-Rubio 1991 & Preliminary publication. \\
\hline Douglass 1983 & Final publication: Douglass 1984 (excluded). \\
\hline Douglass 1984 & $\begin{array}{l}\text { Not all participants were randomised. Some were directly assigned to } 1 \text { study arm according to } \\
\text { their prior treatment. }\end{array}$ \\
\hline Duffour 2006 & Interventions not relevant for any of the comparisons specified. \\
\hline Figoli 1991 & Study not randomised. Two consecutive regimens were compared. \\
\hline Ford 2014 & Second-line CTX. \\
\hline Fuchs 2014 & Testing VEGF inhibitor (ramucirumab) as second-line therapy. \\
\hline Fujii 1983 & Study not randomised. \\
\hline Furue 1985 & $\begin{array}{l}\text { Schizophyllan: mushroom polysaccharide with immunomodulatory properties (biologic therapy), } \\
\text { no chemotherapy. }\end{array}$ \\
\hline Furukawa 1995 & $\begin{array}{l}\text { Although described as advanced gastric cancer in the title, according to the text of the article the } \\
\text { study compared different adjuvant chemotherapy regimens. }\end{array}$ \\
\hline Gao 2010 & inclusion pf patients with squamous epithelium carcinoma. \\
\hline Gioffre 1984 & Study not randomised. \\
\hline Glimelius 1994 & Final publication: Glimelius 1997 (excluded). \\
\hline Glimelius 1995 & $\begin{array}{l}\text { Study includes participants with different inoperable cancers. Cross-over from BSC to chemothera- } \\
\text { py arm permitted. Primary aim: cost-effectiveness. }\end{array}$ \\
\hline Glimelius 1997 & $\begin{array}{l}\text { Study compares chemotherapy versus best supportive care. Provision of chemotherapy upon re- } \\
\text { quest in the best supportive care group was requested by the research ethics committee, and } 12 \text { of }\end{array}$ \\
\hline
\end{tabular}




\begin{tabular}{ll}
\hline Study & Reason for exclusion \\
\hline $\begin{array}{l}\text { 30 participants (19.6\%) randomised to best supportive care finally received chemotherapy (cross- } \\
\text { over). }\end{array}$ \\
\hline $\begin{array}{l}\text { Participants were not randomised between different chemotherapy regimens but to methion- } \\
\text { ine-depleted total parenteral nutrition versus a conventional amino acid solution. }\end{array}$ \\
\hline Grau 1988 & All participants were treated with chemotherapy after resection (no advanced/metastatic disease). \\
\hline Grieco 1984 & Study not randomised. \\
\hline Gubanski 2010 & Prescheduled cross-over between study arms after four courses. \\
\hline Guimbaud 2014 & Considerable use of second-line therapy. \\
\hline Gupta 1982 & Insufficient data on survival available. \\
\hline Haas 1983 & Cross-over after failure was encouraged. \\
\hline Hawkins 2003 & Preliminary data. \\
\hline
\end{tabular}

\begin{tabular}{ll}
\hline Hoffman 1998 & $\begin{array}{l}\text { Retrospective analysis of clinical benefit and quality of life in participants with different inoperable } \\
\text { gastrointestinal cancers. }\end{array}$
\end{tabular}

\begin{tabular}{|c|c|}
\hline Icli 1993 & Study not randomised. \\
\hline Imada 1999 & Includes participants treated in adjuvant intention after curative resection of gastric cancer. \\
\hline Inoue 1989 & Participants with ascites were treated with intraperitoneal chemotherapy. \\
\hline Jeung 2011 & Interventions not relevant for any of the comparisons specified. \\
\hline Kang 2007 & Interventions not relevant for any of the comparisons specified. \\
\hline Kelsen 1990 & Preliminary publication. \\
\hline Kilickap 2011 & Not an RCT. \\
\hline Kim 1991 & Final publication: Kim 1993 (excluded). \\
\hline Kim 1993 & $\begin{array}{l}\text { According to information provided by author (YSP) allocation was done by alternation (not truly } \\
\text { randomised). }\end{array}$ \\
\hline Kim 2012 & Interventions not relevant for any of the comparisons specified. \\
\hline Kim 2013 & Meta-analysis is examining second-line therapy vs BSC. \\
\hline Kitamura 1995 & $\begin{array}{l}\text { Study compares the effect of different amino-acid solutions (methionine-free amino-acid solution } \\
\text { versus commercial amino-acid solution) in addition to 5-FU chemotherapy. }\end{array}$ \\
\hline Koizumi 1996 & $\begin{array}{l}\text { Compares different dosages of cisplatin ( } 60 \mathrm{mg} \text { and } 80 \mathrm{mg} \text { ) within the same chemotherapy regi- } \\
\text { men. }\end{array}$ \\
\hline Koizumi 2004 & Interventions not relevant for any of the comparisons specified. \\
\hline Koizumi 2012 & Not an RCT. \\
\hline
\end{tabular}




\begin{tabular}{|c|c|}
\hline Study & Reason for exclusion \\
\hline Koizumi 2013 & Testing irinotecan plus cisplatin versus irinotecan as second-line therapy. \\
\hline Kolaric 1986 & $\begin{array}{l}\text { Participants with stomach and rectosigmoid cancer included. No separate information about gas- } \\
\text { tric cancer provided. }\end{array}$ \\
\hline Kondo 2000 & Study uses oral 5-FU (no intravenous chemotherapy, varying bioavailability). \\
\hline Kono 2002 & Study treatment: adoptive immunotherapy. \\
\hline Kornek 2002 & $\begin{array}{l}\text { Does not compare different chemotherapy regimens but the same chemotherapy with or without } \\
\text { G-CSF and/or erythropoietin. }\end{array}$ \\
\hline Kosaka 1995 & One group was treated with intra-arterial chemotherapy. \\
\hline Kovach 1974 & Insufficient data for calculation of HRs given (P value missing). \\
\hline Kuitunen 1991 & Final publication: Pyrhönen 1995 (included). \\
\hline Kurihara 1991 & $\begin{array}{l}\text { Compared: tegafur + mitomycin C (FTM), uracil-tegafur + mitomycin C (UFTM), 5'deoxy-flurorouri- } \\
\text { dine + cisplatin (5'P), etoposide + doxorubicin + cisplatin (EAP), and 5-fluorouracil + cisplatin (FP). } \\
\text { Firstly, } \\
\text { none of the possible permutations between these regimens fit our study comparisons. Secondly, } \\
\text { the Ohkuwa } 2000 \text { paper resembles a "pooled" analysis (of other RCTs such as Kurihara 1991) rather } \\
\text { than an original RCT. }\end{array}$ \\
\hline
\end{tabular}

\section{Kurihara 1995}

Participants randomised to either methionine-free or commercial amino-acid solution, with the same (mitomycin C/fluorouracil) chemotherapy in both groups.

\begin{tabular}{ll}
\hline Kurihara 1995a & Final publication: Koizumi 1996 (excluded). \\
\hline Lacave 1985 & Final publication: Lacave 1987 (excluded). \\
\hline Lacave 1987 & $\begin{array}{l}\text { Does not compare different intravenous chemotherapy regimens but } 1 \text { intravenous chemotherapy } \\
\text { with or without an additional oral chemotherapy (methyl-CCNU). }\end{array}$ \\
\hline Lee 2008 & Interventions not relevant for any of the comparisons specified. \\
\hline Lee 2012 & Gastrointestinal endoscopy. \\
\hline Levard 1998 & Participants had oesophageal squamous cell carcinoma. \\
\hline $\begin{array}{l}\text { Drug under investigation was never approved, and the regimen does not fit any of our } 10 \text { compar- } \\
\text { isons. Also their trial was not solely done in gastric cancer patients, but also included patients with } \\
\text { colorectal, oesophageal, and liver cancer. }\end{array}$
\end{tabular}

\begin{tabular}{ll}
\hline Li 2007 & Missing information to calculate HRs for OS. \\
\hline Li 2011 & Not relevant for any of the comparisons. \\
\hline Li 2013 & Testing second-line apatinib. \\
\hline Lim 2011 & Not relevant for any of the comparisons. \\
\hline Livstone 1977 & Radiochemotherapy is compared to systemic intravenous chemotherapy.
\end{tabular}




\begin{tabular}{ll}
\hline Study & Reason for exclusion \\
\hline Lordick 2013 & $\begin{array}{l}\text { Testing whether cetuximab (EGFR targeted mAB) should be included as first-line in combination } \\
\text { with capecitabine and cisplatin. }\end{array}$
\end{tabular}

\begin{tabular}{|c|c|}
\hline Lorenzen 2007 & Not a randomised trial. \\
\hline Luelmo 2006 & Interventions not relevant for any of the comparisons specified. \\
\hline Malik 1990 & Study not randomised. Includes participants with gastric and colorectal cancer. \\
\hline Maruta 2007 & Second-line chemotherapy. \\
\hline Massuti 1994 & Published as abstract only. No further information obtained by contact with the first author. \\
\hline Massuti 1995 & Published as abstract only. No further information obtained by contact with the first author. \\
\hline Mochiki 2012 & Interventions not relevant for any of the comparisons specified. \\
\hline Moertel 1976 & Insufficient information for calculation of HRs given. \\
\hline Moertel 1979 & $\begin{array}{l}\text { The combination therapy arm consisted of only 1ne oral agent (methyl-CCNU, no intravenous } \\
\text { chemotherapy), in addition to 5-FU which was used as single-agent. }\end{array}$ \\
\hline Moertel 1979a & $\begin{array}{l}\text { Not all participants were randomised (some were directly assigned to } 1 \text { treatment arm according to } \\
\text { their prior treatment). Systematic cross-over between study groups. }\end{array}$ \\
\hline Moore 2005 & Secondary publication. \\
\hline Mustacchi 1997 & Study included participants with different advanced cancers (only 3 patients with gastric cancer). \\
\hline Nakajima 1984 & Study compares different adjuvant chemotherapies. \\
\hline Nakao 1983 & $\begin{array}{l}\text { Study treatment included schizophyllan (mushroom polysaccharide with immunomodulatory ef- } \\
\text { fects, biological therapy). }\end{array}$ \\
\hline Nakashima 2008 & $\begin{array}{l}\text { The treatment for each patient was decided by the patient's choice or randomisation (not a ran- } \\
\text { domised trial). }\end{array}$ \\
\hline Niitani 1987 & $\begin{array}{l}\text { Compares different modes of application of the same chemotherapy (continuous and intermittent } \\
\text { oral administration of } 5{ }^{\prime} \text { deoxy-5-fluorouridine), not different chemotherapy regimens. }\end{array}$ \\
\hline Nordin 2001 & $\begin{array}{l}\text { Study presents different interpretations of quality of life data from a previously performed study } \\
\text { (Glimelius 1997). The study included advanced gastric cancer participants, but was excluded be- } \\
\text { cause of cross-over. }\end{array}$ \\
\hline Novik 1999 & Compares different single agents. \\
\hline Ohtsu 2011 & $\begin{array}{l}\text { Testing whether bevacizumab (VEGF targeted } \mathrm{mAB} \text { ) should be included in first-line chemotherapy } \\
\text { combinations. }\end{array}$ \\
\hline Okines 2010 & Not an RCT. \\
\hline Osawa 1996 & Study treatment: adjuvant chemo-immunotherapy. \\
\hline Pannettiere 1984 & $\begin{array}{l}\text { Compares } 2 \text { modes of application (sequential versus simultaneous) of } 1 \text { chemotherapy regimen } \\
\text { (FAM). }\end{array}$ \\
\hline
\end{tabular}




\begin{tabular}{|c|c|}
\hline Study & Reason for exclusion \\
\hline Park 2004 & Interim analysis of Park 2006. \\
\hline Park 2006 & Interventions not relevant for any of the comparisons specified. \\
\hline Park 2008 & Interventions not eligible for any of the comparisons specified. \\
\hline Popliela 1982 & Study treatment: chemo-immunotherapy. \\
\hline Popov 1999 & Final publication: Popov 2000 (excluded). \\
\hline Popov 2000 & $\begin{array}{l}\text { Compares different applications of doxorubicin (bolus versus 8-hour infusion) in the same } \\
\text { chemotherapy regimen (EAP), not different chemotherapy regimens. }\end{array}$ \\
\hline Pozzo 2004 & Interventions not relevant for any of the comparisons specified. \\
\hline Pyrhonen 1992 & Final publication: Pyrhönen 1995 (included). \\
\hline Queisser 1984 & $\begin{array}{l}\text { Compared 5-fluorouracil and carmustine with or without adriamycin. This does not fit our study } \\
\text { comparisons. }\end{array}$ \\
\hline Rake 1979 & $\begin{array}{l}39 \text { of } 77 \text { included participants receiving chemotherapy as additive therapy after non-curative re- } \\
\text { section with histological evidence of residual disease. }\end{array}$ \\
\hline Roth 1994 & Final publication: Roth 1999 (included). \\
\hline Roth 1995 & Final publication: Roth 1999 (included). \\
\hline Roth 1997 & Final publication: Roth 1999 (included). \\
\hline Sakata 1982 & Participants were treated with OK-432 (streptococcal preparation, biological response modifier). \\
\hline Sakata 1988 & $\begin{array}{l}\text { Study included participants with various gastrointestinal tumors, which were treated with a biolog- } \\
\text { ical therapy. }\end{array}$ \\
\hline Sakata 1992 & Study included participants with different adenocarcinomas. \\
\hline Sasagawa 1994 & Insufficient information for calculation of HRs given. \\
\hline Sasaki 1989 & $\begin{array}{l}\text { Publication presents only preliminary results of this study. No information about final results pro- } \\
\text { vided by the first author. }\end{array}$ \\
\hline Sasaki 1990 & Study not randomised. \\
\hline Sasaki 1992 & $\begin{array}{l}\text { Study includes participants with colorectal and gastric cancer. Insufficient information given about } \\
\text { results in gastric cancer. }\end{array}$ \\
\hline Sasaki 1995 & $\begin{array}{l}\text { Study includes participants with colorectal and gastric cancer. Insufficient information given about } \\
\text { results in gastric cancer. }\end{array}$ \\
\hline Sato 1991 & $\begin{array}{l}\text { Study summarises the experience of angiotensin II-induced hypertension to enhance drug delivery } \\
\text { for chemotherapy. Participants were not randomised to different chemotherapy regimens. }\end{array}$ \\
\hline Sato 1995 & $\begin{array}{l}\text { Participants were not randomised to different chemotherapy regimens but to angiotensin II-in- } \\
\text { duced hypertension to enhance chemotherapy effects or control. }\end{array}$ \\
\hline
\end{tabular}




\begin{tabular}{|c|c|}
\hline Study & Reason for exclusion \\
\hline Satoh 2013 & Text needed. \\
\hline Satoh 2014 & $\begin{array}{l}\text { Testing whether lapatinib (HER2 inhibitor) should be used in second-line therapy in HER2-ampli- } \\
\text { fied Asian population. }\end{array}$ \\
\hline Schmid 2003 & Study not randomised. \\
\hline Shen 2009 & No information on overall survival. \\
\hline Shin 2007 & Interventions not relevant for any of the comparisons specified. \\
\hline Shinoda 1995 & Reporting standards to be insufficient and/or the dose schedule to be different from other studies. \\
\hline Shu 1999 & $\begin{array}{l}\text { Study compared the effect of intraperitoneal combined with intravenous to only intravenous } \\
\text { chemotherapy. }\end{array}$ \\
\hline Shudong 1996 & Insufficient information for calculation of HRs given. \\
\hline Smith 1983 & $\begin{array}{l}\text { Study included various advanced adenocarcinomas of the gastrointestinal tract (only } 5 \text { partici- } \\
\text { pants with gastric cancer). }\end{array}$ \\
\hline Sun 2004 & Interventions not relevant for any of the comparisons specified (radiochemotherapy). \\
\hline Sym 2013 & A study in participants refractory to first-line chemotherapy - thus no first-line treatment. \\
\hline Taal 1990 & Study not randomised. \\
\hline Taguchi 1985 & $\begin{array}{l}\text { Study treatment includes lentinan (mushroom polysaccharide with immunomodulatory proper- } \\
\text { ties, biological therapy). }\end{array}$ \\
\hline Takahashi 1991 & Study participants had resectable tumours. One group received intraarterial chemotherapy. \\
\hline Tebbutt 2002 & Not eligible for any of the comparisons specified. \\
\hline Tebbutt 2007 & Not relevant for any of the comparisons (docetaxel in both treatment arms). \\
\hline Tebbutt 2010 & Included esophageal cancer patients. \\
\hline Thuss-Patience 2011 & Second-line therapy. \\
\hline Tsushima 1991 & Study treatment includes OK (streptococcal preparation, biologic response modifier). \\
\hline Van Cutsem 2009 & Targeted therapy. \\
\hline Vanhoefer 2000 & $\begin{array}{l}\text { Compared methotrexate, fluorouracil, and doxorubicin versus etoposide, leucovorin, and fluo- } \\
\text { rouracil versus infusional fluorouracil and cisplatin. None of the possible permutations between } \\
\text { these regimens fit our study comparisons }\end{array}$ \\
\hline Vaughn 1980 & $\begin{array}{l}\text { Study included participants with advanced gastrointestinal malignancies (only } 11 \text { participants with } \\
\text { gastric cancer). }\end{array}$ \\
\hline Vestlev 1990 & Inconclusive data (time to progression and survival identical). \\
\hline Villar 1987 & Study included participants ( 13 of 46 ) with only microscopic disease in the resection margins. \\
\hline
\end{tabular}




\begin{tabular}{ll}
\hline Study & Reason for exclusion \\
\hline Voznyi 1978 & $\begin{array}{l}\text { One study arm consisted only of oral chemotherapy (CCNU). Two other of } 5 \text { study arms differed } \\
\text { from others only in the addition of oral CCNU (does not compare different intravenous chemother- } \\
\text { apy regimens). }\end{array}$
\end{tabular}

\begin{tabular}{|c|c|}
\hline Wadler 2002 & Study treatment includes interferon and filgrastim (biological therapy). \\
\hline Wakui 1983 & $\begin{array}{l}\text { Participants had various gastrointestinal malignancies. Therapy includes levamisole (antihelmintic } \\
\text { drug with immunomodulatory properties). }\end{array}$ \\
\hline Wakui 1983a & $\begin{array}{l}\text { Participants had various gastrointestinal malignancies. Therapy included levamisole (antihelmintic } \\
\text { drug with immunomodulatory properties). }\end{array}$ \\
\hline Wakui 1986 & $\begin{array}{l}\text { Study treatment includes lentinan (mushroom polysaccharide with immunomodulatory proper- } \\
\text { ties, biological therapy). }\end{array}$ \\
\hline Wang 2007 & Not relevant for any of the comparisons. \\
\hline Waters 1999 & Paper reports long-term follow-up of the study published by Webb 1997 (included) \\
\hline Wilke 2014 & Testing VEGF inhibitor (ramucirumab) as second-line therapy. \\
\hline Wils 1991 & $\begin{array}{l}\text { Compared 5-fluorouracil, adriamycin and methotrexate vs 5-fluorouracil, adriamycin and mito- } \\
\text { mycin-C. This does not fit our study comparisons }\end{array}$ \\
\hline Wils 1994 & $\begin{array}{l}\text { Published as abstract only, no further information about final results obtained by contacting the } \\
\text { first author. }\end{array}$ \\
\hline Xu 2013 & Tested recombinant human endostatin, and regimen does not fit our comparisons. \\
\hline Yamada 1994 & According to information provided by the first author the study was not randomised. \\
\hline Yin 1996 & $\begin{array}{l}\text { Study treatment includes Elemene (product isolated from the Chinese medical herb Rhizoma ze- } \\
\text { doariae, biological therapy). }\end{array}$ \\
\hline Yoshida 2003 & $\begin{array}{l}\text { Compares the feasibility of personalised chemotherapy (according to the expression of molecular } \\
\text { markers) with standard therapy. }\end{array}$ \\
\hline Yoshikawa 2011 & Tested a chemoimmunotherapy combination. \\
\hline Yoshino 2007 & Intervention not eligible for any of the comparisons specified. \\
\hline Yun 2010 & Intervention not eligible for any of the comparisons specified. \\
\hline Zhao 2009 & missing information to calculate HRs for OS. \\
\hline Zironi 1992 & Final publication: Cocconi 1994 (included) \\
\hline
\end{tabular}

5-FU: 5-Fluorouracil

A: adriamycin (also known as doxorubicin)

BSC: best supportive care

CTX: chemotherapy

FA: folinic acid

FAMe: 5 -FU $325 \mathrm{mg} / \mathrm{m}^{2} \mathrm{~d} 1-5$, A $40 \mathrm{mg} / \mathrm{m}^{2} \mathrm{~d} 1$ until $\mathrm{d} 36, \mathrm{Me} 110 \mathrm{mg} / \mathrm{m}^{2}$ orally at $\mathrm{d} 1$ repeated at $\mathrm{d} 71$

FAMi: 5-FU $275 \mathrm{mg} / \mathrm{m}^{2} \mathrm{~d} 1-5$, A $30 \mathrm{mg} / \mathrm{m}^{2} \mathrm{~d} 1$ until $\mathrm{d} 36, \mathrm{M} 10 \mathrm{mg} / \mathrm{m}^{2} \mathrm{~d} 1$ repeated at $\mathrm{d} 71$

FIMe: 5 -FU $325 \mathrm{mg} / \mathrm{m}^{2} \mathrm{~d} 1-5$ repeated at $\mathrm{d} 36, \mathrm{ICRF}-159500 \mathrm{mg} / \mathrm{m}^{2}$ orally at $\mathrm{d} 2-4$ and $\mathrm{d} 36-38, \mathrm{Me} 110 \mathrm{mg} / \mathrm{m}^{2}$ orally at $\mathrm{d} 1$ repeated at $\mathrm{d} 71$

FMe: 5 -FU $300 \mathrm{mg} / \mathrm{m}^{2} \mathrm{~d} 1-5$ repeated at $\mathrm{d} 36$, Me $175 \mathrm{mg} / \mathrm{m}^{2}$ orally at $\mathrm{d} 1$ repeated at $\mathrm{d} 50$ 
G-CSF: granulocyte-macrophage colony-stimulating factor HR: hazard ratio

ICRF: razoxane

M: mitomycin C

Me: semustine (also known as methyl-CCNU)

OS: overall survival

$\mathrm{RCT}$ : randomised controlled trial

VEGF: vascular endothelial growth factor

Characteristics of ongoing studies [ordered by study ID]

\section{Elsaid 2005}

Trial name or title

Randomized phase III trial of docetaxel, carboplatin and 5FU versus epirubicin, cisplatin and 5FU for locally advanced gastric cancer (final publication not found)

\begin{tabular}{ll}
\hline Methods & RCT \\
& 2 arms
\end{tabular}

\begin{tabular}{ll}
\hline Participants & $\mathrm{N}=64$ \\
\hline Interventions & $\begin{array}{l}\text { Arm A: docetaxel }\left(75 \mathrm{mg} / \mathrm{m}^{2} \mathrm{~d} 1\right)+\text { carboplatin (AUC6 d2) + continuous infusion } 5 \mathrm{FU}\left(1200 \mathrm{mg} / \mathrm{m}^{2} /\right. \\
\text { day d1-3), repeated at d } 21\end{array}$ \\
& versus \\
& $\begin{array}{l}\text { Arm B: Epirubicin }\left(50 \mathrm{mg} / \mathrm{m}^{2} \mathrm{~d} 1\right)+\text { cisplatin }\left(60 \mathrm{mg} / \mathrm{m}^{2} \mathrm{~d} 1\right)+\text { continuous infusion } 5 \mathrm{FU}\left(200 \mathrm{mg} / \mathrm{m}^{2} /\right. \\
\text { day d } 1-21)\end{array}$ \\
& Prophylactically G-CSF day 4-9 to all participants \\
\hline Outcomes & Toxicity, tumour response, progression-free and overall survival \\
\hline Starting date & 1999 \\
\hline Contact information & Amr Abdelaziz Elsaid \\
& amrelsaid@yahoo.com \\
& Alexandria University, Alexandria, Egypt \\
\hline Notes & This study is currently published as abstract only. Participants were enrolled between 1999 and \\
\hline
\end{tabular}

\section{Higuchi 2012}

\section{Trial name or title}

Methods RCT

\section{2 arms}

\begin{tabular}{ll}
\hline Participants & $\mathrm{N}=685$ with unresectable advanced or recurrent gastric cancer, PS 0-2, age $\geq 20$ years \\
\hline Interventions & $\begin{array}{l}\text { Arm A (SOX): (oral S-1 } 40 \mathrm{mg} / \mathrm{m}^{2} \text { twice a day d } 1-14+\text { oxaliplatin } 100 \mathrm{mg} / \mathrm{m}^{2} \text { iv day } 1 \text {, repeated at } 3 \\
\text { weeks) versus }\end{array}$
\end{tabular}


Higuchi 2012 (Continued)

Arm B (SP): (oral S-1 $40 \mathrm{mg} / \mathrm{m}^{2}$ twice a day d $1-21+$ cisplatin $60 \mathrm{mg} / \mathrm{m}^{2}$ iv day 8 , repeated at 5 weeks)

\begin{tabular}{ll}
\hline Outcomes & Progression-free survival, response rate (RR), safety, and length of hospital stay per cycle \\
\hline Starting date & $\begin{array}{l}\text { Yakult Honsha Co., Ltd., Clinical Development, Medical Development Department, Pharmaceutical } \\
\text { Division, Tel 813-5550-8966 Fax 813-3248-5502 }\end{array}$ \\
\hline Contact information & $\begin{array}{l}\text { The study is registered (JapicCTI-101021) and has recruited } 685 \text { participants from January } 2010 \\
\text { and October 2011. }\end{array}$ \\
\hline
\end{tabular}

Kurihara

\begin{tabular}{ll}
\hline Trial name or title & Isovorin: Phase Ill study \\
\hline Methods & RCT \\
\hline Participants & $\begin{array}{l}\text { Participants with histologically confirmed, advanced gastric adenocarcinoma without prior } \\
\text { chemotherapy, PS 0-2, age } 20 \text { to } 70 \text { years }\end{array}$ \\
\hline Interventions & $\begin{array}{l}\text { 5-FU+ isovorin (active form of leucovorin) versus } \\
\text { S-1 alone }\end{array}$ \\
\hline Outcomes & Overall survival, response rates, time to progression, safety, quality of life \\
\hline Starting date & - \\
\hline Contact information & Minoru Kurihara, M.D., Showa University, Japan \\
\hline Notes & Sponsor: Wyeth Pharmaceuticals. Final publication not found. \\
\hline
\end{tabular}

\section{Maiello 2011}

\begin{tabular}{|c|c|}
\hline Trial name or title & $\begin{array}{l}\text { Epirubicin (E) in combination with cisplatin (CDDP) and capecitabine }(C) \text { versus docetaxel }(D) \text { com- } \\
\text { bined with } 5 \text {-fluorouracil ( } 5-F U) \text { by continuous infusion as front-line therapy in participants with } \\
\text { advanced gastric cancer (AGC) }\end{array}$ \\
\hline \multirow[t]{2}{*}{ Methods } & $\mathrm{RCT}$ \\
\hline & 2 arms \\
\hline Participants & $\mathrm{N}=77$ with advanced gastric cancer and measurable disease \\
\hline \multirow[t]{3}{*}{ Interventions } & $\begin{array}{l}\text { Arm A (ECX): epirubicin }\left(50 \mathrm{mg} / \mathrm{m}^{2} \mathrm{~d} 1\right)+\text { cisplatin }\left(60 \mathrm{mg} / \mathrm{m}^{2} \mathrm{~d} 1\right)+\text { capecitabine }\left(625 \mathrm{mg} / \mathrm{m}^{2} \text { twice }\right. \\
\text { a day, } \mathrm{d} 1-21) \text { repeated at } \mathrm{d} 21\end{array}$ \\
\hline & versus \\
\hline & Arm B (DF): docetaxel $\left(85 \mathrm{mg} / \mathrm{m}^{2} \mathrm{~d} 1\right)+5-\mathrm{FU}\left(750 \mathrm{mg} / \mathrm{m}^{2} /\right.$ day, d1-5) qd 21 \\
\hline
\end{tabular}


Maiello 2011 (Continued)

Outcomes Response rate, toxicity

\section{Starting date}

Contact information G.Colucci, Instituto Oncologici Bari, Bari, Italy

Notes Preliminary results of this study are currently published as abstract only. Final publication not
found.

\section{NCT01498289}

\begin{tabular}{|c|c|}
\hline Trial name or title & $\begin{array}{l}\text { A randomized phase II pilot study prospectively evaluating treatment for participants based on ER- } \\
\mathrm{CC} 1 \text { (excision repair cross-complementing } 1 \text { ) for advanced/metastatic oesophageal, gastric or gas- } \\
\text { troesophageal junction (GEJ) cancer }\end{array}$ \\
\hline Methods & $\begin{array}{l}\text { Multicentre RCT } \\
2 \text { arms } \\
\text { stratification according to ERCC1 }\end{array}$ \\
\hline Participants & $\mathrm{N}=225$ with unresectable, advanced or recurrent gastric cancer, age $\geq 18$ years, HER- 2 negative \\
\hline Interventions & $\begin{array}{l}\left.\text { Arm A (FOLFOX): 4-FU (bolus } 400 \mathrm{mg} / \mathrm{m}^{2} \text {, ci } 2400 \mathrm{mg} / \mathrm{m}^{2}\right)+\mathrm{LV}\left(400 \mathrm{mg} / \mathrm{m}^{2}\right)+\text { oxaliplatin }\left(85 \mathrm{mg} / \mathrm{m}^{2}\right) \\
\text { d 1, repeated at d } 14 \text {. } \\
\text { Arm B docetaxel }\left(30 \mathrm{mg} / \mathrm{m}^{2} \text { on day } 1+8 \mathrm{qd} 21\right)+\text { irinotecan }\left(65 \mathrm{mg} / \mathrm{m}^{2} \text { on day } 1+8 \mathrm{qd} 21\right) .\end{array}$ \\
\hline
\end{tabular}

$\begin{array}{ll}\text { Outcomes } & \text { Progression-free survival (PFS) between high-ERCC1 and low-ERCC1 participants treated with FOL- } \\ & \text { FOX versus irinotecan hydrochloride plus docetaxel, overall survival, response rate, toxicity }\end{array}$

\begin{tabular}{ll}
\hline Starting date & February 2012 \\
\hline Contact information & Contact: Kimberly Kaberle: kkaberle@swog.org; Dana Sparks: dsparks@swog.org \\
& Principal Investigator: Syma Iqbal \\
\hline Notes & Sponsors: Southwest Oncology Group and National Cancer Institute (NCI) \\
\hline
\end{tabular}

\section{NCT01558947}

\section{Trial name or title}

$$
\text { Methods }
$$

Peri-operative chemotherapy with ECX (Epirubicin + Cisplatin + Capecitabine) or XP (Capecitabine + Cisplatin) in the treatment of advanced gastric cancer: a randomized, multicentre, parallel vontrol

\begin{tabular}{ll}
\hline Participants & Gastric cancer participants, $\geq$ T2 or N +; or staging II, IIIA, IIIB. \\
\hline Interventions & Experimental: chemotherapy with ECX \\
\hline
\end{tabular}


Preoperative chemotherapy of ECX for 3 cycles (Epirubicin $50 \mathrm{mg} / \mathrm{m}^{2}$ on day 1 ; capecitabine 1000 $\mathrm{mg} / \mathrm{m}^{2}, 2$ times /day, 1 to 14 days; cisplatin $60 \mathrm{mg} / \mathrm{m}^{2}$ on day 1 , need hydration, 21 day/cycle), operation after $2^{\sim} 4$ weeks, and postoperative chemotherapy of ECX for 3 cycles $4 \sim 6$ weeks after surgery.

Experimental: chemotherapy with XP

Preoperative chemotherapy of XP for 3 cycles(capecitabine $1000 \mathrm{mg} / \mathrm{m}^{2}, 2$ times / day, 1 to 14 days; cisplatin $60 \mathrm{mg} / \mathrm{m}^{2}$ on day 1, need hydration, 21 day/cycle), operation after $2^{\sim} 4$ weeks, and postoperative chemotherapy of XP for 3 cycles $4 \sim 6$ weeks after surgery.

Other Name: XP chemotherapy

\begin{tabular}{ll}
\hline Outcomes & Relapse-free survival time/rate [ Time Frame: 3 years ] \\
\hline Starting date & January 2011 \\
\hline Contact information & Xiangdong Cheng, MD, Zhejiang Cancer Hospital \\
\hline Notes & \\
\hline
\end{tabular}

\section{NCT01967875}

$\begin{array}{ll}\text { Trial name or title } & \begin{array}{l}\text { A prospective, multi-center, randomized controlled phase } 2 \text { trial of optimising platinum-based } \\ \text { chemotherapy based on ERCC1 expression as first-line treatment in participants with locally ad- } \\ \text { vanced or metastatic gastric cancer }\end{array}\end{array}$

\begin{tabular}{|c|c|}
\hline Methods & $\begin{array}{l}\text { Multicentre RCT } \\
3 \text { arms }\end{array}$ \\
\hline Participants & $\mathrm{N}=180$, advanced gastric cancer, $18-65$ years, KPS 70, measurable disease \\
\hline \multirow[t]{3}{*}{ Interventions } & $\begin{array}{l}\text { Active comparator: ERCC1 high expression-group A: Cisplatin } 75 \mathrm{mg} / \mathrm{m}^{2}, \mathrm{~d} 1 \text {; Capecitabine } 1700 \\
\mathrm{mg} / \mathrm{m}^{2} / \text { day to } 2000 \mathrm{mg} / \mathrm{m}^{2} / \text { day } \mathrm{d} 1-14 \text { repeated at } \mathrm{d} 21 \text { for } 6 \text { cycles.Capecitabine is to be continued } \\
\text { until disease progression or intolerable toxicity. }\end{array}$ \\
\hline & $\begin{array}{l}\text { Experimental: ERCC1 high expression-group B: Docetaxel } 75 \mathrm{mg} / \mathrm{m}^{2}, \mathrm{~d} \text { 1; Capecitabine } 1700 \mathrm{mg} / \\
\mathrm{m}^{2} / \text { day to } 2000 \mathrm{mg} / \mathrm{m}^{2} / \text { day on days } 1-14 \text { every } 21 \text { days, } 6 \text { cycles. Capecitabine is to be continued } \\
\text { until disease progression or intolerable toxicity. }\end{array}$ \\
\hline & $\begin{array}{l}\text { Active comparator: ERCC1 low expression group: Cisplatin } 75 \mathrm{mg} / \mathrm{m}^{2}, \mathrm{~d} 1 \text {; Capecitabine } 1700 \mathrm{mg} / \\
\mathrm{m}^{2} / \text { day to } 2000 \mathrm{mg} / \mathrm{m}^{2} / \text { day } \mathrm{d} 1-14 \text { repeated at } \mathrm{d} 21 \text { for } 6 \text { cycles. Capecitabine is continued until dis- } \\
\text { ease progression or intolerable toxicity. }\end{array}$ \\
\hline Outcomes & $\begin{array}{l}\text { Progression-free survival, overall survival, objective response rate, disease control rate, duration of } \\
\text { response, safety, quality of life }\end{array}$ \\
\hline Starting date & July 2013 \\
\hline Contact information & Yunpeng Liu: cmuliuyunpeng@hotmail.com, Jing Liu:liujing_cmu@hotmail.com \\
\hline Notes & Sponsor: China Medical University, China \\
\hline
\end{tabular}




\section{NCT02076594}

Trial name or title
A randomized phase III study of low-docetaxel oxaliplatin, capecitabine (low-tox) vs epirubicin, oxaliplatin and capecitabine (Eox) In patients with locally advanced unresectable or metastatic gastric cancer

\begin{tabular}{ll}
\hline Methods & Phase 3 \\
& Allocation: Randomised \\
Intervention Model: Parallel assignment \\
Masking: Open-label \\
Primary Purpose: Treatment
\end{tabular}

\begin{tabular}{ll}
\hline Participants & Age 18 to 69 years \\
$\cdot$ & Histologically proven diagnosis of adenocarcinoma of the stomach \\
$\cdot$ & HER2 negative tumour or HER2+ tumours not qualifying for herceptin therapy \\
$\cdot$ & Locally advanced (non resectable) or metastatic gastric cancer
\end{tabular}

Interventions

Experimental arm A: docetaxel \& oxaliplatin \& capecitabine

Participants will receive cycles every 3 weeks of docetaxel $\left(35 \mathrm{mg} / \mathrm{m}^{2}\right.$, intravenous at days 1 and 8 by 1 -hour infusion)and oxaliplatin $\left(80 \mathrm{mg} / \mathrm{m}^{2}\right.$, intravenous at day 1 by 2 -hour infusion) and capecitabine $\left(750 \mathrm{mg} / \mathrm{m}^{2}\right.$, oral tablets of $500 \mathrm{mg}$ and $150 \mathrm{mg}$, $\times 2$ daily for 2 weeks)

Experimental arm B: epirubicin \& oxaliplatin \& capecitabine

Participants will receive cycles every 3 weeks of epirubicin $\left(50 \mathrm{mg} / \mathrm{m}^{2}\right.$, intravenous on day 1 by 2 -hour infusion)and oxaliplatin ( $130 \mathrm{mg} / \mathrm{m}^{2}$, intravenous on day 1 by 2 -hour infusion) and capecitabine $\left(625 \mathrm{mg} / \mathrm{m}^{2}\right.$,oral tablets of $500 \mathrm{mg}$ and $150 \mathrm{mg}$, $\times 2$ daily for 3 weeks)

Outcomes

Overall survival (OS) [Time frame: Measured as the time from randomisation to the date of death from any cause, assessed up to 18 months of follow-up]

Progression-free survival (PFS) [Time frame: Measured as the time from randomisation to the date of local or regional progression, distant metastasis, second primary malignancy or death from any cause, whichever comes first, assessed up to 18 months of follow-up]

Objective Response Rate (CR + PR) according to RECIST 1.1 guideline [Time frame: Measured as the time from randomisation, assessed up to 18 months of follow-up]

Disease control rate: $\mathrm{CR}+\mathrm{PR}+\mathrm{SD}$ lasting > 12 weeks [Time frame: Measured as the time from randomisation, assessed up to 18 months of follow-up]

To assess tolerability of the treatments of participants with locally advanced unresectable or metastatic gastric cancer treated with docetaxel plus oxaliplatin plus capecitabine (Arm A) or with epirubicin plus oxaliplatin plus capecitabine (Arm B)

\begin{tabular}{ll}
\hline Starting date & January 2013 \\
\hline Contact information & Contact: Roberto Labianca, MD +390352673691 rlabianca@hpg23.it \\
\hline
\end{tabular}

Notes 
Trial name or title
Comparison of efficacy and tolerance between combination therapy and monotherapy as first line chemotherapy in elderly participants with advanced gastric cancer: a multicenter randomized phase 3 study

\begin{tabular}{ll}
\hline Methods & Multicentre RCT \\
Phase 3 \\
Allocation: Randomised \\
Intervention Model: Parallel assignment \\
Masking: Open-label \\
Primary Purpose: Treatment
\end{tabular}

Participants $N=332, \geq 70$ years, Eastern Cooperative Oncology Group 0-2, Measurable or evaluable disease, HER-2 negative
Experimental: Platinum/fluoropyrimidine combination chemotherapy

- Drug: Capecitabine/cisplatin

Capecitabine/cisplatin (XP) : cisplatin $50 \mathrm{mg} / \mathrm{m}^{2}\left(80 \%\right.$ dose of $\left.60 \mathrm{mg} /{ }^{2} \mathrm{~m}\right)$ iv over $15 \mathrm{~min} \mathrm{D} 1$, capecitabine $1000 \mathrm{mg} / \mathrm{m}^{2}$ ( $80 \%$ dose of $1250 \mathrm{mg} / \mathrm{m}^{2}$ ) orally twice a day D1-14, repeated at 3 weeks

- Drug: S-1/cisplatin

S-1/cisplatin (SP) : cisplatin $50 \mathrm{mg} / \mathrm{m}^{2}\left(80 \%\right.$ dose of $\left.60 \mathrm{mg} /{ }^{2} \mathrm{~m}\right)$ iv ov $15 \mathrm{~min} \mathrm{D} 1, \mathrm{~S}-130 \mathrm{mg} / \mathrm{m}^{2}(80 \%$ dose of $40 \mathrm{mg} / \mathrm{m}^{2}$ ) orally twice a day D1-14, repeated at 3 weeks

- Drug: Capecitabine/oxaliplatin

Capecitabine+oxaliplatin (XELOX): oxaliplatin $100 \mathrm{mg} / \mathrm{m}^{2}\left(80 \%\right.$ dose of $\left.130 \mathrm{mg} / \mathrm{m}^{2}\right)$ iv ov $120 \mathrm{~min}$ D1, capecitabine $800 \mathrm{mg} / \mathrm{m}^{2}$ ( $80 \%$ dose of $1000 \mathrm{mg} / \mathrm{m}^{2}$ ) orally twice a day D1-14, repeated at 3 weeks

- Drug: 5-fluorouracil/oxaliplatin

5-fluorouracil/oxaliplatin (FOLFOX): oxaliplatin $80 \mathrm{mg} / \mathrm{m}^{2}$ (80\% dose of $100 \mathrm{mg} / \mathrm{m}^{2}$ ) iv ov $120 \mathrm{~min}$, leucovorin $80 \mathrm{mg} / \mathrm{m}^{2}\left(80 \%\right.$ dose of $\left.100 \mathrm{mg} / \mathrm{m}^{2}\right)$ iv ov $120 \mathrm{~min}, 5$-fluorouracil $1900 \mathrm{mg} / \mathrm{m}^{2}(80 \%$ dose of $2400 \mathrm{mg} / \mathrm{m}^{2}$ ) iv ov $46 \mathrm{~h} \mathrm{D1}$, repeated at 2 weeks

Active Comparator: Fluoropyrimidine mono chemotherapy

- Drug: Capecitabine

Capecitabine : $1250 \mathrm{mg} / \mathrm{m}^{2}$ orally twice a day D1-14 repeated at 3 weeks (if $\mathrm{Ccr}<60 \mathrm{~mL} / \mathrm{min}, 1000$ $\mathrm{mg} / \mathrm{m}^{2}$ orally twice a day)

- Drug: S-1

S-1 : $40 \mathrm{mg} / \mathrm{m}^{2}$ orally twice a day D1-14 repeated at 3 weeks (if $\mathrm{Ccr}<60 \mathrm{~mL} / \mathrm{min}, 30 \mathrm{mg} / \mathrm{m}^{2}$ orally twice a day)

- Drug: 5-fluorouracil

5-fluorouracil (FL) : leucovorin $100 \mathrm{mg} / \mathrm{m}^{2}$ iv ov $2 \mathrm{~h}, 5$-fluorouracil $2400 \mathrm{mg} / \mathrm{m}^{2}$ iv ov $46 \mathrm{~h}$ D1, repeated at 2 weeks

Arm A (XP): cisplatin $50 \mathrm{mg} / \mathrm{m}^{2} \mathrm{~d} 1$, capecitabine $1000 \mathrm{mg} / \mathrm{m}^{2}$ orally twice a day $\mathrm{d} 1-14$, repeated at day 21

Arm B (SP): cisplatin $50 \mathrm{mg} / \mathrm{m}^{2} \mathrm{~d} 1, \mathrm{~S}-130 \mathrm{mg} / \mathrm{m}^{2}$ orally twice a day $\mathrm{d} 1-14$, repeated at $\mathrm{d} 21$ 
NCT02114359 (Continued)

Arm C (XELOX): oxaliplatin $100 \mathrm{mg} / \mathrm{m}^{2} \mathrm{~d} 1$, capecitabine $800 \mathrm{mg} /{ }^{2}$ orally twice a day $\mathrm{d} 1-14$, repeated at day 21

Arm D (FOLFOX): oxaliplatin $80 \mathrm{mg} / \mathrm{m}^{2}$, leucovorin $80 \mathrm{mg} / \mathrm{m}^{2}, 5$-fluorouracil $1900 \mathrm{mg} / \mathrm{m}^{2} \mathrm{ci} 46 \mathrm{~h} \mathrm{~d} 1$, repeated at day 14

Comparison of overall survival [Time frame: up to 3 years]
Comparison of progression-free survival [Time frame: up to 2 years]
Comparison of response rate [Time frame: up to 2 years]
Comparison of adverse events [Time frame: up to 2 years]
Comparison of quality of life [Time frame: up to 2 years]

\begin{tabular}{ll}
\hline Starting date & February 2014 \\
\hline Contact information & In Sil Choi, M.D., Ph.D.; 82-10-9137-3883; hmoischoi@hanmail.net \\
\hline Notes & $\begin{array}{l}\text { Sponsor and Collaborators: Seoul National University Hospital, Ministry of Health \& Welfare, Korea, } \\
\text { Korean Cancer Study Group }\end{array}$ \\
\hline
\end{tabular}

NCT02289378

Trial name or title

Dose-dense biweekly docetaxel, oxaliplatin and 5-fluorouracil as first-line treatment in advanced gastric cancer (DaeMon-Plus)

\begin{tabular}{ll}
\hline Methods & Phase 2 \\
& Intervention Model: Single-group assignment \\
& Masking: Open-label \\
& Primary Purpose: Treatment \\
\hline Participants & $\mathrm{N}=30$ \\
& Age $18-75$ years \\
& Participants with histologically or cytologically confirmed unresectable gastric adenocarcinoma \\
& whose ECOG performance status are 0-2 \\
\hline Interventions & Experimental: docetaxel, oxaliplatin and 5-Fu \\
\hline Outcomes & Docetaxel 50 mg/m² Oxaliplatin 85 mg/m ${ }^{2} 5$-Fu $2800 \mathrm{mg} / \mathrm{m}^{2}$ Repeated every two weeks \\
\hline Starting date & Progression-free survival [Time frame: 2 years] \\
\hline Contact information & November 2014 \\
\hline Notes & Ping Lan, MD The Sixth Affilated Hospital of Sun Yat-sen University \\
\hline
\end{tabular}


NCT02289547

Trial name or title

Randomized phase 3 study of XELOX (capecitabine plus oxaliplatin) followed by maintenance

capecitabine or observation in participants with advanced gastric adenocarcinoma

\begin{tabular}{|c|c|}
\hline \multirow[t]{7}{*}{ Methods } & Multicentre RCT \\
\hline & 2 arms \\
\hline & Phase 3 \\
\hline & Allocation: Randomised \\
\hline & Intervention Model: Parallel assignment \\
\hline & Masking: Open-label \\
\hline & Primary Purpose: Treatment \\
\hline Participants & $\begin{array}{l}\mathrm{N}=184 \text { advanced or recurrent gastric cancer, age } \geq 18 \text { years, HER-2 negative, with more than sta- } \\
\text { ble disease after } 6 \text { cycles } 1 \text { st line of XELOX chemotherapy (objective response, non-complete re- } \\
\text { sponse/non-progressive disease in cases of non-measurable disease before XELOX chemotherapy) }\end{array}$ \\
\hline \multirow[t]{2}{*}{ Interventions } & Arm A : Capecitabine: capecitabine $1000 \mathrm{mg} / \mathrm{m}^{2}$ twice a day D1-14, repeated at 3 weeks \\
\hline & Arm B : Observation \\
\hline Outcomes & $\begin{array}{l}\text { Progression-free survival, overall survival, quality of life (as measured by QLQ-c30 and STO-22), } \\
\text { Toxicity profile }\end{array}$ \\
\hline Starting date & January 2015 \\
\hline Contact information & Byoungyong Shim: shimby@catholic.ac.kr; Ho Jung An: \\
\hline Notes & Sponsor: The Catholic University of Korea \\
\hline
\end{tabular}

\section{NCT02549911}

\section{Trial name or title}

Hyperthermic intraperitoneal chemotherapy, intravenous chemotherapy combined with surgery for the treatment of advanced gastric cancer with peritoneal metastasis

\begin{tabular}{|c|c|}
\hline \multirow[t]{4}{*}{ Methods } & Phase 2 \\
\hline & Intervention Model: Single-group assignment \\
\hline & Masking: Open-label \\
\hline & Primary Purpose: Treatment \\
\hline \multirow[t]{3}{*}{ Participants } & $N=40$ \\
\hline & $18-75$ years \\
\hline & $\begin{array}{l}\text { Gastric cancer confirmed by endoscopic biopsy, and enhanced CT suspected to have peritoneal } \\
\text { metastasis, including ascites, ovarian metastasis, omentum or peritoneal metastasis. }\end{array}$ \\
\hline \multirow[t]{3}{*}{ Interventions } & Experimental: HIPEC,Chemotherapy AND surgery \\
\hline & 1. Surgical exploration, if $\mathrm{PCl}<20$,then we perform this study \\
\hline & $\begin{array}{l}\text { 2. HIPEC (RHL-2000B, Madain Medical Devices Co., Ltd., Jilin, China): Taxol (Paclitaxel Injection) } \\
75 \mathrm{mg} / \mathrm{m}^{2} \text {, twice, within } 72 \text { hours after surgical exploration ; oral chemotherapy:S-1(Tega- }\end{array}$ \\
\hline
\end{tabular}


fur,Gimeracil and Oteracil Potassium Capsules): $80 \mathrm{mg} / \mathrm{m}^{2}$, twice daily (after the breakfast and supper) for two weeks, and then suspend for one week.

3. Chemotherapy (3 cycles) : Taxol $150 \mathrm{mg} / \mathrm{m}^{2}$,d 1, S-1: $80 \mathrm{mg} / \mathrm{m}^{2}$, twice daily (after breakfast and supper) for two weeks, and then suspend for one week.

4. Surgery: Secondary surgical exploration:if $\mathrm{PCl}$ less than 20,then perform the cytoreductive surgery (resection of primary tumours and metastases )

5. after the surgery,HIPEC for two cycles, and PS chemotherapy for 3 cycles

Intervention: Other: HIPEC, chemotherapy AND surgery

\begin{tabular}{ll}
\hline Outcomes & Ro resection [Time frame: 3 months] \\
& Adverse events [Time frame: 6 months] \\
& Overall survival time [Time Frame: 3 years]
\end{tabular}

\begin{tabular}{ll}
\hline Starting date & September 2015 \\
\hline Contact information & Yian Du, MD; ypfzmu@163.com; 86-571-88128031
\end{tabular}

Notes

\section{NCT02583659}

Trial name or title

clinical study

\section{Observational Model: Cohort}

Time Perspective: Prospective

\section{$N=250$}

Histopathology or cytopathology confirmed unresectable locally advanced, or recurrent, or metastatic chemotherapy-naive gastric cancer and gastroesophageal adenocarcinoma participants

$\begin{array}{ll}\text { Interventions } & \text { Observational Model: Cohort } \\ \text { Time Perspective: Prospective }\end{array}$

Outcomes

Overall survival (OS) [Time frame: From date of enrolment until the date of death from any cause, assessed up to 60 months]

Progression-free survival (PFS) [Time frame: From date of enrolment until the date of first documented progression or date of death from any cause, whichever came first, assessed up to 60 months]

Objective response rate (ORR) [Time frame: The sum of complete remission (CR) rate and partial remission (PR) rate. Response will be measured through first-line treatment completion, up to 1 year]

Disease control rate (DCR) [Time frame: The sum of CR rate, PR rate and stable disease (SD) rate. Response will be measured through first-line treatment completion, up to 1 year]

Number of participants with treatment-related adverse events as assessed by CTCAE v4.0 [Time frame: Through first-line treatment completion, up to 24 weeks.] 
NCT02583659 (Continued)

Contact information Xianglin Yuan, MD,PHD

Tongji hospital of Tongji Medical College, Huazhong University of Science and Technology

\section{Notes}

\section{NCT02855788}

Trial name or title

Phase II study of weekly metronomic chemotherapy using weekly aclitaxel, Oxaliplatin, Leucovorin and 5-FU (POLF) in participants with advanced gastric cancer

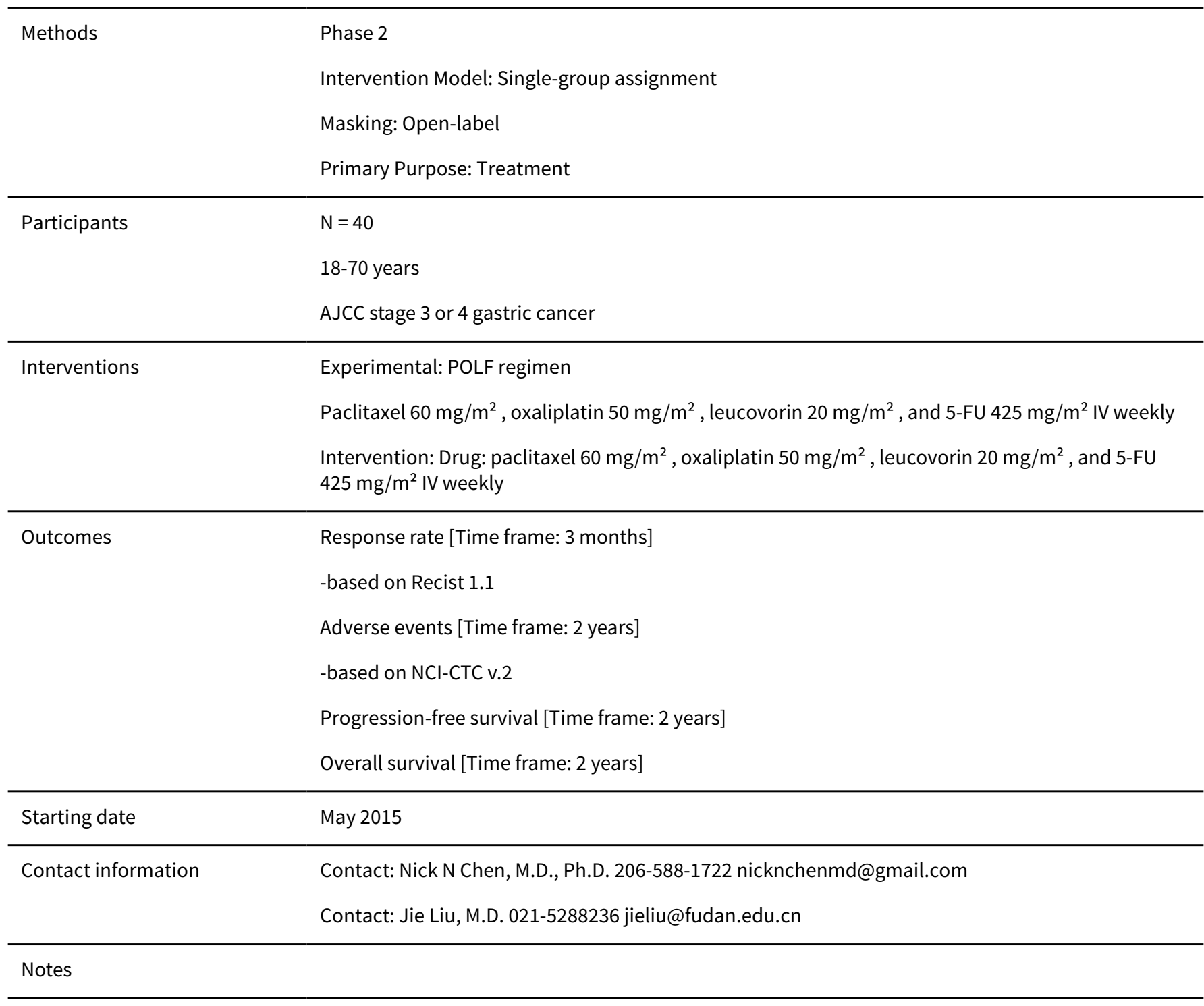

\section{NCT03006432}

Trial name or title

ASE III randomised trial to evaluate folfox with or without docetaxel (TFOX) as 1st line chemotherapy for locally advanced or metastatic oesophago-gastric carcinoma (GASTFOX) 
NCT03006432 (Continued)

Methods
Phase 3

Allocation: Randomised

Intervention Model: Parallel assignment

Masking: No masking

Primary Purpose: Treatment

\begin{tabular}{ll}
\hline Outcomes & Progression-free survival [Time frame: 12 months after last randomisation] \\
& Overall survival toxicity events (adverse events) according to NCI-CTC v4.0 [Time frame: 12 months \\
after last randomisation] \\
Objective response rate [Time frame: 12 months after last randomisation] \\
Toxicity events according to NCl-CTC v4.0 [Time frame: 12 months after last randomisation]
\end{tabular}

\begin{tabular}{ll}
\hline Starting date & December 2016 \\
\hline Contact information & Contact: Marie MOREAU +33 (0)380393404 marie.moreau@u-bourgogne.fr \\
\hline Notes & PRODIGE 51 \\
\hline
\end{tabular}

Tsuburaya 2012

\section{Trial name or title}

\section{$N=506$}

Gastric or gastro-oesophageal junction adenocarcinoma (all Siewert), histologically proven (on primary tumour or metastatic lesion),

HER2 negative (positive HER2 status is defined by a positive IHC test of $3+$ or IHC of 2+ with positive FISH)

Metastatic or non-resectable (locally advanced) disease

Active Comparator: FOLFOX

Cycles every 15 days until progression disease

Experimental: TFOX

Cycles every 15 days until progression disease

Interventions: Drug: oxaliplatin

1. Drug: 5Fluorouracil bolus

2. Drug: 5Fluorouracil continuous

3. Drug: docetaxel

4. Drug: folinic Acid

Overall survival toxicity events (adverse events) according to NCI-CTC v4.0 [Time frame: 12 months isation]

December 2016 
Tsuburaya 2012 (Continued)

\begin{tabular}{ll} 
Participants & $\mathrm{N}=100$ (planned) \\
\hline Interventions & Arm A: S-1 $\left(40 \mathrm{mg} / \mathrm{m}^{2}\right.$ twice a day d1-21) + cisplatin $\left(60 \mathrm{mg} / \mathrm{m}^{2} \mathrm{~d} 8\right)$ repeated at d 35 \\
& versus \\
& Arm B: capecitabine $\left(1000 \mathrm{mg} /{ }^{2} \mathrm{~d} 1-14\right)+$ cisplatin $\left(80 \mathrm{mg} / \mathrm{m}^{2} \mathrm{~d} 1\right)$ repeated at $\mathrm{d} 21$ \\
\hline Outcomes & Progression-free survival, overall survival, time to treatment failure, tumour response, safety \\
\hline Starting date & August 2011 \\
\hline Contact information & $\begin{array}{l}\text { Akira Tsuburaya, Department of Gastrointestinal Surgery, Kanagawa Cancer Center, 1-1-2, Nakao, } \\
241-0815, \text { Yokohama, Asahi-ku, Japan, tuburayaa@kcch.jp }\end{array}$ \\
\hline Notes & $\begin{array}{l}\text { The study is registered (NCT01406249), the study protocol is published. Estimated study comple- } \\
\text { tion date is June 2015. The study is not yet published. }\end{array}$ \\
\hline
\end{tabular}

5-FU: 5-fluorouracil

ci: continuous infusion

d: day

E: epirubicin

G-CSF: granulocyte colony stimulating factor

PFS: progression-free survival

$\mathrm{RCT}$ : randomised controlled trial

\section{DATA AND ANALYSES}

Comparison 1. Chemotherapy versus best supportive care

\begin{tabular}{lllll}
\hline Outcome or subgroup title & No. of studies & $\begin{array}{l}\text { No. of partici- } \\
\text { pants }\end{array}$ & Statistical method & Effect size \\
\hline 1 Overall survival & 3 & 184 & Hazard ratio (Random, 95\% Cl) & $0.37[0.24,0.55]$ \\
\hline 2 Time to progression & 2 & 144 & Hazard ratio (Fixed, 95\% Cl) & $0.31[0.22,0.43]$ \\
\hline
\end{tabular}

Analysis 1.1. Comparison 1 Chemotherapy versus best supportive care, Outcome 1 Overall survival.

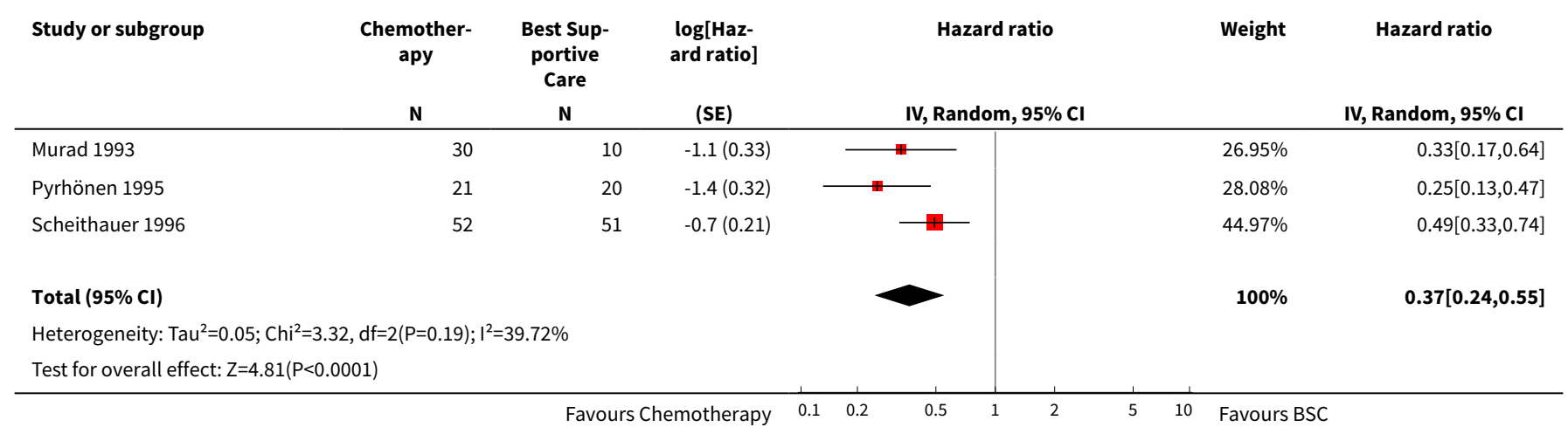


Analysis 1.2. Comparison 1 Chemotherapy versus best supportive care, Outcome 2 Time to progression.

\begin{tabular}{|c|c|c|c|c|c|c|}
\hline \multirow[t]{2}{*}{ Study or subgroup } & \multirow{2}{*}{$\begin{array}{c}\text { Chemother- } \\
\text { apy } \\
\text { N }\end{array}$} & \multirow{2}{*}{$\begin{array}{c}\text { Best Sup- } \\
\text { portive } \\
\text { Care } \\
\text { N }\end{array}$} & \multirow{2}{*}{$\begin{array}{c}\log [\mathrm{Haz}- \\
\text { ard ratio }] \\
\text { (SE) }\end{array}$} & Hazard ratio & Weight & Hazard ratio \\
\hline & & & & IV, Fixed, $95 \% \mathrm{CI}$ & & IV, Fixed, 95\% CI \\
\hline Scheithauer 1996 & 52 & 51 & $-1.2(0.2)$ & 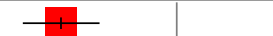 & $76.42 \%$ & $0.31[0.21,0.45]$ \\
\hline Pyrhönen 1995 & 21 & 20 & $-1.2(0.36)$ & & $23.58 \%$ & $0.31[0.15,0.63]$ \\
\hline Total $(95 \% \mathrm{Cl})$ & & & & & $100 \%$ & $0.31[0.22,0.43]$ \\
\hline \multicolumn{7}{|c|}{ Heterogeneity: $\operatorname{Tau}^{2}=0 ; \mathrm{Chi}^{2}=0, \mathrm{df}=1(\mathrm{P}=0.96) ; \mathrm{I}^{2}=0 \%$} \\
\hline Test for overall effec & & & & & & \\
\hline
\end{tabular}

Comparison 2. Combination versus single-agent chemotherapy

\begin{tabular}{llllll}
\hline Outcome or subgroup title & No. of studies & $\begin{array}{l}\text { No. of partici- } \\
\text { pants }\end{array}$ & Statistical method & Effect size \\
\hline 1 Overall survival & 23 & 4447 & Hazard ratio (Fixed, 95\% Cl) & $0.84[0.79,0.89]$ \\
\hline 2 Tumour response & 18 & 2833 & Odds Ratio (M-H, Fixed, 95\% Cl) & $2.30[1.94,2.72]$ \\
\hline 3 Time to progression & 4 & 720 & Hazard ratio (Random, 95\% Cl) & $0.69[0.55,0.87]$ \\
\hline 4 Treatment-related death & 18 & 3876 & Odds Ratio (M-H, Fixed, 95\% Cl) & $1.64[0.83,3.24]$ \\
\hline
\end{tabular}

Analysis 2.1. Comparison 2 Combination versus single-agent chemotherapy, Outcome 1 Overall survival.

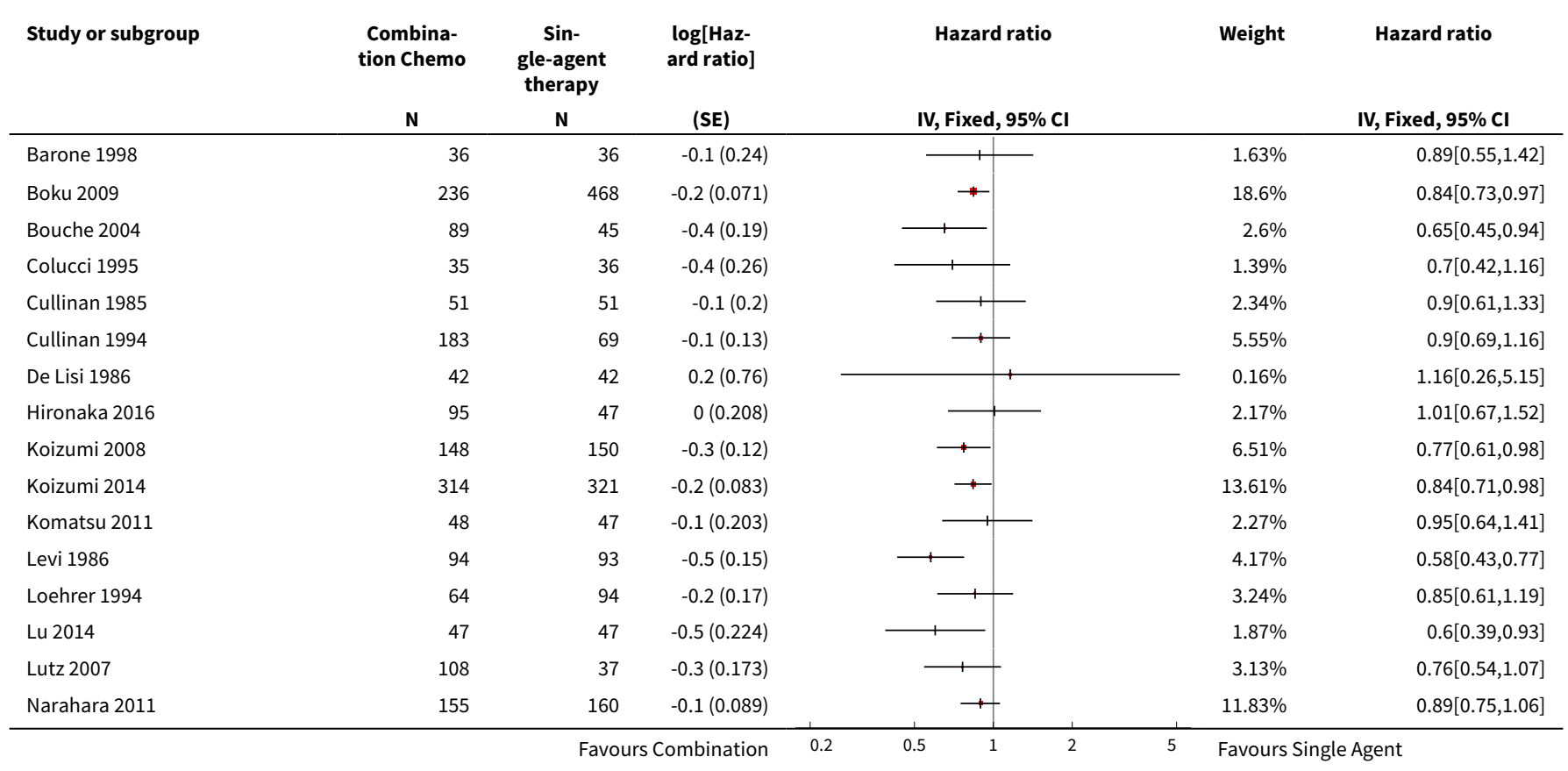




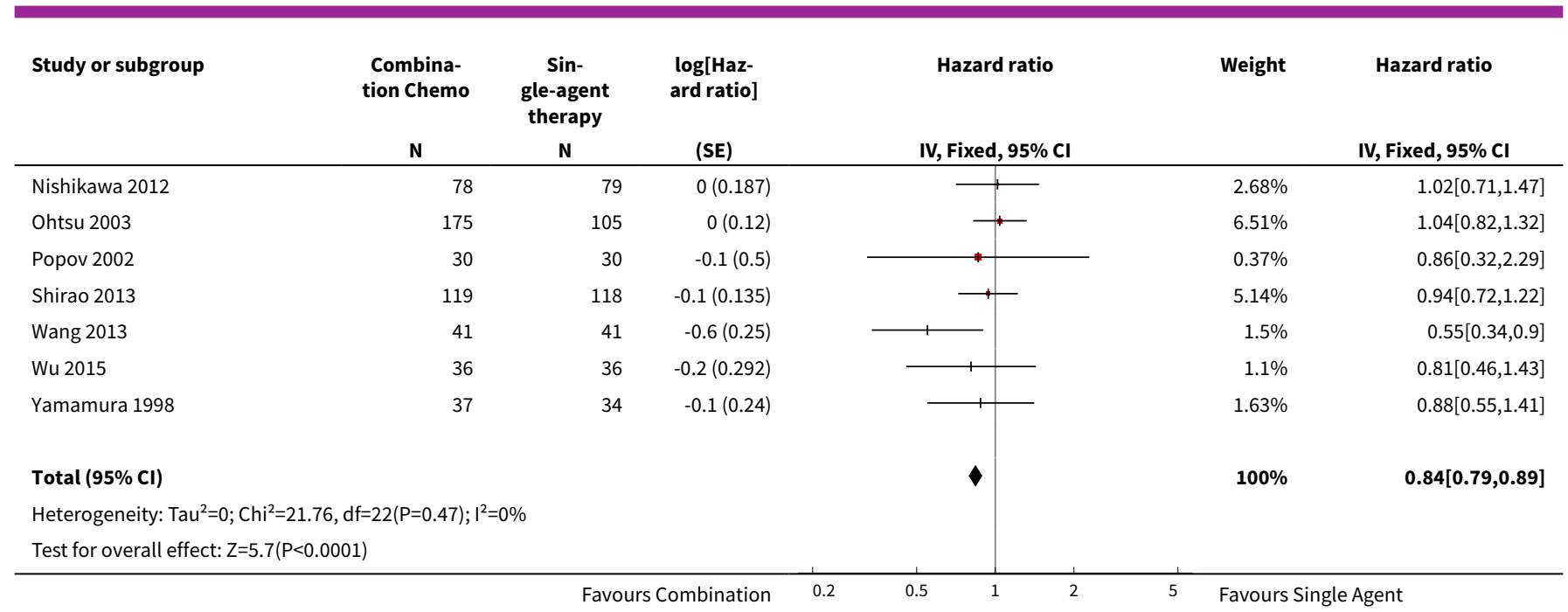

\section{Analysis 2.2. Comparison 2 Combination versus single-agent chemotherapy, Outcome 2 Tumour response.}

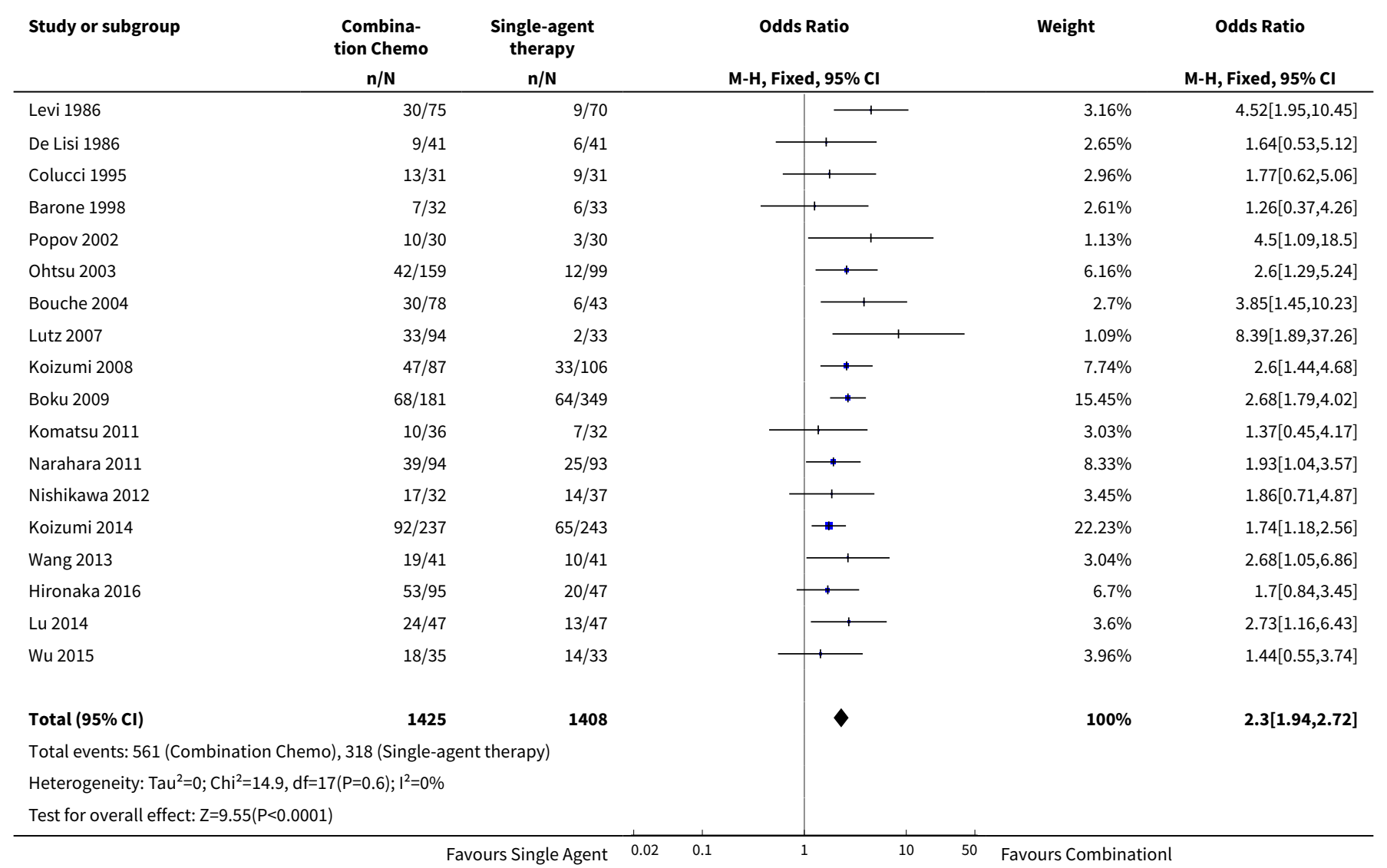


Analysis 2.3. Comparison 2 Combination versus single-agent chemotherapy, Outcome 3 Time to progression.

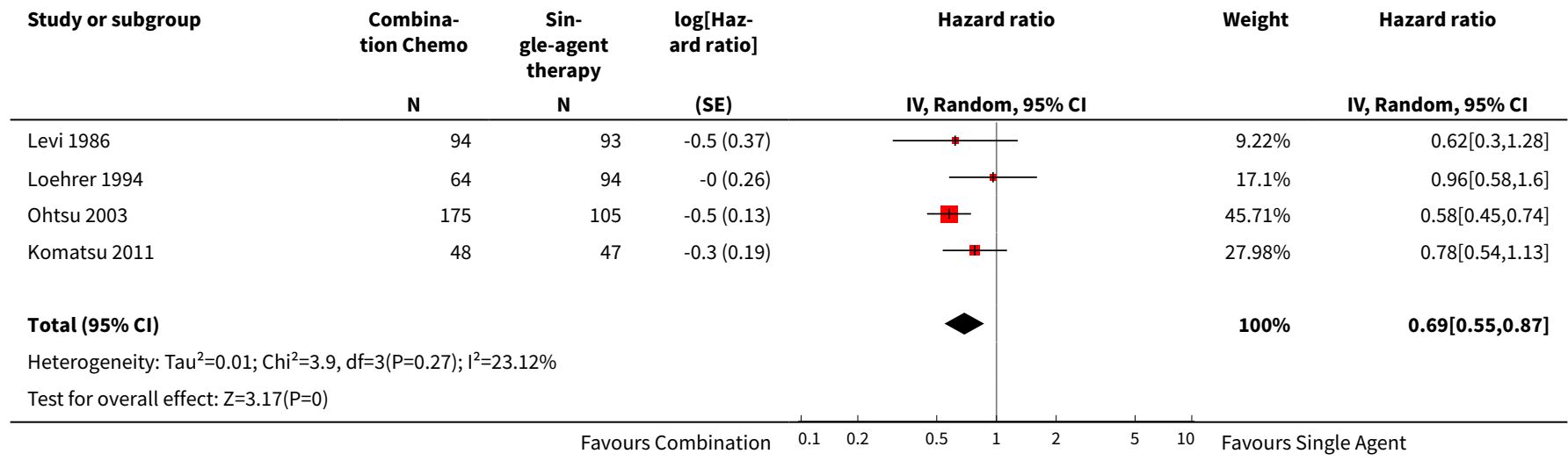

Analysis 2.4. Comparison 2 Combination versus single-agent chemotherapy, Outcome 4 Treatment-related death.

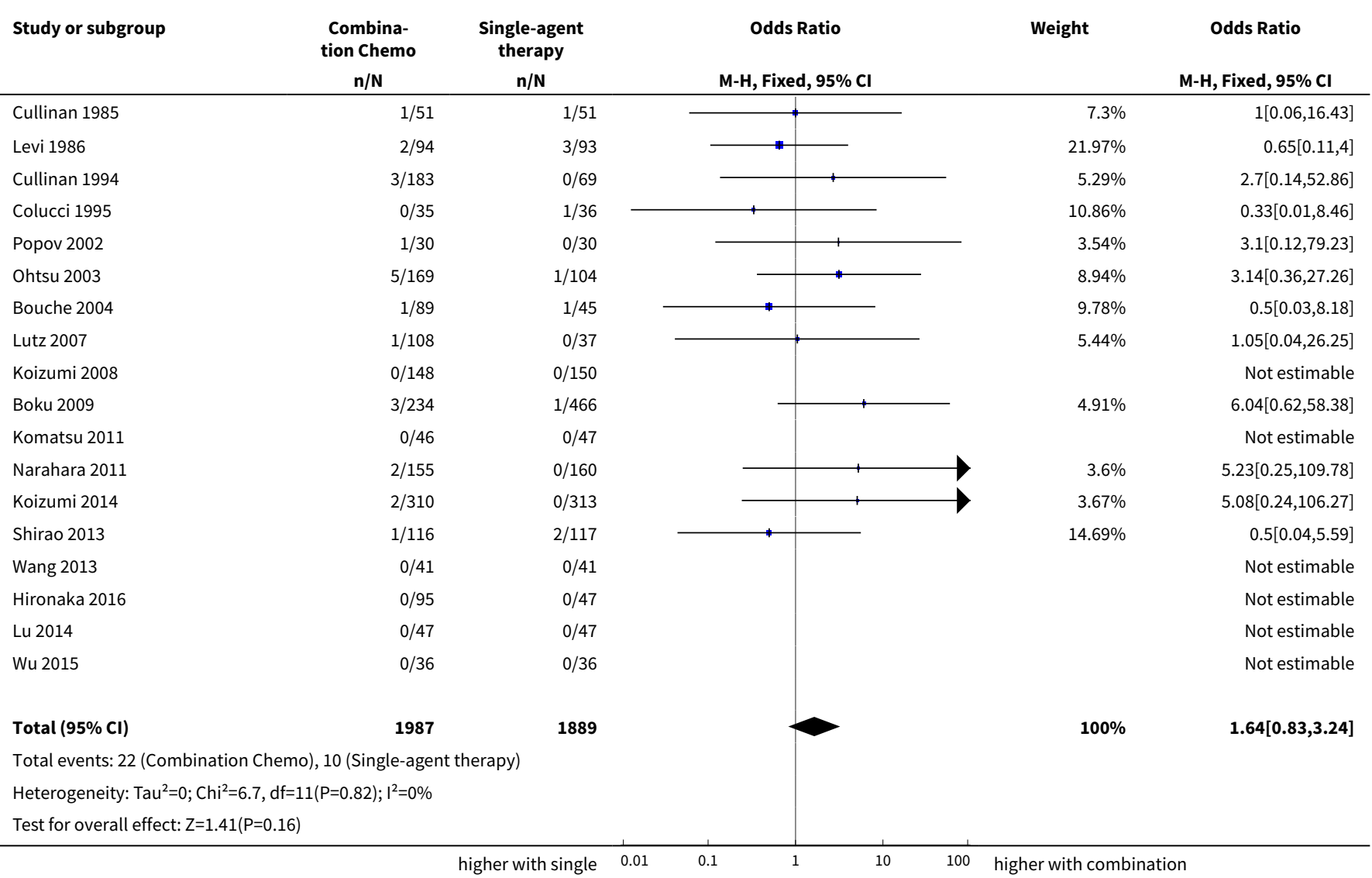


Comparison 3. 5-FU/cisplatin/anthracycline combinations versus 5-FU/cisplatin combinations (without anthracyclines)

\begin{tabular}{lllll}
\hline Outcome or subgroup title & No. of studies & $\begin{array}{l}\text { No. of partici- } \\
\text { pants }\end{array}$ & Statistical method & Effect size \\
\hline 1 Overall survival & 4 & 579 & Hazard ratio (Fixed, 95\% Cl) & $0.74[0.61,0.89]$ \\
\hline 2 Tumour response & 1 & Odds Ratio (M-H, Fixed, 95\% Cl) & Subtotals only \\
\hline 3 Time to progression & 1 & Hazard Ratio (Fixed, 95\% Cl) & Subtotals only \\
\hline
\end{tabular}

Analysis 3.1. Comparison 35 -FU/cisplatin/anthracycline combinations versus 5-

FU/cisplatin combinations (without anthracyclines), Outcome 1 Overall survival.

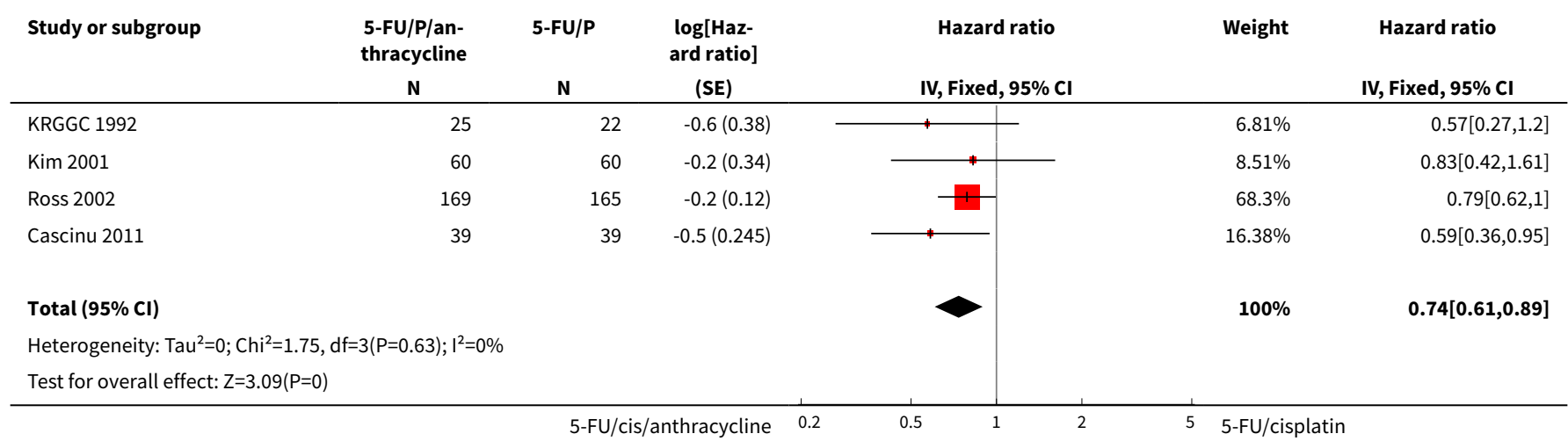

Analysis 3.2. Comparison 3 5-FU/cisplatin/anthracycline combinations versus 5FU/cisplatin combinations (without anthracyclines), Outcome 2 Tumour response.

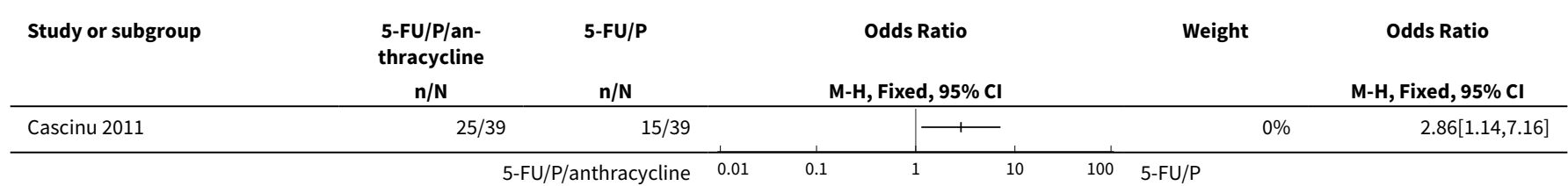

Analysis 3.3. Comparison 3 5-FU/cisplatin/anthracycline combinations versus 5FU/cisplatin combinations (without anthracyclines), Outcome 3 Time to progression.

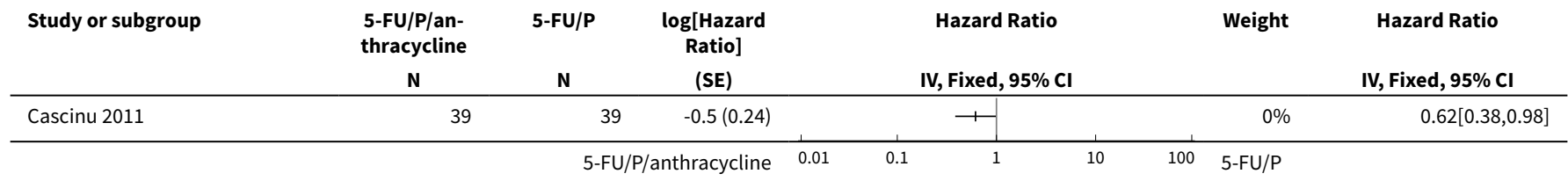


Comparison 4. 5-FU/cisplatin/anthracycline combinations versus 5-FU/anthracycline combinations (without cisplatin)

\begin{tabular}{lllll}
\hline Outcome or subgroup title & No. of studies & $\begin{array}{l}\text { No. of partici- } \\
\text { pants }\end{array}$ & Statistical method & Effect size \\
\hline 1 Overall survival & 7 & 1147 & Hazard ratio (Random, 95\% Cl) & $0.82[0.73,0.92]$ \\
\hline
\end{tabular}

Analysis 4.1. Comparison 4 5-FU/cisplatin/anthracycline combinations versus 5$\mathrm{FU} /$ anthracycline combinations (without cisplatin), Outcome 1 Overall survival.

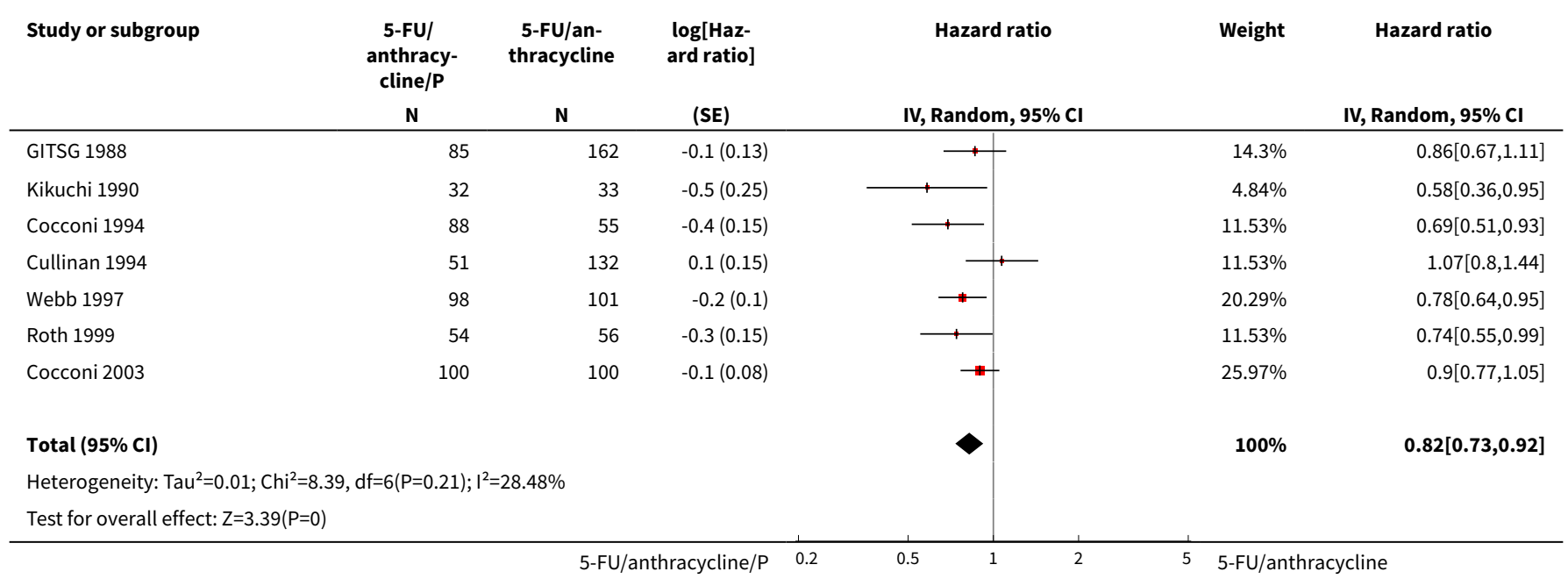

Comparison 5. Chemotherapy with irinotecan versus non-irinotecan-containing regimes

\begin{tabular}{lllll}
\hline Outcome or subgroup title & No. of studies & $\begin{array}{l}\text { No. of partici- } \\
\text { pants }\end{array}$ & Statistical method & Effect size \\
\hline 1 Overall survival & 10 & 2135 & Hazard Ratio (Fixed, 95\% Cl) & 0.87 [0.80, 0.95] \\
\hline 1.1 Substitutive comparisons & 6 & 826 & Hazard Ratio (Fixed, 95\% Cl) & $0.87[0.75,1.00]$ \\
\hline 1.2 Additive comparisons & 3 & 500 & Hazard Ratio (Fixed, 95\% Cl) & $0.88[0.76,1.03]$ \\
\hline 1.3 Other comparisons & 2 & 809 & Hazard Ratio (Fixed, 95\% Cl) & $0.87[0.76,1.00]$ \\
\hline 2 Tumour response & 10 & 1266 & Odds Ratio (M-H, Random, 95\% Cl) & $1.72[1.24,2.40]$ \\
\hline 2.1 Substitutive comparisons & 6 & 756 & Odds Ratio (M-H, Random, 95\% Cl) & 1.53 [0.93, 2.50] \\
\hline 2.2 Additive comparisons & 3 & 345 & Odds Ratio (M-H, Random, 95\% Cl) & $2.18[1.25,3.80]$ \\
\hline 2.3 Other Comparisons & 2 & 165 & Odds Ratio (M-H, Random, 95\% Cl) & $1.87[0.89,3.91]$ \\
\hline 3 Progression-free survival & 7 & 1640 & Hazard Ratio (Fixed, 95\% Cl) & $0.76[0.69,0.84]$ \\
\hline 3.1 Substitutive comparison & 5 & 741 & Hazard Ratio (Fixed, 95\% Cl) & $0.85[0.72,1.00]$ \\
\hline
\end{tabular}




\begin{tabular}{lllll}
\hline Outcome or subgroup title & No. of studies & $\begin{array}{l}\text { No. of partici- } \\
\text { pants }\end{array}$ & Statistical method & Effect size \\
\hline 3.2 Additive comparisons & 1 & 90 & Hazard Ratio (Fixed, 95\% Cl) & $0.51[0.33,0.77]$ \\
\hline 3.3 Other comparisons & 2 & 809 & Hazard Ratio (Fixed, 95\% Cl) & $0.74[0.66,0.84]$ \\
\hline 4 Treatment-related death & 9 & 1979 & Odds Ratio (M-H, Random, 95\% Cl) & $0.88[0.23,3.32]$ \\
\hline $\begin{array}{l}\text { 5 Treatment discontinuation } \\
\text { due to toxicity }\end{array}$ & 9 & 1979 & Odds Ratio (M-H, Random, 95\% Cl) & $1.00[0.46,2.20]$ \\
\hline
\end{tabular}

\section{Analysis 5.1. Comparison 5 Chemotherapy with irinotecan versus non-irinotecan-containing regimes, Outcome 1 Overall survival.}

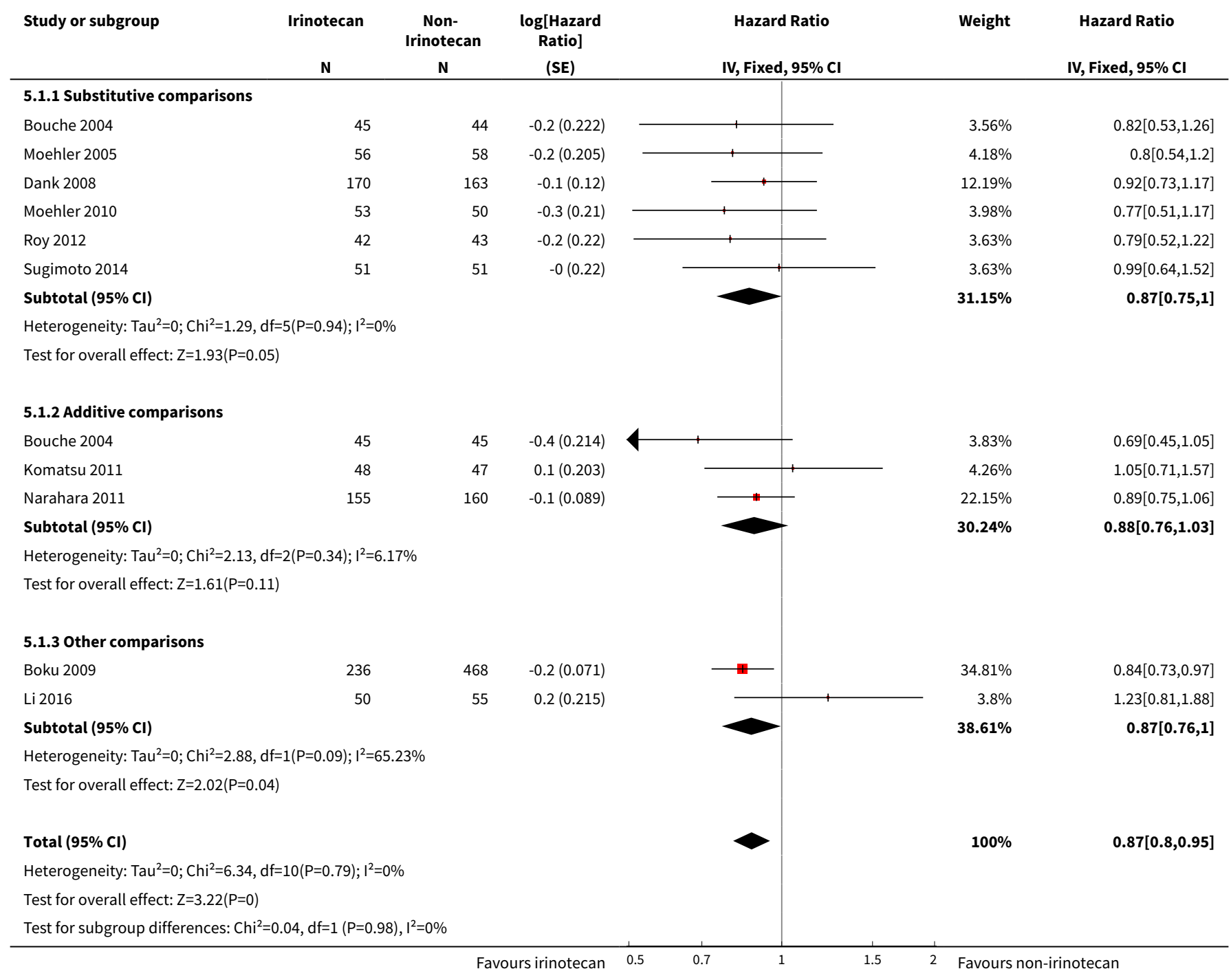


Analysis 5.2. Comparison 5 Chemotherapy with irinotecan versus non-irinotecan-containing regimes, Outcome 2 Tumour response.

\begin{tabular}{|c|c|c|c|c|c|}
\hline Study or subgroup & $\begin{array}{c}\text { Irinotecan } \\
\mathbf{n} / \mathbf{N} \\
\end{array}$ & $\begin{array}{c}\text { Non-Irinotecan } \\
\mathrm{n} / \mathrm{N} \\
\end{array}$ & $\begin{array}{c}\text { Odds Ratio } \\
\text { M-H, Random, } 95 \% \text { Cl } \\
\end{array}$ & Weight & $\begin{array}{c}\text { Odds Ratio } \\
\text { M-H, Random, } 95 \% \mathrm{Cl} \\
\end{array}$ \\
\hline \multicolumn{6}{|c|}{ 5.2.1 Substitutive comparisons } \\
\hline Bouche 2004 & $18 / 38$ & $6 / 43$ & & $6.64 \%$ & $5.55[1.9,16.22]$ \\
\hline Dank 2008 & $54 / 154$ & $42 / 134$ & $\longrightarrow$ & $14.86 \%$ & $1.18[0.72,1.94]$ \\
\hline Moehler 2005 & $24 / 48$ & $14 / 51$ & $\rightarrow$ & $9.17 \%$ & $2.64[1.15,6.1]$ \\
\hline Moehler 2010 & $20 / 53$ & $21 / 48$ & $\longrightarrow$ & $9.69 \%$ & $0.78[0.35,1.73]$ \\
\hline Sugimoto 2014 & $17 / 51$ & $16 / 51$ & & $9.24 \%$ & $1.09[0.48,2.51]$ \\
\hline Subtotal $(95 \% \mathrm{Cl})$ & 386 & 370 & & $57.46 \%$ & $1.53[0.93,2.5]$ \\
\hline \multicolumn{6}{|c|}{ Total events: 146 (Irinotecan), 110 (Non-Irinotecan) } \\
\hline \multicolumn{6}{|c|}{ Heterogeneity: $\operatorname{Tau}^{2}=0.21 ; \mathrm{Chi}^{2}=11.46, \mathrm{df}=5(\mathrm{P}=0.04) ; \mathrm{I}^{2}=56.37 \%$} \\
\hline \multicolumn{6}{|c|}{ Test for overall effect: $Z=1.68(P=0.09)$} \\
\hline Bouche 2004 & $18 / 45$ & $6 / 45$ & $\rightarrow$ & $6.88 \%$ & $4.33[1.52,12.34]$ \\
\hline Komatsu 2011 & $10 / 36$ & $7 / 32$ & & $6.32 \%$ & $1.37[0.45,4.17]$ \\
\hline Narahara 2011 & $39 / 94$ & $25 / 93$ & - & $12.54 \%$ & $1.93[1.04,3.57]$ \\
\hline Subtotal $(95 \% \mathrm{Cl})$ & 175 & 170 & & $25.73 \%$ & $2.18[1.25,3.8]$ \\
\hline \multicolumn{6}{|c|}{ Total events: 67 (Irinotecan), 38 (Non-Irinotecan) } \\
\hline \multicolumn{6}{|c|}{ Heterogeneity: Tau $^{2}=0.05 ; \mathrm{Chi}^{2}=2.47, \mathrm{df}=2(\mathrm{P}=0.29) ; \mathrm{I}^{2}=19.04 \%$} \\
\hline \multicolumn{6}{|c|}{ Test for overall effect: $Z=2.74(P=0.01)$} \\
\hline \multicolumn{6}{|c|}{ 5.2.3 Other Comparisons } \\
\hline Dong 2014 & $18 / 30$ & $10 / 30$ & & $6.81 \%$ & $3[1.05,8.6]$ \\
\hline Li 2016 & $24 / 50$ & $22 / 55$ & & $10 \%$ & $1.38[0.64,3]$ \\
\hline Subtotal $(95 \% \mathrm{Cl})$ & 80 & 85 & & $16.81 \%$ & $1.87[0.89,3.91]$ \\
\hline \multicolumn{6}{|c|}{ Total events: 42 (Irinotecan), 32 (Non-Irinotecan) } \\
\hline Total $(95 \% \mathrm{Cl})$ & 641 & 625 & & $100 \%$ & $1.72[1.24,2.4]$ \\
\hline \multicolumn{6}{|c|}{ Total events: 255 (Irinotecan), 180 (Non-Irinotecan) } \\
\hline \multicolumn{6}{|c|}{ Heterogeneity: $\mathrm{Tau}^{2}=0.13 ; \mathrm{Chi}^{2}=17.53, \mathrm{df}=10(\mathrm{P}=0.06) ; \mathrm{I}^{2}=42.96 \%$} \\
\hline \multicolumn{6}{|c|}{ Test for overall effect: $\mathrm{Z}=3.23(\mathrm{P}=0)$} \\
\hline Test for subgroup dif & $9, \mathrm{df}=1(\mathrm{P}=0.64)$, & $=0 \%$ & & & \\
\hline
\end{tabular}

Analysis 5.3. Comparison 5 Chemotherapy with irinotecan versus nonirinotecan-containing regimes, Outcome 3 Progression-free survival.

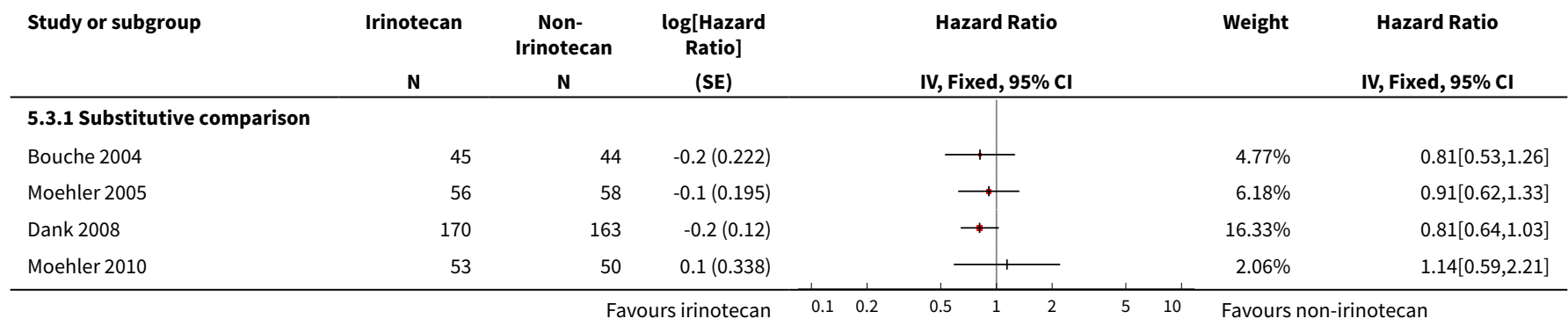




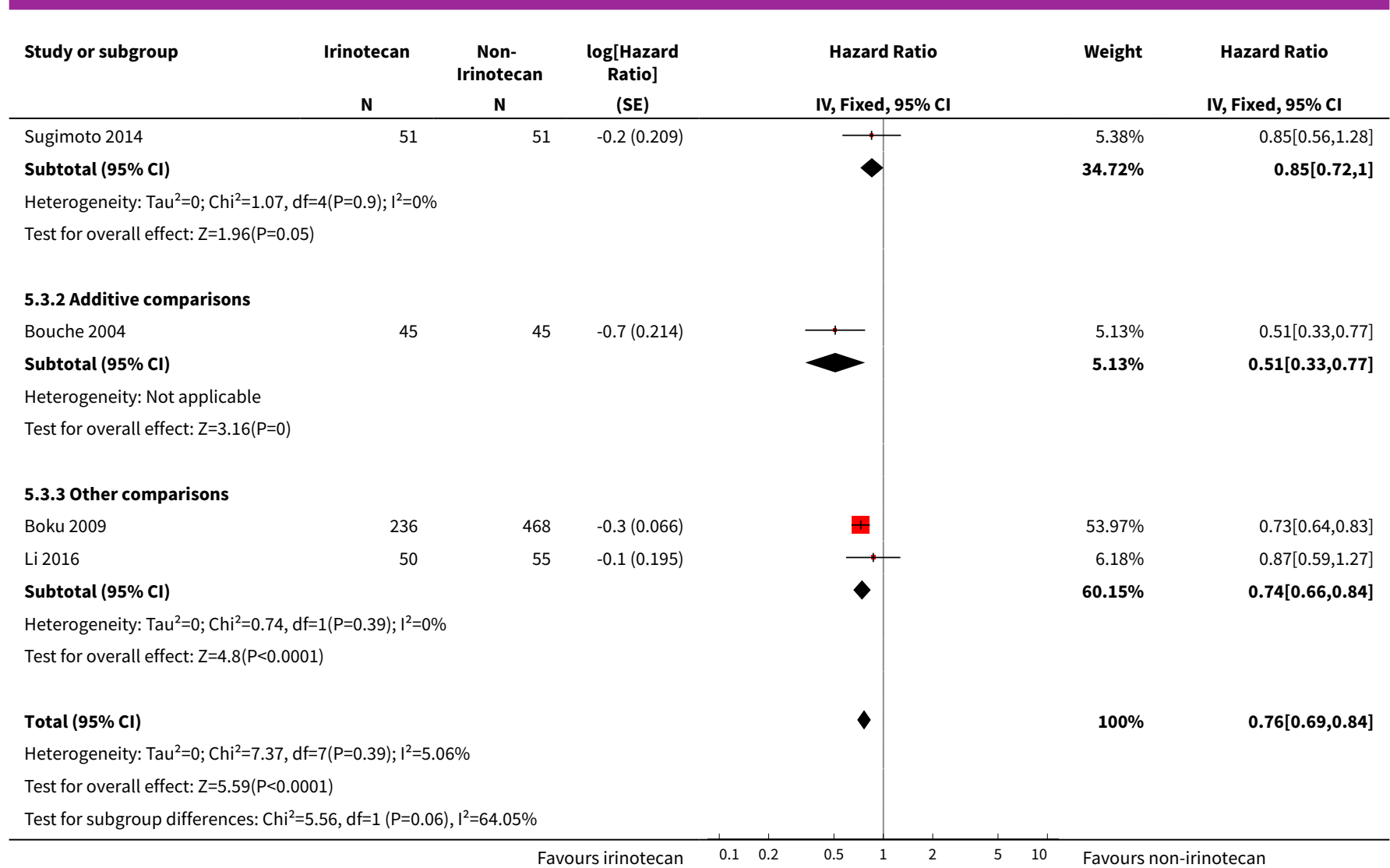

Analysis 5.4. Comparison 5 Chemotherapy with irinotecan versus nonirinotecan-containing regimes, Outcome 4 Treatment-related death.

\begin{tabular}{|c|c|c|c|c|c|}
\hline Study or subgroup & $\begin{array}{c}\text { Irinotecan } \\
\mathbf{n} / \mathbf{N}\end{array}$ & $\begin{array}{c}\text { Non-Irinotecan } \\
\mathbf{n} / \mathbf{N} \\
\end{array}$ & $\begin{array}{c}\text { Odds Ratio } \\
\text { M-H, Random, } 95 \% \mathrm{Cl}\end{array}$ & Weight & $\begin{array}{c}\text { Odds Ratio } \\
\text { M-H, Random, } 95 \% \mathrm{Cl} \\
\end{array}$ \\
\hline Sugimoto 2014 & $0 / 51$ & $0 / 51$ & & & Not estimable \\
\hline Roy 2012 & $0 / 42$ & $0 / 43$ & & & Not estimable \\
\hline Komatsu 2011 & $0 / 46$ & $0 / 47$ & & & Not estimable \\
\hline Moehler 2010 & $0 / 53$ & $2 / 50$ & & $13.84 \%$ & $0.18[0.01,3.87]$ \\
\hline Dank 2008 & $1 / 170$ & $5 / 163$ & - & $21.93 \%$ & $0.19[0.02,1.62]$ \\
\hline Moehler 2005 & $1 / 56$ & $1 / 58$ & & $15.75 \%$ & $1.04[0.06,16.98]$ \\
\hline Narahara 2011 & $2 / 155$ & $0 / 160$ & $\rightarrow$ & $13.95 \%$ & $5.23[0.25,109.78]$ \\
\hline Boku 2009 & $3 / 234$ & $1 / 466$ & - & $20.67 \%$ & $6.04[0.62,58.38]$ \\
\hline Total $(95 \% \mathrm{Cl})$ & 852 & 1127 & & $100 \%$ & $0.88[0.23,3.32]$ \\
\hline \multicolumn{6}{|c|}{ Total events: 7 (Irinotecan), 11 (Non-Irinotecan) } \\
\hline Test for overall effect & & & & & \\
\hline
\end{tabular}


Analysis 5.5. Comparison 5 Chemotherapy with irinotecan versus non-irinotecancontaining regimes, Outcome 5 Treatment discontinuation due to toxicity.

\begin{tabular}{|c|c|c|c|c|c|c|}
\hline Study or subgroup & $\begin{array}{c}\text { Irinotecan } \\
\mathrm{n} / \mathrm{N} \\
\end{array}$ & $\begin{array}{c}\text { Non-Irinotecan } \\
\mathbf{n} / \mathbf{N} \\
\end{array}$ & $\begin{array}{r}\text { Odds } \\
\text { M-H, Rand } \\
\end{array}$ & $\begin{array}{l}\text { Ratio } \\
\text { om, } 95 \% \mathrm{Cl}\end{array}$ & Weight & $\begin{array}{c}\text { Odds Ratio } \\
\text { M-H, Random, } 95 \% \text { Cl }\end{array}$ \\
\hline Bouche 2004 & $11 / 45$ & $20 / 89$ & & 4 & $11.99 \%$ & $1.12[0.48,2.59]$ \\
\hline Moehler 2005 & $1 / 56$ & $1 / 58$ & & & $5.05 \%$ & $1.04[0.06,16.98]$ \\
\hline Dank 2008 & $17 / 170$ & $35 / 163$ & $\longrightarrow$ & & $12.78 \%$ & $0.41[0.22,0.76]$ \\
\hline Boku 2009 & $75 / 234$ & $40 / 466$ & & $\rightarrow$ & $13.36 \%$ & $5.02[3.29,7.68]$ \\
\hline Moehler 2010 & $10 / 53$ & $16 / 50$ & & & $11.73 \%$ & $0.49[0.2,1.23]$ \\
\hline Narahara 2011 & $23 / 155$ & $12 / 160$ & & $\longrightarrow$ & $12.39 \%$ & $2.15[1.03,4.49]$ \\
\hline Roy 2012 & $6 / 42$ & $12 / 43$ & & & $10.97 \%$ & $0.43[0.14,1.28]$ \\
\hline Sugimoto 2014 & $4 / 51$ & $7 / 51$ & 1 & - & $10.1 \%$ & $0.53[0.15,1.95]$ \\
\hline Total $(95 \% \mathrm{Cl})$ & 852 & 1127 & & & $100 \%$ & $1[0.46,2.2]$ \\
\hline \multicolumn{7}{|c|}{ Total events: 160 (Irinotecan), 154 (Non-Irinotecan) } \\
\hline Test for overall effect & & & & & & \\
\hline
\end{tabular}

\section{Comparison 6. Chemotherapy with docetaxel versus non-docetaxel-containing regimes}

\begin{tabular}{|c|c|c|c|c|}
\hline Outcome or subgroup title & No. of studies & $\begin{array}{l}\text { No. of partici- } \\
\text { pants }\end{array}$ & Statistical method & Effect size \\
\hline 1 Overall survival & 8 & 2001 & Hazard Ratio (Fixed, 95\% Cl) & $0.86[0.78,0.95]$ \\
\hline 1.1 Substitutive comparisons & 3 & 479 & Hazard Ratio (Fixed, 95\% Cl) & $1.05[0.87,1.27]$ \\
\hline 1.2 Additive comparisons & 4 & 1466 & Hazard Ratio (Fixed, 95\% Cl) & $0.80[0.71,0.91]$ \\
\hline 1.3 Other comparisons & 1 & 56 & Hazard Ratio (Fixed, 95\% Cl) & $0.80[0.46,1.39]$ \\
\hline 2 Tumour response & 9 & 1820 & Odds Ratio (M-H, Random, 95\% Cl) & $1.37[1.03,1.83]$ \\
\hline 2.1 Substitutive comparison & 4 & 525 & Odds Ratio (M-H, Random, 95\% Cl) & $1.03[0.71,1.50]$ \\
\hline 2.2 Additive comparison & 4 & 1235 & Odds Ratio (M-H, Random, 95\% Cl) & $1.83[1.45,2.32]$ \\
\hline 2.3 Other comparisons & 1 & 60 & Odds Ratio (M-H, Random, 95\% Cl) & $0.33[0.12,0.96]$ \\
\hline 3 Time to progression & 2 & 360 & Hazard Ratio (Random, 95\% Cl) & $1.06[0.85,1.32]$ \\
\hline 4 Progression-free survival & 5 & 1498 & Hazard Ratio (Random, 95\% Cl) & $0.76[0.63,0.91]$ \\
\hline 4.1 Substitutive comparisons & 1 & 119 & Hazard Ratio (Random, 95\% Cl) & $1.15[0.77,1.72]$ \\
\hline $\begin{array}{l}\text { 4.2 Additive comparison } \\
\text { (PFS) }\end{array}$ & 3 & 1323 & Hazard Ratio (Random, 95\% Cl) & $0.70[0.61,0.81]$ \\
\hline 4.3 Other comparisons & 1 & 56 & Hazard Ratio (Random, 95\% Cl) & $0.94[0.55,1.60]$ \\
\hline 5 Treatment-related death & 7 & 2113 & Odds Ratio (M-H, Fixed, 95\% Cl) & $1.10[0.55,2.20]$ \\
\hline
\end{tabular}




\begin{tabular}{lllll}
\hline Outcome or subgroup title & No. of studies & $\begin{array}{l}\text { No. of partici- } \\
\text { pants }\end{array}$ & Statistical method & Effect size \\
\hline $\begin{array}{l}\text { 6 Treatment discontinuation } \\
\text { due to toxicity }\end{array}$ & 5 & 1066 & Odds Ratio (M-H, Random, 95\% Cl) & $0.81[0.53,1.25]$ \\
\hline
\end{tabular}

Analysis 6.1. Comparison 6 Chemotherapy with docetaxel versus non-docetaxel-containing regimes, Outcome 1 Overall survival.

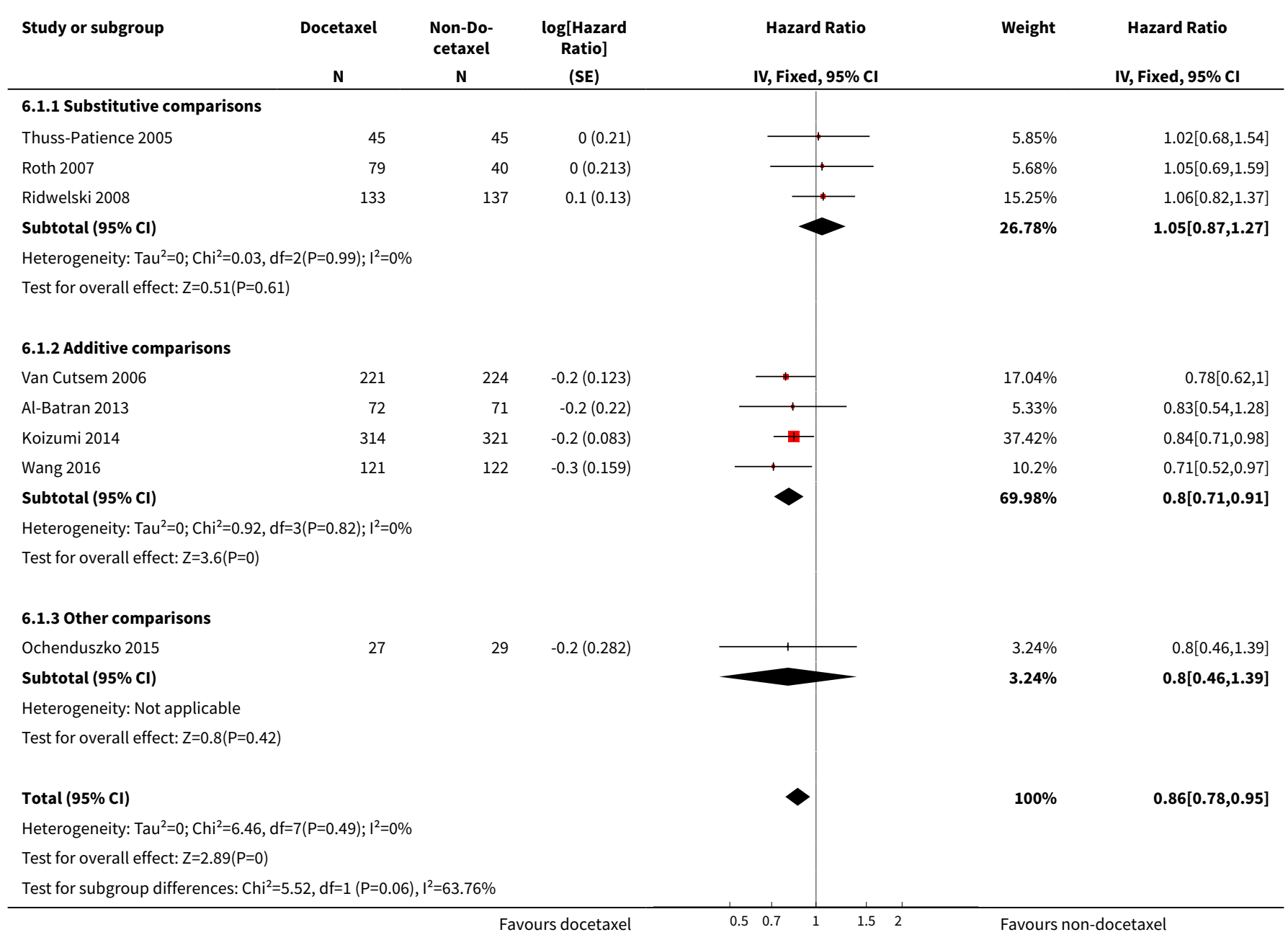

Analysis 6.2. Comparison 6 Chemotherapy with docetaxel versus non-docetaxel-containing regimes, Outcome 2 Tumour response.

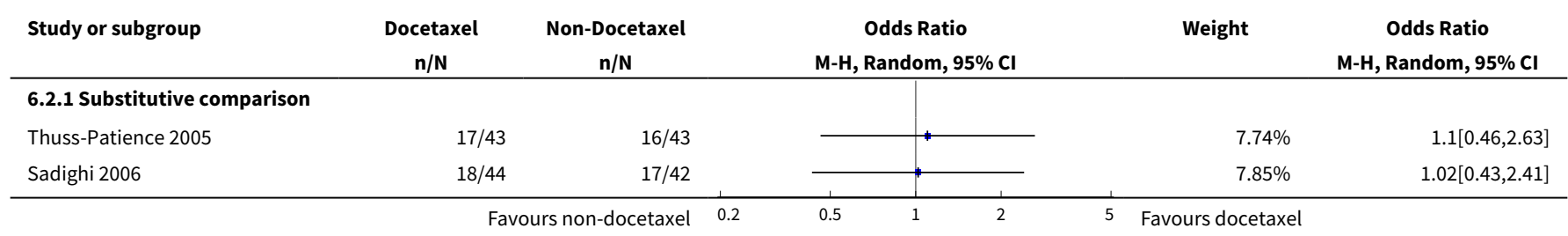




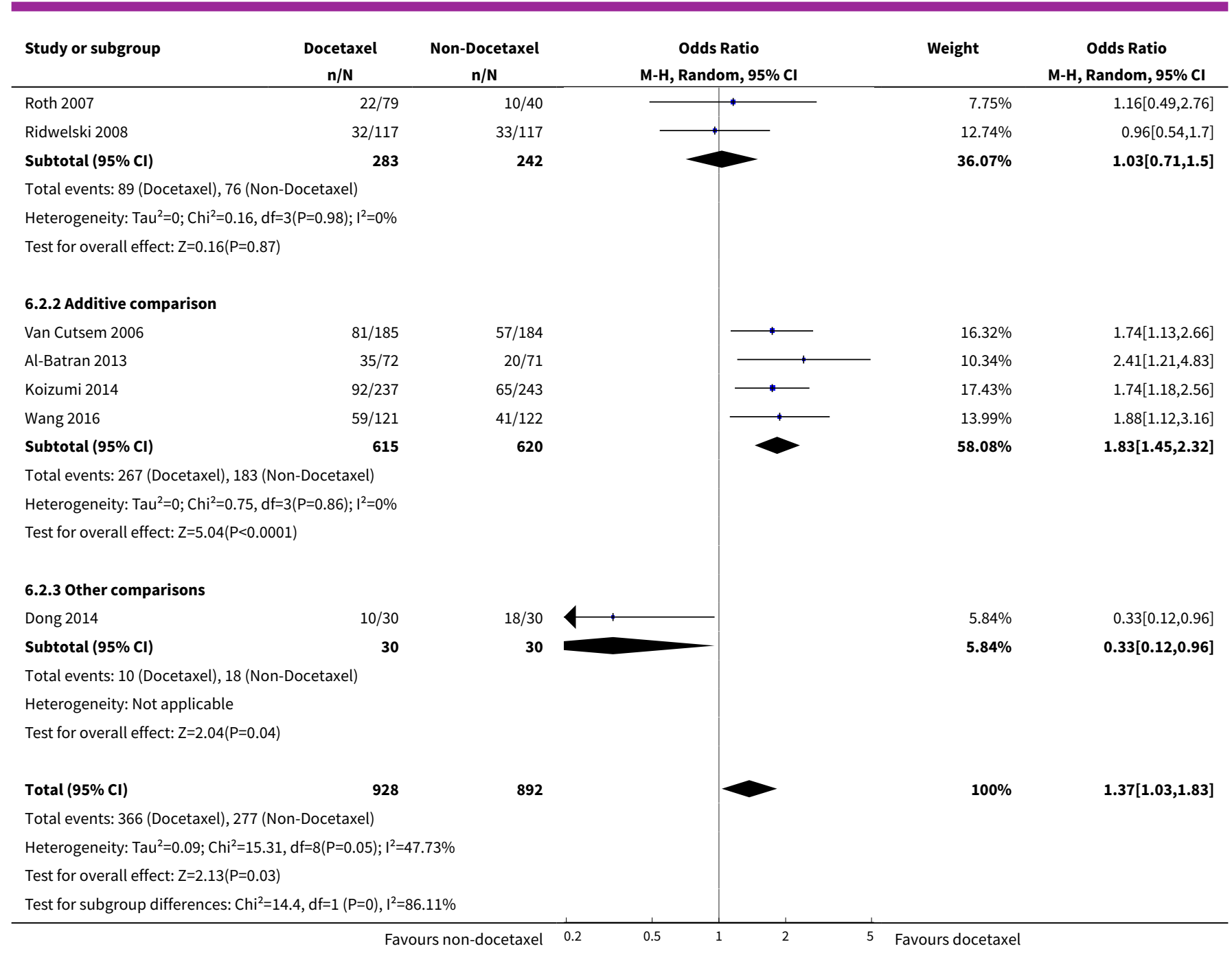

Analysis 6.3. Comparison 6 Chemotherapy with docetaxel versus
non-docetaxel-containing regimes, Outcome 3 Time to progression.

\begin{tabular}{|c|c|c|c|c|c|c|}
\hline Study or subgroup & $\begin{array}{c}\text { Docetaxel } \\
\text { N } \\
\end{array}$ & $\begin{array}{c}\text { Non-Do- } \\
\text { cetaxel } \\
\mathrm{N} \\
\end{array}$ & $\begin{array}{c}\log [\text { Hazard } \\
\text { Ratio] } \\
\text { (SE) }\end{array}$ & $\begin{array}{c}\text { Hazard Ratio } \\
\text { IV, Random, } 95 \% \mathrm{CI}\end{array}$ & Weight & $\begin{array}{c}\text { Hazard Ratio } \\
\text { IV, Random, } 95 \% \mathrm{Cl}\end{array}$ \\
\hline Thuss-Patience 2005 & 45 & 45 & $-0(0.22)$ & $\square$ & $25.59 \%$ & $0.96[0.63,1.48]$ \\
\hline Ridwelski 2008 & 133 & 137 & $0.1(0.129)$ & & $74.41 \%$ & $1.1[0.85,1.42]$ \\
\hline Total $(95 \% \mathrm{Cl})$ & & & & & $100 \%$ & $1.06[0.85,1.32]$ \\
\hline Test for overall effect: & & & & & & \\
\hline
\end{tabular}


Analysis 6.4. Comparison 6 Chemotherapy with docetaxel versus nondocetaxel-containing regimes, Outcome 4 Progression-free survival.

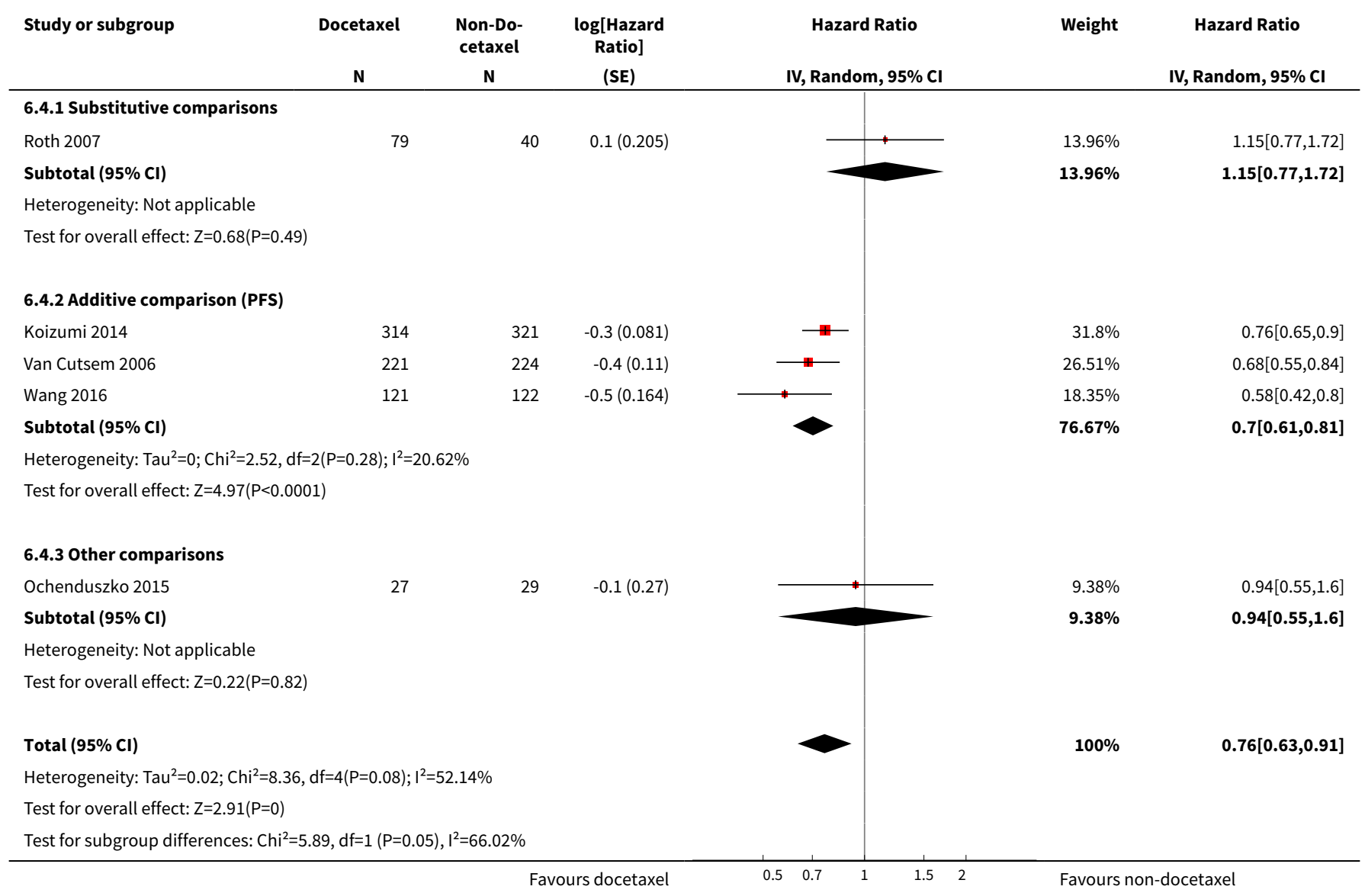

Analysis 6.5. Comparison 6 Chemotherapy with docetaxel versus nondocetaxel-containing regimes, Outcome 5 Treatment-related death.

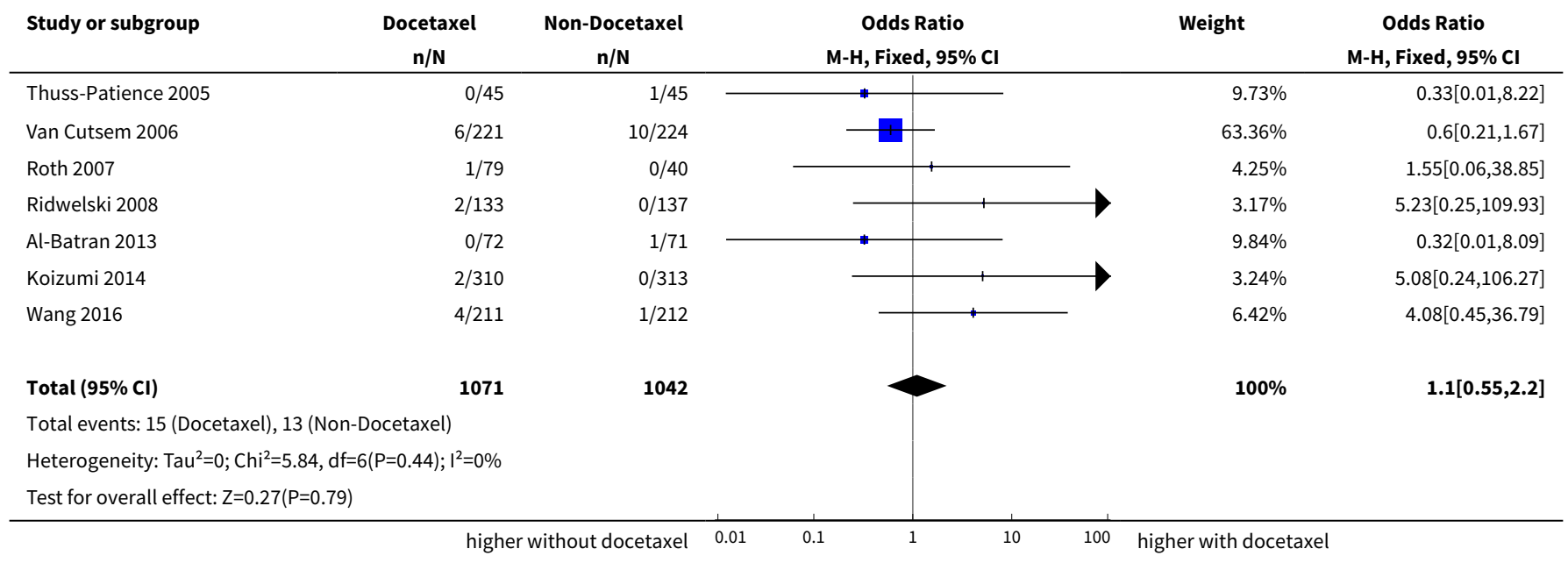


Analysis 6.6. Comparison 6 Chemotherapy with docetaxel versus non-docetaxelcontaining regimes, Outcome 6 Treatment discontinuation due to toxicity.

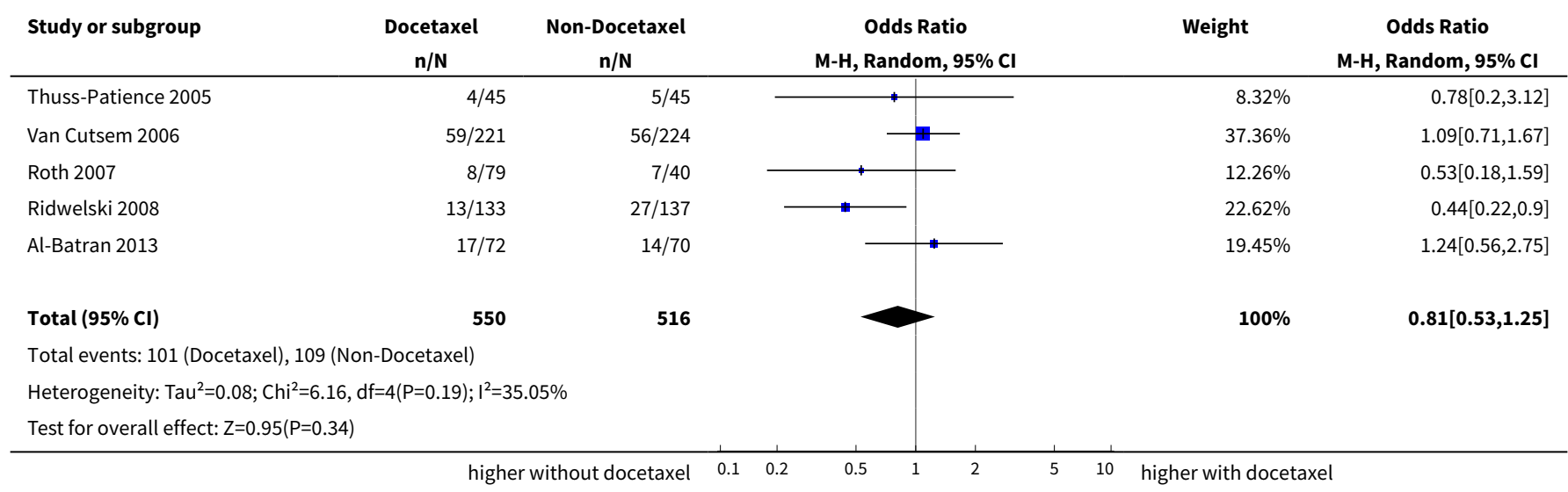

\section{Comparison 7. Chemotherapy with capecitabine versus 5-FU-containing regimes}

\begin{tabular}{llllll}
\hline Outcome or subgroup title & No. of studies & $\begin{array}{l}\text { No. of partici- } \\
\text { pants }\end{array}$ & Statistical method & Effect size \\
\hline 1 Overall Survival & 5 & 732 & Hazard Ratio (Fixed, 95\% Cl) & $0.94[0.79,1.11]$ \\
\hline 2 Tumour response & 4 & 636 & Odds Ratio (M-H, Random, 95\% Cl) & $0.85[0.40,1.79]$ \\
\hline 3 Time to progression & 1 & & Hazard Ratio (Fixed, 95\% Cl) & Subtotals only \\
\hline $\begin{array}{l}\text { 4 Progression-free survival } \\
\text { 5 Treatment-related death }\end{array}$ & 4 & 647 & Hazard Ratio (Random, 95\% Cl) & $0.98[0.77,1.23]$ \\
\hline $\begin{array}{l}\text { 6 Treatment discontinuation } \\
\text { due to toxicity }\end{array}$ & 1 & 481 & Odds Ratio (M-H, Random, 95\% Cl) & $1.88[0.23,15.15]$ \\
\hline
\end{tabular}

Analysis 7.1. Comparison 7 Chemotherapy with capecitabine versus 5-FU-containing regimes, Outcome 1 Overall Survival.

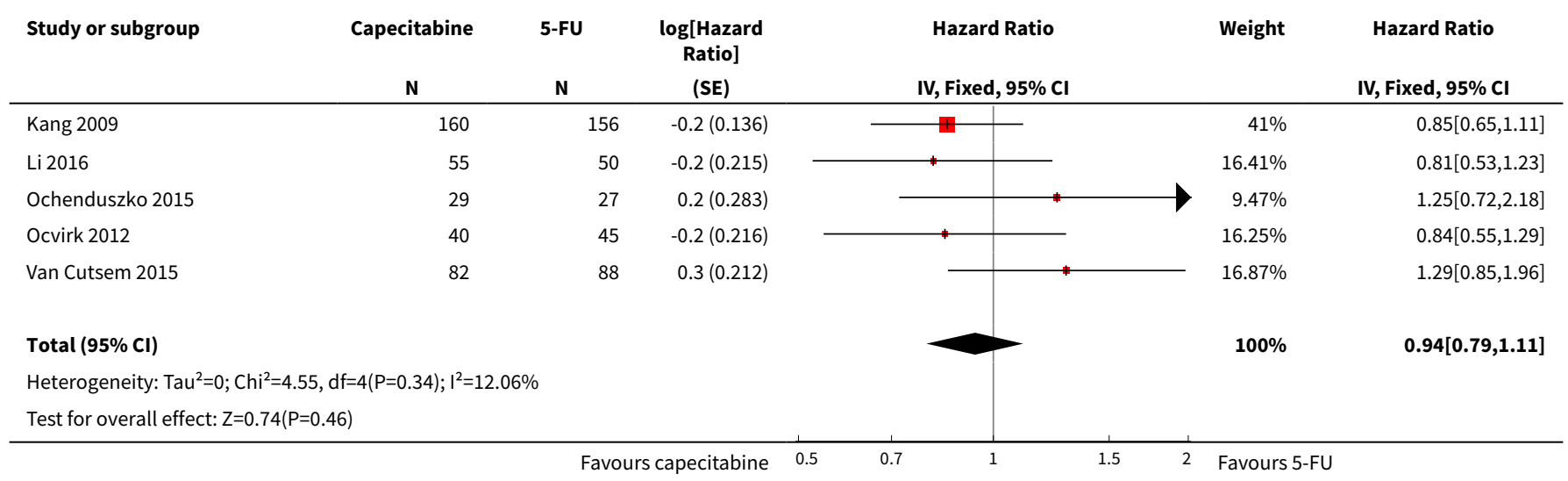


Analysis 7.2. Comparison 7 Chemotherapy with capecitabine versus 5-FU-containing regimes, Outcome 2 Tumour response.

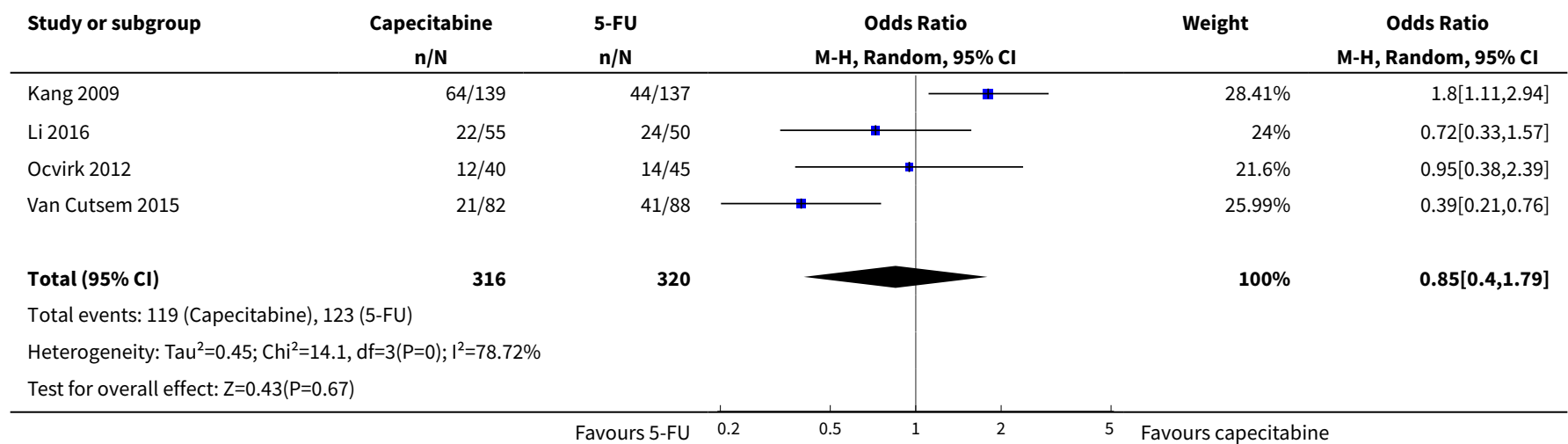

Analysis 7.3. Comparison 7 Chemotherapy with capecitabine versus 5-FU-containing regimes, Outcome 3 Time to progression.

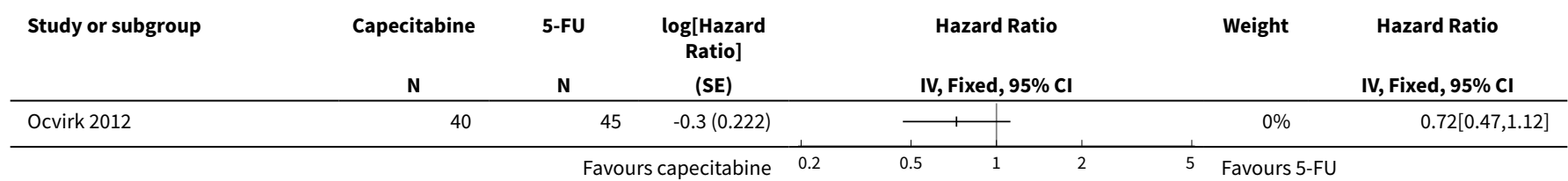

Analysis 7.4. Comparison 7 Chemotherapy with capecitabine versus 5-FU-containing regimes, Outcome 4 Progression-free survival.

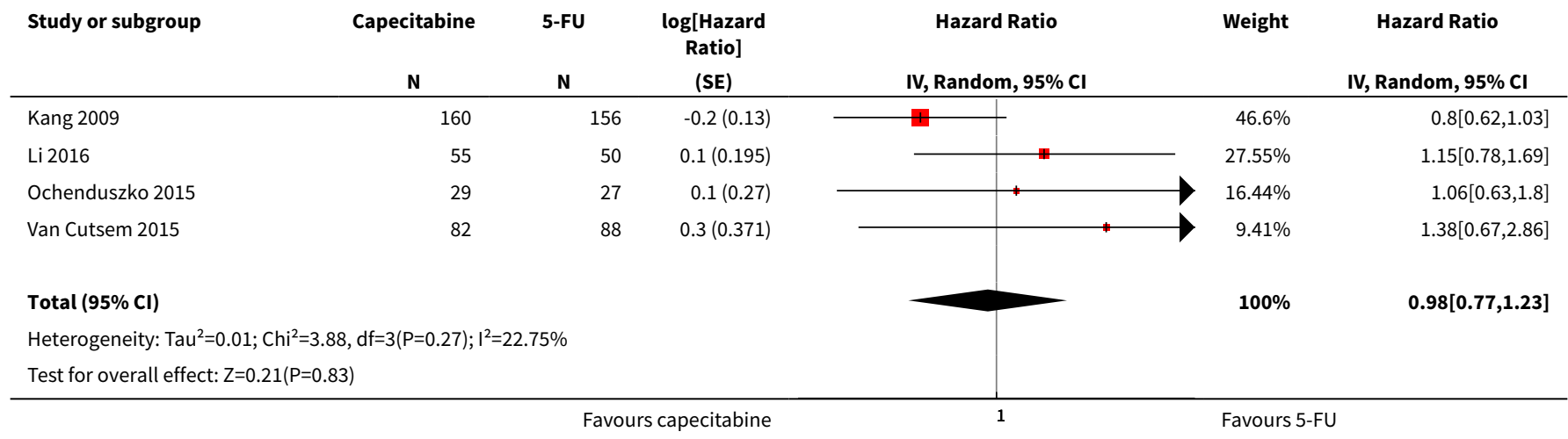


Analysis 7.5. Comparison 7 Chemotherapy with capecitabine versus 5-FU-containing regimes, Outcome 5 Treatment-related death.

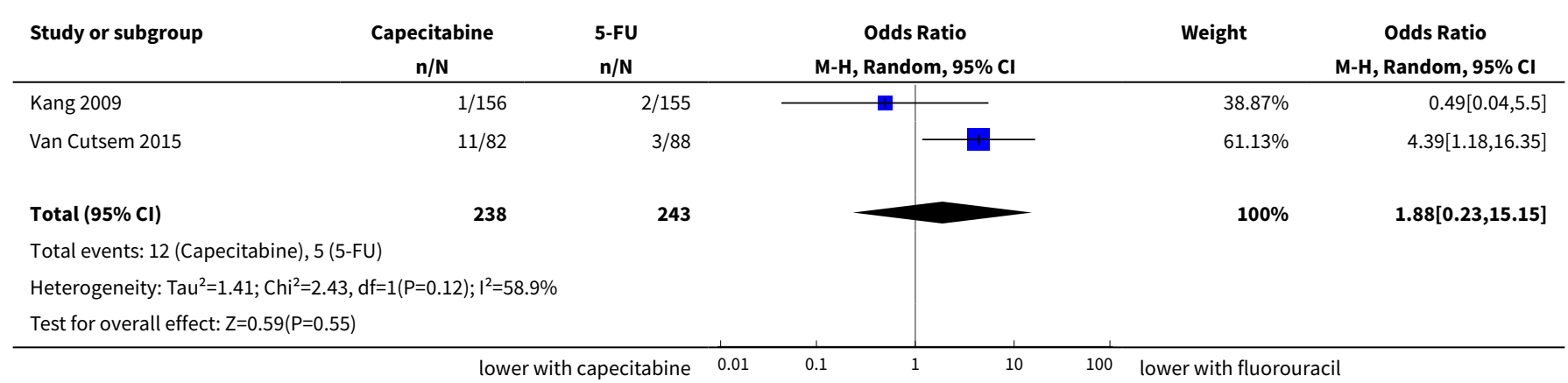

Analysis 7.6. Comparison 7 Chemotherapy with capecitabine versus 5-FUcontaining regimes, Outcome 6 Treatment discontinuation due to toxicity.

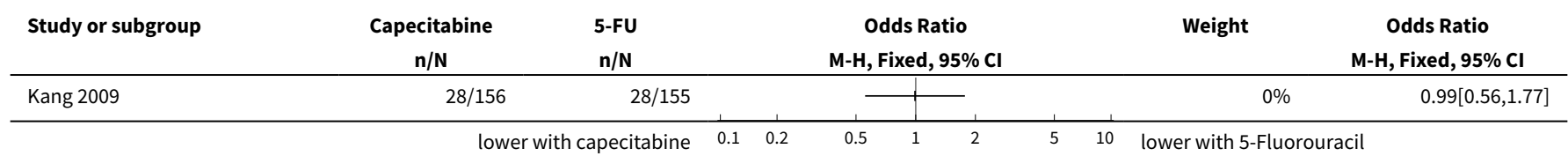

Comparison 8. Chemotherapy with oxaliplatin versus the same regime including cisplatin

\begin{tabular}{llllll}
\hline Outcome or subgroup title & No. of studies & $\begin{array}{l}\text { No. of partici- } \\
\text { pants }\end{array}$ & Statistical method & Effect size \\
\hline 1 Overall Survival & 5 & 1105 & Hazard Ratio (Random, 95\% Cl) & $0.81[0.67,0.98]$ \\
\hline 2 Tumour response & 5 & 1081 & Odds Ratio (M-H, Fixed, 95\% Cl) & $1.38[1.08,1.76]$ \\
\hline 3 Progression-free survival & 4 & 1034 & Hazard Ratio (Random, 95\% Cl) & $0.88[0.66,1.19]$ \\
\hline $\begin{array}{l}\text { 4 Treatment-related death } \\
\text { 5 Treatment discontinuation } \\
\text { due to toxicity }\end{array}$ & 5 & 1132 & Odds Ratio (M-H, Fixed, 95\% Cl) & $0.47[0.17,1.30]$ \\
\hline
\end{tabular}

Analysis 8.1. Comparison 8 Chemotherapy with oxaliplatin versus the same regime including cisplatin, Outcome 1 Overall Survival.

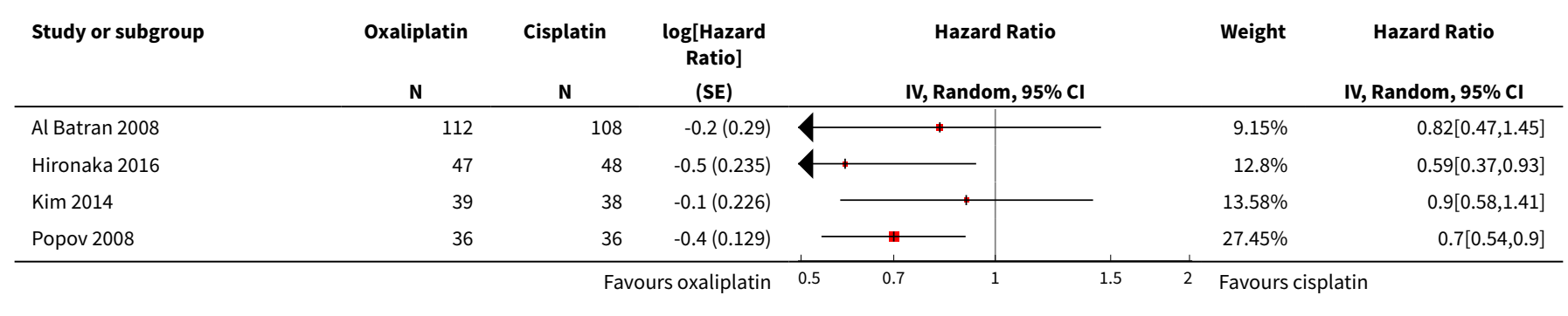




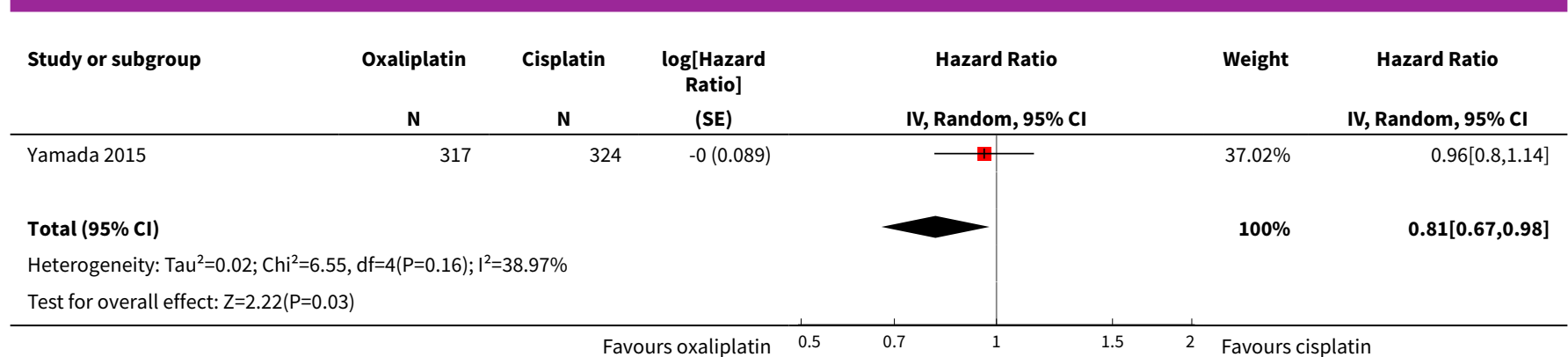

Analysis 8.2. Comparison 8 Chemotherapy with oxaliplatin versus the same regime including cisplatin, Outcome 2 Tumour response.

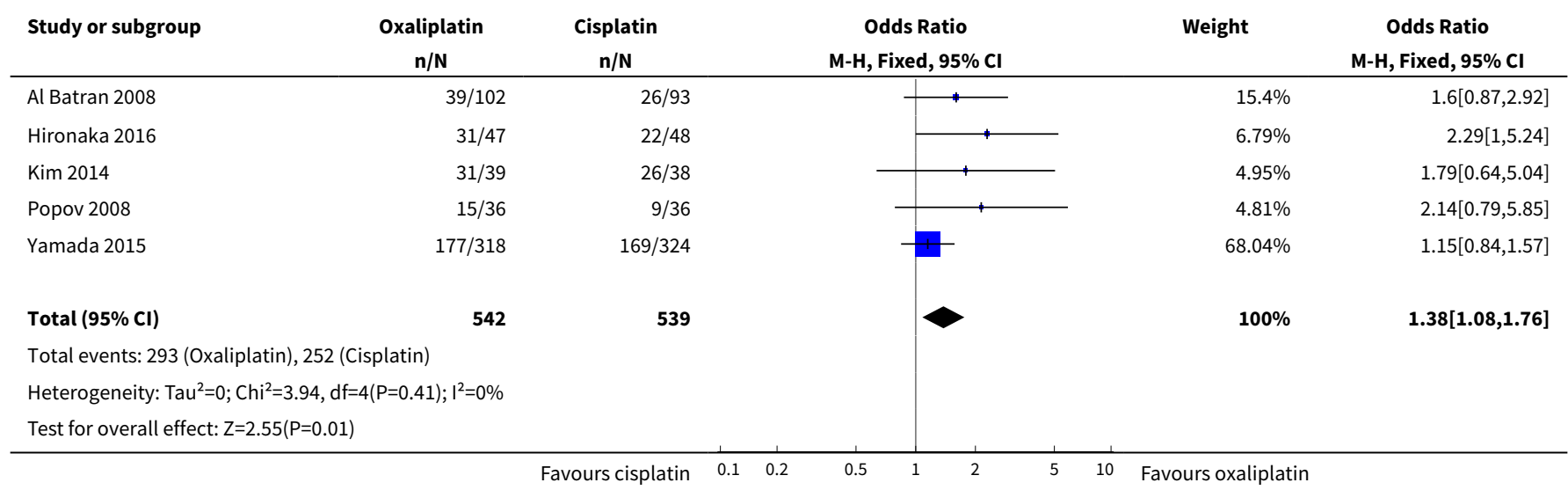

Analysis 8.3. Comparison 8 Chemotherapy with oxaliplatin versus the same regime including cisplatin, Outcome 3 Progression-free survival.

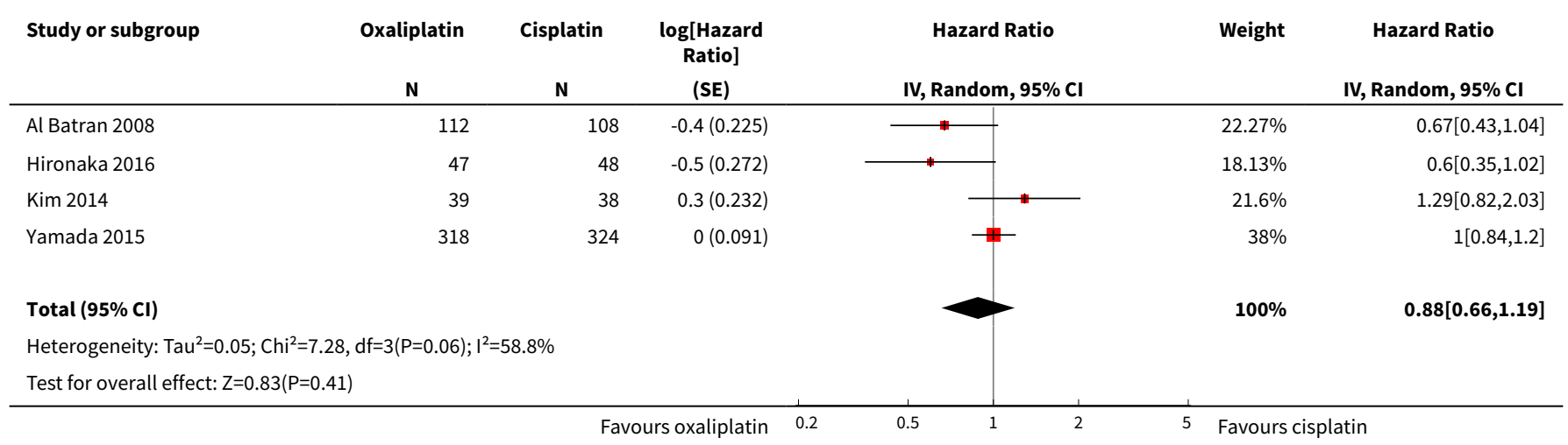


Analysis 8.4. Comparison 8 Chemotherapy with oxaliplatin versus the same regime including cisplatin, Outcome 4 Treatment-related death.

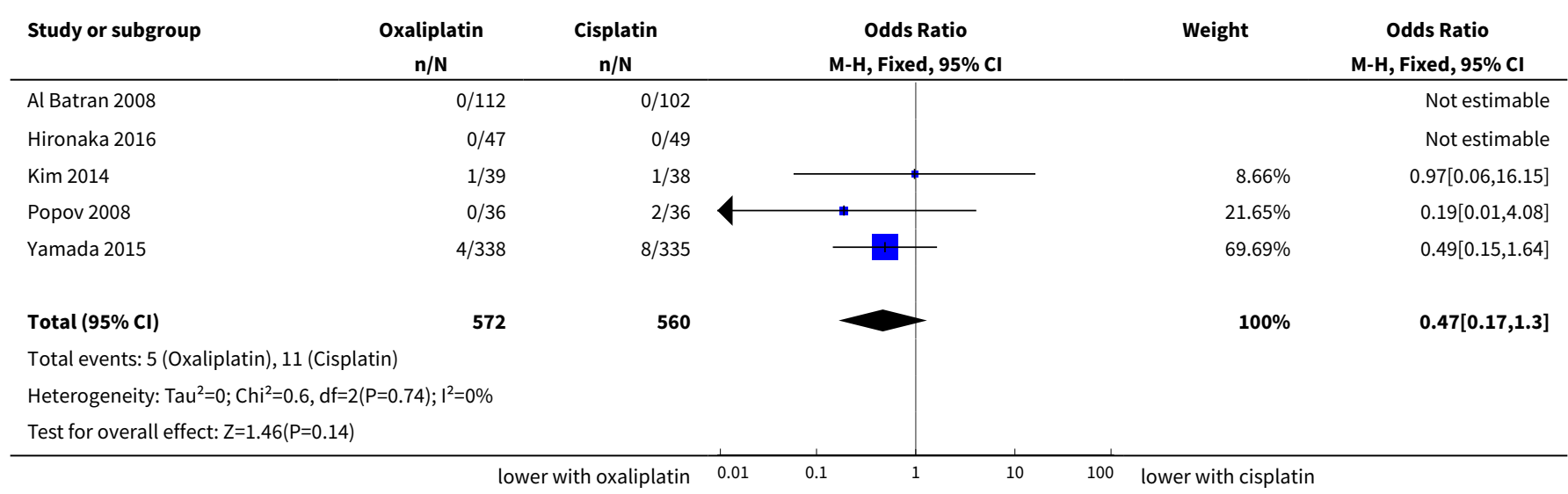

Analysis 8.5. Comparison 8 Chemotherapy with oxaliplatin versus the same regime including cisplatin, Outcome 5 Treatment discontinuation due to toxicity.

\begin{tabular}{|c|c|c|c|c|c|}
\hline Study or subgroup & $\begin{array}{c}\text { Oxaliplatin } \\
\text { n/N }\end{array}$ & $\begin{array}{c}\text { Cisplatin } \\
n / N\end{array}$ & $\begin{array}{c}\text { Odds Ratio } \\
\text { M-H, Random, } 95 \% \mathrm{Cl}\end{array}$ & Weight & $\begin{array}{c}\text { Odds Ratio } \\
\text { M-H, Random, } 95 \% \mathrm{Cl}\end{array}$ \\
\hline Al Batran 2008 & $12 / 112$ & $11 / 102$ & 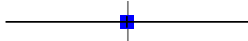 & $33.25 \%$ & $0.99[0.42,2.36]$ \\
\hline Hironaka 2016 & $10 / 47$ & $5 / 49$ & & $25.2 \%$ & $2.38[0.75,7.58]$ \\
\hline Yamada 2015 & $17 / 328$ & $30 / 332$ & -m & $41.55 \%$ & $0.55[0.3,1.02]$ \\
\hline Total $(95 \% \mathrm{Cl})$ & 487 & 483 & & $100 \%$ & $0.97[0.44,2.13]$ \\
\hline \multicolumn{6}{|c|}{ Heterogeneity: $\mathrm{Tau}^{2}=0.29 ; \mathrm{Chi}^{2}=5.04, \mathrm{df}=2(\mathrm{P}=0.08) ; \mathrm{I}^{2}=60.34 \%$} \\
\hline \multicolumn{6}{|c|}{ Test for overall effect: $\mathrm{Z}=0.08(\mathrm{P}=0.94)$} \\
\hline
\end{tabular}

Comparison 9. Taxane-platinum-fluoropyrimidine combinations versus taxane-platinum (without fluoropyrimidine)

\begin{tabular}{llllll}
\hline Outcome or subgroup title & No. of studies & $\begin{array}{l}\text { No. of partici- } \\
\text { pants }\end{array}$ & Statistical method & Effect size \\
\hline 1 Overall survival & 3 & 482 & Hazard Ratio (Fixed, 95\% Cl) & $0.86[0.71,1.06]$ \\
\hline 2 Tumour response & 3 & 482 & Odds Ratio (M-H, Fixed, 95\% Cl) & $2.08[1.37,3.15]$ \\
\hline 3 Progression-free survival & 3 & 482 & Hazard Ratio (Fixed, 95\% Cl) & $0.74[0.59,0.93]$ \\
\hline $\begin{array}{l}\text { 4 Treatment-related death } \\
\text { 5 Treatment discontinuation }\end{array}$ & 2 & 482 & Odds Ratio (M-H, Fixed, 95\% Cl) & $1.95[0.73,5.17]$ \\
\hline \begin{tabular}{l} 
due to toxicity \\
\hline
\end{tabular} & 234 & Odds Ratio (M-H, Fixed, 95\% Cl) & $1.71[0.79,3.69]$ \\
\hline
\end{tabular}


Analysis 9.1. Comparison 9 Taxane-platinum-fluoropyrimidine combinations versus taxane-platinum (without fluoropyrimidine), Outcome 1 Overall survival.

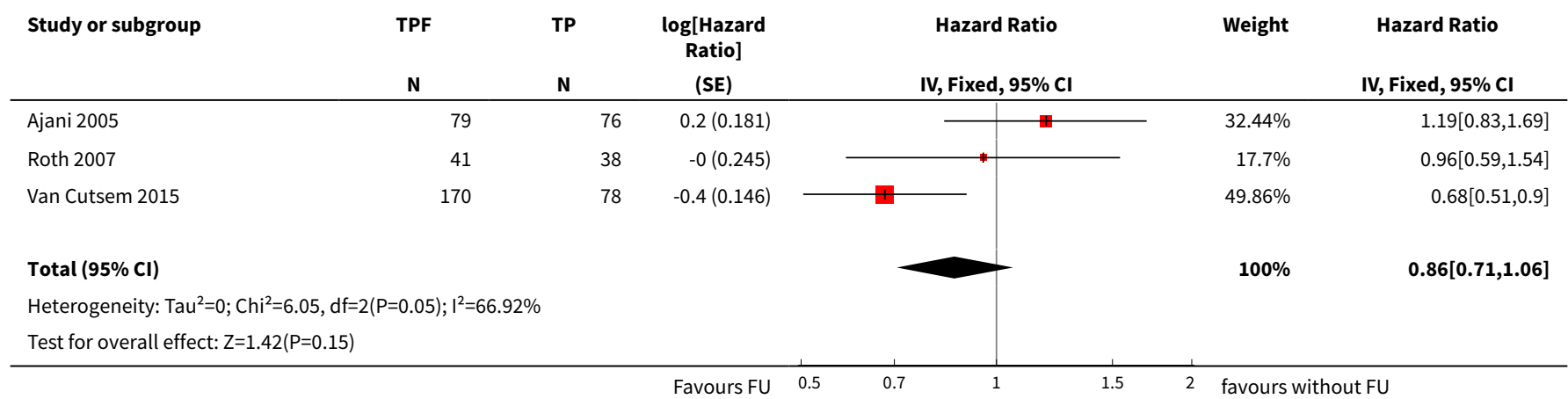

Analysis 9.2. Comparison 9 Taxane-platinum-fluoropyrimidine combinations versus taxane-platinum (without fluoropyrimidine), Outcome 2 Tumour response.

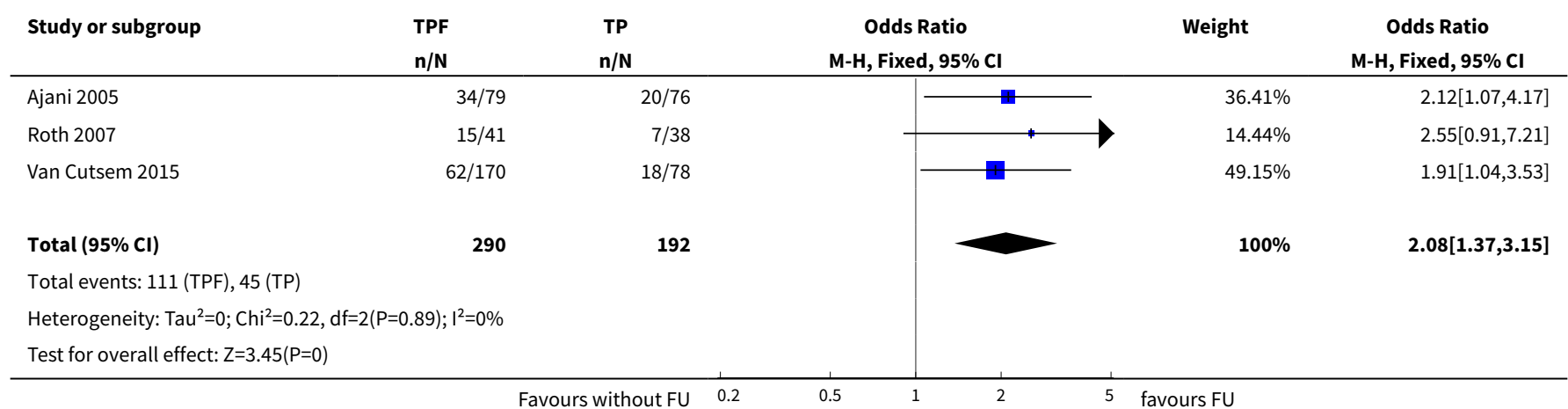

Analysis 9.3. Comparison 9 Taxane-platinum-fluoropyrimidine combinations versus taxane-platinum (without fluoropyrimidine), Outcome 3 Progression-free survival.

\begin{tabular}{|c|c|c|c|c|c|c|}
\hline \multirow[t]{2}{*}{ Study or subgroup } & \multirow{2}{*}{$\begin{array}{l}\text { TPF } \\
\mathbf{N} \\
\end{array}$} & \multirow{2}{*}{$\begin{array}{l}\text { TP } \\
\mathbf{N} \\
\end{array}$} & \multirow{2}{*}{$\begin{array}{c}\log [\text { Hazard } \\
\text { Ratio] } \\
\text { (SE) }\end{array}$} & \multirow{2}{*}{$\begin{array}{c}\text { Hazard Ratio } \\
\text { IV, Fixed, } 95 \% \mathrm{CI}\end{array}$} & \multirow[t]{2}{*}{ Weight } & \multirow{2}{*}{$\begin{array}{c}\text { Hazard Ratio } \\
\text { IV, Fixed, } 95 \% \text { CI }\end{array}$} \\
\hline & & & & & & \\
\hline Ajani 2005 & 79 & 76 & $-0.2(0.217)$ & $\longrightarrow-$ & $28.69 \%$ & $0.8[0.52,1.22]$ \\
\hline Roth 2007 & 41 & 38 & $-0.2(0.243)$ & $\longrightarrow+1$ & $22.88 \%$ & $0.79[0.49,1.27]$ \\
\hline Van Cutsem 2015 & 170 & 78 & $-0.4(0.167)$ & $\longrightarrow$ & $48.44 \%$ & $0.69[0.5,0.96]$ \\
\hline Total $(95 \% \mathrm{Cl})$ & & & & & $100 \%$ & $0.74[0.59,0.93]$ \\
\hline \multicolumn{7}{|c|}{ Heterogeneity: Tau $^{2}=0 ; \mathrm{Chi}^{2}=0.38, \mathrm{df}=2(\mathrm{P}=0.83) ; \mathrm{I}^{2}=0 \%$} \\
\hline Test for overall effect & & & & & & \\
\hline
\end{tabular}


Analysis 9.4. Comparison 9 Taxane-platinum-fluoropyrimidine combinations versus taxane-platinum (without fluoropyrimidine), Outcome 4 Treatment-related death.

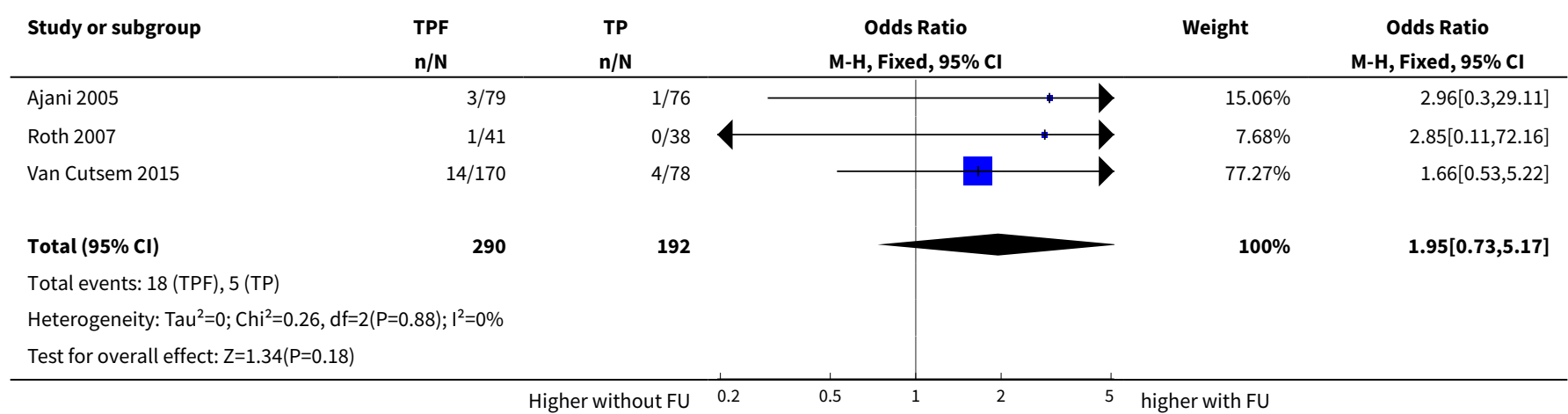

Analysis 9.5. Comparison 9 Taxane-platinum-fluoropyrimidine combinations versus taxaneplatinum (without fluoropyrimidine), Outcome 5 Treatment discontinuation due to toxicity.

\begin{tabular}{|c|c|c|c|c|c|}
\hline Study or subgroup & $\begin{array}{l}\text { TPF } \\
\mathrm{n} / \mathrm{N}\end{array}$ & $\begin{array}{c}\mathrm{TP} \\
\mathrm{n} / \mathrm{N}\end{array}$ & $\begin{array}{c}\text { Odds Ratio } \\
\text { M-H, Fixed, } 95 \% \mathrm{Cl}\end{array}$ & Weight & $\begin{array}{c}\text { Odds Ratio } \\
\text { M-H, Fixed, } 95 \% \mathrm{Cl}\end{array}$ \\
\hline Ajani 2005 & $15 / 79$ & $9 / 76$ & t & $73.11 \%$ & $1.74[0.71,4.27]$ \\
\hline Roth 2007 & $5 / 41$ & $3 / 38$ & & $26.89 \%$ & $1.62[0.36,7.3]$ \\
\hline Total $(95 \% \mathrm{Cl})$ & 120 & 114 & & $100 \%$ & $1.71[0.79,3.69]$ \\
\hline \multicolumn{6}{|c|}{ Total events: 20 (TPF), 12 (TP) } \\
\hline Test for overall effect & & & & & \\
\hline
\end{tabular}

\section{Comparison 10. S-1 versus 5-FU-containing regimes}

\begin{tabular}{llllll}
\hline Outcome or subgroup title & No. of studies & $\begin{array}{l}\text { No. of partici- } \\
\text { pants }\end{array}$ & Statistical method & Effect size \\
\hline 1 Overall Survival & 4 & 1793 & Hazard Ratio (Fixed, 95\% Cl) & $0.91[0.83,1.00]$ \\
\hline 2 Tumour response & 7 & 1753 & Odds Ratio (M-H, Random, 95\% Cl) & $1.73[1.01,2.94]$ \\
\hline 3 Progression-free survival & 4 & 1942 & Hazard Ratio (Random, 95\% Cl) & $0.85[0.70,1.04]$ \\
\hline 4 Time-to treatment failure & 5 & 1818 & Hazard Ratio (Random, 95\% Cl) & $0.88[0.76,1.01]$ \\
\hline 5 Treatment-related deaths & 4 & 1962 & Odds Ratio (M-H, Fixed, 95\% Cl) & $0.56[0.30,1.06]$ \\
\hline $\begin{array}{l}\text { 6 Treatment discontinuation } \\
\text { due to toxicity }\end{array}$ & 3 & 1726 & Odds Ratio (M-H, Fixed, 95\% Cl) & $0.85[0.63,1.13]$ \\
\hline
\end{tabular}


Analysis 10.1. Comparison 10 S-1 versus 5-FU-containing regimes, Outcome 1 Overall Survival.

\begin{tabular}{|c|c|c|c|c|c|c|}
\hline \multirow[t]{2}{*}{ Study or subgroup } & \multirow{2}{*}{$\begin{array}{l}\mathrm{S}-1 \\
\mathrm{~N} \\
\end{array}$} & \multirow{2}{*}{$\begin{array}{c}\text { 5-FU } \\
\mathrm{N}\end{array}$} & \multirow{2}{*}{$\begin{array}{c}\log [\text { Hazard } \\
\text { Ratio] } \\
\text { (SE) }\end{array}$} & \multirow{2}{*}{$\begin{array}{c}\text { Hazard Ratio } \\
\text { IV, Fixed, } 95 \% \text { CI }\end{array}$} & \multirow[t]{2}{*}{ Weight } & \multirow{2}{*}{$\begin{array}{c}\text { Hazard Ratio } \\
\text { IV, Fixed, } 95 \% \text { CI }\end{array}$} \\
\hline & & & & & & \\
\hline Ajani 2010 & 521 & 508 & $-0.1(0.068)$ & 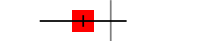 & $50.66 \%$ & $0.92[0.8,1.05]$ \\
\hline Boku 2009 & 234 & 234 & $-0.2(0.095)$ & \#- & $25.96 \%$ & $0.83[0.69,1]$ \\
\hline Chen 2015 & 30 & 30 & $-0(0.116)$ & & $17.41 \%$ & $0.97[0.78,1.22]$ \\
\hline Li 2015 & 120 & 116 & $0(0.198)$ & 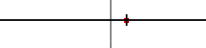 & $5.98 \%$ & $1.05[0.71,1.54]$ \\
\hline Total $(95 \% \mathrm{Cl})$ & & & & & $100 \%$ & $0.91[0.83,1]$ \\
\hline \multicolumn{7}{|c|}{ Heterogeneity: $\mathrm{Tau}^{2}=0 ; \mathrm{Chi}^{2}=1.81, \mathrm{df}=3(\mathrm{P}=0.61) ; \mathrm{I}^{2}=0 \%$} \\
\hline Test for overall effect & & & & & & \\
\hline
\end{tabular}

Analysis 10.2. Comparison $10 \mathrm{~S}-1$ versus 5-FU-containing regimes, Outcome 2 Tumour response.

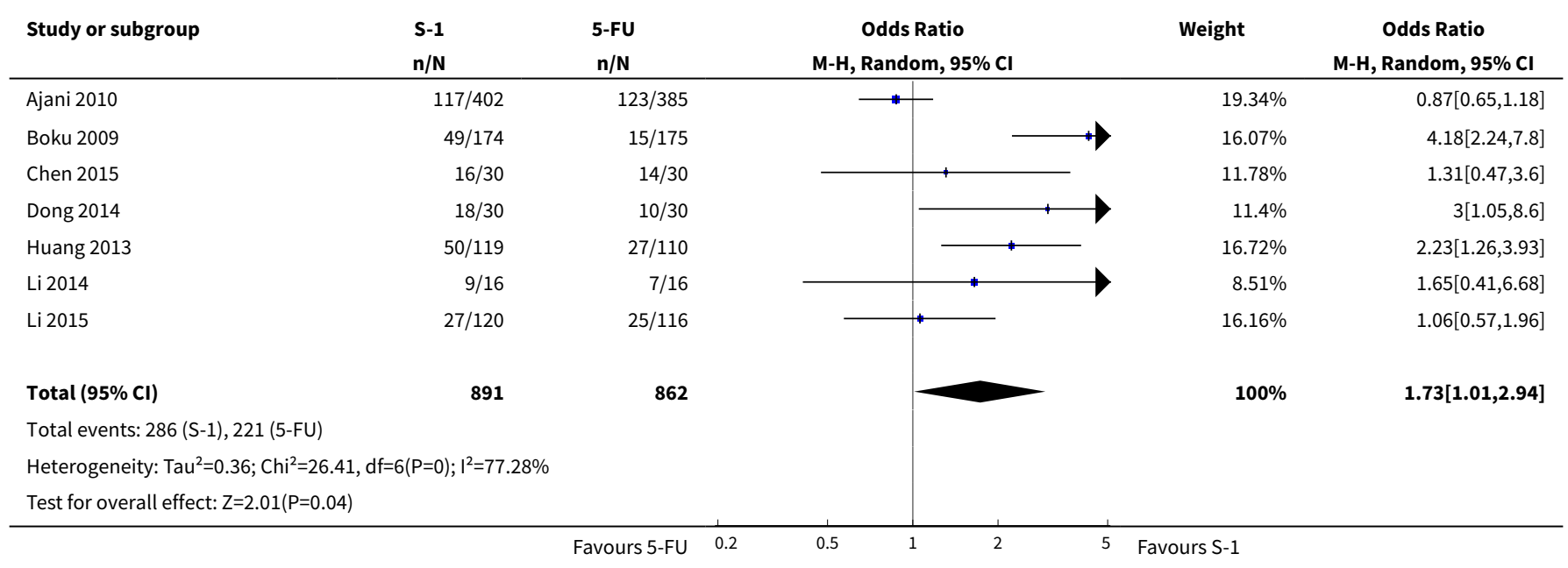

Analysis 10.3. Comparison 10 S-1 versus 5-FU-containing regimes, Outcome 3 Progression-free survival.

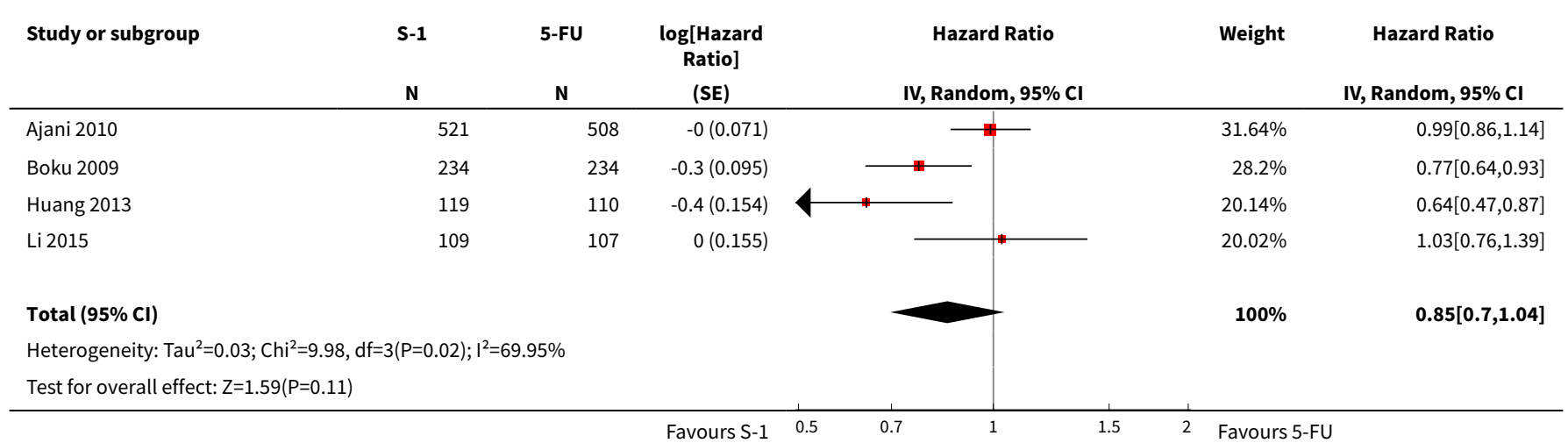


Analysis 10.4. Comparison 10 S-1 versus 5-FU-containing regimes, Outcome 4 Time-to treatment failure.

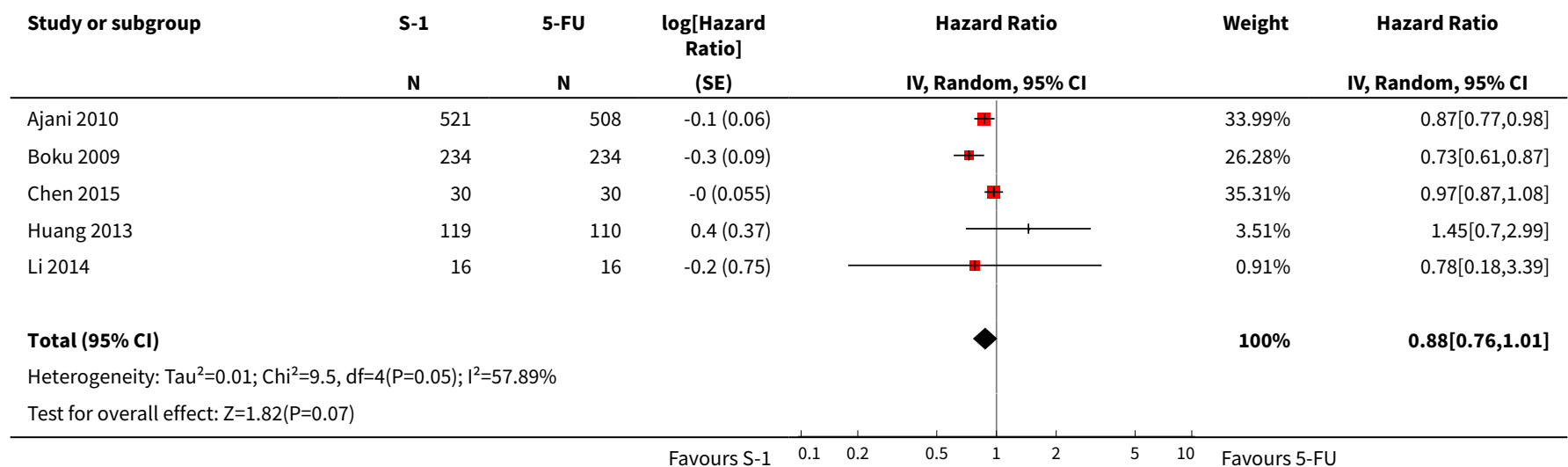

Analysis 10.5. Comparison $10 \mathrm{~S}-1$ versus 5-FU-containing regimes, Outcome 5 Treatment-related deaths.

\begin{tabular}{|c|c|c|c|c|c|}
\hline Study or subgroup & $\begin{array}{l}S-1 \\
n / N\end{array}$ & $\begin{array}{l}5-\mathrm{FU} \\
\mathrm{n} / \mathrm{N}\end{array}$ & $\begin{array}{c}\text { Odds Ratio } \\
\text { M-H, Fixed, } 95 \% \mathrm{Cl}\end{array}$ & Weight & $\begin{array}{c}\text { Odds Ratio } \\
\text { M-H, Fixed, } 95 \% \mathrm{Cl}\end{array}$ \\
\hline Ajani 2010 & $13 / 521$ & $25 / 508$ & & $94.17 \%$ & $0.49[0.25,0.98]$ \\
\hline Boku 2009 & $1 / 234$ & $0 / 234$ & & $1.9 \%$ & $3.01[0.12,74.34]$ \\
\hline Huang 2013 & $1 / 119$ & $1 / 110$ & & $3.93 \%$ & $0.92[0.06,14.95]$ \\
\hline Li 2015 & $0 / 120$ & $0 / 116$ & & & Not estimable \\
\hline \multicolumn{6}{|c|}{ Total events: 15 (S-1), 26 (5-FU) } \\
\hline \multicolumn{6}{|c|}{ Heterogeneity: $\mathrm{Tau}^{2}=0 ; \mathrm{Chi}^{2}=1.31, \mathrm{df}=2(\mathrm{P}=0.52) ; \mathrm{I}^{2}=0 \%$} \\
\hline \multicolumn{6}{|c|}{ Test for overall effect: $Z=1.79(P=0.07)$} \\
\hline
\end{tabular}

Analysis 10.6. Comparison $10 \mathrm{~S}-1$ versus 5-FU-containing regimes, Outcome 6 Treatment discontinuation due to toxicity.

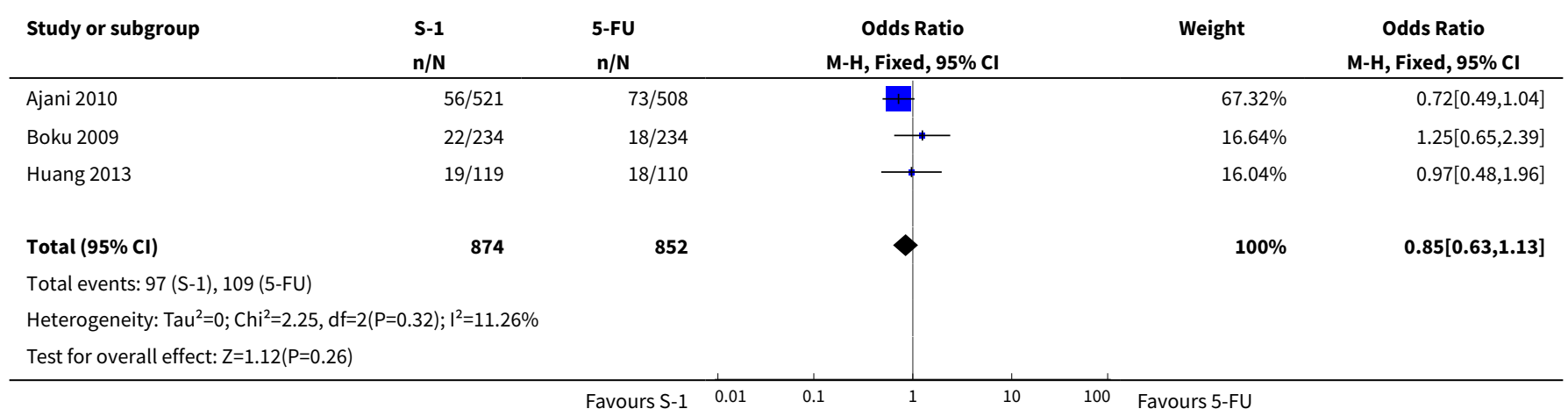




\section{A P P E N D I CES}

\section{Appendix 1. CENTRAL update January 2013}

1. exp stomach neoplasms/

2. (stomach adj5 neoplas\$).ti,ab.

3. (stomach adj5 cancer\$).ti,ab.

4. (stomach adj5 carcin\$).ti,ab.

5. (stomach adj5 tumo\$).ti,ab.

6. (stomach adj5 metasta\$).ti,ab.

7. (stomach adj5 malig\$).ti,ab.

8. (gastric adj5 neoplas\$).ti,ab.

9. (gastric adj5 cancer\$).ti,ab.

10. (gastric adj5 carcin\$).ti,ab.

11. (gastric adj5 tumo\$).ti,ab.

12. (gastric adj5 metasta\$).ti,ab.

13. (gastric adj5 malig\$).ti,ab.

14. or/1-13

15. exp drug therapy/

16. chemothera\$.ti,ab.

17. drug therap\$.ti,ab.

18. antineoplastic\$.ti,ab.

19. or $/ 15-18$

20. exp palliative care/

21. palliat\$.ti,ab.

22. unresect\$.ti,ab.

23. inopera\$.ti,ab.

24. advanc\$.ti,ab.

25. (best adj5 support\$ adj5 care).ti,ab.

26. unopera\$.ti,ab.

27. (non adj5 resect\$).ti,ab.

28. nonresect\$.ti,ab.

29. or $/ 20-28$

30. 14 and 19

31.29 and 30

32. limit 31 to $y r=" 2009-2013 "$ 


\section{Appendix 2. MEDLINE update March 2009-Jan 2013}

1. randomized controlled trial.pt.

2. controlled clinical trial.pt.

3. randomized.ab.

4. placebo.ab.

5. drug therapy.fs.

6. randomly.ab.

7. trial.ab.

8. groups.ab.

9. or/1-8

10. exp animals/ not humans.sh.

11.9 not 10

12. exp stomach neoplasms/

13. (stomach adj5 neoplas\$).tw.

14. (stomach adj5 cancer\$).tw.

15. (stomach adj5 carcin\$).tw.

16. (stomach adj5 tumo\$).tw.

17. (stomach adj5 metasta\$).tw.

18. (stomach adj5 malig\$).tw.

19. (gastric adj5 neoplas\$).tw.

20. (gastric adj5 cancer\$).tw.

21. (gastric adj5 carcin\$).tw.

22. (gastric adj5 tumo\$).tw.

23. (gastric adj5 metasta\$).tw.

24. (gastric adj5 malig\$).tw.

25. or/12-24

26. exp drug therapy/

27. chemothera\$.tw.

28. drug therap\$.tw.

29. antineoplastic\$.tw.

30. or $/ 26-29$

31. exp palliative care/

32. palliat\$.tw.

33. unresect\$.tw.

34. inopera\$.tw. 
35. advanc\$.tw.

36. (best adj5 support\$ adj5 care).tw.

37. unopera\$.tw.

38. (non adj5 resect\$).tw.

39. nonresect\$.tw.

40. or/31-39

41. 25 and 30

42. 40 and 41

43. 42 and 11

44. limit 43 to ed=20090309-20130131

\section{Appendix 3. Embase update March 2009-Jan 2013}

1. exp randomized controlled trial/

2. randomi?ed controlled trial\$.tw.

3. exp randomization/

4. exp single blind procedure/

5. exp double blind procedure/

6. or/1-5

7. animal.hw.

8. human.hw.

9. 7 not (7 and 8)

10. 6 not 9

11. exp clinical trial/

12. (clin\$ adj3 stud\$).ti,ab,tw.

13. (clin\$ adj3 trial\$).ti,ab,tw.

14. ((singl\$ or doubl\$ or treb\$ or tripl\$) adj3 (blind\$ or mask\$)).ti,ab,tw.

15. exp placebo/

16. placebo\$.ti,ab,tw.

17. random.ti,ab,tw.

18. (crossover\$ or cross-over\$).ti,ab,tw.

19. or $/ 11-18$

20. 19 not 9

21. 20 not 10

22. exp comparative study/

23. exp evaluation/

24. exp prospective study/ 
25. exp controlled study/

26. (control\$ or prospective\$ or volunteer\$).ti,ab,tw.

27. or $/ 22-26$

28. 27 not 9

29. 10 or 21 or 28

30. exp stomach tumor/

31. (stomach adj5 neoplas\$).tw.

32. (stomach adj5 cancer\$).tw.

33. (stomach adj5 carcin\$).tw.

34. (stomach adj5 tumo\$).tw.

35. (stomach adj5 metasta\$).tw.

36. (stomach adj5 malig\$).tw.

37. (gastric adj5 neoplas\$).tw.

38. (gastric adj5 cancer\$).tw.

39. (gastric adj5 carcin\$).tw.

40. (gastric adj5 tumo\$).tw.

41. (gastric adj5 metasta\$).tw.

42. (gastric adj5 malig\$).tw.

43. or $/ 30-42$

44. exp drug therapy/

45. chemothera\$.tw.

46. drug therap\$.tw.

47. antineoplastic\$.tw.

48. or/44-47

49. exp palliative therapy/

50. palliat\$.tw.

51. unresect\$.tw.

52. inopera\$.tw.

53. advanc\$.tw.

54. (best adj5 support\$ adj5 care).tw.

55. unopera\$.tw.

56. (non adj5 resect\$).tw.

57. nonresect\$.tw.

58. or/49-57

59. 43 and 48

Chemotherapy for advanced gastric cancer (Review) 
60.58 and 59

61.29 and 60

62. limit 61 to em=200910-201306

WHAT'S NEW

\begin{tabular}{lll}
\hline Date & Event & Description \\
\hline 30 June 2016 & New search has been performed & Searches rerun and results incorporated \\
\hline 30 June 2016 & New citation required and conclusions & $\begin{array}{l}\text { We added 26 included studies, two new comparisons (9) Tax- } \\
\text { ane-platinum-fluoropyrimidine combinations versus tax- } \\
\text { ane-platinum (without fluoropyrimidine) and (10) S-1 versus 5- } \\
\text { FU containing regimens and subgroup analyses to comparisons } \\
\end{array}$ \\
& $\begin{array}{l}\text { 5 and 6; Irinotecan versus non-irinotecan-containing regimens } \\
\text { and docetaxel versus non-docetaxel-containing regimens }\end{array}$ \\
\hline
\end{tabular}

\section{H I S T O R Y}

Protocol first published: Issue 1, 2003

Review first published: Issue 2, 2005

\begin{tabular}{lll}
\hline Date & Event & Description \\
\hline 6 December 2009 & $\begin{array}{l}\text { New citation required and conclusions } \\
\text { have changed }\end{array}$ & Conclusions changed, authors changed. \\
\hline 3 December 2009 & New search has been performed & $\begin{array}{l}\text { Updated, new studies added and change of statistical model due } \\
\text { to heterogeneity. }\end{array}$ \\
\hline 30 October 2008 & Amended & Converted to new review format. \\
\hline 28 May 2004 & Amended & Conclusions changed. \\
\hline 1 February 2004 & Amended & New studies found and included or excluded. \\
\hline
\end{tabular}

\section{CONTRIBUTIONS OF AUTHORS}

Wagner AD: Protocol development, eligibility and quality assessment, data extraction and analysis, drafting of final review. Unverzagt S: Eligibility and quality assessment in the update, responsible statistician of the current update. Data extraction and analysis, and drafting of the final review (2017 update).

Moehler, M: Review of search results, drafting of the final review (2017 update).

Grothe W: Literature searches, eligibility and quality assessment, data extraction and analysis.

Haerting J: Protocol development, statistician in initial version of the review.

Syn, NL: Review of search results, quality assessment, data extraction and analysis, drafting of final review (2017 update).

Ho, J: Review of search results, data extraction and analysis, drafting of final review (2017 update).

Yong, WP: Review of search results, drafting of final review (2017 update).

Tai, BC: Data extraction and analysis (2017 update).

\section{DECLARATIONS OF INTEREST}

ADW: has received consulting fees from Eli Lilly, Celgene, MerckKG/Phizer, MSD, TAIHO and Roche pharmaceuticals for consultancy work over the past three years, travel and accomodation support from Janssen and support from Merck Serono to conduct a clinical trial of 
targeted treatment for gastric cancer, which is beyond the scope of this review. The overall number of consultancy agreements per year is low (usually less than five advisory boards/year, with fees of between 500 and 1500 Euro per event). All funds were paid to her institution in accordance with their guidelines. A portion of the money that the institution receives is transferred to ADW and represents a trivial percentage of her salary.

NLXS: none known.

MM: has received consulting fees from Eli Lilly, Onyx, Roche, Nordic, Amgen, MSD, Merck Serono, Pfizer and BMS. He has received payment for lectures from Falk, Nordic, Amgen, mci, MSD, Merck Serono, Pfizer and BMS. His institution has received funds for independent research grants from Merck, Amgen, BMS, Taiho, Roche, AIO, MSD, and the EORTC.

WG: none known.

WPY: has received payment from Eli Lilly for service on speaker bureaus and travelling/accommodation for conferences from BMS and Taiho, unrelated to this review.

BCT: has received a payment from Boehringer Ingelheim for providing a lecture, and royalties from Wiley-Blackwell from a publication. Her institution has received funds from the Health Science Authority (Singapore) for statistical consultancy.

$\mathrm{JH}$ : none known.

SU: none known.

\section{SOURCES OF SUPPORT}

\section{Internal sources}

- Department of Internal Medicine I, Martin-Luther-University Halle-Wittenberg, Germany.

- Department of Internal Medicine IV, Martin-Luther-University Halle-Wittenberg, Germany.

- Institute of Medical Epidemiology, Biometry and Informatics, Martin-Luther-University, Halle-Wittenberg, Germany.

- Co-ordinating Centre for Clinical Trials, Halle (supported by German Ministry of Education \& Research, Grant Number BMBF/FKZ: 01GH0105 KKS, Halle), Germany.

\section{External sources}

- No sources of support supplied

\section{DIFFERENCES BETWEEN PROTOCOL AND REVIEW}

There were a large number of categories of different combination chemotherapy regimens and the number of relevant studies in each category was not known when writing the protocol. For this reason we were unable to plan in advance the best way to compare categories of all relevant categories of combination chemotherapies (Van Cutsem 2009).

We clarified how we dealt with multiple study arms from one study.

In the first update of this review (Wagner 2010, submitted in November 2009), we chose to add the following comparisons based on their clinical relevance and the availability of a sufficient number of relevant studies. Among these, comparisons 3 and 4 have been added in the discussion of the previously published version of this review as they were not specified in advance. Comparisons 5 to 8 have been specified in advance in the last update of the review.

In this second update of this review (submitted in March 2017), we added two additional comparisons (9 and 10) and we differentiated between additive and substitutive comparisons in comparisons 5 and 6.

Comparison number:

3. 5-FU/cisplatin/anthracycline combinations versus 5-FU/cisplatin (without anthracyclines)

4. 5-FU/cisplatin/anthracycline-combinations versus 5-FU/anthracycline combinations (without cisplatin)

5. Irinotecan versus non-irinotecan-containing regimens

6. Docetaxel versus non-docetaxel-containing regimens

7. Regimens including oral 5-FU prodrugs versus intravenous fluoropyrimidines

8. Oxaliplatin versus cisplatin-containing regimens

9. Taxane-platinum-fluoropyrimidin combinations versus taxane-platinum (without fluoropyrimidine)

10. S-1 versus 5-FU-containing regimens 
The method for statistical analysis in case of significant heterogeneity $\left(I^{2}>20 \%\right)$ is a random-effects model. Although the original version of the protocol does not state this, these changes were requested after methodological review by the Cochrane UGPD group. This methodological change is responsible for differences in HRs between this and the previously published version of the review (Wagner 2006).

As recent studies have increasingly reported progression-free survival instead of time to progression, we included the former as secondary endpoints in this update.

While there was no evidence for both - the use of second-line therapy and targeted therapies - at the time the protocol for this review was written, both second-line and these targeted agents (trastuzumab in first-line for HER-2 positive people and ramucirumab in secondline) have changed the management options for advanced gastric cancer significantly and are therefore included in the discussion of the treatment options although not analysed in detail by this review.

In this updated review, we no longer use the Jadad scale to assess methodological quality (Jadad 1996). Instead we independently assessed the risk of bias in the included studies using the 'Risk of bias' assessment tool described in Chapter 8 of theCochrane Handbook for Systematic Reviews of Interventions (Higgins 2011).

\section{NDEX TERMS}

\section{Medical Subject Headings (MeSH)}

Anthracyclines [administration \& dosage]; Antineoplastic Combined Chemotherapy Protocols [*therapeutic use]; Camptothecin [administration \& dosage] [analogs \& derivatives]; Cisplatin [administration \& dosage]; Docetaxel; Fluorouracil [administration \& dosage]; Irinotecan; Randomized Controlled Trials as Topic; Stomach Neoplasms [ ${ }^{\star}$ drug therapy] [mortality]; Taxoids [administration \& dosage]

\section{MeSH check words}

Humans 